
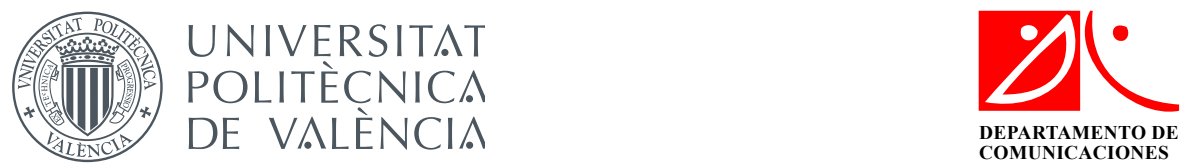

\title{
Planificación y Optimización Automática de Redes Móviles LTE
}

\author{
Departamento de Comunicaciones \\ Universitat Politècnica de València \\ Tesis presentada para la obtención del título de \\ Doctor en Telecomunicación \\ Valencia, Mayo de 2013
}

Autor:

Vicente Osa Ginés

Directores:

Dr. José F. Monserrat del Río

Dr. Narcís Cardona Marcet 



\section{Resumen}

Actualmente, las comunicaciones móviles inalámbricas se encuentran en pleno proceso de evolución. Las tecnologías 3G dan paso a las $4 \mathrm{G}$, en un contexto de tremendo crecimiento de la demanda de tráfico por parte de los usuarios de banda ancha móvil, y la implantación de la tecnología LTE comienza a extenderse.

En este proceso de mejora, el cual supone un gran desembolso económico por parte de los operadores, crece el interés por la reducción de los gastos operativos derivados de la planificación y optimización de la red, para lo cual los mecanismos automáticos que desempeñen estas funciones emergen como solución idónea.

Esta Tesis Doctoral aporta distintos mecanismos automáticos de planificación y optimización de redes LTE y realiza un estudio detallado de sus prestaciones. El contenido de la misma se estructura en tres grandes bloques, precedidos por una descripción de la metodología seguida, la cual está basada en simulaciones, y las distintas suposiciones realizadas.

La primera parte se centra en el tratamiento de la información disponible y describe una serie de herramientas diseñadas que ayudan en los procesos propuestos. De gran relevancia para el resto de la Tesis Doctoral es el algoritmo de localización diseñado, el cual supone una herramienta fundamental en todos los mecanismos de planificación y optimización automática planteados por las capacidades de geo-referenciar la información utilizada. La gran ventaja del algoritmo reside en que es posible su utilización sin necesidad de introducir ningún elemento nuevo en la red que lo habilite, ya que se basa en medidas realizadas durante la operación normal de la red capturadas a través de herramientas de call tracing. Asimismo destaca la utilización de sistemas expertos basados en redes neuronales para la obtención de recomendaciones de cambio para determinados parámetros que complementen la salida obtenida por la herramienta de optimización diseñada.

En segundo lugar, se trata la planificación y optimización de la red de acceso radio LTE mediante la utilización de métodos heurísticos 
de búsqueda de la solución óptima. La utilización de mapas de tráfico realistas, gracias al algoritmo de localización, y la estimación de la carga en cada celda permiten realizar evaluaciones precisas del rendimiento de las distintas soluciones candidatas en un tiempo asumible, gracias a la linealización de los modelos utilizados entre otros métodos de ejecución eficiente propuestos. Asimismo se evalúa el impacto que tiene el error cometido por el algoritmo de localización sobre las soluciones de planificación y optimización obtenidas.

Por último, debido a que los recursos del espectro radioeléctrico son limitados y es necesario gestionarlos adecuadamente, se analizan las mejores opciones en lo que respecta a reutilización de los recursos disponibles y a la migración de estaciones base de tecnologías predecesoras. Asimismo, con el objetivo de mitigar la escasez de recursos disponibles en frecuencia, se propone la utilización de mecanismos de acceso oportunista al espectro que hagan uso de recursos infrautilizados en otros sistemas inalámbricos. Este acceso oportunista se aplica tanto a entornos macrocelulares, en los que de nuevo el algoritmo de localización supone una herramienta fundamental, como femtocelulares, proporcionando detalles de implementación de los mecanismos de coordinación necesarios y evaluando sus prestaciones. 


\section{Resum}

Actualment, les comunicacions mòbils es troben en ple procés d'evolució. Les tecnologies $3 \mathrm{G}$ donen pas a les $4 \mathrm{G}$, en un context de tremend creixement de la demanda de tràfic per part dels usuaris de banda ampla mòbil, i la implantació de la tecnologia LTE comença a estendre's.

En aquest procés de millora, el qual suposa un gran desemborsament econòmic per part dels operadors, creix l'interès per la reducció de les despeses operatives derivades de la planificació i optimització de la xarxa. Per aquesta raó els mecanismes automàtics que exercisquen aquestes funcions emergeixen com a solució idònia.

Aquesta Tesi Doctoral aporta diferents mecanismes automàtics de planificació i optimització de xarxes LTE i realitza un estudi detallat de les seues prestacions. El contingut de la mateixa s'estructura en tres grans blocs, precedits per una descripció de la metodologia seguida, la qual està basada en simulacions, i les diferents suposicions realitzades.

La primera part se centra en el tractament de la informació disponible i descriu una sèrie d'eines dissenyades que ajuden en els processos proposats. De gran rellevància per a la resta de la Tesi Doctoral és l'algorisme de localització dissenyat, el qual suposa una eina fonamental en tots els mecanismes de planificació i optimització automàtica plantejats per les capacitats de geo-referenciar la informació utilitzada. El gran avantatge de l'algorisme es la possibilitat d'utilització sense necessitat d'introduir cap element nou en la xarxa que ho habilite, ja que es basa en mesures realitzades durant l'operació normal de la xarxa capturades mitjançant eines de call tracing. Així mateix destaca la utilització de sistemes experts basats en xarxes neuronals per a l'obtenció de recomanacions de canvi per a determinats paràmetres que complementen l'eixida obtinguda per l'eina d'optimització dissenyada.

En segon lloc, es tracta la planificació i optimització de la xarxa d'accés radioelèctric LTE mitjançant la utilització de mètodes heurístics de cerca de la solució òptima. La utilització de mapes de tràfic 
realistes, gràcies a l'algorisme de localització, i l'estimació de la càrrega en cada cel-la permeten realitzar avaluacions precises del rendiment de les diferents soluciones candidates en un temps assumible, gràcies a la linealització dels models utilitzats entre altres mètodes d'execució eficient proposats. Així mateix s'avalua l'impacte que té l'error comès per l'algorisme de localització sobre les solucions de planificació i optimització obtingudes.

Finalment, a causa que els recursos de l'espectre radioelèctric són limitats i és necessari gestionar-los adequadament, s'analitzen les millors opcions pel que fa a la reutilització dels recursos disponibles i a la migració d'estacions base de tecnologies predecessores. Així mateix, amb l'objectiu de mitigar l'escassetat de recursos disponibles en freqüència, es proposa la utilització de mecanismes d'accés oportunista a l'espectre que facen ús de recursos infrautilitzats en altres sistemes sense fils. Aquest accés oportunista s'aplica tant a entorns macrocel-lulars, en els quals de nou l'algorisme de localització suposa una eina fonamental, com femtocel-lulars, proporcionant detalls d'implementació dels mecanismes de coordinació necessaris i avaluant les seues prestacions. 


\begin{abstract}
Currently, wireless mobile communications are immersed in a process of evolution. $3 \mathrm{G}$ technologies give way to $4 \mathrm{G}$, in a context of tremendous growth in traffic demand by users of mobile broadband, and the introduction of LTE technology is starting to spread.

In this process of improvement, which is a major financial outlay for mobile operators, there is a growing interest in reducing operational expenditures of planning and network optimization, for which automatic mechanisms that perform these functions emerge as the ideal solution.

This $\mathrm{PhD}$ Thesis proposes various automatic mechanisms for planning and optimization of LTE networks and provides a detailed study of its performance. The content is structured in three sections, preceded by a description of the followed methodology, which is based on simulations, and the different assumptions made.

The first part focuses on the treatment of available information and describes a set of tools designed to assist in the proposed processes. Of great relevance to the rest of the thesis is the designed location algorithm, which is a fundamental tool in all automatic planning and optimisation mechanisms due to the ability of geo-referencing the information used. The great advantage of the algorithm is that it is possible to use it without introducing any new elements in the network which enable it, as it is based on measurements made during normal operation of the network, acquired through call tracing tools. It is also worth mentioning the use of expert systems based on neural networks for obtaining feedback for specific recommendations given by the designed optimization tool.

Secondly, the planning and optimization of LTE radio access network using heuristic search methods of the optimal solution are treated. The use of realistic traffic maps, enabled by the location algorithm, and the estimation of the load in each cell allows accurate assessment of the performance of the different candidate solutions in an acceptable time, thanks to the linearization of the models used among other methods proposed for efficient execution of the process. It also assesses the impact of the localization algorithm error on the planning and optimization solutions obtained.
\end{abstract}


Finally, because of radio spectrum resources are limited and need to be managed properly, the best options are analysed when it comes to the reuse of available resources and the migration of base stations of legacy technologies. Furthermore, in order to mitigate the shortage of available resources in frequency, the usage of opportunistic spectrum access mechanisms are proposed to make use of underutilized resources in other wireless systems. This opportunistic access applies to macrocellular environments, where again the location algorithm is an essential tool, and femtocellular environments. Additionally, implementation details of the necessary coordination mechanisms and performance evaluation results are provided. 


\section{Índice general}

Índice de figuras $\quad$ IX

Índice de tablas $\quad$ XII

$\begin{array}{lll}\text { Acrónimos } & \text { XIII }\end{array}$

1. Introducción $\quad \mathbf{1}$

1.1. Motivación de la Tesis Doctoral . . . . . . . . . . . . . . 1

1.2. Estado del Arte . . . . . . . . . . . . . . . . . . . . 3

1.3. Objetivos Planteados . . . . . . . . . . . . . 6

1.4. Principales Aportaciones de la Tesis . . . . . . . . . . . 7

1.5. Estructura de la Tesis . . . . . . . . . . . . . . . . . 7

1.6. Publicaciones Relacionadas con la Tesis . . . . . . . . . . . . . 9

1.7. Otras Publicaciones . . . . . . . . . . . . . . 10

2. Metodología $\quad \mathbf{1 3}$

2.1. Necesidades . . . . . . . . . . . . . . . . . . . 13

2.2. Simulador Estático . . . . . . . . . . . . . . . 16

2.2.1. Descripción . . . . . . . . . . . . . . . 16

2.2.2. Suposiciones . . . . . . . . . . . . . . . . . . . . 19

2.2.2.1. Caracterización de las antenas . . . . . . . 19

2.2.2.2. Pérdidas de propagación . . . . . . . . . . . . 19

2.2.2.3. Balance de potencias . . . . . . . . . . 20

2.2.2.4. Tráfico cursado . . . . . . . . . . . . . 21

2.2.2.5. Scheduling .............. . . 23

2.2.2.6. Impacto del error de localización . . . . . . . . 24

2.3. Simulador Dinámico . . . . . . . . . . . . . . . . . . . 24

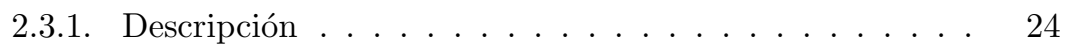

2.3.2. Suposiciones ................ 26 
2.3.2.1. Escenario de simulación . . . . . . . . . . . . 26

2.3.2.2. Caracterización de las antenas . . . . . . . . 27

2.3.2.3. Modelo de canal y propagación . . . . . . . . . . . 28

2.3.2.4. Modelos de tráfico . . . . . . . . . . . . . 28

2.3.2.5. Modelos de movilidad . . . . . . . . . . . . 30

2.3.2.6. Modelado de recursos radio . . . . . . . . . . 30

3. Procesamiento de la Información 33

3.1. Información Disponible en la Red . . . . . . . . . . . . . 33

3.2. Localización . . . . . . . . . . . . . . . . . . . . 34

3.2.1. Mecanismos de Localización en UMTS . . . . . . . . . 36

3.2.1.1. Triangulación . . . . . . . . . . . . . 36

3.2.1.2. Fingerprinting . . . . . . . . . . . 39

3.2.2. Mecanismos de Reducción de Error de la Localización Basada en Triangulación . . . . . . . . . . . . . . . . 42

3.2.3. Resultados y Discusión . . . . . . . . . . . . . . 45

3.2.3.1. Resultados de triangulación . . . . . . . . . . 47

3.2.3.2. Resultados de fingerprinting . . . . . . . . . 47

3.2.3.3. Hibridación . . . . . . . . . . . . . . . . 50

3.2.4. Adaptación del Mecanismo de Localización a LTE . . . 51

3.3. Información Geo-referenciada . . . . . . . . . . . . 55

3.4. Sistemas Expertos . . . . . . . . . . . . . . 56

4. Planificación y Optimización de la Red de Acceso Radio 61

4.1. Objetivos y Formulación del Problema . . . . . . . . . . . . 62

4.2. Linealización del Sistema LTE . . . . . . . . . . . . . . . 65

4.3. Procedimientos de Búsqueda de Solución . . . . . . . . . . . . 69

4.3.1. Introducción . . . . . . . . . . . . . . . . 69

4.3.2. Métodos Heurísticos de Búsqueda _ . . . . . . . . 70

4.3.2.1. Simulated Annealing . . . . . . . . . . . . 70

4.3.2.2. Algoritmos genéticos . . . . . . . . . . . . . . 72

4.3.2.3. Particle Swarm Optimisation . . . . . . . . . 76

4.3.2.4. Resultados comparativos . . . . . . . . . 80

4.4. Proceso de Planificación . . . . . . . . . . . . . . . . . 83

4.5. Optimización . . . . . . . . . . . . . . . . 86

4.6. Métodos de Ejecución Eficiente . . . . . . . . . . . . . . 87

4.7. Aplicación de Sistemas Expertos . . . . . . . . . . . . . . 89

4.7.1. Datos de Entrada . . . . . . . . . . . . . . . . . 91

4.7.2. Entrenamiento . . . . . . . . . . . . . . . . 93

4.8. Resultados y Discusión . . . . . . . . . . . . . . . . . . . 94

4.8.1. Planificación y Optimización . . . . . . . . . . . 94 
4.8.2. Impacto del Error de Localización _ . . . . . . . . . . 98

4.8.3. Sistemas Expertos . . . . . . . . . . . . . . . . 104

5. Optimización del Uso del Espectro 107

5.1. Reutilización de Frecuencias . . . . . . . . . . . . . . . . 108

5.1.1. Introducción . . . . . . . . . . . . . . . . 108

5.1.2. Técnicas ICIC . . . . . . . . . . . . . . . . . 109

5.1.2.1. Reutilización de frecuencias de factor $3 \ldots 111$

$5.1 .2 .2 . \quad F F R \ldots \ldots \ldots \ldots \ldots \ldots 111$

$5.1 .2 .3 . \quad$ SFR . . . . . . . . . . . . . . . . 113

5.1.3. Resultados y Discusión . . . . . . . . . . . . . . 113

5.1.3.1. Escenario y parámetros de simulación . . . . . 114

5.1.3.2. Clasificación de usuarios . . . . . . . . . . . . 115

5.1.3.3. Barrido de parámetros . . . . . . . . . . 117

5.1.3.4. Distancia entre emplazamientos . . . . . . . 121

5.1.3.5. Comparativa entre alternativas . . . . . . . . . 123

5.1.3.6. Condiciones extremas . . . . . . . . . . . . 125

5.1.3.7. Conclusiones . . . . . . . . . . . . . . . . . 129

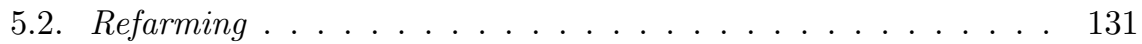

5.2.1. Introducción . . . . . . . . . . . . . . . 131

5.2.2. Resultados y Discusión . . . . . . . . . . . . . . 134

5.3. Planificación Automática de Frecuencias . . . . . . . . . . . 137

5.3.1. Restricciones del Problema . . . . . . . . . . . . 138

5.3.2. Fases del Proceso . . . . . . . . . . . . . . . . . . . . 138

5.3.2.1. Definición de escenario y restricciones . . . . . 139

5.3.2.2. Cálculo de matriz de interferencias . . . . . . . 139

5.3.2.3. Búsqueda de la solución de planificación de frecuencias . . . . . . . . . . . . . . 140

5.3.2.4. Planificación de BSICs . . . . . . . . . . . 143

5.4. Acceso Oportunista al Espectro . . . . . . . . . . . . . . . . . 144

5.4.1. Características y Herramientas de CR en LTE-A . . . . 148

5.4.1.1. Posible escenario de despliegue . . . . . . . . . 149

5.4.1.2. Detección del espectro . . . . . . . . . . . . . . 149

5.4.1.3. Reporte de medidas . . . . . . . . . . . . . 153

5.4.1.4. Localización de usuarios . . . . . . . . . . . . . 155

5.4.1.5. Base de datos geo-localizados . . . . . . . . 155

5.4.2. Procedimiento de Acceso Oportunista al Espectro . . . 158

5.4.2.1. Toma de decisiones cooperativa . . . . . . . 158

5.4.2.2. Reparto de recursos para la minimización de interferencias . . . . . . . . . . . . 161

5.4.2.3. Procedimiento de acceso . . . . . . . . . 163 
5.4.3. Resultados y Discusión _. . . . . . . . . . . . 165

5.4.3.1. Escenario de simulación y configuración de parámetros . . . . . . . . . . . 165

5.4.3.2. Calibración de la detección . . . . . . . . . . 166

5.4.3.3. Evaluación del algoritmo cooperativo . . . . . 170

5.4.3.4. Impacto del solape y actividad del sistema primario . . . . . . . . . . . 170

5.5. Auto-organización de Femtoceldas . . . . . . . . . . . . . 172

5.5.1. Coordinación de Interferencias entre HeNBs LTE-A . . 175

5.5.2. Procedimiento de Auto-organización . . . . . . . . . 176

5.5.3. Resultados y Discusión . . . . . . . . . . . . . 179

5.5.3.1. Escenario y parámetros de simulación . . . . . 179

5.5.3.2. Prestaciones del sistema . . . . . . . . . . . . . 179

6. Conclusiones y Trabajo Futuro 183

6.1. Conclusiones . . . . . . . . . . . . . . . . . . . 183

6.2. Líneas Futuras de Investigación . . . . . . . . . . . . 186

A. Datos Disponibles para las Herramientas de Procesamiento de Información $\quad 191$

$\begin{array}{ll}\text { Referencias } & 194\end{array}$ 


\section{Índice de figuras}

2.1. Diagrama de bloques de la metodología seguida . . . . . . . . . 14

2.2. Leyenda del diagrama de bloques de la metodología . . . . . . 15

2.3. Mapa de Signal-to-Interference plus Noise Ratio (SINR) de una celda obtenido con el simulador estático . . . . . . . . . . 16

2.4. Mapa de serving cell obtenido con el simulador estático . . . . 17

2.5. Mapa de tráfico cursado obtenido con el simulador estático . . 17

2.6. Mapa de tráfico cursado por una celda obtenido con el simulador estático . . . . . . . . . . . . . . . . . . 18

2.7. Ajuste de la fórmula de capacidad de Shannon a los datos de SINR vs. throughput disponibles de simulaciones de enlace LTE con MIMO 1x2 y $10 \mathrm{MHz}$ de ancho de banda . . . . . . . . . 23

2.8. Esquema funcional de SPHERE . . . . . . . . . . . . . . . 26

2.9. Escenario sintético de Simulation Platform for Heterogeneous Wireless Systems (SPHERE) con 57 celdas sectoriales . . . . . 27

3.1. Localización por triangulación . . . . . . . . . . . . . . . . . . 38

3.2. Medidas de Received Signal Strength (RSS) capturadas durante una campaña de drive-test . . . . . . . . . . . . . . . . . . 40

3.3. Estimación de RSS utilizando Digital Terrain Map (DTM) (arriba) y altura de edificios (abajo) . . . . . . . . . .

3.4. Funcionamiento del promediado de ventana deslizante en el caso de MRs periódicos (arriba) o generados por eventos (abajo) . .

3.5. Ejemplos de salida de Algoritmo de Localización basado en Triangulación con Promediado temporal (ALT-P), linea amarilla de la figura superior, y Algoritmo de Localización basado en Triangulación con Promediado temporal y Suavizado (ALT-PS), linea blanca de la figura inferior, respecto a la ruta Global Positioning System (GPS) seguida durante la llamada, linea azul en ambas figuras 
3.6. Ejemplo de resultado del Algoritmo de Localización basado en Triangulación Mejorado (ALT-M), punto blanco, para una llamada estática, línea azul . . . . . . . . . . . . . . . .

3.7. Resultado obtenido por Algoritmo de Localización basado en Fingerprinting con datos Topográficos (ALF-T) (verde), Algoritmo de Localización basado en Fingerprinting con datos Topográficos y Altura de edificios (ALF-TA) (rojo) y Algoritmo de Localización basado en Fingerprinting con datos de Drive Test (ALF-DT) (blanco) para la misma llamada (azul) . . . . . . . .

3.8. Obtención de mapas de pérdidas de propagación con medidas de distintos UEs . . . . . . . . . . . . . . . . 56

3.9. Ejemplo de mapa de densidad de usuarios . . . . . . . . . . . . 56

3.10. Representación gráfica de la función logística . . . . . . . . 58

3.11. Neurona artificial . . . . . . . . . . . . . . . . . 58

3.12. Red neuronal artificial . . . . . . . . . . . . . . 59

4.1. Aproximación de $h(x)$ alrededor de $x=0,5$ mediante desarrollo de Taylor de primer orden . . . . . . . . . . . . . 68

4.2. Escenario simple con matriz de tráfico sintética . . . . . . . 75

4.3. Población inicial forzada a estar parcialmente diversificada . . . 76

4.4. Comparación de frente óptimo de Pareto forzando y sin forzar diversidad en la población inicial, para el mismo número de generaciones . . . . . . . . . . . . . . . . .

4.5. Comparación de frente óptimo de Pareto forzando y sin forzar diversidad en la población inicial, con doble número de generaciones en el caso forzado . . . . . . . . . . . . . . 78

4.6. Escenario a optimizar y mapa de tráfico sintético . . . . . . . 81

4.7. Proceso de planificación automática propuesto . . . . . . 84

4.8. Proceso de optimización automática propuesto . . . . . . . 86

4.9. Aplicación del sistema experto al proceso de optimización automática ....................... 90

4.10. Resultados de cobertura y carga obtenidos de la herramienta automática de planificación y optimización en función del número de emplazamientos . . . . . . . . . . . . . . . . .

4.11. Mapa de serving cell de la solución propuesta por la herramienta automática de planificación y optimización . . . . . . . . . . .

4.12. Resultados de SINR media obtenidos de la herramienta automática de planificación y optimización en función del número de emplazamientos . . . . . . . . . . . . . . 
4.13. Comparación del mapa de SINR para las soluciones obtenidas para 7 emplazamientos en el modo con estimación de carga (arriba) y suponiendo carga al $100 \%$ (abajo) . . . . . . . . . .

4.14. Comparación del mapa de tráfico considerado real (arriba) y del afectado por el error de localización (abajo) . . . . . . . . .

4.15. Impacto del error de localización sobre el tráfico cursado por la solución obtenida en la planificación de 7 emplazamientos (21 celdas) . . . . . . . . . . . . . . . . .

4.16. Impacto del error de localización sobre el tráfico cursado por la solución obtenida en la planificación de 9 emplazamientos $(27$ celdas) . . . . . . . . . . . . . . . .

4.17. Función de transferencia para conversión de niveles de certeza en valores de incrementos de tilt comparables con la salida de la herramienta de optimización . . . . . . . . . . . . . .

5.1. Reutilización de factor $3 \ldots \ldots$. . . . . . . . . . . . 112

5.2. Esquema FFR . . . . . . . . . . . . . . . 113

5.3. Esquema SFR . . . . . . . . . . . . . . . . . . . . 114

5.4. CDF del throughput de usuarios para SFR según modo de clasificación de usuarios . . . . . . . . . . . . . . 116

5.5. Fairness, eficiencia espectral por celda y eficiencia espectral de CEUs para SFR según modo de clasificación de usuarios . . . .

5.6. CDF del throughput de usuario para FFR según modo de clasificación de usuarios . . . . . . . . . . . . . . . . 118

5.7. Fairness, eficiencia espectral por celda y eficiencia espectral de CEUs para FFR según modo de clasificación de usuarios . . . .

5.8. Throughput medio de usuario CEU para FFR y varios valores de $\alpha$ y . . . . . . . . . . . . . . . 120

5.9. Throughput medio de celda para FFR y varios valores de $\alpha$ y $\beta$

5.10. CDF del throughput de usuario para SFR y varios valores de $\alpha$

5.11. Eficiencia espectral del sistema para los distintos modos en función de la distancia entre emplazamientos . . . . . . . . . . .

5.12. Throughput medio de usuario CEU para los distintos modos en función de la distancia entre emplazamientos . . . . . . . . .

5.13. Fairness para los distintos modos en función de la distancia entre emplazamientos . . . . . . . . . . . . . . . .

5.14. Comparación de la Cumulative Distribution Function (CDF) del throughput de usuarios para los distintos métodos de reutilización de frecuencias . . . . . . . . . . . . . 
5.15. Comparación del fairness, eficiencia espectral del sistema y eficiencia espectral de Cell-Edge Users (CEUs) para los distintos métodos de reutilización de frecuencias . . . . . . . . . . .

5.16. Distribución de usuarios no uniforme en el caso extremo de concentración del $50 \%$ en el borde de la celda . . . . . . . . . .

5.17. CDF del throughput de usuario para distintos modos de reutilización de frecuencias en el caso extremo planteado y scheduling $\mathrm{PF} \ldots \ldots \ldots \ldots \ldots \ldots$

5.18. Zoom de la CDF del throughput de usuario para distintos modos de reutilización de frecuencias en el caso extremo planteado y scheduling $\mathrm{PF} \ldots \ldots \ldots \ldots$

5.19. CDF del throughput de usuario para distintos modos de reutilización de frecuencias en el caso extremo planteado y scheduling

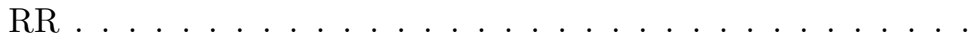

5.20. Zoom de la CDF del throughput de usuario para distintos modos de reutilización de frecuencias en el caso extremo planteado y scheduling $\mathrm{RR}$

5.21. CDF del Throughput medio por celda para GSM y Long Term Evolution (LTE) en los casos de refarming contemplados . . . .

5.22. $C / I$ en canales TCH antes de la replanificación de frecuencias . 141

5.23. $C / I$ en canales TCH después de la replanificación de frecuencias 142

5.24. Zonas de mejora y empeoramiento de $C / I$ tras las replanificación 142

5.25. Problema de coincidencia de par frecuencia-BSIC en vecindario de segundo orden . . . . . . . . . . . . . . . . . . . . . . 144

5.26. Problema del nodo oculto en DL . . . . . . . . . . . . . . . . . 146

5.27. Parámetros del patrón de huecos para los procedimientos de medida en LTE-A . . . . . . . . . . . . . . . . . . . . . . 150

5.28. Detección de actividad en el sistema primario . . . . . . . . . . 152

5.29. Flujo de eventos para $M I H \_L i n k \_$Parameters_Report.indication 155

5.30. Esquema de los nodos implicados en el mantenimiento de la BD-Geo . . . . . . . . . . . . . . . 156

5.31. Acceso Oportunista al Espectro basado en datos geo-localizados 157

5.32. Escenario de AOE simplificado . . . . . . . . . . . . . . . 162

5.33. Posibilidades de señalización en LTE-A con CA habilitado . . . 164

5.34. Rendimiento del sistema en función del umbral de decisión . . . 168

5.35. Rendimiento del sistema en función del mecanismo de decisión y el periodo de detección . . . . . . . . . . . . . . . . . . . . . 169

5.36. Impacto de la precisión del mecanismo de localización . . . . . 171

5.37. Impacto sobre el throughput del factor de actividad del sistema primario y el solape con el secundario . . . . . . . . . . . . . 172 
5.38. Impacto sobre la tasa de colisiones del factor de actividad del sistema primario y el solape con el secundario . . . . . . . . . 173 5.39. Arquitectura de sistema LTE-A con Coordinador de Espectro (CE) 176 5.40. Comparación de porcentaje de usuarios sin servicio . . . . . . . 181 5.41. Comparación de throughput medio por Femtocelda Cognitiva (FC) 181 
ÍNDICE DE FIGURAS 


\section{Índice de tablas}

3.1. Comparación de los mecanismos de triangulación . . . . . . . . 47

3.2. Comparación de los mecanismos de fingerprinting . . . . . . . . 49

3.3. Comparación de los mecanismos híbridos . . . . . . . . . . 51

3.4. Granularidad de la información útil para localización reportada en LTE . . . . . . . . . . . . . . . . . . . . . . . . . . . . . . 53

4.1. Posibles valores de las variables a optimizar . . . . . . . . . . 80

4.2. Parámetros más relevantes utilizados en los algoritmos de búsqueda 82

4.3. Resultados comparativos de las distintas heurísticas de búsqueda planteadas.................... 83

4.4. Entradas de la red neuronal para la optimización de tilt . . . . 92

4.5. Interpretación de los valores de salida de la red neuronal . . . . 93

4.6. Parámetros de configuración de Simulated Annealing (SA) . . . 94

4.7. Parámetros de configuración del simulador estático . . . . . . . 95

4.8. Parámetros de configuración de la herramienta de planificación y optimización . . . . . . . . . . . . . . . 96

5.1. Parámetros de las simulaciones de reutilización de frecuencias . 115

5.2. Valores del barrido de parámetros $\alpha$ y $\beta$ para Fractional Frequency Reuse (FFR) . . . . . . . . . . . . . . . . . 117

5.3. Valores del barrido de parámetros $\alpha$ para Soft Frequency Reuse (SFR) . . . . . . . . . . . . . . . . . 119

5.4. Parámetros alterados para las simulaciones de reutilización de frecuencias en condiciones extremas . . . . . . . . . . . . 127

5.5. Resumen de valores medios para el caso extremo y scheduling PF 128

5.6. Resumen de valores medios para el caso extremo y scheduling RR129

5.7. Distintas posibilidades de refarming contempladas . . . . . . . 134

5.8. Parámetros comunes de simulación . . . . . . . . . . . . 135 


\section{ÍNDICE DE TABLAS}

5.9. Parámetros de simulación de Global System for Mobile communications (GSM) . . . . . . . . . . . . . 135

5.10. Parámetros de simulación de LTE . . . . . . . . . . . 135

5.11. Throughput medio por celda . . . . . . . . . . . . . 136

5.12. Restricciones de separación de canales. . . . . . . . . . . . . 138

5.13. Contenido de la base de datos geolocalizados . . . . . . . 157

5.14. Parámetros de simulación . . . . . . . . . . . . . . . 167

5.15. Parámetros de simulación _. . . . . . . . . . . . . 180

A.1. Datos utilizados en las herramientas de procesamiento de información . . . . . . . . . . . . . . . . . . . . 193 


\section{Acrónimos}

2G Segunda Generación

3G Tercera Generación

4G Cuarta Generación

3GPP Third Generation Partnership Project

A-GNSS Assisted-Global Navigation Satellite System

A-GPS Assisted-Global Positioning System

ALF-AT Algoritmo de Localización basado en Fingerprinting Acotado por Triangulación

ALF-T Algoritmo de Localización basado en Fingerprinting con datos Topográficos

ALF-TA Algoritmo de Localización basado en Fingerprinting con datos Topográficos y Altura de edificios

ALF-DT Algoritmo de Localización basado en Fingerprinting con datos de Drive Test

ALT Algoritmo de Localización basado en Triangulación

ALT-AF Algoritmo de Localización basado en Triangulación Asistida por Fingerprinting

ALT-M Algoritmo de Localización basado en Triangulación Mejorado

ALT-P Algoritmo de Localización basado en Triangulación con Promediado temporal 
ALT-PS Algoritmo de Localización basado en Triangulación con Promediado temporal y Suavizado

AoA Angle of Arrival

AMC Adaptive Modulation and Coding

AOE Acceso Oportunista al Espectro

ARFCN Absolute Radio-Frequency Channel Number

AWGN Additive White Gaussian Noise

BCC Base station Color Code

BCCH Broadcast Control Channel

BD-Geo Base de Datos Geo-localizados

BLER Block Error Rate

BS Base Station

BSIC Base Station Identity Code

BTS Base station Transceiver Subsystem

CA Carrier Aggregation

CBE Celda Bajo Estudio

CBR Call Blocking Rate

CC Component Carrier

CCU Cell-Center User

CDF Cumulative Distribution Function

CE Coordinador de Espectro

Cell-ID Cell Identifier

CEU Cell-Edge User

CFC Cluster de Femtoceldas Cognitivas

COR Características de Operación del Receptor 
CP Control de Potencia

CPICH Common Pilot Channel

CPICH RSCP Common Pilot Channel Received Signal Code Power

CRRM Common Radio Resource Management

CQI Channel Quality Indicator

CR Cognitive Radio

DEP Densidad Espectral de Potencia

DL Down Link

DTM Digital Terrain Map

EARFCN E-UTRA Absolute Radio-Frequency Channel Number

ECGI Evolved Cell Global Identifier

E-CID Enhanced-Cell ID

EDGE Enhanced Data Rates for GSM Evolution

E-MBMS Enhanced Multimedia Broadcast Multicast Services

eNB evolved Node B

EPS Evolved Packet System

E-SMLC Evolved Serving Mobile Location Centre

E-UTRA Evolved Universal Terrestrial Radio Access

FA False Alarm

FC Femtocelda Cognitiva

FCC Federal Communications Commission

FCFS First Come First Served

FDD Frequency-Division Duplexing

FFR Fractional Frequency Reuse

FFT Fast Fourier Transform 
GA Genetic Algorithm

GNSS Global Navigation Satellite System

GPRS General Packet Radio Service

GPS Global Positioning System

GRC Gestor de Recursos Cognitivos

GSM Global System for Mobile communications

HARQ Hybrid Automatic Repeat Request

HeNB Home evolved Node B

HeNB-GW Home evolved Node B Gateway

HFR Hard Frequency Reuse

HII High Interference Indication

HSDPA High Speed Downlink Packet Access

HSPA High Speed Packet Access

HSPA+ Evolved High Speed Packet Access

IA Inteligencia Artificial

ICIC Inter-Cell Interference Coordination

ILP Integer Linear Programming

IMT-Advanced International Mobile Telecommunications-Advanced

InH Indoor Hotspot

IOI Interference Overload Indication

IP Internet Protocol

iTEAM Instituto de Telecomunicaciones y Aplicaciones Multimedia de la Universidad Politécnica de Valencia

ITU International Telecommunications Union

ITU-R International Telecommunications Union - Radiocommunication sector 
KPI Key Performance Indicator

LCS-AP Location Services Application Protocol

LTE Long Term Evolution

LTE-A Long Term Evolution Advanced

LPP LTE Positioning Protocol

LPPa LPP Annex

LUT Look-Up Table

MaxCIR Maximum Carrier-to-Interference Ratio

MCQI Maximum Channel Quality Indicator

MCS Modulation and Coding Scheme

MD Missed Detection

MDT Minimization of Drive Tests

MICS Media Independent Command Services

MIES Media Independent Event Services

MIH Multimedia Independent Handover

MIHF Multimedia Independent Handover Function

MIIS Media Independent Information Services

MIMO Multiple-Input Multiple-Output

MGL Measurement Gap Length

MGRP Measurement Gap Repetition Period

MME Mobility Management Entity

MR Measurement Report

N.A. No Aplicable

NAS Non-Access-Stratum

NASA National Aeronautics and Space Administration 
NBAP Node B Application Part

NC-OFDMA Non-Contiguous Orthogonal Frequency-Division Multiple Access

NCC Network Color Code

NLoS Non Line of Sight

NSGA-II Non-dominated Sorting Genetic Algorithm II

OTDoA Observed Time Difference of Arrival

OFCOM Office of Communications

OFDM Orthogonal Frequency-Division Multiplexing

OFDMA Orthogonal Frequency-Division Multiple Access

OMC Operations and Maintenance Center

PCI Physical Cell Identifier

PF Proportional Fair

PMI Precoding Matrix Indicator

PRACH Physical Random Access Channel

PRS Positioning Reference Signals

PSC Primary Scrambling Code

PSO Particle Swarm Optimisation

QoE Quality of Experience

QoS Quality of Service

RAB Radio Access Bearer

RACH PD Random Access Channel Propagation Delay

RI Rank Indicator

RANAP Radio Access Network Application Part

RAP Random Access Preamble 
RB Resource Block

RE Resource Element

RMa Rural Macro

RNSAP Radio Network Subsystem Application Part

RNTP Relative Narrowband Transmit Power

RR Round Robin

RRC Radio Resource Control

RRM Radio Resource Management

RS Reference Signal

RSCP Received Signal Code Power

RSRP Reference Signal Received Power

RSRQ Reference Signal Received Quality

RSS Received Signal Strength

RSSI Received Signal Strength Indicator

RSTD Reference Signal Time Difference

RTT Round Trip Time

RxLev Received Signal Level

SA Simulated Annealing

SC-FDMA Single Carrier Frequency Division Multiple Access

SETSI Secretaría de Estado de Telecomunicaciones y para la Sociedad de la Información

SFR Soft Frequency Reuse

SINR Signal-to-Interference plus Noise Ratio

SPHERE Simulation Platform for Heterogeneous Wireless Systems

SPM Standard Propagation Model 
SRTM Shuttle Radar Topography Mission

TA Timing Advance

TB Transport Block

TCH Traffic Channel

TDD Time-Division Duplexing

TDT Televisión Digital Terrestre

TETRA Terrestrial Trunked Radio

TRX Transceiver

TS Tabu Search

TTI Transmit Time Interval

TxLev Transmitted Signal Level

UARFCN UTRA Absolute Radio-Frequency Channel Number

UE User Equipment

UHF Ultra High Frequency

UL Up Link

UMa Urban Macro

UMi Urban Micro

UMTS Universal Mobile Telecommunications System

UPV Universidad Politécnica de Valencia

UTRA UMTS Terrestrial Radio Access

UWB Ultra-Wideband

VDT Virtual Drive Test

VoIP Voice over Internet Protocol

WiFi Wireless Fidelity

WLAN Wireless Local Area Network 
WiMAX Worldwide Interoperability for Microwave Access

WINNER+ Wireless World Initiative New Radio+

WWW World Wide Web

X2-AP X2 Application Protocol 


\section{Capítulo 1}

\section{Introducción}

\subsection{Motivación de la Tesis Doctoral}

El estándar Third Generation Partnership Project (3GPP) Long Term Evolution (LTE) representa la evolución de los sistemas actuales de Tercera Generación (3G) hacia la Cuarta Generación (4G) y responde a la demanda creciente de los consumidores de comunicaciones móviles de banda ancha. Mientras que a las tecnologías actuales - Universal Mobile Telecommunications System (UMTS), High Speed Packet Access (HSPA) y Evolved High Speed Packet Access (HSPA+) - se las conoce conjuntamente como 3G, LTE es un precursor de las tecnologías 4G y, de hecho, la Release 10, conocida como Long Term Evolution Advanced (LTE-A), cumple con los requisitos marcados por la International Telecommunications Union (ITU) para ser considerada como tecnología 4G. La especificación de LTE garantiza velocidades de pico en enlace descendente por encima de $100 \mathrm{Mbps}$, velocidades de pico de subida mínimas de $50 \mathrm{Mbps}$ y retardos de ida-y-vuelta menores a $10 \mathrm{~ms}$. Además, LTE puede operar en distintas bandas de frecuencia y soporta anchos de banda escalables desde $1,4 \mathrm{MHz}$ hasta $20 \mathrm{MHz}$ en modos Frequency-Division Duplexing (FDD) y Time-Division Duplexing (TDD).

Las principales novedades introducidas en LTE están relacionadas con la interfaz radio y la evolución del núcleo de red. Respecto a la interfaz radioeléctrica, ésta se basa en Orthogonal Frequency-Division Multiple Access (OFDMA) para el Down Link (DL) y Single Carrier Frequency Division Multiple Access (SC-FDMA) para el Up Link (UL). La modulación elegida por el estándar 3GPP hace que las diferentes tecnologías de antenas Multiple-Input MultipleOutput (MIMO) tengan una mayor facilidad de implementación. Esto permite, según las características específicas del canal, hasta cuadruplicar la eficacia de 


\section{CAPÍTULO 1. INTRODUCCIÓN}

la transmisión de datos. Respecto a la arquitectura del sistema, ésta consiste en una red basada en Internet Protocol (IP) destinada a sustituir la red troncal de General Packet Radio Service (GPRS) al mismo tiempo que se asegura la compatibilidad con los sistemas predecesores del 3GPP y también con otros sistemas como Worldwide Interoperability for Microwave Access (WiMAX) o Wireless Fidelity (WiFi).

Algunas de las ventajas de LTE son: una mayor capacidad de transmisión por parte de los usuarios, baja latencia, funcionamiento plug-and-play, FDD y TDD coexistiendo en una misma plataforma, experiencia de usuario mejorada y una arquitectura de red más simple, con la consiguiente reducción de costes de operación.

En términos de mercado, se preveía el despliegue inicial de LTE a nivel mundial para 2012, aunque la actual situación económica ha provocado que no se cumplan estas previsiones. La mayoría de los operadores de comunicaciones móviles se encuentran actualmente inmersos en pruebas piloto, aunque existen algunos que ya tienen su red LTE operativa, como es el caso de Telia Sonera [1], que fue el primero en lanzar comercialmente LTE. A finales de 2012 el número de redes LTE comerciales alcanzó la cifra de 130, aunque en España el despliegue de red comercial aún no se ha llevado a cabo.

En cualquier caso, la situación económica mundial no favorece la revolución tecnológica por lo que son necesarios estudios en profundidad sobre el proceso de adopción de este nuevo estándar que minimicen el desembolso económico asociado a la transición. El inminente despliegue de LTE por parte de los operadores requiere la adaptación de los procesos de planificación y optimización a esta nueva tecnología, tema en el que se centra esta Tesis Doctoral.

Planificar una red móvil consiste en determinar los elementos necesarios, equipos concretos, su ubicación y su configuración, para cumplir con unos determinados requisitos de cobertura, capacidad y calidad que vienen fijados por un determinado modelo de negocio, unas previsiones de crecimiento del número de usuarios y la experiencia con los sistemas predecesores si la hubiera. Por otro lado, optimizar la red consiste en el ajuste de los parámetros y elementos configurables del sistema, de forma que se maximice el rendimiento de la red. Por lo tanto, la optimización puede verse como un paso necesario al final del proceso de planificación, aunque va más allá de la planificación inicial y se mantiene a lo largo del tiempo, con optimizaciones periódicas o puntuales ante la detección de algún problema en la red móvil. El rendimiento de la red se puede estimar con la utilización de modelos adecuados y medir, una vez implementados los cambios resultantes de la optimización, a través de estadísticas recogidas de la red. Esta Tesis Doctoral está únicamente centrada en la planificación y optimización de la red de acceso radio, es decir, suponiendo que la red de transmisión y el núcleo de red están correctamente dimensionados. 
Por último, cabe destacar que esta Tesis Doctoral está enmarcada y regida por el convenio de colaboración establecido entre la Universidad Politécnica de Valencia y la empresa Ingenia Telecom S.L. Con el desarrollo de esta Tesis Doctoral, la empresa podrá seguir avanzando en el desarrollo de nuevos servicios de análisis y optimización con la inclusión de funcionalidades LTE que le proporcionen una ventaja estratégica frente a sus competidoras. El hecho de que esta Tesis Doctoral se enmarque dentro de una empresa, también implica determinadas restricciones en cuanto a la confidencialidad de los datos y los procedimientos aquí descritos.

\subsection{Estado del Arte}

La planificación de la red de acceso radio comprende tres fases [2]:

1. El dimensionamiento de la red, en la que a partir de los requisitos de cobertura, capacidad y calidad, las características del área a planificar y una predicción de tráfico se hace una estimación del número de estaciones base necesarias, siendo posible la variación de este número en fases posteriores.

2. La planificación de cobertura y capacidad, que a partir de los requisitos marcados por el operador selecciona los mejores emplazamientos entre los posibles candidatos, determina la configuración de las estaciones base y otros elementos de la red y realiza análisis de cobertura, capacidad y calidad.

3. La optimización de la red en la que, a partir de medidas y estadísticas obtenidas de la red o Key Performance Indicators (KPIs), se realiza un ajuste de parámetros.

Durante la planificación se utilizan predicciones en base a modelos [3], ajustados o no a través de medidas [4], para determinar la mejor configuración inicial y estimar el rendimiento de la red planificada. Por su parte, en la optimización también se utilizan medidas (ya sean procedentes de la red, de los terminales de usuario o de campañas de drive test [5]) como complemento a la información que proporcionan los modelos del sistema para analizar el rendimiento actual de la red, detectar cambios necesarios o estimar el rendimiento del sistema tras la implementación de dichos cambios.

Una manera de mejorar la utilidad de las medidas adquiridas consiste en geo-referenciar las estadísticas e incluso las propias medidas de cada terminal. Con esta información se pueden obtener mapas de distribución de tráfico, de nivel de cobertura, de señal recibida o de throughput en cada punto del área de 


\section{CAPÍTULO 1. INTRODUCCIÓN}

optimización en el que haya medidas disponibles. Esta información, procesada adecuadamente, será de gran utilidad como entrada para la fase de planificación y optimización. Esta técnica se conoce como Virtual Drive Test (VDT) [6], XMap Estimation [7, 8] o Minimization of Drive Tests (MDT) [9] y requiere disponer de la capacidad de localizar a los usuarios en base a las medidas que éstos reportan.

Existen múltiples estudios que analizan distintos métodos de localización en redes móviles, que han sido de gran interés prácticamente desde la aparición de las mismas y, sin embargo, continúan siéndolo, como muestra la gran cantidad de estudios recientes sobre esta temática [10-12]. En [13-16] se analizan distintas alternativas de métodos de localización en redes móviles basados en medidas. Los métodos se pueden clasificar en tres grupos: basados en Global Positioning System (GPS), en procesado geométrico y en fingerprinting. Los basados en GPS son los que mayor precisión aportan, aunque no pueden usarse siempre, sobre todo en entornos urbanos al haber un gran número de usuarios en interiores (más del $75 \%$ ), entre edificios altos, en túneles, etc. Por otro lado se encuentran los métodos basados en medidas de red, métodos con menor precisión pero total disponibilidad. Entre ellos destacan los métodos basados en procesar estas medidas de forma geométrica y estadística y, por otro lado, los métodos basados en fingerprinting, es decir, en cuadrar las medidas reportadas por la red con las medidas almacenadas en una base de datos. Las medidas de base de datos pueden proceder de campañas de drive test o de la utilización de alguna herramienta que aplique algún modelo de predicción de pérdidas de propagación como las utilizadas en planificación.

Debido a su total disponibilidad y a la independencia con el equipo de usuario, los métodos basados en medidas están recibiendo un mayor interés por parte de operadores e investigadores, como refleja el gran número de propuestas para mejorar la precisión conseguida [11, 17-19]. Sin embargo, la mayoría de estos estudios consideran disponibles medidas de la red que en las redes operativas actualmente no se capturan y/o no hay posibilidad para ello. Además, ninguno de los estudios existentes realiza una comparación de las implementaciones de los distintos métodos para obtener de forma empírica cuál es el que proporciona lo mejores resultados, sobre todo bajo la suposición de tener disponibles los mismos datos que en una red real operativa. Respecto a las prestaciones de los métodos de localización en LTE, dado el reciente despliegue en algunos países y la inexistencia, salvo en fase de test y pruebas piloto, en otros, no abundan las publicaciones de estudios y resultados en relación con esta tecnología, aunque sí es posible encontrar algunos basados en simulaciones [7, 8, 20,21] o prototipos simples [22] y también manuales de fabricantes abordando las posibilidades de localización que ofrece LTE [23]. 
Una vez obtenidos los datos de entrada necesarios, tanto la planificación como la optimización automática requieren la evaluación de un gran número de alternativas de configuración en el proceso de minimización de la función de coste objetivo. Se trata de un problema de optimización que en términos de complejidad computacional es de clase NP-complejo [24]. Simulated Annealing (SA) es un método probabilístico de búsqueda meta-heurística que se utiliza muy a menudo para resolver problemas de optimización complejos y, concretamente, es muy utilizado en planificación y optimización automática de redes móviles [24-26]. Sin embargo, existe una gran variedad de propuestas alternativas de resolución de este problema, como la utilización del método de Taguchi [27, 28] o de teoría de juegos [29]. Además, existen estudios donde se comparan las prestaciones de SA con respecto a Genetic Algorithm (GA) y Tabu Search (TS) [24].

La función de coste objetivo es otro punto crítico de la planificación y optimización automáticas, pues durante su funcionamiento los métodos de búsqueda evalúan en numerosas ocasiones esta función. Además, su correcto diseño determinará el éxito de la planificación y posterior optimización y su adecuación a los objetivos finales del operador. Por último, de la correcta formulación de la función de coste dependerá la posibilidad de poder utilizar métodos más eficientes que los métodos de búsqueda local para la obtención de la solución óptima, como Integer Linear Programming (ILP) [30-32] o métodos de optimización convexa [33]. Además, dado que la evaluación de la función de coste puede implicar realizar cálculos en cada punto de la rejilla en que se divide el escenario de planificación/optimización, es posible ahorrar coste computacional en el proceso limitando la cantidad de re-cálculos según los cambios realizados $[34]$.

Las salidas de la herramienta de planificación/optimización incluyen la selección de los mejores emplazamientos, la inclinación - o tilt - y acimut de la antena y potencia de los canales de control [5, 25, 35]. En algunos casos, esta optimización radio va acompañada de otro tipo de optimización logística que incluye la lista de vecinas o la asignación de identificadores de celda o de áreas de localización [36-38].

El problema de la selección de bandas de frecuencia [39, 40] y gestión de la reutilización de recursos $[41,42]$ es otro de los aspectos clave en el futuro de las redes de comunicaciones móviles LTE. Para permitir una óptima calidad de servicio en las comunicaciones y una máxima utilización del espectro asignado, es necesaria la aplicación de una serie de algoritmos dinámicos de asignación conjunta de portadoras radio y potencia transmitida que minimicen las interferencias introducidas en el sistema. En la actualidad todos los estudios se basan en escenarios sintéticos y en distribuciones uniformes del tráfico [43]. Es necesario abordar algoritmos capaces de calcular una máscara de asignación 


\section{CAPÍTULO 1. INTRODUCCIÓN}

de frecuencia/potencia como base para la asignación de recursos a cada usuario LTE en función de su situación concreta. Para ello es fundamental incorporar las técnicas de predicción de localización de manera que se pueda identificar un mapa de distribución de usuarios y calidad de servicio que permita aplicar soluciones a medida de la máscara de frecuencia/potencia a cada zona en función de la carga experimentada.

De manera particular, las prestaciones de las redes LTE dependen en gran medida de la correcta gestión de la interferencia [42, 44]. Además de los mecanismos estandarizados de Inter-Cell Interference Coordination (ICIC), habrá que tener en cuenta los nuevos paradigmas de despliegue celular que incluyen múltiples estratos, con macro/micro/femto celdas que se interfieren entre sí y que deben operar lo más autónomamente posible [45-47], así como nuevas tecnologías que permitan aprovechar al máximo el espectro, como la radio cognitiva y, en particular, el Acceso Oportunista al Espectro (AOE) [48, 49].

\subsection{Objetivos Planteados}

El objetivo principal de la investigación es desarrollar mecanismos y algoritmos que permitan la planificación y optimización de redes LTE de forma semi-autónoma. Este objetivo principal comprende varios sub-objetivos que se detallan a continuación:

- Diseñar mecanismos de localización de terminales basados únicamente en la información disponible en la red. Estos algoritmos de localización permitirán elaborar colecciones de información geo-referenciada que ayuden en los procesos de planificación de despliegue inicial y optimización de una red LTE ya existente.

- Estudiar la optimización del proceso de planificación de la red LTE teniendo en cuenta su coexistencia con redes plenamente operativas $2 \mathrm{G}$ y $3 \mathrm{G}$. Se estudiará la viabilidad y precisión de distintos modelos del sistema que permitan simplificar matemáticamente la evaluación de las prestaciones. Para ello se analizarán modelos convexos y lineales.

- Seleccionar funciones de coste que reflejen los requisitos de los operadores y permitan una rápida evaluación. Esta función de coste debe comprender los requisitos de cobertura, capacidad y calidad fijados. También será necesario evaluar distintas alternativas de simplificación del propio proceso de búsqueda. 
- Desarrollar un sistema experto que permita capturar el conocimiento de ingenieros con una dilatada experiencia para asistir en la toma de decisiones relativa a la optimización radio de LTE.

- Diseñar mecanismos de optimización del uso del espectro para la tecnología LTE, contemplando el estudio de la mejor configuración de reutilización de frecuencias y las posibilidades del uso oportunista del espectro fuera de la banda propia de LTE.

- Investigar mecanismos ICIC y estudiar diferentes opciones de implementación para conseguir balancear la carga de forma óptima en redes heterogéneas que incluyan femto-celdas.

\subsection{Principales Aportaciones de la Tesis}

Esta Tesis Doctoral pone mayor énfasis en tres puntos, sobre los que recaen las mayores aportaciones de la investigación realizada:

- El algoritmo de localización, porque habilita geo-referenciar estadísticas y medidas obtenidas de la red, sin necesidad de introducir ninguna nueva entidad lógica en el sistema ya que se basa únicamente en medidas ya disponibles en la red.

- El correcto modelado del sistema y el diseño de la función de coste utilizada en los procesos de planificación y optimización automáticas, por las ventajas en cuanto a calidad de la solución final y menor tiempo de ejecución requerido.

- Las técnicas de AOE, por el gran interés de los operadores en ampliar la capacidad de sus redes más allá del limitado ancho de banda asignado por parte de las autoridades reguladoras del espectro radioeléctrico y la gran utilidad de su aplicación a entornos femto-celulares.

\subsection{Estructura de la Tesis}

Esta Tesis Doctoral se basa en las siguientes hipótesis:

- La localización de terminales móviles a partir de datos procedentes de logs de la mensajería generada por la red durante las llamadas constituye una herramienta básica para la planificación y optimización automática de una red móvil LTE. 


\section{CAPÍTULO 1. INTRODUCCIÓN}

- La linealización de los modelos utilizados para la estimación de la carga de las celdas en los procesos automáticos de planificación y optimización de redes móviles LTE permite acelerar su cálculo manteniendo la precisión y evitando así tener que adoptar criterios conservadores.

- Los sistemas de inteligencia artificial como las redes neuronales, pueden ayudar en los procesos de planificación y optimización automática con el entrenamiento adecuado basado en el conocimiento de ingenieros de optimización expertos.

- El uso oportunista del espectro, habilitado por un conjunto de herramientas disponibles, incluida entre ellas la localización de terminales móviles, permite optimizar la utilización de los recursos en frecuencia tanto en entornos macro-celulares como femto-celulares.

En función de las hipótesis formuladas, el resto del documento se ha estructurado como se detallada a continuación.

En primer lugar, en el capítulo 2 se describe la metodología seguida en esta Tesis Doctoral en base a unas necesidades detectadas, concentrándose principalmente en los simuladores utilizados y las suposiciones y modelos empleados en cada uno de ellos. Por un lado, se ha utilizado un simulador estático que servirá para evaluar las prestaciones de las distintas soluciones candidatas en los procesos de planificación y optimización de la red de acceso radio. Las matrices de interferencia generadas se utilizarán asimismo en la herramienta de planificación automática de frecuencias. Por otro lado, se ha hecho uso de un simulador dinámico para el bloque de optimización del espectro radioeléctrico, concretamente para la evaluación de las prestaciones de distintas mecanismos de reutilización de frecuencias analizados, para la evaluación de la ganancia potencial alcanzable tras un proceso de refarming y para la simulación y evaluación de prestaciones de distintos mecanismos de $\mathrm{AOE}$ tanto en entornos macro-celulares como femto-celulares.

A continuación, en el capítulo 3, se detalla el conjunto de datos disponibles que se han utilizado en los procesos de planificación y optimización semiautomática desarrollados en esta Tesis Doctoral. Por otro lado, se describe el conjunto de herramientas principales utilizadas en los procesos automáticos propuestos de planificación y optimización, además de evaluar las prestaciones que ofrecen. Para el algoritmo de localización de terminales móviles basado en medidas reportadas, se realizará un estudio comparativo de sus resultados con otras alternativas de localización, además de proponer distintos mecanismos que mejoran su precisión. Además, se utilizará este algoritmo para la generación de mapas con información geo-referenciada que serán utilizados en los procesos de planificación y optimización. Por otro lado, se describirá un sistema experto 
basado en redes neuronales que habilita la optimización automática aplicando el conocimiento adquirido mediante el entrenamiento realizado por ingenieros de optimización.

El capítulo 4 desarrolla las ideas propuestas para planificar y optimizar la red de acceso radio de un sistema LTE de forma semi-autónoma. Después de concretar objetivos y formular el problema, se describe la linealización realizada para poder estimar de forma rápida la carga de cada celda del sistema. Además, se estudian distintas alternativas para la búsqueda de la solución óptima del problema combinacional. El detalle de los procesos automáticos propuestos de planificación y optimización de redes LTE se desarrolla también en este capítulo. Por último, se estudia un ejemplo de aplicación del sistema experto descrito en el capítulo anterior.

A continuación, se trata la optimización del espectro radioeléctrico en el capítulo 5, que abarca distintos temas complementarios. Concretamente se aborda la reutilización de frecuencias para aumentar la eficiencia espectral del sistema sin llegar a perjudicar la equidad en el reparto de recursos, el refarming del espectro con el fin de hacer un uso más eficiente del mismo, la planificación automática de frecuencias tras el refarming, el AOE para aprovechar los huecos disponibles creados por sistemas que no hacen un uso exhaustivo de las bandas de frecuencia que tienen asignadas y la auto-organización de femto-celdas para evitar situaciones de excesiva interferencia en los esquemas donde se realiza acceso oportunista a una misma banda compartida.

Por último, en la sección 6 se presentarán las conclusiones derivadas de esta Tesis Doctoral y se propondrán posibles líneas futuras de investigación que den continuidad al trabajo llevado a cabo.

\subsection{Publicaciones Relacionadas con la Tesis}

\section{Revistas}

- V. Osa, J. Matamales, J. F. Monserrat, y J. López, "Localization in Wireless Networks: The Potential of Triangulation Techniques", Wireless Personal Communications, vol. 68, no. 4, pp. 1525-1538, Febrero 2013.

- V. Osa, C. Herranz, J. F. Monserrat, y X. Gelabert, "Implementing Opportunistic Spectrum Access in LTE-A", EURASIP Journal on Wireless Communications and Networking, vol. 2012, no. 1, p. 99, Marzo 2012.

- V. Osa, J. Matamales, J. F. Monserrat, J. López, V. Soler, y N. Cardona, "Expert Systems for the Automatic Optimisation of 3G Networks", WAVES, pp. 97-105, 2010. 


\section{Congresos y Workshops}

- C. Herranz, V. Osa, J. F. Monserrat, D. Calabuig, N. Cardona y X. Gelabert, "Cognitive Radio Enabling Opportunistic Spectrum Access in LTE-Advanced Femtocells", en 2012 IEEE International Conference on Communications (ICC), Junio 2012, pp. 5593-5597.

- C. Herranz, V. Osa, J. F. Monserrat, D. Calabuig, N. Cardona y X. Gelabert, "Cognitive Radio Enabling Opportunistic Spectrum Access in LTE-Advanced Femtocells", en Proc. of the 3rd COST IC1004 Management Committee Meeting, TD(12)03011, Barcelona, Febrero 2012.

- C. Herranz, V. Osa, X. Gelabert, P. Chaparro, J. F. Monserrat, y J. A. Fernández-Luque, "Análisis de Viabilidad y Rendimiento de un Sistema LTE Cognitivo", en Actas de las XXI Jornadas Telecom I+D, Santander, Septiembre 2011, pp. 118-125.

- J. Matamales, V. Osa, J. F. Monserrat, N. Cardona, J. López, y V. Soler, "Sistemas Expertos para la Optimización Automática de Redes 3G", en Actas del XXV Simposium Nacional de la Unión Cientíca Internacional de Radio, Bilbao, 2010.

- J. Matamales, V. Osa, J. F. Monserrat, N. Cardona, J. López, y V. Soler, "Optimización Automática de Redes UMTS Operativas", en Actas del XXIV Simposium Nacional de la Unión Científica Internacional de Radio, Santander, 2009.

- J. Matamales, V. Osa, J. F. Monserrat, N. Cardona, J. López, y V. Soler, "Automatic Optimisation of Operative UMTS Networks", en Proc. of the 8th COST2100 Management Committee Meeting, TD(09)830, Valencia, Febrero 2009.

\subsection{Otras Publicaciones}

\section{Revistas}

- D. Martín-Sacristán, J. F. Monserrat, V. Osa, y J. Cabrejas, "LTE-A System Level Simulation Platform for IMT-Advanced Evaluation", WAVES, pp. 15-24, 2011.

\section{Congresos y Workshops}

- R. Gimenez, I. Luengo, A. Mereu, D. Gimenez, R. Casar, J. Pertejo, S. Diaz, J. F. Monserrat, V. Osa, J. Herrera, y I. Arizaga, "PROSIMOS 
A Tool for Identifying Business Cases in the Implementation of a Priority Communications Systems for First Responders in Public Mobile Networks", en Proceedings of the 6th Future Security Research Conference 2011, Berlin, Septiembre 2011.

- E. García-Couto, M. Cañete, C. del Castillo, J. A. Fernández-Luque, C. Herranz, L. Juan-Llacer, J. M. Molina-Garcia-Pardo, C. Mosquera, y V. Osa, "CORAGE: an OFDMA-based cognitive radio system in emergency scenarios", en Proceedings of the 4th International Conference on Cognitive Radio and Advanced Spectrum Management, ser. CogART '11. New York, NY, USA: ACM, 2011, p. 9:1-9:6.

- R. Gimenez, I. Luengo, A. Mereu, D. Gimenez, R. Casar, J. Pertejo, S. Díaz, J. F. Monserrat, V. Osa, J. Herrera, M. Ortega, y I. Arizaga, "Simulator for PROSIMOS (PRiority communications for critical SItuations on MObile networkS) Service", en Towards a Service-Based Internet. ServiceWave 2010 Workshops, ser. Lecture Notes in Computer Science, M. Cezon y Y. Wolfsthal, Eds. Springer Berlin / Heidelberg, 2011, vol. 6569, pp. $74-81$. 


\section{Capítulo 2}

\section{Metodología}

Esta Tesis Doctoral plantea distintas soluciones complementarias a la cuestión de cómo realizar automáticamente la planificación y optimización de una red de comunicaciones móviles LTE. Concretamente, se busca optimizar la planificación de la red de acceso radio - y las posteriores optimizaciones de la misma - utilizando como dato de entrada la distribución de tráfico observada en tecnologías preexistentes sobre la misma región. Asimismo, se pretende optimizar el uso del espectro de la red LTE, en lo concerniente al uso tanto de las frecuencias licenciadas como de aquellas bandas de las que se pueda hacer un uso oportunista.

La figura 2.1 representa el diagrama de bloques de la metodología seguida, pudiéndose consultar la leyenda de los distintos tipos de bloques en la figura 2.2. En la sección 2.1 se realiza una descripción de las necesidades detectadas a lo largo de la investigación llevada a cabo. Posteriormente, en las secciones 2.2 y 2.3 , se detallan las herramientas de simulación utilizadas, ya que estas entidades concentran la mayor parte de las suposiciones realizadas en todo el proceso seguido.

\subsection{Necesidades}

Los distintos algoritmos propuestos en los que se sustenta esta Tesis Doctoral se basan en la realización de simulaciones para la evaluación tanto de los resultados finales conseguidos como de las distintas alternativas propuestas en el proceso de búsqueda de la mejor solución. Para la consecución de este objetivo ha sido necesaria la utilización de distintos simuladores que se han integrado con las herramientas y algoritmos desarrollados. 
CAPÍTULO 2. METODOLOGÍA

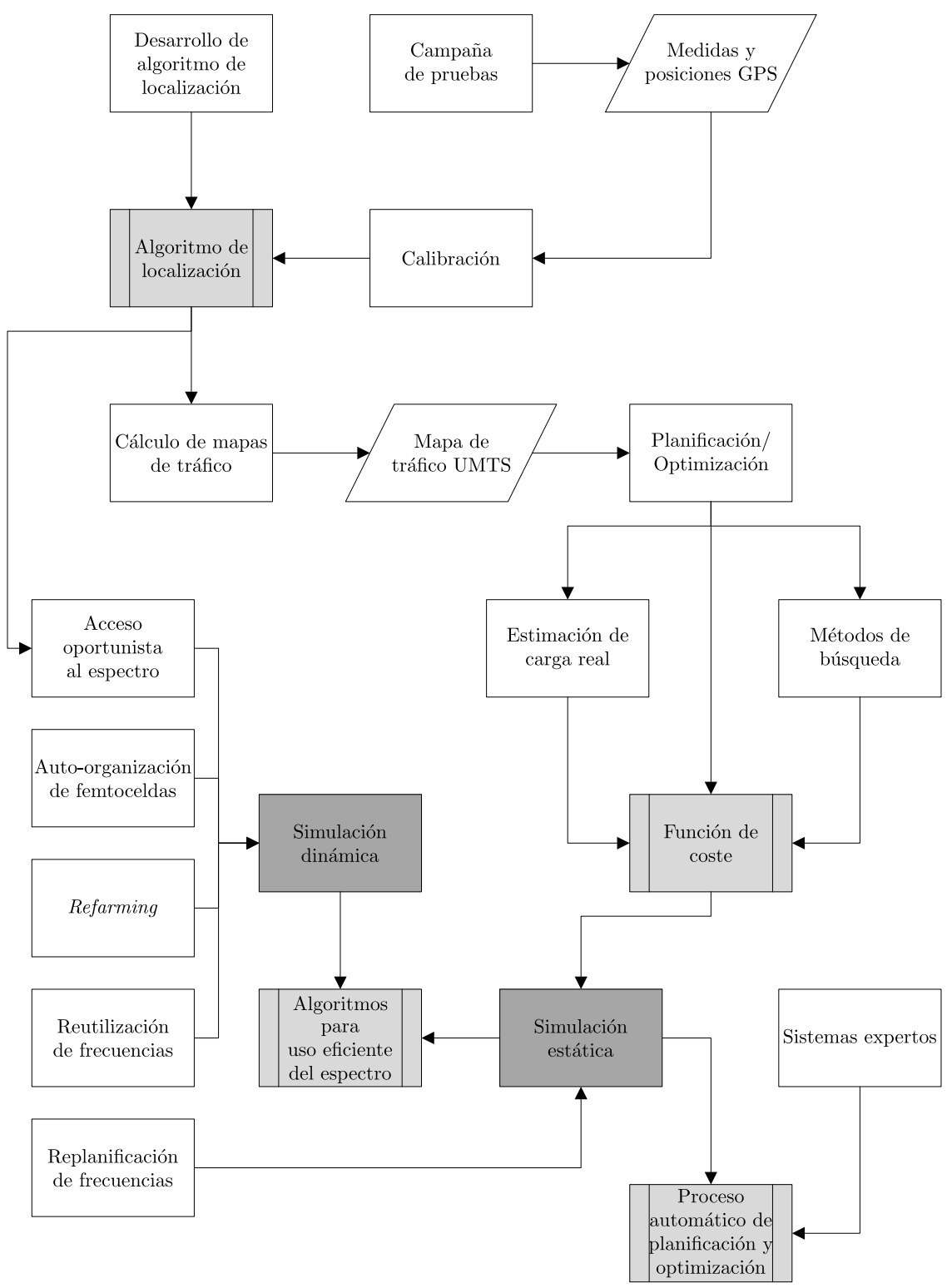

Figura 2.1: Diagrama de bloques de la metodología seguida 


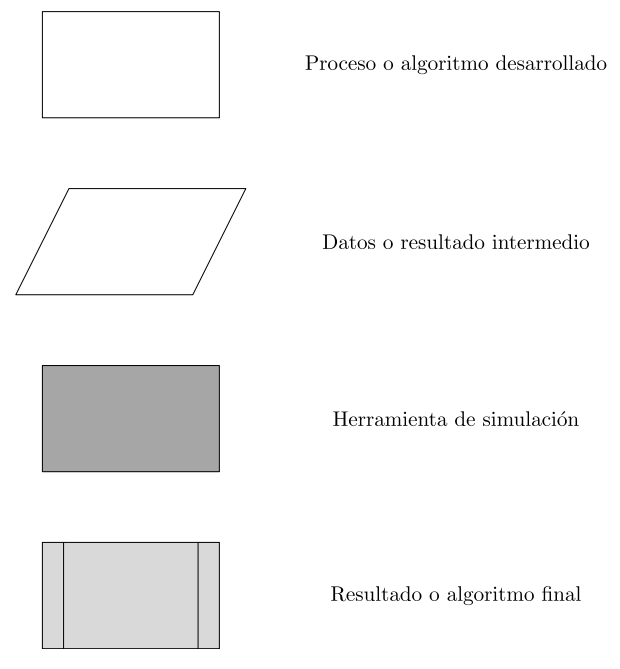

Figura 2.2: Leyenda del diagrama de bloques de la metodología

Como excepción a lo anterior, el algoritmo de localización propuesto en esta Tesis Doctoral no hace uso de ninguna herramienta de simulación, si bien sí es necesaria la aplicación de una serie de modelos para la estimación de distancias entre el usuario y las celdas - de las que éste reporta medidasmediante un simulador simplificado. Este algoritmo ha requerido, además, la realización de una campaña de medidas para la recopilación de llamadas de prueba que permitiera tener disponibilidad de datos para la calibración del algoritmo. En esta campaña de medidas ha colaborado activamente la empresa Ingenia Telecom S.L. sin la que no se dispondría de la información necesaria.

En lo que respecta a los algoritmos basados en simulaciones, por un lado ha sido necesaria la utilización de un simulador estático, en el sentido de que no se realiza una simulación a nivel de paquete y no existe una dimensión temporal en los resultados. El simulador estático deberá evaluar las prestaciones de la red LTE en una ubicación concreta en base a la aplicación de una serie de modelos y suposiciones. Esta herramienta de simulación será utilizada en la planificación y optimización de la red de acceso radio y la replanificación automática de frecuencias.

Por otro lado, se ha requerido la utilización de un simulador dinámico del sistema LTE, con capacidad de emular la transmisión real de paquetes y los procesos de retransmisión y Hybrid Automatic Repeat Request (HARQ) para obtener así una evolución temporal del comportamiento de la red. Esta otra plataforma de simulación se ha utilizado únicamente para optimizar el uso 
del espectro por parte de LTE, concretamente para la evaluación de distintas técnicas de reutilización de frecuencias, para el análisis de prestaciones de las propuestas de $\mathrm{AOE}$ contempladas, para el estudio de los mecanismos propuestos de auto-organización de femtoceldas y para el análisis de coexistencia de LTE con tecnologías predecesoras dentro del proceso de refarming. El resto de esta sección está dedicado a describir ambos simuladores.

\subsection{Simulador Estático}

\subsubsection{Descripción}

La utilización de un simulador estático permite evaluar las prestaciones que una red móvil ofrece en una determinada posición del escenario bajo estudio. Factores como el tipo de tráfico generado en el escenario no tienen influencia alguna en los resultados pues la dimensión temporal no interviene en este tipo de simulaciones. Los resultados obtenidos por este tipo de simulador serán los valores de Signal-to-Interference plus Noise Ratio (SINR) y throughput en cada casilla de la rejilla definida sobre el escenario, a partir de los que se podrán derivar mapas de cobertura por celda (véase la figura 2.3), áreas de serving cell (figura 2.4) o distribución del tráfico cursado total y por celda (figuras 2.5 y 2.6 , respectivamente).

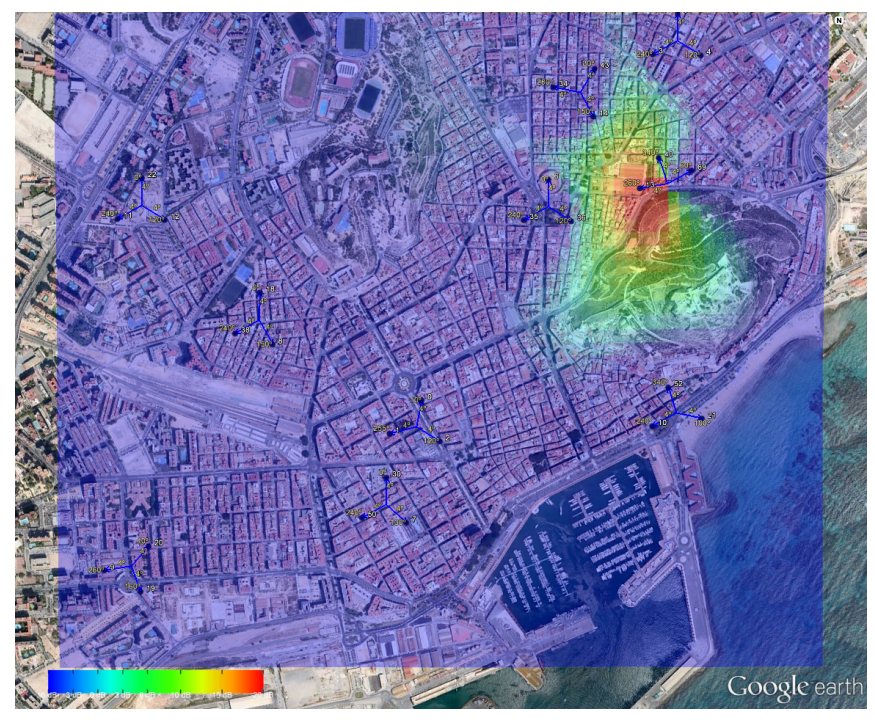

Figura 2.3: Mapa de SINR de una celda obtenido con el simulador estático 


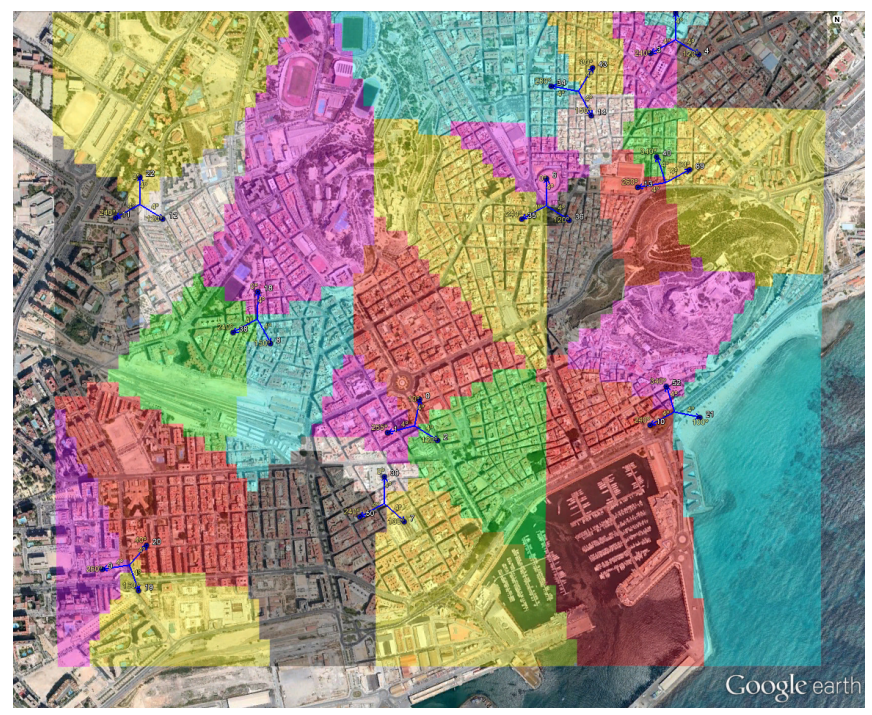

Figura 2.4: Mapa de serving cell obtenido con el simulador estático

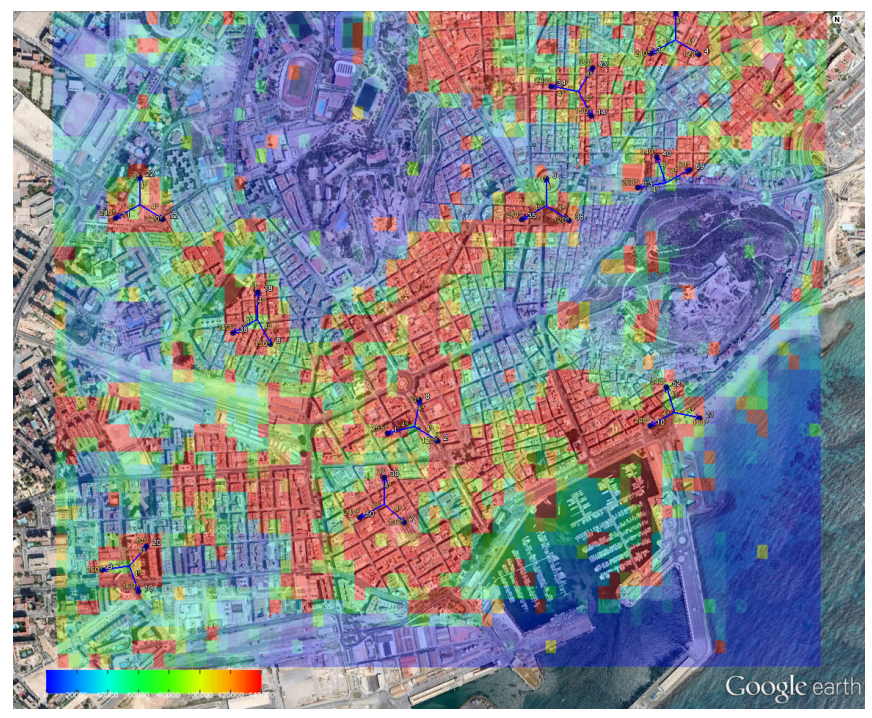

Figura 2.5: Mapa de tráfico cursado obtenido con el simulador estático 


\section{CAPÍTULO 2. METODOLOGÍA}

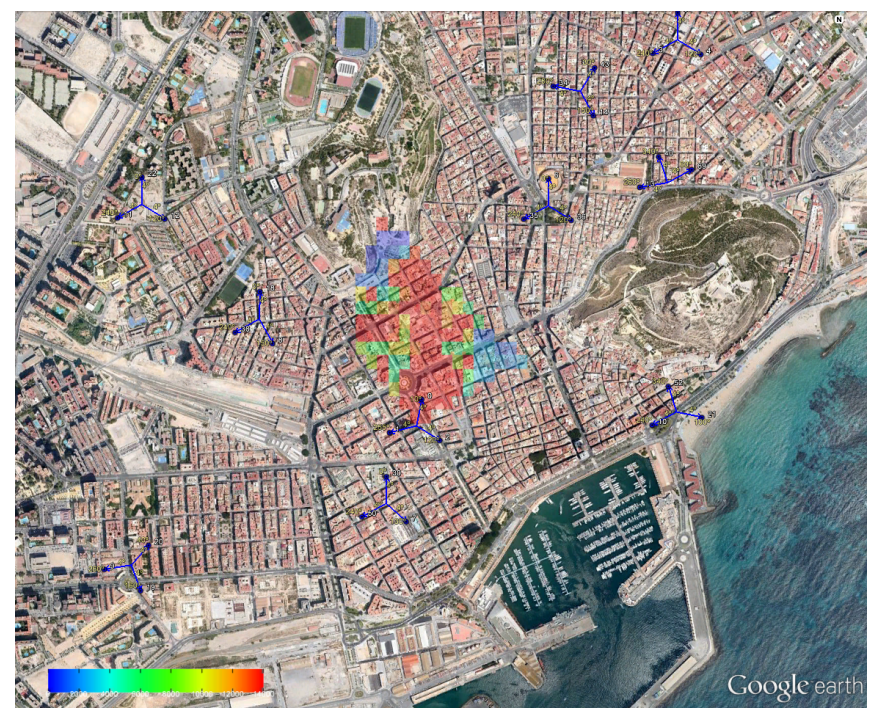

Figura 2.6: Mapa de tráfico cursado por una celda obtenido con el simulador estático

El simulador estático desarrollado en esta Tesis Doctoral se utilizará en los procesos de planificación y optimización de redes LTE propuestos, así como en la herramienta de replanificación automática de frecuencias. Los datos de entrada necesarios son, básicamente, la topología de la red a simular, es decir, posición de cada celda, frecuencia de operación, ancho de banda, acimut, tilt, potencia total disponible y potencia de las señales de referencia.

La herramienta de simulación diseñada no es específica de la tecnología LTE, sino que podría ser igualmente empleada para estudiar las prestaciones de redes Global System for Mobile communications (GSM) y UMTS. De hecho, para la herramienta de replanificación de frecuencias propuesta en esta Tesis Doctoral será necesario poder simular las prestaciones de una red GSM y decidir cuál es la mejor redistribución de frecuencias una vez se ha eliminado un determinado conjunto de portadoras por el refarming de GSM a LTE.

A continuación se detallan las suposiciones consideradas en esta herramienta de simulación estática. 


\subsubsection{Suposiciones}

\subsubsection{Caracterización de las antenas}

En esta sección se describen los diagramas de radiación horizontal y vertical de la estación base contemplados en el simulador estático, si bien podrían utilizarse los diagramas de radiación reales si se conociera el fabricante y modelo de antena de cada una de las celdas del escenario, aportando resultados más realistas.

El patrón horizontal viene dado por

$$
A_{h}(\phi)=-\min \left[12 \cdot\left(\frac{\phi}{\phi_{3 d B}}\right)^{2}, A_{m}\right],
$$

donde $A_{h}(\phi)$ es la ganancia relativa de la antena en decibelios en la dirección $\phi$, siendo $-180^{\circ} \leq \phi \leq 180^{\circ}, \phi_{3 d B}$ el ancho de haz a $3 \mathrm{~dB}$, que se supone igual a $70^{\circ}$, y $A_{m}=20 \mathrm{~dB}$ la máxima atenuación producida por la antena.

En elevación se define una patrón muy similar definido como

$$
A_{v}(\theta)=-\operatorname{mín}\left[12 \cdot\left(\frac{\theta-\theta_{\text {tilt }}}{\theta_{3 d B}}\right)^{2}, A_{m}\right]
$$

donde $A_{v}(\theta)$ es la ganancia relativa de la antena en decibelios en la dirección de elevación $\theta$, siendo $-90^{\circ} \leq \theta \leq 90^{\circ}, \theta_{3 d B}$ el ancho de haz a $3 \mathrm{~dB}$, que se supone que es $15^{\circ}, \theta_{\text {tilt }}$ es el tilt de la instalación y $A_{m}=20 \mathrm{~dB}$ la máxima atenuación producida por la antena.

La combinación de ambos patrones de radiación se expresa como

$$
A(\phi, \theta)=-\min \left[-\left(A_{h}(\phi)+A_{v}(\theta)\right), A_{m}\right] .
$$

En lo que respecta al User Equipment (UE), la antena se supone omnidireccional y $\sin$ ganancia.

\subsubsection{Pérdidas de propagación}

El cálculo de las pérdidas de propagación en el simulador estático se realiza siguiendo modelos distintos según la frecuencia de operación de la red cuyas prestaciones se evalúan. Suponiendo que el simulador se utiliza en entorno urbano y sin visión directa, para la banda de 2 a $6 \mathrm{GHz}$ se utiliza el modelo Non Line of Sight (NLoS) Urban Macro mostrado en la ecuación (2.4). Este modelo es el propuesto por la International Telecommunications Union - Radiocommunication sector (ITU-R) para la evaluación de tecnologías candidatas a International Mobile Telecommunications-Advanced (IMT-Advanced) [50]. 


$$
\begin{aligned}
L_{f \geq 2 G H z}= & 161,04-7,1 \log _{10}(W)+7,5 \log _{10}(h) \\
& -\left(24,37-3,7\left(h / h_{B S}\right)^{2}\right) \log _{10}\left(h_{B S}\right) \\
& +\left(43,42-3,1 \log _{10}\left(h_{B S}\right)\right)\left(\log _{10}(d)-3\right) \\
& +20 \log _{10}\left(f_{c}\right)-\left(3,2\left(\log _{10}\left(11,75 h_{U E}\right)\right)^{2}-4,97\right),
\end{aligned}
$$

donde $W$ es el ancho medio de las calles, $h$ la altura media de los edificios, $h_{B S}$ la altura de la estación base, $d$ la distancia entre la estación base y el UE, $f_{c}$ la frecuencia de la portadora en $\mathrm{GHz}$ y $h_{U E}$ la altura del equipo de usuario. Todas las medidas de longitud se expresan en metros.

Para el resto de frecuencias por debajo de $2 \mathrm{GHz}$ se utiliza el modelo COST 231 - Hata. El modelo original Okumura-Hata [51, 52] es aplicable al rango de frecuencias entre $150 \mathrm{MHz}$ y $1,5 \mathrm{GHz}$, pero la acción COST 231 diseñó una extensión de dicho modelo hasta los $2 \mathrm{GHz}$ [53]. Las pérdidas calculadas siguiendo este modelo vienen dadas por la siguiente ecuación:

$$
\begin{aligned}
L_{f<2 G H z}= & 46,3+33,9 \log 10(f)-13,82 \log \left(h_{B S}\right)-a\left(h_{U E}\right) \\
& +\left(44,9-6,55 \log _{10}\left(h_{B S}\right)\right) \log _{10}(d)+C_{m},
\end{aligned}
$$

donde $f$ es la frecuencia de operación que viene expresada en $\mathrm{MHz}, h_{B S}$ y $h_{U E}$ la altura de la estación base y del terminal de usuario respectivamente, expresadas en metros, $d$ la distancia entre la estación base y el terminal de usuario expresada en $\mathrm{km}, C_{m}$ un factor de corrección según el entorno que vale $0 \mathrm{~dB}$ para ciudades de tamaño medio entornos sub-urbanos con una densidad media de árboles y $3 \mathrm{~dB}$ para centros metropolitanos y $a\left(h_{U E}\right)$ viene dada por la siguiente expresión:

$$
a\left(h_{U E}\right)=\left(1,1 \log _{10}(f)-0,7\right) h_{U E}-\left(1,56 \log _{10}(f)-0,8\right) .
$$

Para otros posibles entornos se podría hacer uso de las alternativas que propone la ITU-R para la evaluación de entornos urbanos macro-celulares y micro-celulares, sub-urbanos, rurales e incluso para interiores, distinguiendo los casos en los que hay y no hay visión directa. Además el modelo COST 231 - Hata contempla distintas correcciones según el escenario sea urbano, suburbano o rural [54].

\subsubsection{Balance de potencias}

Para estimar la potencia recibida desde cada estación base en cada casilla del escenario y así poder estimar la SINR se tienen en cuenta los siguientes términos: 
- Potencia transmitida: 40/43/46 dBm (5/10/20 MHz)

- Ganancia de antena del evolved Node B (eNB): $17 \mathrm{dBi}$

- Pérdidas de cableado hasta antena del eNB: $3 \mathrm{~dB}$

- Ganancia según patrón de radiación horizontal y vertical: según lo descrito en la sección 2.2.2.1

- Pérdidas de propagación: según lo descrito en la sección 2.2.2.2

- Margen de shadowing: $9,87 \mathrm{~dB}$

- Pérdidas de penetración en edificios: $20 \mathrm{~dB}$

- Ganancia de antena del UE: 0 dBi

Conviene aclarar que el margen de shadowing contemplado se corresponde con una probabilidad de cobertura del $95 \%$, al considerarse una distribución log-normal del shadowing con una desviación típica de 6 dB [55].

Para el cálculo de la SINR también se considera el ruido térmico, con una densidad espectral de potencia de $-174 \mathrm{dBm} / \mathrm{Hz}$ y una figura de ruido en el UE de $7 \mathrm{~dB}$. Además, es necesario estimar la carga real en cada celda para que el nivel de SINR se mida atendiendo a la potencia realmente transmitida por cada estación base. La alternativa que consiste en asumir un nivel de potencia fijo de las estaciones base interferentes requiere la suposición conservadora de potencia máxima transmitida, lo que conlleva resultados poco realistas. La sección 4.2 detalla el procedimiento propuesto en esta Tesis Doctoral para la estimación de la carga real de las celdas LTE.

\subsubsection{Tráfico cursado}

La estimación de tráfico que una celda puede cursar en una determinada casilla del escenario bajo estudio se realiza utilizando una correspondencia entre valores de SINR y el throughput que podría conseguir un usuario que experimentara dicha SINR. Los datos utilizados en esta Tesis Doctoral provienen de simulaciones de nivel de enlace realizadas por el Instituto de Telecomunicaciones y Aplicaciones Multimedia de la Universidad Politécnica de Valencia (iTEAM) en el marco del proyecto Celtic Wireless World Initiative New Radio+ (WINNER+) [56]. Se ha utilizado una configuración de LTE con MIMO 1x2 y un ancho de banda de $10 \mathrm{MHz}$. Este cálculo permite obtener resultados conservadores, de manera que si posteriormente se utilizara un esquema MIMO de orden superior — $2 \times 2,4 \times 2$, etc. - o mayor ancho de banda, se obtendrían mejores prestaciones. 


\section{CAPÍTULO 2. METODOLOGÍA}

La correspondencia entre SINR y throughput para distintos Modulation and Coding Schemes (MCSs) y tamaños de bloque - determinados por el Channel Quality Indicator (CQI) reportado por el UE - pueden servir para calibrar la fórmula de la capacidad de Shannon [57] para el caso particular de LTE con MIMO 1x2. La fórmula original viene dada por la siguiente expresión:

$$
B=W \log _{2}(1+\gamma)
$$

donde $B$ es el throughput alcanzado en bps, $W$ es el ancho de banda del sistema en $\mathrm{Hz}$ y $\gamma$ es la SINR en recepción expresada en unidades lineales. Para el caso particular del simulador estático se utilizará un ecuación similar, modificada a partir de la anterior, de forma que refleje que no se consigue el mismo throughput que en el límite que marca la fórmula de la capacidad Shannon [58]. La expresión calibrada es la siguiente:

$$
B=\eta_{B} W \log _{2}\left(1+\frac{\gamma}{\eta_{\gamma}}\right)
$$

donde $\eta_{B}$ es la eficiencia del ancho de banda y $\eta_{\gamma}$ la eficiencia de la SINR, suponiéndose ambas eficiencias constantes para todas las celdas y todas las casillas.

La figura 2.7 muestra el ajuste de la curva proporcionada por la ecuación (2.8) que consigue menor error cuadrático medio con los datos disponibles de la simulaciones de nivel de enlace. Los valores para la eficiencia del ancho de banda y de la SINR que mejor ajuste proporcionan son $\eta_{B}=0,57$ y $\eta_{\gamma}=1,37$

Se ha obviado en el ajuste de la correspondencia SINR-throughput la curva de CQI 15, pues no presenta una continuidad de la evolución del throughput alcanzado para CQI y SINR crecientes. Esta anomalía se debe a que no existe ningún tamaño de bloque estándar que consiga la tasa de código establecida para el CQI 15, por lo que se ha descartado del análisis.

En las simulaciones de nivel de enlace se descartó la ganancia por utilizar múltiples Resource Blocks (RBs) para transportar bloques más grandes, por lo que para calcular el throughput que se puede alcanzar en un único RB basta con dividir el throughput entre el número de RBs disponibles, en este caso 50 RBs al ser $10 \mathrm{MHz}$ el ancho de banda del sistema utilizado en las simulaciones de nivel de enlace.

Otra de las suposiciones realizadas en el simulador estático consiste en que las celdas pueden cursar tráfico en casillas donde no son la mejor celda - best server - en los casos en los que la que sí es mejor celda no pueda cursar más tráfico por saturación. Asimismo, se supone que todo el tráfico de una casilla lo generan tantos usuarios como RBs se asignen por parte del scheduler, el cual reparte un RB por usuario. Por lo tanto, no hay ganancia alguna por transmitir bloques más grandes asignando varios RBs a un sólo usuario. Ésta es, de nuevo, 


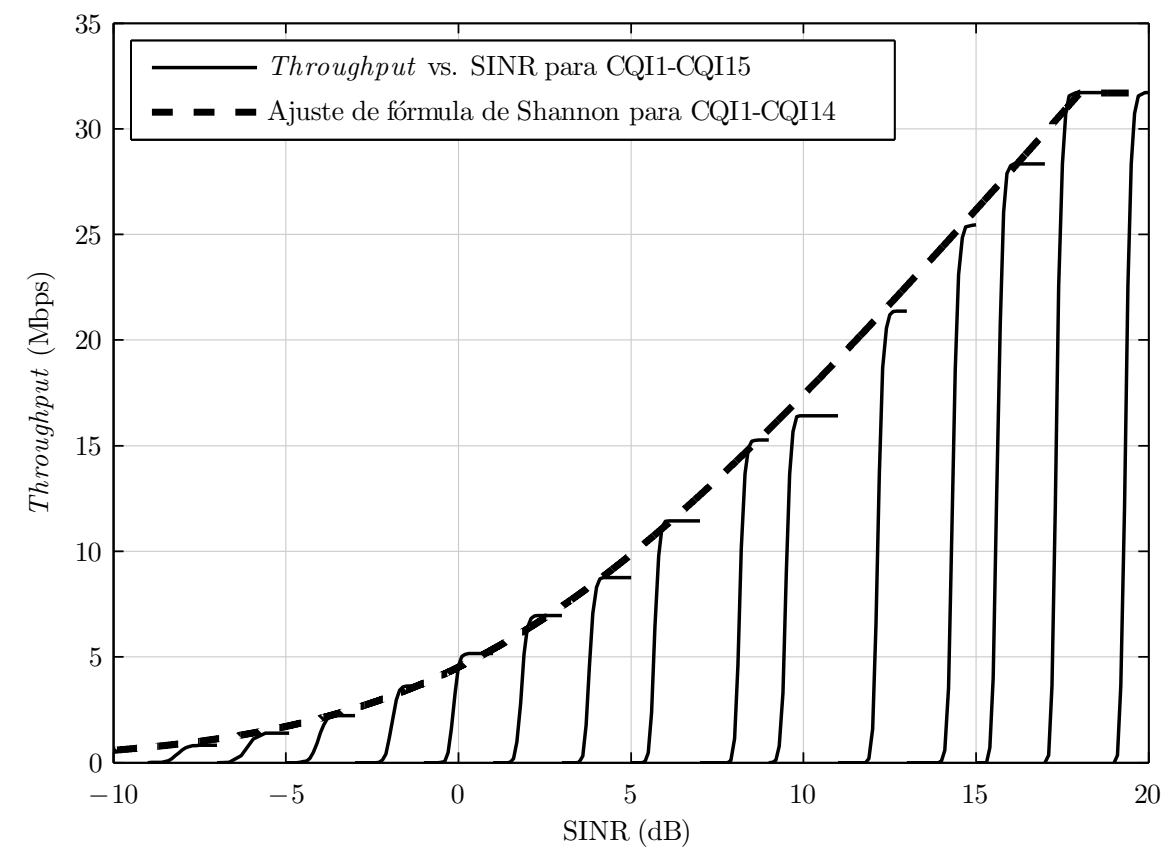

Figura 2.7: Ajuste de la fórmula de capacidad de Shannon a los datos de SINR vs. throughput disponibles de simulaciones de enlace LTE con MIMO 1x2 y 10 $\mathrm{MHz}$ de ancho de banda

una suposición conservadora, ya que el throughput conseguido por un mismo usuario utilizando varios RBs sería mayor que el agregado de los throughputs conseguidos por varios usuarios en los RBs por separado.

\subsubsection{Scheduling}

En la aplicación del simulador estático a la planificación y optimización de una red LTE para la que se dispone de una estimación de tráfico, se hace necesario simular de alguna forma el reparto de recursos radio - o schedulingque realiza el eNB. Se ha supuesto un algoritmo de scheduling de tipo Maximum Carrier-to-Interference Ratio (MaxCIR), por lo que primero se cursará el tráfico de las casillas que mejor SINR experimenten. 


\section{CAPÍTULO 2. METODOLOGÍA}

\subsubsection{Impacto del error de localización}

Como se ha comentado anteriormente, la herramienta propuesta de planificación y optimización hace uso de un algoritmo de localización de UEs que permite geo-localizar el tráfico y, por tanto, ajustar la red a las necesidades reales de cobertura. Obviamente los errores en la localización afectarán a las prestaciones del procedimiento global por lo que interesa saber en qué medida se degradan los resultados de la solución obtenida.

Al no disponer de la distribución de tráfico real para el análisis del impacto del error de localización en los resultados de planificación, se ha tomado como referencia el mapa calculado mediante localización para comparar los resultados con esa misma distribución tráfico en la que se introduce un error siguiendo una distribución gaussiana de media 100 metros y desviación típica 87 metros. Estos valores son coherentes con los resultados del propio algoritmo de localización diseñado, como se verá en la sección 3.2.3.1. Además de analizar los resultados para ese caso concreto de error de localización se estudiará lo que ocurre para otros valores del mismo.

\subsection{Simulador Dinámico}

\subsubsection{Descripción}

El simulador dinámico utilizado es Simulation Platform for Heterogeneous Wireless Systems (SPHERE), una plataforma de simulación radio para sistemas inalámbricos heterogéneos basada en eventos discretos. Actualmente la plataforma dispone de cinco simuladores avanzados de nivel sistema, GPRS, Enhanced Data Rates for GSM Evolution (EDGE), High Speed Downlink Packet Access (HSDPA), Wireless Local Area Network (WLAN) y LTE, que permiten emular estas tecnologías en paralelo o independientemente a nivel de paquete. De esta forma SPHERE proporciona una herramienta dinámica y precisa para evaluar la Quality of Service (QoS) percibida por el usuario cuando se utilizan distintos mecanismos de Common Radio Resource Management (CRRM) y Radio Resource Management (RRM), trabajando con una resolución temporal del orden de milisegundos. Centrando la atención en las capacidades como simulador del sistema LTE, a continuación se describen las principales características de SPHERE.

A pesar de que la interfaz radio de LTE está basada en OFDMA y permite su despliegue tanto en FDD como en TDD, la actual implementación del simulador está restringida al caso de FDD. Los datos de usuario se transmiten del eNB al UE utilizando un canal común. Se realiza scheduling rápido en el eNB para decidir cómo se distribuyen entre los UEs los recursos compartidos en 


\subsection{Simulador Dinámico}

DL (tiempo, frecuencia y potencia). Por cada uno de los receptores, se pueden transmitir uno o dos (con MIMO) Transport Blocks (TBs) en cada Transmit Time Interval (TTI) de $1 \mathrm{~ms}$, que es la resolución temporal mínima de la simulación. Estos TBs se pueden transmitir de acuerdo a diferentes combinaciones de modulación y tasa de codificación. Se usan mecanismos HARQ. Además, se pueden utilizar varios esquemas MIMO. Las características específicas del simulador LTE más relevantes son las siguientes:

- Modelos link-to-system basados en cálculo de SINR efectiva. Se calcula la SINR efectiva en base a un muestreo de la SINR que se realiza en el dominio de la frecuencia usando funciones calibradas previamente. Después, el valor de SINR efectiva se mapea en un valor de Block Error Rate (BLER) utilizando Look-Up Tables (LUTs) obtenidas para canales Additive White Gaussian Noise (AWGN). Tanto las funciones calibradas como las LUTs se han obtenido mediante un simulador de nivel de enlace.

- Como LTE está basado en OFDMA, el scheduling se realiza en tiempo y en frecuencia.

- Los CQIs tienen una definición diferente en LTE respecto a UMTS. Es posible tener información realimentada por el UE a través de los CQIs a nivel de RB y con una periodicidad configurable. Además, se utilizan otros indicadores como Precoding Matrix Indicator (PMI) y Rank Indicator (RI) para los modos de operación que incluyen MIMO.

- Se pueden transmitir uno o dos TBs en cada TTI por lo que puede haber hasta dos procesos HARQ activos al mismo tiempo.

En la figura 2.8 se muestra una descripción funcional por bloques del simulador SPHERE. Es necesario aclarar la relación del escenario con el scheduling tal como se refleja en la misma. El sentido de que se haya marcado esta relación se encuentra en las posibles configuraciones de reutilización de recursos de frecuencia que pueda haber en algunos escenarios y que influyen en la forma en que se reparten los recursos entre los usuarios.

Cabe destacar que, tras una primera fase de desarrollo del simulador, se realizó un proceso de calibración. Esta segunda etapa es de gran importancia para garantizar la validez de los resultados obtenidos por cualquier plataforma de simulación. La calibración se realizó mediante la comparación de los resultados obtenidos con los de otros centros de investigación. Este trabajo fue realizado por investigadores del instituto universitario iTEAM de la Universidad Politécnica de Valencia (UPV) en el contexto del proyecto europeo WINNER+ [59]. 


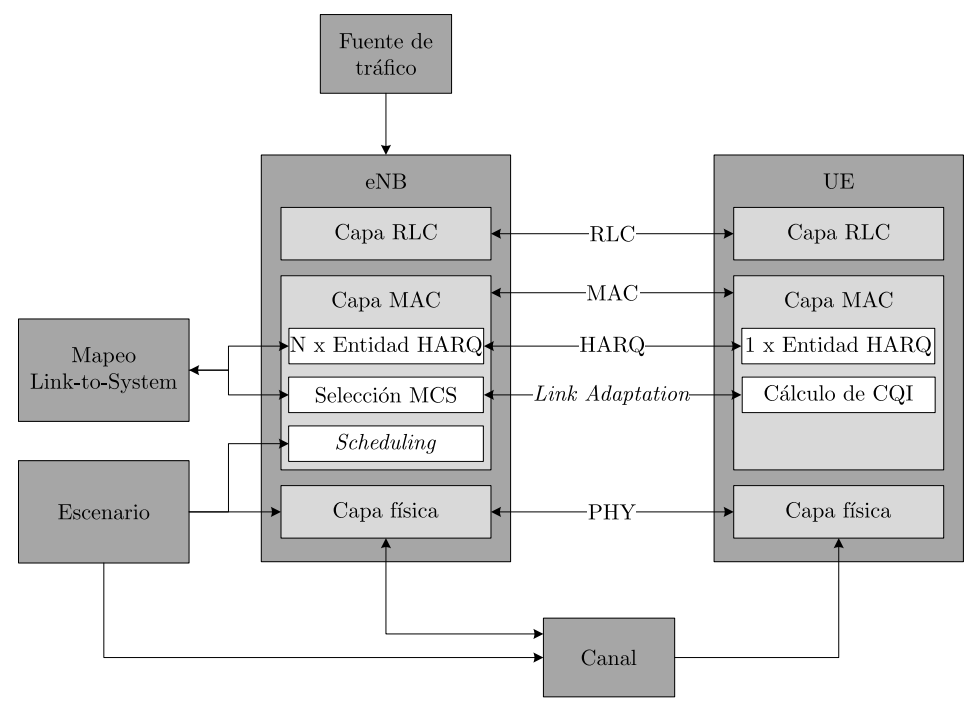

Figura 2.8: Esquema funcional de SPHERE

\subsubsection{Suposiciones}

El simulador SPHERE es muy flexible y altamente configurable para permitir realizar simulaciones bajo diferentes suposiciones. En las siguientes secciones se detallan las características, modelos y suposiciones del simulador SPHERE.

\subsubsection{Escenario de simulación}

Existen dos posibles configuraciones del escenario de simulación en lo que se refiere al posicionamiento de las celdas. Por un lado se puede seleccionar un escenario sintético o bien situar las celdas en posiciones arbitrarias. Respecto a la primera alternativa, se ha contemplado un conjunto de escenarios sintéticos regulares, existiendo la posibilidad de tener tanto celdas sectoriales como omnidireccionales. En el caso más extremo se pueden considerar hasta 57 celdas sectoriales, como se muestra en la figura 2.9 .

Se podrá configurar un número determinado de usuarios por celda, que será el mismo para todas ellas. El hecho de que un usuario esté asociado a una celda delimita la zona geográfica donde éste se puede ubicar aleatoriamente. Posteriormente, según el modo de selección de celda configurado, es posible que cada celda sirva a un número de usuarios distinto del original debido a las condiciones radio percibidas por cada usuario desde distintas celdas. 


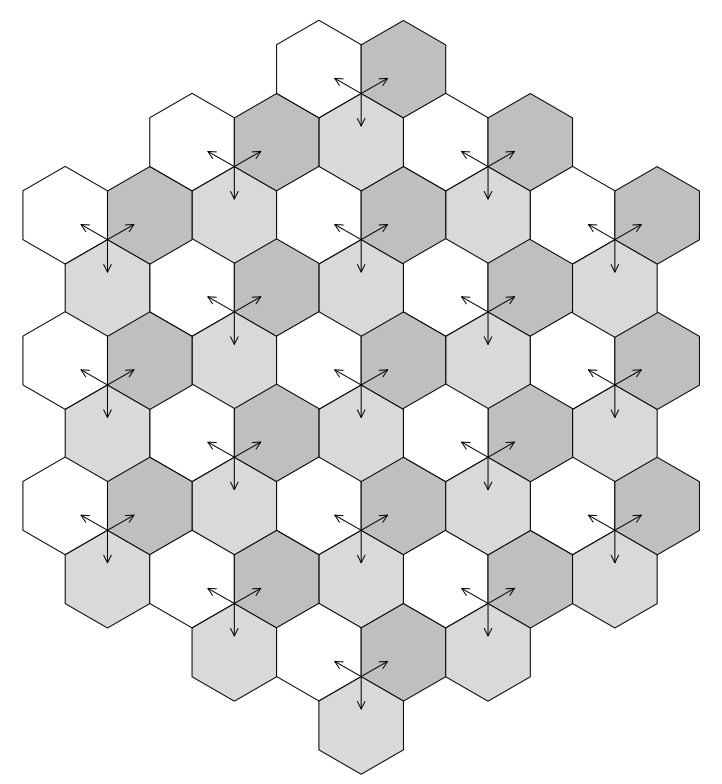

Figura 2.9: Escenario sintético de SPHERE con 57 celdas sectoriales

En caso de utilizar escenarios realistas, será posible configurar de forma independiente la posición de cada celda y el número de usuarios que se generarán dentro de su área de cobertura, determinada por el radio de la celda, el acimut y el ancho de sector, dentro de la que se ubicarán los usuarios. Asimismo, será posible seleccionar un modelo de pérdidas de propagación distinto para cada celda, lo que permite modelar escenarios heterogéneos.

Por último, el simulador permite utilizar patrones de reutilización de frecuencias distintos, además de la reutilización universal. Así, es posible configurar reutilización de frecuencias de factor 3, Soft Frequency Reuse (SFR) y Fractional Frequency Reuse (FFR) siendo estos dos últimos completamente configurables.

\subsubsection{Caracterización de las antenas}

Las antenas se han modelado de igual modo que en el caso del simulador estático, tal y como se describe en la sección 2.2.2.1. 


\subsubsection{Modelo de canal y propagación}

Los modelos de canal son necesarios para caracterizar con precisión las condiciones de propagación entre transmisor y receptor. Así pues, el simulador SPHERE cuenta con la implementación de los modelos de propagación recomendados por la ITU-R para diferentes entornos y escenarios. En general, existen pérdidas por propagación, pérdidas debidas al efecto multi-camino, y pérdidas debidas al shadowing. Las pérdidas por propagación se pueden modelar de acuerdo con el modelo de Okumura-Hata [54] o utilizando los modelos de pérdidas de propagación definidos por la ITU [50]:

- Indoor, para el escenario Indoor Hotspot (InH)

- Microcellular, para el escenario Urban Micro (UMi)

- Base coverage urban, para el escenario Urban Macro (UMa)

- High speed, para el escenario Rural Macro (RMa)

En cuanto al modelo de pérdidas de propagación por multi-camino - o desvanecimiento rápido-, se ha adoptado el modelo estadístico de Rayleigh. En particular, se ha usado el modelo de Jakes [60] para generar el proceso aleatorio de Rayleigh. La variabilidad de la señal recibida viene determinada en gran medida por la velocidad en que se mueven transmisor y/o receptor, es decir, por el efecto Doppler.

Finalmente, el desvanecimiento lento —o shadowing - provocado, entre otras causas, por la obstrucción de la señal directa producida por edificaciones, accidentes geográficos, etc. atenuará la señal recibida. Dicha atenuación en la amplitud se ha modelado, como es habitual, utilizando una distribución log-normal con una desviación típica acorde con el modelo de pérdidas por propagación.

\subsubsection{Modelos de tráfico}

En cuanto a modelos de tráfico, el simulador tiene implementadas varias fuentes de tráfico que permiten simular el comportamiento de distintos tipos de usuario. Las fuentes son de tráfico web, e-mail, Voice over Internet Protocol (VoIP) y transmisión de video y dan lugar a diferentes tipos de sesiones que funcionan simultáneamente en el sistema. Asimismo, es posible configurar la fuente de tráfico en modo full-buffer, en el que siempre hay datos para transmitir y, por tanto, no influye en los resultados de las simulaciones el tipo de tráfico seleccionado. A continuación se describen las distintos fuentes de tráfico configurables: 


\section{- Full buffer}

Siempre hay datos para transmitir a todos los usuarios, como si existiera una cola infinita de datos, al contrario de lo que ocurre en otros modelos de tráfico donde los datos se trasmiten a ráfagas con una cierta distribución de probabilidad de llegada. Esta fuente de tráfico permite evaluar la eficiencia espectral del sistema sin que ésta se vea afectada por el tipo de distribución del tráfico de los usuarios.

- Web

Las sesiones web se generan siguiendo una distribución de Poisson con una determinada tasa de llegada. Cada sesión incluye la visita de un número de páginas web que viene dado por una distribución geométrica. Entre visitas a las distintas páginas web de la sesión, existe un tiempo de inactividad que está modelado por una distribución de Pareto. Durante la visita de una página es necesario descargar un cierto número de objetos que viene dado por una distribución de Pareto, existiendo un tiempo de inactividad entre descargas de objetos que se modela mediante una distribución Weibull. Por último, el tamaño de cada uno de los objetos viene determinado por una distribución de Pareto.

Cada una de las distribuciones de probabilidad descritas en este modelo se puede configurar de manera independiente a través del fichero de configuración del simulador.

\section{- E-mail}

De forma similar al caso de tráfico web, las sesiones de e-mail se generan siguiendo una distribución de Poisson. Cada sesión de e-mail incluye la descarga de un número de mensajes que viene determinado por una distribución Log-Normal. El tiempo entre correos de una misma sesión viene modelado por una distribución de Pareto y el tamaño de cada uno de los correos se determina con una distribución Weibull con dos conjuntos de parámetros distintos según si el correo lleva o no adjuntos. La probabilidad de que un correo lleve adjunto se ha establecido en un $50 \%$.

\section{- VoIP}

La generación de sesiones de VoIP se modela con una distribución de Poisson y la duración de las mismas con una distribución exponencial. Por otro lado, se ha supuesto una tasa de codificación de 12,2 kbps, una longitud de trama del codificador de $20 \mathrm{~ms}$, y un factor de actividad del $50 \%$.

- Video H.263 


\section{CAPÍTULO 2. METODOLOGÍA}

El modelo de transmisión de video se basa en el estándar H.263. De igual forma que para el tráfico VoIP, la generación de sesiones de transmisión de video se modela con una distribución de Poisson y se supone que la duración de las sesiones sigue una distribución exponencial. La tasa de codificación es configurable entre 16 kbps y 8192 kbps.

\subsubsection{Modelos de movilidad}

El simulador SPHERE contempla varios supuestos en cuanto a los modelos de movilidad. En primer lugar, es posible llevar a cabo una simulación de tipo Montecarlo, es decir, ubicando a los usuarios en una localización especifica y realizando la simulación para esta posición fija de los usuarios. Con esto se obtiene un snapshot que se va promediando con los resultados de otros snapshots obtenidos después de situar a los usuarios en localizaciones nuevas.

Por otro lado, el simulador permite un modelo de trazas en donde los usuarios se van moviendo siguiendo una determinada ruta. La posición inicial de cada terminal móvil dentro de una celda se establece de forma aleatoria de acuerdo a una distribución uniforme y el desplazamiento dentro de dicha celda se realiza a velocidad constante. Se contemplan modelos dinámicos en los que los usuarios se mueven en una determinada zona de acuerdo con los tipos de usuarios considerados: estáticos, pedestres y vehiculares. Para un determinado servicio, se determina como parámetro de entrada las probabilidades de tener usuarios de cada uno de los tipos mencionados. En estos casos, para calcular las nuevas posiciones de los usuarios se utiliza tanto la velocidad, que suele ser fija, como el ángulo, que sigue una cierta distribución.

\subsubsection{Modelado de recursos radio}

En OFDMA los recursos radio asignados a los usuarios se definen en forma de RBs. Dichos RBs se asignan de forma dinámica con una periodicidad definida por el TTI. Para el caso particular del DL en LTE, los RBs asignados tienen un ancho de banda de $180 \mathrm{kHz}$ y el scheduling se realiza cada TTI que equivale a 1 ms. A modo de ejemplo, en una portadora LTE de $20 \mathrm{MHz}$ de ancho de banda existen 100 RBs.

La asignación de dichos RBs requiere una asignación en tiempo y frecuencia. Esto es, para un determinado TTI, se deben asignar los diferentes RBs a los distintos usuarios (asignación en frecuencia). En el siguiente TTI, la asignación de usuarios debe realizarse acorde con la asignación en el anterior TTI (asignación temporal).

Existen diferentes mecanismos de asignación de recursos. En lo que se refiere a los algoritmos de scheduling, el simulador implementa los siguientes: 
- Round Robin (RR): Este método asigna recursos a todos los usuarios de manera equitativa y en un orden racional, normalmente comenzando por el primer usuario de la lista hasta llegar al último y empezando de nuevo desde el primer elemento. La sencillez y el criterio de justicia son las características principales de este esquema. Por el contrario, este algoritmo no tiene en cuenta los constantes cambios en las condiciones del canal, potencialmente dando lugar a que se asignen recursos a usuarios con muy malas condiciones de canal mientras que a otros usuarios con mejores condiciones no se les asignan recursos.

- Maximum Channel Quality Indicator (MCQI): Este esquema se propone con el objeto de añadir información sobre el estado del canal al mecanismo de asignación de recursos. Como su nombre indica, el CQI es una medida de la calidad de un determinado canal inalámbrico. Cuanto mayor sea el CQI, mayor calidad tendremos en el canal. De esta forma, el esquema de asignación MCQI seleccionará con mayor prioridad a aquellos usuarios que disfruten de unas mejores condiciones para la transmisión. Mientras que esto solventa el problema presentado en el esquema RR, el esquema MCQI puede incurrir en problemas de justicia al no permitir a usuarios con pobre CQI la transmisión durante un periodo de tiempo largo. El esquema descrito a continuación, pretende solventar este hecho.

- Proportional Fair (PF): Este esquema intenta mantener un compromiso entre dos magnitudes confrontadas: por un lado, maximizar la tasa binaria mediante la transmisión en condiciones de buena CQI, y por otro lado, garantizar a todos los usuarios una mínima calidad de servicio. Esto se consigue asignando recursos a usuarios de manera inversamente proporcional al uso que han estado haciendo de ellos en el pasado.

Cabe mencionar que, por sus mejores prestaciones, se utilizará el PF en la mayoría de simulaciones, pero para el caso de la evaluación de las prestaciones de los distintos mecanismos de reutilización de frecuencias de la sección 5.1, será interesante tener en cuenta las otras dos alternativas, sobre todo RR, pues permitirá dejar en igualdad de condiciones a todos los usuarios a la hora de repartir recursos.

Dentro del scheduler del simulador SPHERE se localizarán la mayor parte de los cambios necesarios para la simulación de las distintos mecanismos de reutilización de frecuencias, ya que es en este bloque funcional donde se tiene el control de asignación de los distintos bloques de recurso y la potencia de transmisión en cada uno de ellos. 
CAPÍTULO 2. METODOLOGÍA 


\section{Capítulo 3}

\section{Procesamiento de la Información}

\subsection{Información Disponible en la Red}

La información obtenida de la red móvil es una importante fuente de datos ampliamente utilizada por los operadores en los procesos de optimización del sistema. En planificación también se puede explotar este recurso, recopilando y procesando información de los sistemas ya implantados en el escenario bajo estudio e intentando convertirlos en información útil para el despliegue de la nueva red.

Se puede obtener información útil de la red de distintas maneras: analizando la información que queda registrada en logs - lo que se conoce como call tracing - , recopilando estadísticas, contadores y KPIs que se almacenan en el Operations and Maintenance Center (OMC), utilizando sondas para monitorizar determinada información o midiendo de la propia red mediante campañas de drive-test.

En los logs de call tracing se almacena toda la mensajería generada por el sistema durante una llamada. Por ejemplo, es posible obtener los Measurement Reports (MRs) que envía el UE a la red, aunque el nivel de detalle y cantidad de la información depende del fabricante, pudiéndose dar el caso de que no se tengan todos los MRs de cada llamada sino un subconjunto de los mismos.

De igual forma, la cantidad y significado de las estadísticas, contadores y KPIs recopilados en la OMC también depende del fabricante, existiendo una gran variedad de ellos. 


\section{CAPÍTULO 3. PROCESAMIENTO DE LA INFORMACIÓN}

Otro tipo de información necesaria para planificación y optimización de redes móviles es la topología de la red. La topología incluye las posiciones de los emplazamientos, acimut y tilt de las antenas y potencia de transmisión. Además, es importante conocer las restricciones existentes en esa topología. Por ejemplo, en ocasiones se comparten las antenas entre distintos sistemas, por lo que un cambio del tilt mecánico de una antena, puede ser beneficioso para un sistema pero perjudicar al otro.

La consistencia de los datos disponibles es importante para el buen funcionamiento de las herramientas orientadas a explotar esta información. En ocasiones, los datos de topología que tienen los operadores almacenados son incorrectos, debido a que muchas veces el procedimiento de actualización de estos datos es manual, o se encuentran sin actualizar tras la implementación de algún cambio. Estas inconsistencias repercuten en las prestaciones del sistema tras la implementación de los cambios propuestos en un proceso de planificación u optimización.

En el anexo A se encuentra un listado detallado de los datos que se han utilizado en las distintas herramientas de procesado de información que se tratan en este capítulo. Se han incluido los datos de GSM y UMTS además de los considerados para LTE, ya que las herramientas detalladas en este capítulo son fácilmente trasladables a cualquier tecnología.

\subsection{Localización}

La localización de usuarios es un servicio que va tomando cada vez más importancia dentro de las comunicaciones móviles, no sólo por el valor añadido de los servicios que se pueden ofrecer al usuario sino también por sus posibilidades comerciales - por ejemplo con la publicidad dependiente de la ubicación del usuario- y en el campo de la seguridad civil. Viéndolo desde otro punto de vista, este servicio es de igual forma importante para los operadores para incorporarlo a sus procesos internos, como refleja la tendencia a introducir la capacidad de localizar a usuarios dentro de los procesos y herramientas de optimización automática de la red de muchas empresas líderes en este sector como Ingenia Telecom S.L. [61], Optimi [62], Actix [63], Tektronix Communications [64], Telenity [65], Celcite [66] o Ascom [67]. Esta capacidad permitiría, por ejemplo, obtener mapas de distribución de tráfico que sirvan como dato de entrada a las herramientas de planificación y optimización de la red.

En una red móvil operativa, se producen cambios en la distribución espaciotemporal del tráfico y en los requisitos de QoS a lo largo del tiempo. Esta variabilidad afecta también a la distribución de interferencias y crea la necesidad de reconfigurar continuamente los parámetros de la red con el objetivo de 
mantener los niveles de QoS deseados [6]. Con este fin, en los últimos años se han propuesto varias alternativas para la optimización asistida por ordenador [32]. Este tipo de herramientas tienen la ventaja de considerar una gran cantidad de datos e integrar datos procedentes de trazas de llamadas, simulaciones ajustadas con datos reales y algoritmos de optimización combinatoria, como se describe en la sección 3.4.

La importancia de la localización para el modelo de negocio de los operadores ha motivado la aparición de gran cantidad de técnicas —en [13] y [16] se pueden encontrar dos buenos estudios comparativos- que están basadas principalmente en un conjunto de medidas disponibles incluyendo desde tiempos de llegada de la señal hasta mapas de potencia recibida. De hecho, los estándares del 3GPP, tanto para UMTS como para LTE, proporcionan, a través de los mensajes asociados en sus respectivos protocolos de Radio Resource Control (RRC) y Non-Access-Stratum (NAS), un conjunto de parámetros que permiten obtener la localización del usuario en tiempo real. Además, también los UE, mediante la información que realimentan a través de los MR, facilitan el desarrollo de los servicios de localización.

La pregunta ahora es si existe un algoritmo que destaque sobre los demás en cuestión de precisión y si este algoritmo se puede implementar en la práctica. Las técnicas de localización se pueden dividir en tres categorías principales: basadas en triangulación, basadas en correlación con base de datos de medidas (huellas de señal) o fingerprinting y basadas en el uso de GPS. El primer grupo usa una estimación de las distancias o ángulos desde tres o más celdas para obtener la posición del usuario. El valor de las distancias se extrae de la señal recibida y/o medidas del tiempo de propagación experimentado por dicha señal procedente de las distintas celdas.

Los retardos de propagación son mejores a la hora de calcular distancias. Sin embargo, por una lado la cuantificación de esta métrica y por otro la diferencia entre los casos con y sin visión directa, suponen grandes errores en la estimación. Por último, se podrían calcular diferencias temporales entre estaciones base en lugar de valores absolutos, lo cual proporcionaría mayor precisión. Sin embargo, estos sistemas tienen varios inconvenientes [68], relacionados principalmente con la sincronización de red que se requiere, que no se garantiza en las redes GSM, UMTS o LTE, sobre todo si las estaciones base no están conectadas mediante fibra óptica.

Con el objetivo de mejorar la precisión de la estimación de localización basada en medidas de señal, en la literatura se han propuesto diversos algoritmos de localización que utilizan mapas digitales. Estos mapas pueden representar tanto sofisticadas predicciones de señal recibida — contemplando la información de altura de edificios - como datos reales procedentes de medidas [13]. Esta es la base de la segunda categoría de algoritmos de localización. Las medidas to- 


\section{CAPÍTULO 3. PROCESAMIENTO DE LA INFORMACIÓN}

madas por el UE se comparan con las entradas de la base de datos que contiene los mapas de señal y el algoritmo de localización encuentra la entrada que mejor se ajusta a dichas medidas, lo que conduce a una estimación de localización [69].

La última posibilidad de localización consiste en utilizar un receptor Global Navigation Satellite System (GNSS), como por ejemplo GPS. Esta técnica es válida para lugares abiertos con buena visibilidad de los satélites necesarios pero no se puede utilizar para interiores, calles estrechas con edificios altos o túneles. Aunque este inconveniente puede solventarse parcialmente para funcionar en entornos urbanos con ayuda proporcionada por la propia red en la variante Assisted-Global Navigation Satellite System (A-GNSS) - Assisted-Global Positioning System (A-GPS) respectivamente-, se encuentra el problema añadido de que este método de localización depende de la disponibilidad de un receptor GNSS en los terminales a localizar. Aunque en la actualidad es normal ver terminales con esta funcionalidad, la mayoría de ellos no disponen de ella o la tienen inhabilitada, debido al incremento de coste del dispositivo y al consumo de batería, respectivamente.

A pesar de no contemplar las técnicas de localización que utilizan GNSS, este apartado trata de profundizar en las posibilidades de implementación y el análisis de la precisión de distintos mecanismos de localización de los otros dos grupos, intentando resolver el compromiso entre complejidad, precisión y dependencia de otros procesos. Además, en esta sección se identifican puntos de mejora de los mecanismos de triangulación para exprimirlos al máximo, se proporcionan detalles de implementación y se analizan en detalle las prestaciones de cada una de las mejoras propuestas.

\subsubsection{Mecanismos de Localización en UMTS}

Esta sección da una visión general de algunas de las técnicas de localización existentes para redes móviles, centrándose en las versiones basadas en triangulación y fingerprinting. Se ha particularizado este análisis para UMTS ya que en el momento de escritura de esta Tesis Doctoral no se dispone de información relativa a mecanismos de localización en LTE debido a la novedad de esta tecnología.

\subsubsection{Triangulación}

La triangulación implica combinar la información obtenida a través de las medidas hechas por el UE o del Nodo B con el objetivo de estimar la posición del usuario [70]. Ejemplos de medidas que permiten la localización son: Received Signal Strength (RSS) que el UE mide desde diferentes Nodos B, Angle of 
Arrival (AoA) de la señal recibida desde diferentes Nodos B, tiempo de llegada de la señal recibida desde diferentes Nodos B o la diferencia de este tiempo de llegada entre distintos Nodos B [71].

En lo que respecta a las medidas de RSS, la posición del usuario se estima utilizando las medidas que realiza el UE de la señal recibida de la serving cell y las celdas vecinas configuradas en el monitored set. Esta información se incluye en los MRs que el UE manda a la red periódicamente o cuando tienen lugar determinados eventos [72]. Normalmente, en las redes operativas se da con mayor frecuencia este segundo caso, ya que permite generar menos carga de señalización. La RSS de la que se dispondrá en los MRs será del tipo Common Pilot Channel Received Signal Code Power (CPICH RSCP), que permite estimar la distancia entre el UE y cada Nodo B de los que se tengan medidas a través de la aplicación de un modelo de predicción de pérdidas de propagación y el conocimiento de la topología de la red. Este conocimiento incluye posiciones de los Nodos B, potencia de la señal transmitida en el Common Pilot Channel (CPICH), orientación de las antenas y cualquier otro parámetro que afecte a la cobertura de los Nodos B, como ganancia de antena, tilt eléctrico y mecánico, etc.

Teniendo en cuenta las limitaciones de las medidas de RSS en cuestión de precisión - por ejemplo en UMTS tan sólo se requiere al UE una precisión absoluta en las medidas de CPICH RSCP de $\pm 6 \mathrm{~dB}$ en condiciones normales para medidas están entre - 70 y -94 dBm [73] — es necesario tener en consideración más datos de entrada para obtener un buen resultado del método de triangulación. Por ejemplo, en UMTS existen medidas con información de tiempos de propagación que puede utilizarse para mejorar la precisión en la localización. Así pues, el Random Access Channel Propagation Delay (RACH PD) puede utilizarse como complemento para la estimación de la distancia entre en el UE y la serving cell ya que representa el retardo de propagación medido durante el acceso al Physical Random Access Channel (PRACH). La granularidad en el reporte del RACH PD es de \pm 2 chips, lo que se traduce en una resolución espacial de \pm 156 metros [73]. Esta medida sólo está disponible para la celda donde el UE inicia la llamada. Sin embargo, esta información puede aprovecharse para mejorar el punto de localización inicial de una llamada, que es de gran importancia puesto que el resto de puntos de localización se generan a partir de este punto. Además, el primer punto es el único del que no se dispone de medidas de diferencia de potencia recibida, lo cual perjudica la precisión ya que en las medidas relativas de $\mathrm{CPICH}$ RSCP los requisitos de precisión que contempla el estándar son mayores. Concretamente, el requisito de precisión relativa en UMTS es, en general, de $\pm 3 \mathrm{~dB}$ [73].

La figura 3.1 muestra el funcionamiento básico de una posible implementación del método de triangulación, utilizando como datos de entrada la in- 
formación de CPICH RSCP y RACH PD para la estimación del primer punto de localización. La distancia del UE a la serving cell se estima utilizando la información aportada por el RACH PD, mientras que la distancia a las celdas vecinas se estima realizando un balance de potencia y, por tanto, aplicando un modelo de predicción de pérdidas de propagación y teniendo en cuenta información como ganancia de antena, potencia de transmisión en el CPICH, etc. El cruce de las estimaciones de distancia a cada celda genera diferentes tipos de puntos, que se ponderan siguiendo (3.1) para obtener la estimación final.

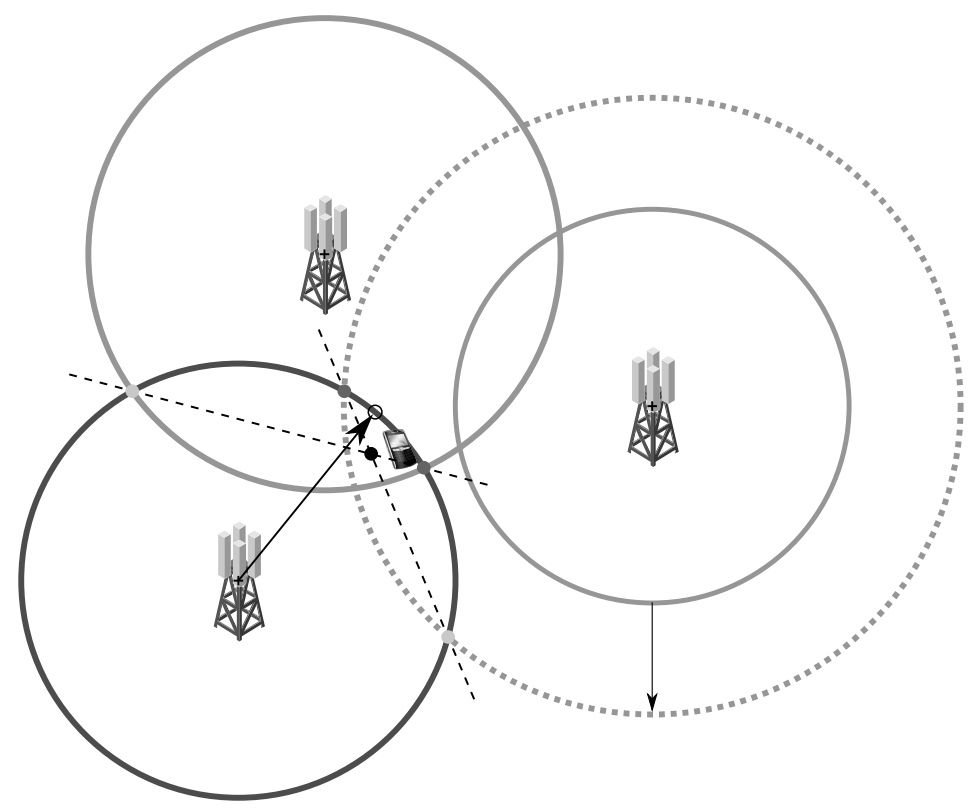

Figura 3.1: Localización por triangulación

$$
p^{*}=\frac{\sum_{i=1}^{N}\left(\prod_{j=1}^{M} w_{i j} \cdot p^{i}\right)}{\sum_{i=1}^{N}\left(\prod_{j=1}^{M} w_{i j}\right)},
$$

donde $p^{*}$ es la estimación de la posición del UE, $p^{i}$ son los $N$ puntos diferentes que se generan durante el proceso de triangulación y $w_{i j} \operatorname{los} M$ pesos diferentes que cada uno de esos puntos tiene. De esta forma, la fiabilidad de cada uno de los puntos depende de varios factores contemplados en el proceso de triangulación. Cada uno de los pesos se puede ajustar realizando una búsqueda iterativa en un rango de valores posibles, de forma que se busquen los valores que mejor 
resultado proporcionen en la localización de un conjunto de llamadas para las que se conozca la posición exacta. Concretamente, para la obtención de los resultados de localización que se detallan en esta Tesis Doctoral se ha realizado una optimización de los pesos utilizando SA. Del total de llamadas disponibles, aproximadamente el $70 \%$ se utilizaron en la búsqueda iterativa para optimizar el valor de los pesos, mientras que el restante $30 \%$ se utilizó en el proceso de validación, para comprobar que no se sobre-ajustaban los pesos. El valor final obtenido para estos pesos así, como la descripción en detalle de los mismos, se omite aquí por motivos de confidencialidad de datos del algoritmo actualmente utilizado por la empresa Ingenia Telecom S.L.

Una vez se ha estimado el punto de localización inicial de la llamada, las siguientes posiciones se estiman utilizando las variaciones de Received Signal Code Power (RSCP) respecto al punto anterior para cada una de las medidas disponibles. Utilizando la diferencia de RSCP de cada estación base respecto al anterior MR y aplicando un modelo de predicción de pérdidas de propagación, el punto de localización que mejor se ajuste a toda la información disponible se estimará como siguiente posición del UE.

\subsubsection{Fingerprinting}

En los últimos años, la localización basada en fingerprinting o correlación de bases de datos de medidas ha emergido como candidata a sustituir al método tradicional de triangulación, principalmente por la relativa facilidad de implementación. El proceso de localización basado en fingerprinting consta de dos fases. En la primera fase, conocida como fase off-line, se construye la base de datos de RSS a partir de campañas de medidas o predicciones de pérdidas de propagación. En la segunda fase, conocida como fase on-line, las medidas de RSS reportadas por el usuario se procesan en una entidad central que, a partir de ellas, estima su localización. Existe la posibilidad de que en esta segunda fase también se tengan en cuenta las medidas de señal que reciben las celdas del usuario, si bien este no es el caso más común.

- Fase off-line.

La primera opción para la generación de la base de datos utilizada en el método de localización basado en fingerprinting es el uso de un equipo convencional para drive-test. Este equipamiento está compuesto por un terminal comercial configurado en modo de ingeniería junto con un ordenador que captura y analiza la señalización de la interfaz radio a través de un software específico. La RSS debe ser medida con un número suficiente de muestras y desde el mayor número posible de celdas en cada punto. Con estas medidas se construye una base de datos con la correspondencia 


\section{CAPÍTULO 3. PROCESAMIENTO DE LA INFORMACIÓN}

entre puntos $(x, y)$ y un vector de medidas de RSS, el cual se considera la huella de señal en ese punto. En la figura 3.2 se muestra un ejemplo de conjunto de medidas de RSS capturadas de una única celda. Idealmente debería cubrirse el área completa con una rejilla rectangular de puntos, cada uno con su vector de medidas de RSS.



Figura 3.2: Medidas de RSS capturadas durante una campaña de drive-test

Como punto positivo, los operadores móviles realizan campañas de drivetest periódicamente ya que utilizan los datos recopilados en ellas para verificar el rendimiento extremo a extremo de la red y para comprobar el estado de la red de la competencia. Por contra, los drive-tests tienen varios inconvenientes. En primer lugar, las campañas de drive-test suponen un coste importante debido a su periodicidad. En segundo lugar, ya que estas campañas de medidas se suelen realizar en un vehículo, sólo se toman medidas de las zonas transitables por el mismo, afectando a la precisión de la localización de usuarios que se encuentren en el interior de edificios, parques o zonas peatonales. En tercer lugar, las medidas se realizan a nivel del suelo por lo que pueden ser muy distintas a la RSS que mide un usuario en la tercera planta de un edificio, ya que la elevación y las pérdidas de penetración no se tienen en cuenta. Dado que la mayoría de las llamadas realizadas en redes móviles comerciales se produce en interiores, esto supone una gran problema. Finalmente, el último problema del drivetest está relacionado con el equipo que realiza las medidas. Para una misma posición, las medidas de RSS pueden variar hasta 10 dB de un 
dispositivo a otro. Por un lado, esto se debe a la laxitud de los requisitos de medida para el UE que se reflejan en el estándar correspondiente a cada tecnología. Por otro lado, el desvanecimiento de pequeña escala contribuye a esta diferencia entre medidas de distintos terminales para la misma posición o para el mismo terminal en instantes diferentes.

Estos inconvenientes motivaron la aparición de una alternativa para la fase off-line basada en la utilización de herramientas de predicción de propagación muy precisas. Existen potentes modelos, como el Standard Propagation Model (SPM), que permiten estimar las pérdidas de propagación considerando tanto información topográfica contenida en Digital Terrain Maps (DTMs) como mapas 3D con información de edificios. Normalmente, los DTMs se pueden conseguir de forma libre y gratuita para resoluciones no muy altas - por ejemplo los proporcionados por el proyecto Shuttle Radar Topography Mission (SRTM) [74] de la National Aeronautics and Space Administration (NASA) de los Estados Unidos de América - mientras que es habitual que los mapas con información 3D de los edificios esté disponible previo pago. En la figura 3.3 se muestra un ejemplo de predicción utilizando DTM e información de la altura de los edificios. Además, estos modelos permiten hacer predicciones en escenarios urbanos que incluyan las pérdidas de penetración en interiores, ya que se dispone de la ubicación de edificios. Por último, estos modelos se pueden calibrar con medidas de drive-test. De esta forma, los modelos de predicción se pueden utilizar de forma individual o como complemento a las medidas de drive-test disponibles, para rellenar en base de datos la RSS en aquellos puntos sin información de drive-test disponible, como en interiores, zonas peatonales, etc.

\section{- Fase on-line.}

La forma más simple y común de estimar la localización del usuario con el método de fingerprinting consiste en calcular la distancia euclídea entre el vector de medidas de RSS reportadas por el UE y todas las huellas de señal disponibles en la base de datos. La localización estimada será la que corresponda con las coordenadas cuya huella en base de datos tenga una menor distancia respecto a la huella medida. A pesar de que se han propuesto algoritmos alternativos para la fase on-line - por ejemplo, utilizando variantes para la distancia (Manhattan [75], exponencial [76]) o basándose en redes neuronales [77] o modelado Bayesiano [78] — su precisión es bastante similar a la conseguida por el basado en distancia euclídea mínima. 

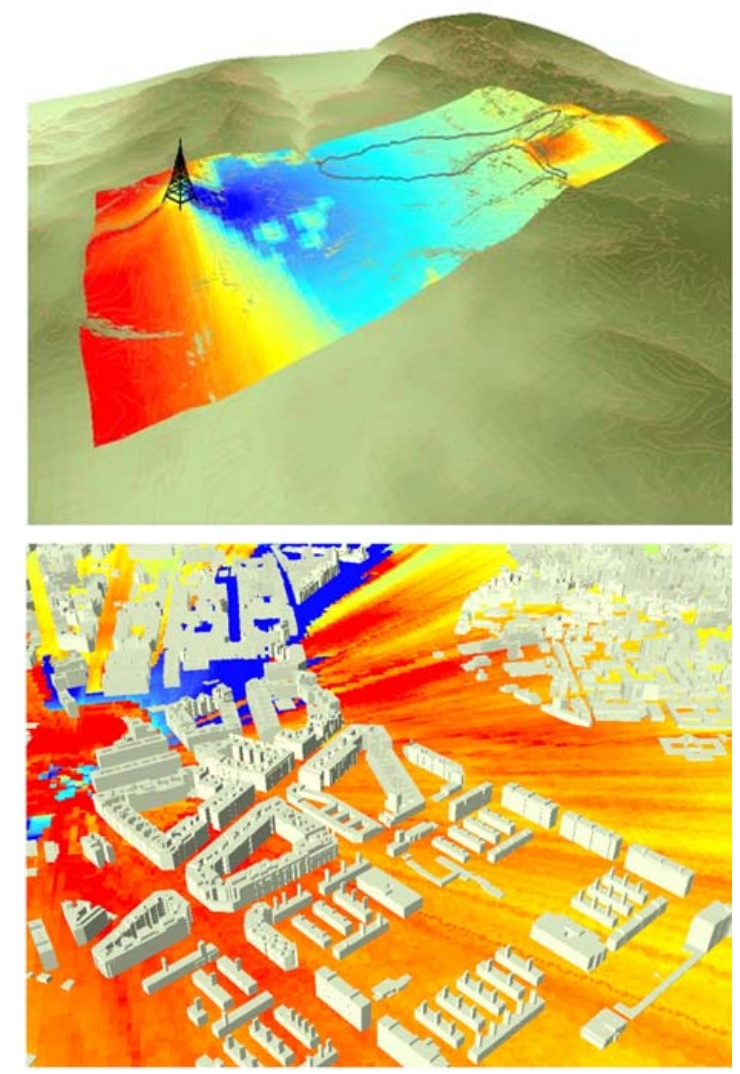

Figura 3.3: Estimación de RSS utilizando DTM (arriba) y altura de edificios (abajo)

\subsubsection{Mecanismos de Reducción de Error de la Localiza- ción Basada en Triangulación}

La triangulación básica, en cualquiera de sus posibles implementaciones como por ejemplo la explicada en la sección 3.2.1.1, presenta varios problemas. El primero es la gran variabilidad de las medidas de RSS reportadas en MRs consecutivos. Debido al desvanecimiento rápido — small scale fading —, los niveles de potencia pueden sufrir variaciones considerables incluso en usuarios estáticos. Esta variabilidad dificulta la tarea de extraer la posición relativa del UE 

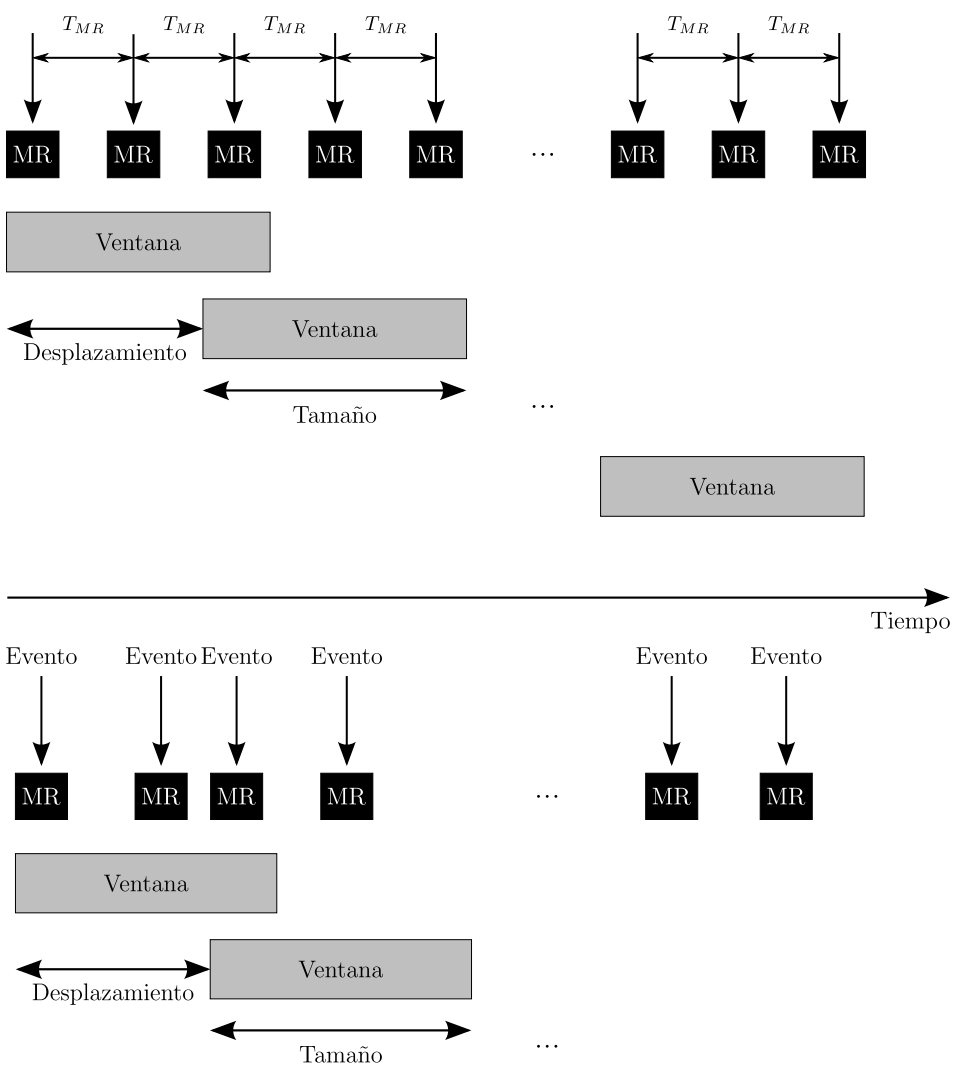

Ventana

Tiempo

Figura 3.4: Funcionamiento del promediado de ventana deslizante en el caso de MRs periódicos (arriba) o generados por eventos (abajo)

respecto a una celda, provocando errores en la estimación de distancias. Como solución, la información de cada MR no se procesa independientemente sino que se pre-procesa mediante un mecanismo de ventana deslizante. En última instancia se utiliza la media de las medidas que caigan en cada ventana [79], centrada en el MR correspondiente al instante en que se localiza al usuario. La figura 3.4 aclara el funcionamiento de este mecanismo. La media aplicada 


\section{CAPÍTULO 3. PROCESAMIENTO DE LA INFORMACIÓN}

sobre varios MRs reduce la variabilidad de la RSS y mejora el rendimiento del proceso de localización, como se muestra en la sección 3.2.3. A pesar del promediado de ventana deslizante, el efecto multicamino no puede ser contrarrestado completamente y sigue produciendo variaciones aleatorias alrededor de la ruta seguida durante la llamada, la cual puede ser claramente identificado en la mayoría de los casos mediante simple inspección visual. Con el objetivo de eliminar estas variaciones y suavizar la ruta resultante, a los puntos derivados de cada MR — siendo más precisos, de cada grupo promediado de MRs - se les puede aplicar una función de suavizado que aproxime y se ajuste a los diferentes puntos. Cada punto, a su vez, dispondrá de un peso relativo que representa la relevancia de la contribución a la ruta resultante del proceso de ajuste. Los puntos con mayor peso harán que la curva resultante pase más cerca de ellos.

El cálculo de los pesos dependerán de varios factores, incluyendo la dispersión de los puntos de intersección derivados de la triangulación. Si la dispersión es pequeña y todas las intersecciones se concentran en una misma área, entonces la estimación final es más fiable. Expresado de forma matemática, el objetivo de la aproximación de los puntos derivados de cada ventana de MRs es encontrar la función $f^{*}: \mathbb{R} \rightarrow \mathbb{R}, f^{*} \epsilon \mathcal{S}$, siendo $\mathcal{S}$ el conjunto de splines de grado 3 , tal que:

$$
f^{*}=\underset{f \in \mathcal{S}}{\operatorname{argmin}} \sum_{i=1}^{N} w_{i}\left|\left(x_{i}, y_{i}\right)-\left(x_{i}, f\left(x_{i}\right)\right)\right|^{2},
$$

donde $w_{i}$ es el peso —o fiabilidad - del i-ésimo punto utilizado en la interpolación y $N$ es el número de puntos disponibles. Es decir, se trata de encontrar la función $f^{*}$ que produzca una curva cuya distancia sea mínima respecto a los puntos derivados de cada MR, ponderados por su correspondiente peso.

Para resolver el problema de que se realicen bucles durante la trayectoria lo que haría que no se pudiera aproximar la salida del algoritmo con una única función - se realizará una aproximación por tramos, los cuales se generarán a partir de la detección de cambios de tendencia en el movimiento a lo largo del tiempo que dura la llamada localizada. Aclarar que la aproximación por tramos realizada no será capaz de detectar bucles pequeños sino que sólo se aproximarán como tramos independientes aquéllos que se generen por cambios en la tendencia del movimiento que se mantenga durante un tiempo mayor a un determinado umbral, para evitar posibles falsas detecciones de bucles ocasionadas por la variabilidad de los niveles de señal debida al desvanecimiento rápido.

El último problema que presentan los mecanismos de triangulación está relacionado con los usuarios estáticos. La variación de la RSS debido al multicamino, provoca que el algoritmo de triangulación sea incapaz de generar rutas 
sin movimiento, con un único punto. Por lo tanto, es necesario algún tipo de procesado posterior para identificar este tipo de llamadas. Realizando tanto comprobaciones geométricas como de variabilidad de la RSS [80] es posible detectar llamadas estáticas y generar como salida un único punto de localización en lugar de una trayectoria. Así, se detecta que una llamada es estática si se cumple cualquiera de las siguientes condiciones. Por un lado, si la salida del algoritmo de localización es una nube de puntos concentrada se clasifica la llamada como estática y se determina la ubicación del usuario como el centroide de los puntos de localización de la salida del algoritmo de localización. Por otro lado, si cada una de las varianzas de la señal recibida por el UE de cada una de las celdas reportadas en los MRs se mantiene por debajo de un determinado umbral, se clasifica la llamada como estática y se procede a determinar la posición final del usuario de la misma manera que para la primera condición.

\subsubsection{Resultados y Discusión}

Con el propósito de evaluar los diferentes algoritmos de triangulación propuestos -incluyendo los mecanismos de reducción de error - y para compararlos con los mecanismos de fingerprinting, se utilizan los datos recopilados durante una campaña de medidas realizada en Valencia, en un entorno urbano. En la campaña de medidas se utilizó un equipo convencional de drive-test, es decir, un terminal comercial configurado en modo ingeniería junto con un receptor GPS que capturaban la información de señalización y las posiciones GPS. De forma paralela y simultánea, toda la información de señalización de la red móvil se capturaba utilizando una herramienta de análisis de llamadas o call tracing.

El objetivo de la campaña de medidas es doble. Por un lado, la información obtenida en el drive-test permite obtener las huellas de señal necesarias para evaluar los algoritmos de fingerprinting, ya que con esta herramienta pueden ser monitorizados los niveles de señal medidos por el terminal. Por otro lado, las llamadas realizadas generan señalización en la red del operador que es procesada por una herramienta de análisis de llamadas desarrollada por Ingenia Telecom S.L. [61], neoAnalysis. Esta herramienta recopila información buscando entre los datos proporcionados por los mensajes de la señalización de red de los protocolos estándar del 3GPP: RRC, Node B Application Part (NBAP), Radio Network Subsystem Application Part (RNSAP) y Radio Access Network Application Part (RANAP). Además, neoAnalysis proporciona información sobre la topología de red, incluyendo la ubicación y configuración de las celdas involucradas en las llamadas monitorizadas, constituyendo toda esta información los datos de entrada de los algoritmos de localización basados en triangulación. 


\section{CAPÍTULO 3. PROCESAMIENTO DE LA INFORMACIÓN}

Las siguientes sub-secciones presentan los resultados obtenidos con diferentes implementaciones tanto de los mecanismos de triangulación como de fingerprinting. La lista de los mecanismos comparados es la siguiente:

- Algoritmo de Localización basado en Triangulación (ALT). Este algoritmo se basa en el método básico de triangulación descrito en la sección 3.2.1.1.

- Algoritmo de Localización basado en Triangulación con Promediado temporal (ALT-P). Este mecanismo incluye el concepto de promediado con ventana deslizante descrito en la sección 3.2.1.1.

- Algoritmo de Localización basado en Triangulación con Promediado temporal y Suavizado (ALT-PS). Este mecanismo incluye, además del promediado de MRs, la aproximación polinómica descrita en la sección 3.2.1.1.

- Algoritmo de Localización basado en Triangulación Mejorado (ALT-M). El ALT-M comprende todas las características del ALT-PS junto con el mecanismo descrito en la sección 3.2.1.1 para la detección de usuarios estáticos.

- Algoritmo de Localización basado en Fingerprinting con datos Topográficos (ALF-T). El ALF-T trabaja con una predicción de niveles de RSS generados con un modelo de predicción de pérdidas de propagación que tiene en consideración mapas de elevación del terreno, publicados por el proyecto SRTM [74]. Este algoritmo tiene la ventaja de tener coste cero ya que no existe la necesidad de realizar drive-test ni de adquirir ningún tipo de mapa con información de altura de terreno. El modelo de predicción de pérdidas de propagación utilizado es el SPM.

- Algoritmo de Localización basado en Fingerprinting con datos Topográficos y Altura de edificios (ALF-TA). Este algoritmo es similar al ALF-T pero considerando además las alturas de los edificios en las estimaciones de pérdidas de propagación.

- Algoritmo de Localización basado en Fingerprinting con datos de Drive Test (ALF-DT). En este caso, se dispone de una gran cantidad de medidas de drive-test del centro de la ciudad. Esta información se complementa, en las zonas en las que no se dispone de estas medidas, con información extraída del modelo calibrado de predicción de pérdidas de propagación, alimentado con datos de altura de terreno y de edificios. 


\subsubsection{Resultados de triangulación}

Los resultados de los mecanismos de triangulación implementados se muestran en la tabla 3.1. Como se puede observar, cada uno de los mecanismos de reducción errores propuesto implica una mejora en la precisión de localización obtenida. Llama la atención la pequeña diferencia existente entre los resultados obtenidos por el ALT-PS y el ALT-M. La razón de esta escasa mejora es que la proporción de llamadas estáticas realizadas durante la campaña de medidas fue menor del $10 \%$.

Tabla 3.1: Comparación de los mecanismos de triangulación

\begin{tabular}{cccc}
\hline & Error medio $(\mathrm{m})$ & Percentil 70 & Percentil 95 \\
\hline \hline ALT & 155 & 184 & 269 \\
ALT-P & 133 & 147 & 257 \\
ALT-PS & 102 & 120 & 189 \\
ALT-M & 100 & 111 & 187 \\
\hline
\end{tabular}

Con el objetivo de apreciar claramente las mejoras progresivas introducidas en el algoritmo ALT, se presentan capturas de pantalla de algunas llamadas localizadas, con la ruta seguida durante las mismas. En la figura 3.5 se muestra un ejemplo de resultados obtenidos en un escenario urbano. La ruta seguida con sus respectivas posiciones GPS está representada por la línea azul. Las líneas de color amarillo y blanco se corresponden con diferentes algoritmos de localización. Se puede apreciar la sustancial mejora introducida por la aproximación mediante splines del algoritmo ALT-PS. Por otro lado, la figura 3.6 muestra el potencial de la detección de usuarios estáticos utilizada en el algoritmo ALT-M.

Todos estos resultados indican que se puede conseguir una precisión aceptable con la versión mejorada de los mecanismos de localización basados en triangulación. Además, la gran ventaja de utilizar ALT-M es que se consiguen buenos resultados sin necesidad de cambiar nada de la red existente y sin requerir ninguna característica especial en los UEs. Únicamente se necesita la posibilidad de acceder a los datos de señalización para obtener la localización del usuario.

\subsubsection{Resultados de fingerprinting}

Los resultados de los mecanismos de fingerprinting implementados se muestran en la tabla 3.2. La precisión del ALF-T es pobre como se esperaba, debido a que no se tiene en cuenta la difracción en los edificios a la hora de calcular los mapas de RSS. Sin embargo, se esperaba que los algoritmos ALF-TA y ALF-DT 


\section{CAPÍTULO 3. PROCESAMIENTO DE LA INFORMACIÓN}
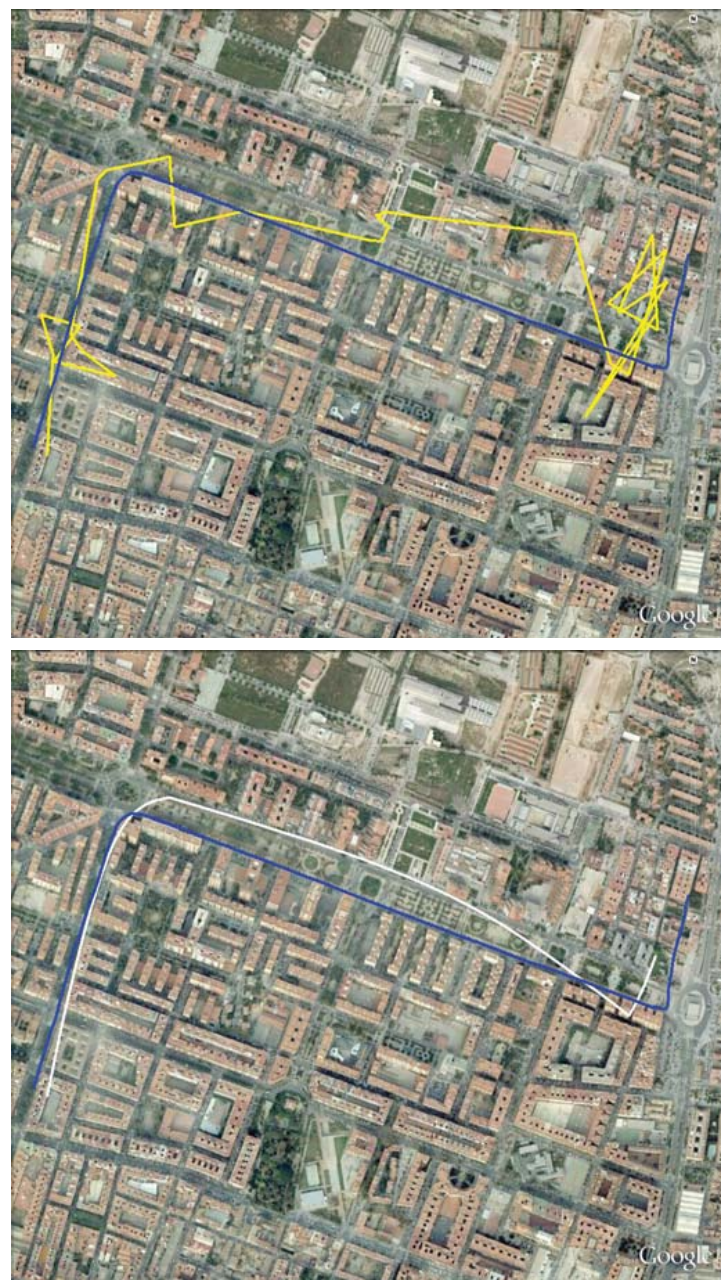

Figura 3.5: Ejemplos de salida de ALT-P, linea amarilla de la figura superior, y ALT-PS, linea blanca de la figura inferior, respecto a la ruta GPS seguida durante la llamada, linea azul en ambas figuras

produjeran mejores resultados que los realmente obtenidos. La razón de este hecho reside en las dificultades para encontrar el punto que mejor se ajuste al vector de medidas proporcionado como entrada y obtenido de los MRs. Esta dificultad tiene su origen en la alta variabilidad entre medidas tomadas por diferentes UE, hecho que se observó durante la realización de la campaña de 


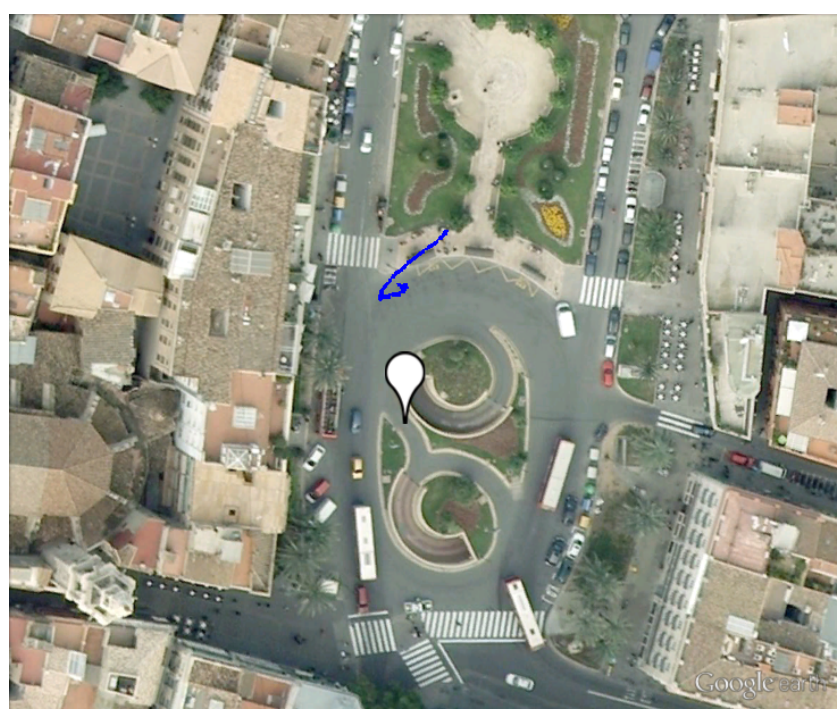

Figura 3.6: Ejemplo de resultado del ALT-M, punto blanco, para una llamada estática, línea azul

medidas y que afecta a la viabilidad práctica de estos mecanismos, ya que los usuarios a localizar muy probablemente no usarán el mismo terminal que el utilizado durante el drive-test.

Tabla 3.2: Comparación de los mecanismos de fingerprinting

\begin{tabular}{cccc}
\hline & Error medio $(\mathrm{m})$ & Percentil $70(\mathrm{~m})$ & Percentil 95 $(\mathrm{m})$ \\
\hline \hline ALF-T & 191 & 263 & 389 \\
ALF-TA & 172 & 237 & 318 \\
ALF-DT & 149 & 201 & 284 \\
\hline
\end{tabular}

La figura 3.7 muestra los resultados obtenidos para la misma llamada en movimiento para la que se presentaron los resultados en la sección 3.2.3.1. Se observa en la comparación de resultados que el ALF-DT es el algoritmo que mejores prestaciones ofrece entre los algoritmos de fingerprinting, aunque está por debajo en cuanto a precisión conseguida respecto a la mejor opción de los mecanismos de triangulación.

En lo que respecta al tiempo de ejecución, es necesario comentar la diferencia en cuanto a carga computacional que supone la generación de los mapas de RSS 


\section{CAPÍTULO 3. PROCESAMIENTO DE LA INFORMACIÓN}

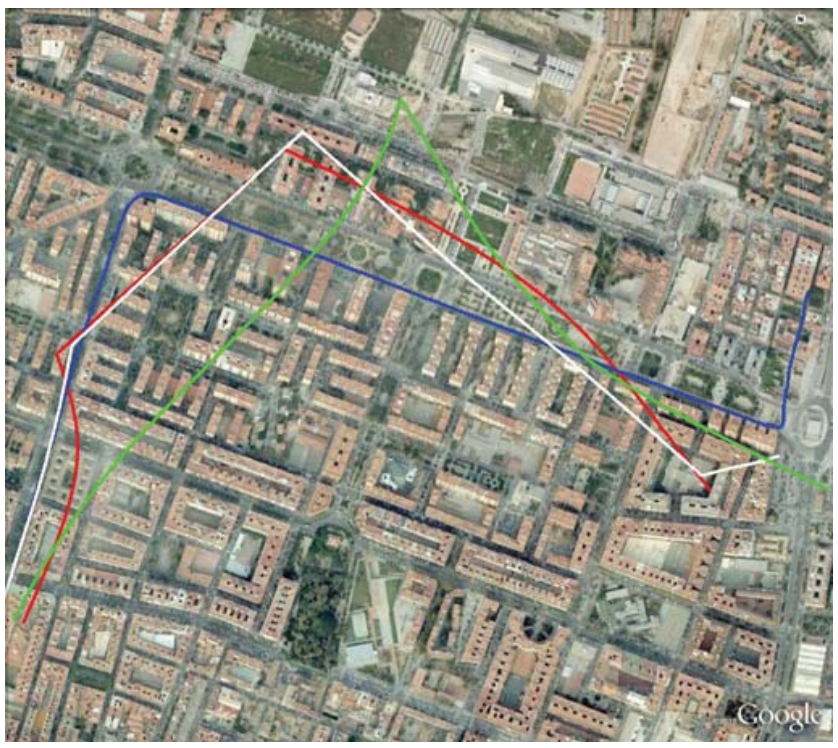

Figura 3.7: Resultado obtenido por ALF-T (verde), ALF-TA (rojo) y ALF-DT (blanco) para la misma llamada (azul)

en las distintas alternativas de mecanismos de fingerprinting. Según se extrae de las pruebas realizadas, existe una diferencia sustancial entre considerar o no la altura de los edificios. Poniendo un ejemplo concreto, la consideración de la altura de los edificios en la estimación de las pérdidas de propagación provoca que se tarde del orden de cuatro veces más en la generación de los mapas, para un área de unos $20 \mathrm{~km}^{2}$.

\subsubsection{Hibridación}

Tras la sorprendente obtención de peores resultados en los algoritmos basados en fingerprinting, en contra de lo esperado, afloran algunas alternativas híbridas como candidatas a evaluar con el fin de obtener mejores prestaciones, resolviendo los problemas detectados como razones del pobre rendimiento de estos mecanismos. Teniendo en cuenta los mejores resultados conseguidos por el ALT-M, la primera propuesta - llamada Algoritmo de Localización basado en Fingerprinting Acotado por Triangulación (ALF-AT) — se basa en la combinación de ambos métodos para restringir el área de búsqueda durante el proceso de correlación de mapas a cierta área acotada por la salida del ALT-M. 
Otra posibilidad híbrida, llamada Algoritmo de Localización basado en Triangulación Asistida por Fingerprinting (ALT-AF), pretende mejorar el algoritmo de triangulación ALT-M añadiendo nuevos puntos a la solución ponderada en cada ventana en la que se promedian medidas. Estos nuevos puntos proceden de la búsqueda de los puntos que mejor se ajustan en la correlación del mapa de RSS disponible y el vector de medidas reportadas por el UE.

Los resultados de ambas alternativas se muestran en la tabla 3.3. Se obtiene mejor precisión con la hibridación si comparamos el ALF-AT con el ALF-DT, que es la mejor alternativa de las propuestas para fingerprinting. Sin embargo, el ALT-M se mantiene como mejor opción, mejorando en precisión al método híbrido propuesto, el ALT-AF. En el ALF-AT, el área reducida de búsqueda no evita el desplazamiento del punto resultante de la correlación del mapa con el vector de medidas reportadas, ocasionada por el descuadre de medidas tomadas por diferentes terminales en la misma ubicación. Además, aunque el error cometido se reduce conforme se reduce el tamaño del área de búsqueda alrededor de la ruta obtenida por triangulación, no se consigue mejorar los resultados conseguidos por el ALT-M. También existe una ganancia respecto al ALF-DT en cuanto al tiempo que se tarda en el proceso de correlación del mapa de RSS con el vector de medidas, ya se sólo es necesario recorrer una zona reducida del mapa de RSS completo.

Por otro lado, el ALT-AF introduce más imprecisiones cuando se consideran puntos procedentes del fingerprinting en la solución ponderada del ALT-M. De hecho, tras el ajuste de pesos realizado para este método híbrido, se aprecia que el proceso tiende a minimizar el peso asignado a estos nuevos puntos.

Tabla 3.3: Comparación de los mecanismos híbridos

\begin{tabular}{cccc}
\hline & Error medio $(\mathrm{m})$ & Percentil $70(\mathrm{~m})$ & Percentil 95 $(\mathrm{m})$ \\
\hline \hline ALF-AT & 125 & 168 & 222 \\
ALT-AF & 136 & 170 & 241 \\
\hline
\end{tabular}

\subsubsection{Adaptación del Mecanismo de Localización a LTE}

Los mecanismos de localización descritos son igualmente válidos para la tecnología LTE, con ligeras diferencias en los parámetros utilizados, precisión de medidas, granularidad de la información reportada y facilidades proporcionadas por el estándar. Estas diferencias requerirán la implementación de las correspondientes modificaciones en el algoritmo de localización diseñado para la tecnología UMTS. 


\section{CAPÍTULO 3. PROCESAMIENTO DE LA INFORMACIÓN}

Las especificaciones de LTE-A contemplan la localización de UEs a través de los protocolos LTE Positioning Protocol (LPP) [81] y LPP Annex (LPPa) [82]. En ellas, se nombran diferentes métodos del localización como Observed Time Difference of Arrival (OTDoA), A-GNSS o Enhanced-Cell ID (E-CID). Todos estos métodos de localización se basan en medidas obtenidas por el UE o el eNB.

El Mobility Management Entity (MME) es la entidad que recibe la petición de localización de un usuario desde otra entidad, como por ejemplo otro UE, un eNB u otros nodos. A continuación, el MME manda una petición de servicio de localización al Evolved Serving Mobile Location Centre (E-SMLC), quién ejecutará el procedimiento de localización a través de los protocolos LPP y LPPa. El interfaz SLs definido entre el E-SMLC y el MME sirve de túnel al E-SMLC para transportar, de forma trasparente a través del MME, los mensajes de los protocolos LPP y LPPa además de los mensajes y parámetros del Location Services Application Protocol (LCS-AP).

El E-SMLC actúa como un servidor de localización que calcula la posición del usuario utilizando las medidas proporcionadas por uno o varios de los métodos de localización. Esta entidad interactúa con el UE (mediante LPP) o con el eNB (utilizando LPPa) a través del MME para obtener estas medidas. Por ejemplo, en el caso del método E-CID, las distintas medidas posibles que el E-SMLC puede recopilar son: Evolved Cell Global Identifier (ECGI)/Physical Cell Identifier (PCI), Reference Signal Received Power (RSRP), Reference Signal Received Quality (RSRQ), UE Rx - Tx time difference, Timing Advance (TA) y AoA. Además de la recolección de esta información, el E-SMLC puede proporcionar asistencia en forma de datos a los métodos A-GNSS y OTDoA. También se especifica el uso de Positioning Reference Signals (PRS) que pueden utilizar los métodos de localización basadas en OTDoA y para los que se reporta información como el Reference Signal Time Difference (RSTD). Si el UE no dispone de funcionalidad A-GNSS, el E-SMLC puede combinar la información recibida de la serving cell y de las celdas vecinas con el objetivo de triangular la posición geográfica del UE. Tanto el RSRP como el TA permiten estimar la distancia del UE a la serving cell, mientras que la distancia a las celdas vecinas puede obtenerse únicamente de los valores de RSRP. Las medidas de AoA, si las hubiera, añaden más precisión al proceso de triangulación. La tabla 3.4 muestra la granularidad con la que se reportan las medidas involucradas en los métodos de localización, la cual afecta directamente a la precisión de la localización. Cabe destacar que, en el caso de las medidas de TA y UE $R x-T x$ time difference, la resolución puede ser tan buena como dos veces el periodo de muestreo, $2 \cdot T_{s}$, que corresponde a una resolución espacial de 10 metros, aproximadamente. 
Tabla 3.4: Granularidad de la información útil para localización reportada en LTE

\begin{tabular}{ccc}
\hline Origen & Medida & Resolución \\
\hline UE & ECGI/PCI & N.A. \\
UE & RSRP & $1 \mathrm{~dB}$ \\
UE & RSRQ & $0,5 \mathrm{~dB}$ \\
UE & UE $R x-$ Tx time difference & $2 \cdot T_{s}\left(8 \cdot T_{s}\right.$ si Medida $\left.\geq 4096 \cdot T_{s}\right)$ \\
UE & RSTD & $2 \cdot T_{s}\left(5 \cdot T_{s}\right.$ si Medida $\left.\geq 4096 \cdot T_{s}\right)$ \\
eNB & TA & $2 \cdot T_{s}$ \\
eNB & AoA & $0,5^{\circ}$ \\
\hline
\end{tabular}

A continuación se describe cada una de estas medidas potencialmente útiles para localizar a un UE.

\section{- ECGI/PCI}

El ECGI es un identificador de celda único y, por tanto, permite acotar la zona de ubicación del UE que se intenta localizar, ya que la posición de las celdas LTE son conocidas.

En caso de disponer del PCI de la celda únicamente, ya que este identificador puede ser reutilizado en la red y existir varias celdas con el mismo, deberá existir un procedimiento que deshaga la ambigüedad en base a información como las relaciones de vecindad y celdas medidas que aparezcan en MRs de la misma llamada.

\section{- RSRP}

El RSRP es el promedio lineal de la potencia recibida por el UE en los Resource Elements (REs) que llevan señales de referencia. El número de REs considerados en el promedio depende de la implementación del fabricante, pero se exige que se cumplan los requisitos de precisión de la medida especificados en el estándar.

A partir de la potencia transmitida en los RE que llevan señales de referencia y el valor de RSRP medido se pueden calcular las pérdidas de propagación que servirán para realizar una estimación de la distancia existente entre el UE y la celda LTE a la que corresponda la medida.

\section{- RSRQ}

El RSRQ es una medida de calidad de la señal recibida por el UE desde una celda LTE. Se define como la relación entre el RSRP multiplicado por 


\section{CAPÍTULO 3. PROCESAMIENTO DE LA INFORMACIÓN}

el número de RBs del ancho de banda considerado y el Received Signal Strength Indicator (RSSI) en ese mismo ancho de banda.

La información que aporta no tiene una utilidad directa para el próposito de localizar un UE, pero puede suponer una ayuda a la hora de calcular la fiabilidad de los puntos intermedios utilizados en algunos algoritmos de localización o para dar pesos diferentes a la información de entrada según el valor concreto de RSRQ.

- UE $R x$ - Tx time difference

Es la diferencia entre el instante de recepción de la trama $i$ en DL desde la serving cell y el instante de transmisión en UL de la trama $i$ desde el UE.

La medida no se corresponde con el Round Trip Time (RTT) ya que incluye el tiempo que tarda el eNB en transmitir la trama $i$ en DL tras la recepción de la trama $i$ en UL.

- RSTD

Es la diferencia temporal relativa entre una celda vecina y una celda de referencia. Se mide mediante unas señales de referencia específicas para localización, las PRS.

\section{- TA}

El procedimiento de TA permite la alineación de las transmisiones en UL de usuarios distintos, cuyas señales transmitidas pueden sufrir retardos de propagación muy diferentes hasta llegar al eNB. Esta alineación se consigue adelantando las transmisiones en UL de cada usuario de acuerdo al retardo de propagación correspondiente.

El tiempo que se han de adelantar las transmisiones en UL lo calcula el eNB y la forma de hacerlo varía según el tipo de TA.

Para el tipo 1, el TA es la suma del eNB $R x$ - Tx time difference y el UE $R x$ - Tx time difference. El eNB Rx - Tx time difference es la diferencia entre el instante de recepción de la trama $i$ en UL desde el UE y el instante de transmisión en DL de la trama $i$ desde el eNB.

Para el tipo 2, el TA es simplemente el eNB $R x$ - Tx time difference, pero calculado sobre una trama radio en UL que contenga una transmisión de PRACH del UE para el que se está midiendo el TA.

La utilización de uno u otro tipo de TA dependerá de la versión del estándar que soporte el UE, ya que el tipo 1 sólo se podrá utilizar en UEs que cumplan con las especificaciones de la Release 9 o posterior. 
- AoA

Es el ángulo estimado de un UE respecto a una dirección de referencia. Concretamente, es el ángulo entre la dirección eNB-UE y la dirección norte, con ángulos crecientes en sentido anti-horario.

\subsection{Información Geo-referenciada}

La disponibilidad de un algoritmo de localización de UEs a partir de medidas disponibles en la red resulta de gran utilidad para geo-referenciar las estadísticas capturadas por la red. Con esta información se pueden obtener mapas con información muy útil para los procesos de planificación y optimización.

A partir de la información de localización es posible obtener los siguientes mapas:

- Densidad de usuarios.

- Tráfico.

- Throughput.

- Nivel de señal recibida en los pilotos o señales de referencia.

- Pérdidas de propagación.

- Calidad de de la señal medida en términos de $E_{c} / N_{0}$ en UMTS o RSRQ en LTE.

- En general, cualquier valor, parámetro o medida que esté disponible en la información capturada por la red y esté asociada a un UE.

El procesamiento de la información necesario para la obtención de estos mapas depende del tipo de información que representen. Así, por ejemplo, para el caso del mapa de pérdidas obtenido a partir de las medidas realizadas por los propios terminales localizados, es necesario promediar las pérdidas percibidas de la misma celda por terminales distintos en la misma ubicación. Un ejemplo de este tipo de mapas se representa en la figura 3.8.

También puede que la operación requerida sea de acumulación de valores por ubicación y unidad de tiempo, como es el caso de los mapas de densidad de usuarios como el mostrado en la figura 3.9. Este tipo de mapas son de gran utilidad para las herramientas de planificación u optimización, donde se pueden tener en cuenta estimaciones de tráfico basadas en la información que contienen, escalándolas adecuadamente según las previsiones de crecimiento del tráfico. 


\section{CAPÍTULO 3. PROCESAMIENTO DE LA INFORMACIÓN}

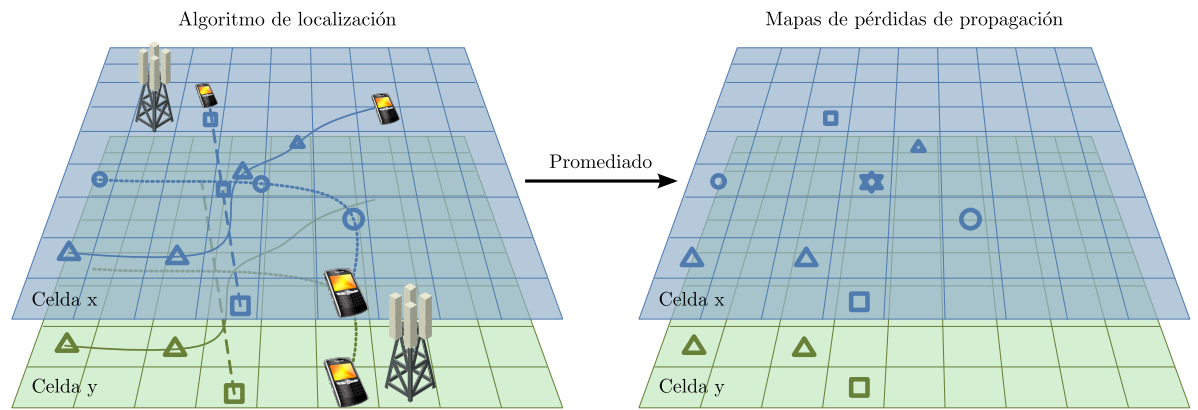

Figura 3.8: Obtención de mapas de pérdidas de propagación con medidas de distintos UEs

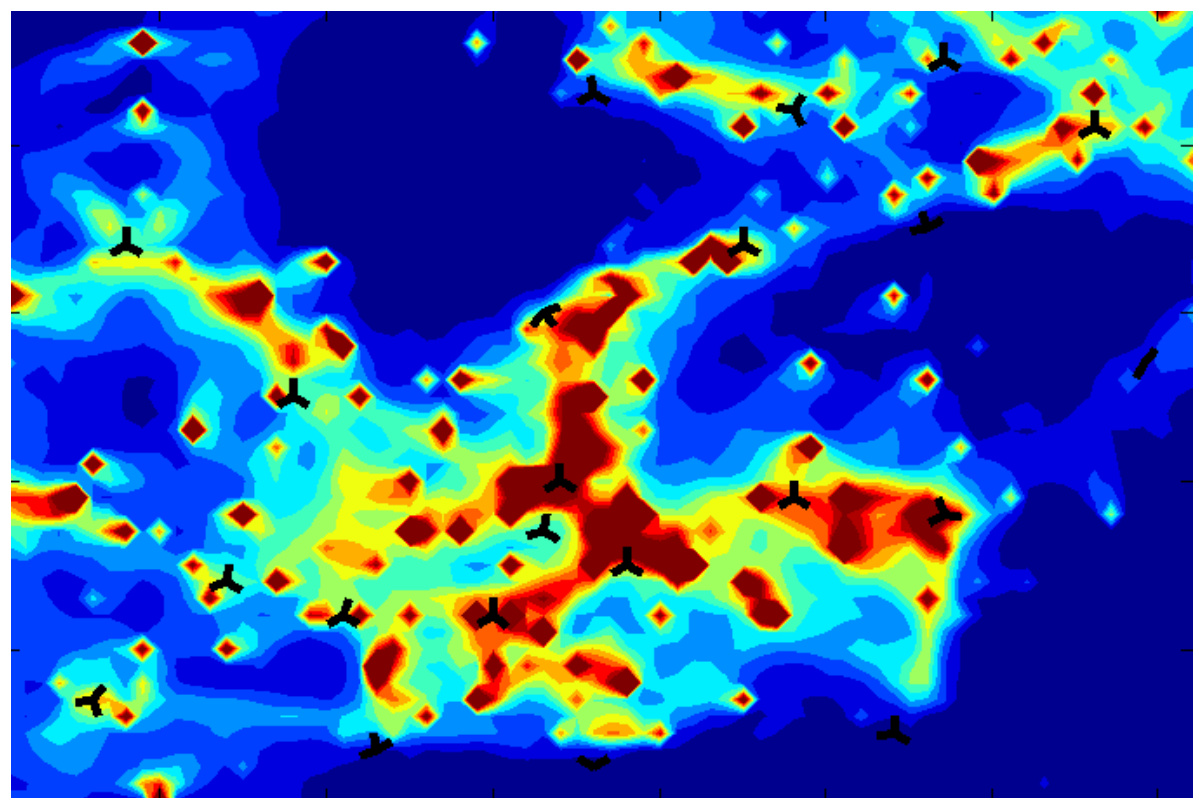

Figura 3.9: Ejemplo de mapa de densidad de usuarios

\subsection{Sistemas Expertos}

Dentro de las alternativas existentes en los procesos de planificación y optimización automática se encuentra la posibilidad de utilizar un sistema inteligente basado en la adquisición del conocimiento de expertos, normalmente 
como complemento a otras herramientas. Dentro de esta clase de sistemas inteligentes se encuentran los sistemas expertos basados en reglas. Estas reglas deben ser introducidas por un humano experto en el proceso que se quiere automatizar y su definición es de gran complejidad, más aún para problemas como la planificación y optimización de redes móviles, donde entran en juego un gran número de variables.

Descartando los sistemas expertos basados en reglas, que exigen una definición precisa y exhaustiva de todas las reglas necesarias para solucionar un problema, se propone la aplicación de sistemas basados en redes neuronales a los procesos de planificación y optimización automática. Las redes neuronales permiten la obtención automática, implícita y transparente de estas reglas además de aportar otras características interesantes como la posibilidad de mejorar de forma sencilla y dinámica su capacidad conforme aparecen nuevos casos de ejemplo a partir de los cuales se pueda inferir conocimiento.

Una red neuronal artificial trata de asemejarse al sistema neuronal humano en cuanto a que está destinada a la obtención de respuestas en función de unos datos de entrada, estando estas respuestas caracterizadas principalmente por su generalización y, por tanto, son capaces de reconocer determinados patrones en los datos de entrada.

Las redes neuronales artificiales están formadas por un conjunto de neuronas interconectadas entre sí y agrupadas en capas, de forma que una neurona sólo puede estar interconectada con neuronas de las capas anterior y posterior, salvo la primera y última capa, que sólo tienen una capa adyacente. Además, la capa de entrada no suele realizar ninguna operación más que el traslado de los datos de entrada a la siguiente capa. Una neurona artificial realiza una combinación lineal de las entradas cuyo resultado será la salida de la neurona tras aplicarlo a una función de activación. La función de activación utilizada será normalmente una sigmoide, cuya representación gráfica tiene forma de "S". En la figura 3.10 se representa un ejemplo de función sigmoide, la función logística, que viene definida por la siguiente ecuación:

$$
S(t)=\frac{1}{1+e^{-t}}
$$

La figura 3.11 representa el funcionamiento de cada una de las neuronas que forman la red. Por otro lado, la figura 3.12 muestra un ejemplo de red neuronal con los distintos tipos de capas que puede tener. En el ejemplo se muestra una única capa oculta pero la red neuronal puede tener varias, dependiendo de la aplicación.

Como se puede apreciar en la figura 3.11, cada una de las entradas $\left(E_{i}\right)$ de las distintas neuronas tiene un peso $\left(P_{i}\right)$ y el valor de cada uno de esos pesos será el que aporte a la red el conocimiento. Este conocimiento debe ser 


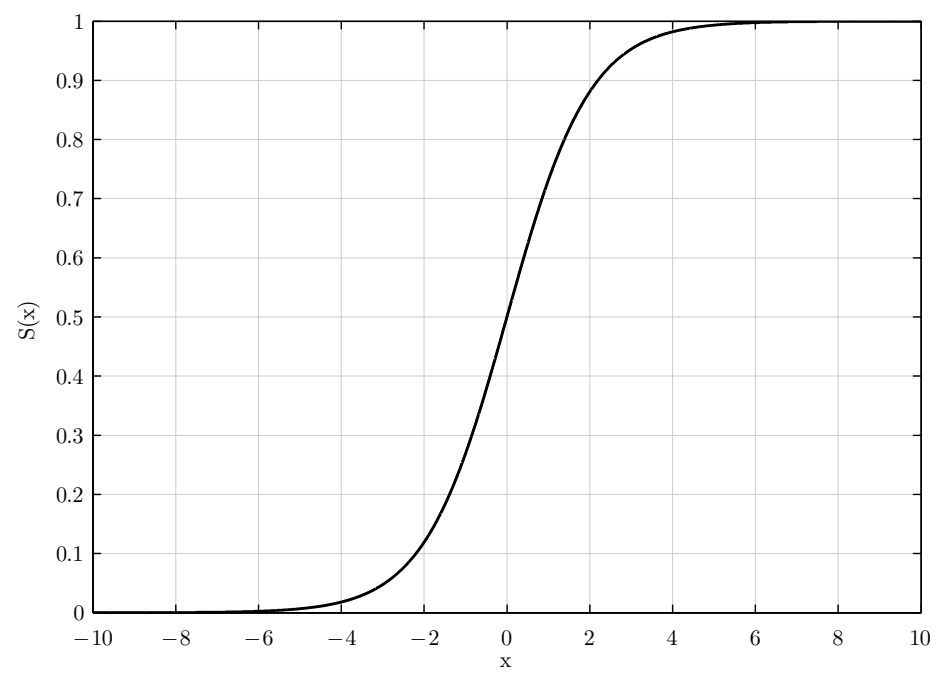

Figura 3.10: Representación gráfica de la función logística

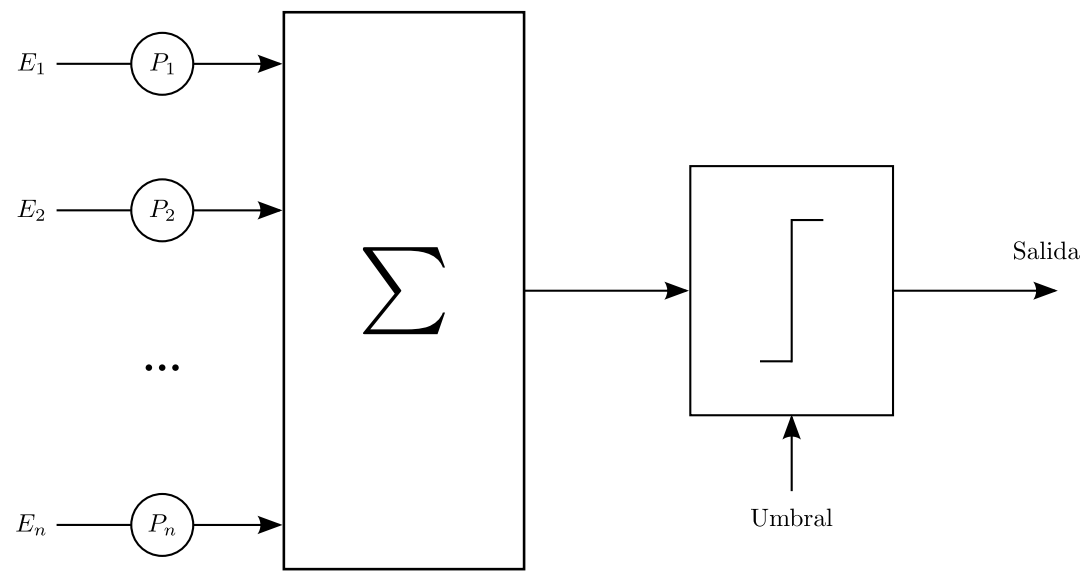

Figura 3.11: Neurona artificial

aprendido, lo que se traduce en que debe existir un proceso de ajuste de estos pesos. Este proceso de ajuste se conoce como entrenamiento.

Para entrenar una red neuronal artificial es necesario disponer de una colección de datos de entrada y los correspondientes resultados deseados. El proceso 


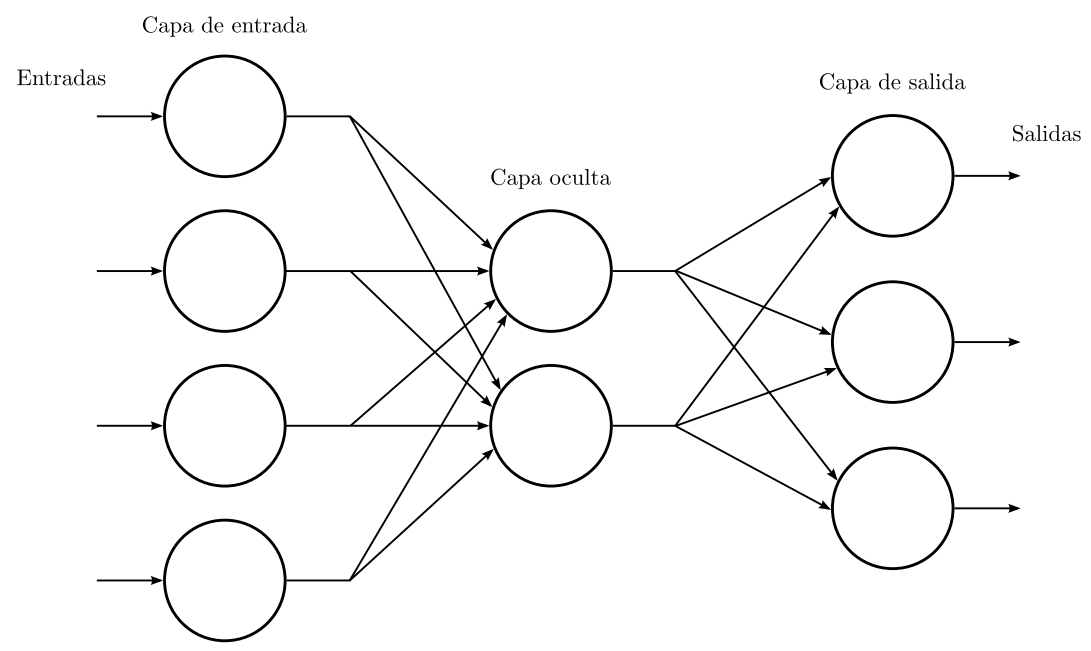

Figura 3.12: Red neuronal artificial

más común de entrenamiento consiste en procesar cada una de las muestras, observar los resultados obtenidos, compararlos con los resultados deseados y ajustar los pesos según esa comparación. Todo este proceso se repite iterativamente hasta que se cumplen ciertas condiciones de parada. El algoritmo más comúnmente utilizado para este proceso es el llamado back-propagation algorithm. Éste es un algoritmo de aprendizaje automático supervisado, es decir, requiere especificar los valores de salida ante determinados valores de entrada, y se basa en la propagación de atrás hacia delante, dentro de la red neuronal, de los errores resultantes de la comparación de la salida obtenida con la que se debería obtener. La utilización de la función sigmoide como función de activación será de gran importancia para el entrenamiento de la red neuronal, ya que es diferenciable, característica que cumple con uno de los requisitos de este tipo de entrenamiento. Este requisito se debe al método utilizado para el aprendizaje. Lo pesos de cada una de las ramas ponderadas a la entrada de cada una de las neuronas, representados matemáticamente por el vector $\boldsymbol{P}$, se van actualizando según la siguiente expresión:

$$
\boldsymbol{P}=\boldsymbol{P}+\Delta \boldsymbol{P}
$$

donde $\Delta \boldsymbol{P}$, si se utiliza el método de descenso de gradiente para el aprendizaje, se calcula según:

$$
\Delta \boldsymbol{P}=-\lambda \frac{\delta E(\boldsymbol{P})}{\delta \boldsymbol{P}}
$$




\section{CAPÍTULO 3. PROCESAMIENTO DE LA INFORMACIÓN}

siendo $\lambda, 0<\lambda<1$, el factor de aprendizaje y $E(\boldsymbol{P})$ el error cuadrático medio de las salidas obtenidas respecto a las salidas que deberían obtenerse.

Otra práctica común en el entrenamiento de redes neuronales consiste en reservar parte de las muestras de las que se dispone con dos objetivos. Por un lado, se reserva una parte de las muestras para detectar sobre-ajuste de los pesos durante el entrenamiento, por lo que su validación sirve como criterio de parada para el proceso iterativo. Por otro lado, se reserva otra parte de las muestras para probar el sistema final tras el entrenamiento, con muestras diferentes a las que han servido para realizar el ajuste.

El número de capas ocultas y el número de neuronas por capa serán parámetros que definirán la capacidad y la precisión que tendrá la red neuronal, teniendo gran impacto en los resultados alcanzables. Cuanto mayor sea el número de capas y de neuronas, mayor será la capacidad de la red. Como contrapartida, el aumento del número de capas ocultas y de neuronas aumenta también el número de pesos que deben ajustarse durante el entrenamiento y, por tanto, se complica el proceso de ajuste. De esta forma, la complejidad de la red puede llegar a ser inviable para ciertas aplicaciones debido al gran tiempo de ejecución necesario para el entrenamiento. Por lo tanto, uno de los estudios necesarios a la hora de aplicar un sistema experto basado en redes neuronales será la comparación de distintas configuraciones de redes neuronales de forma que se obtengan los resultados deseados a la vez que se mantengan los tiempos de entrenamiento en valores razonables. 


\section{Capítulo 4}

\section{Planificación y Optimización de la Red de Acceso Radio}

Planificar una red móvil consiste en determinar los elementos necesarios, equipos concretos, su ubicación y su configuración, para cumplir con unos determinados requisitos de cobertura, capacidad y calidad que vienen fijados por un determinado modelo de negocio, unas previsiones de crecimiento del número de usuarios y la experiencia con los sistemas predecesores si la hubiera.

Por otro lado, la optimización de un sistema de comunicaciones móviles consiste en el ajuste de los parámetros y elementos configurables del sistema, de forma que se maximice el rendimiento de la red. Por lo tanto, la optimización puede verse como un paso necesario al final del proceso de planificación, aunque va más allá de la planificación inicial y se mantiene a lo largo del tiempo, con optimizaciones periódicas o puntuales ante la detección de algún problema en la red móvil.

El rendimiento de la red se puede estimar con la utilización de modelos adecuados y medir, una vez implementados los cambios resultantes de la planificación u optimización, a través de contadores y estadísticas recogidas de la red.

Estos procesos pueden realizarse de forma automática con una herramienta adecuada de forma que, tras su ejecución, se obtenga una solución de configuración del escenario bajo estudio, sin necesidad de intervención humana más allá de definir los requisitos en la herramienta automática, interpretar los resultados e implementar la solución propuesta. 


\subsection{Objetivos y Formulación del Problema}

Centrándonos en el problema de la planificación de la red de acceso radio, los objetivos de diseño son aumentar la cobertura y maximizar el tráfico cursado.

Por un lado, el porcentaje de área con cobertura se puede definir de la siguiente forma: sea $A$ el área de la superficie $S$ que se corresponde con la zona bajo estudio, tal que

$$
A=\int_{S} d S
$$

Sea $C$ el conjunto de celdas a planificar. Sea $P_{c, x}$ la potencia de la señal recibida desde la celda $c \in \mathcal{C}, \mathcal{C}=\{1, \ldots, N\}$, por un usuario ubicado en $x \epsilon S$. Se define $A_{c}$ como el área de servicio de la celda $c$, es decir, el área de la superficie $S_{c}$ de puntos $x \in S$ donde $P_{c, x}$ es igual o superior a un umbral de potencia, $P_{\text {min }}$, siendo $P_{c, x}$ mayor o igual que la potencia de la señal recibida $P_{d, x}$ desde cualquier otra celda $d \epsilon \mathcal{C} \backslash\{c\}$, de manera que

$$
A_{c}=\int_{S_{c}} d S
$$

El umbral de potencia $P_{\min }$ es el que permitirá definir el criterio de cobertura. Este criterio se puede complementar con un requisito de calidad mínima para que una zona se considere cubierta, por ejemplo, en términos de SINR mínima.

Los requisitos establecidos para el proceso de planificación en relación con el área de cobertura se suelen definir en términos relativos al área total de la zona bajo estudio. De esta manera, el requisito de cobertura en tanto por cierto viene dado por la siguiente expresión:

$$
R_{S}^{\text {cobertura }}=\frac{100}{A} \sum_{c \in \mathcal{C}} A_{c}
$$

siendo un valor típico para este objetivo el $95 \%$ o $98 \%$ del total del área de planificación.

Por otro lado, en relación al tráfico a cursar, tal como se indica en la sección 3.3 , se puede hacer uso de métodos de localización en redes móviles a partir de medidas para confeccionar mapas de distribución de tráfico realistas en lugar de basarlos en estimaciones. De esta forma, utilizando por ejemplo datos recopilados de llamadas de una red UMTS en una zona determinada, es posible utilizar este mapa para la planificación de una nueva red LTE en esa misma zona.

La distribución de tráfico reflejada por el mapa de tráfico UMTS se deberá escalar convenientemente para considerar el probable incremento de tráfico que 
se producirá con el tiempo una vez implantada la red LTE. Además, para evitar no tener en cuenta posible tráfico que no ocurra en el sistema predecesor debido a un problema de cobertura, se puede suponer que existe un tráfico mínimo en cada punto del mapa de distribución de tráfico.

Suponiendo una distribución continua de tráfico de datos definida por la función de densidad de tráfico $f_{T}$ — de forma análoga se podría trabajar con número de usuarios - la demanda total de tráfico viene dada por

$$
T=\int_{S} f_{T} d S .
$$

De nuevo, el tráfico a cursar por cada celda en la región en la que actúa como best server sería

$$
T_{c}=\int_{S_{c}} f_{T} d S .
$$

El requisito de tráfico cursado también se suele definir en términos relativos al tráfico total de la zona bajo estudio, de forma porcentual y viene dada por la siguiente expresión:

$$
R_{S}^{\text {tráfico }}=\frac{100}{T} \sum_{c \in \mathcal{C}} T_{c} .
$$

Generalizando para el caso de planificar varios tipos de servicio $p \in \mathcal{P}$ con requisitos distintos, se tiene

$$
R_{S}^{\text {tráfico }}=\frac{100}{\sum_{p \in \mathcal{P}} T_{p}} \sum_{p \in \mathcal{P}} \sum_{c \in \mathcal{C}} T_{c, p},
$$

siendo $T_{p}$ el tráfico total para el tipo de servicio $p$ y $T_{c, p}$ el tráfico de tipo de servicio $p$ cursado por la celda $c$. De nuevo, es habitual definir un requisito de tráfico cursado del $95 \%$ o $98 \%$ respecto al tráfico total.

En caso de no disponer de distribuciones continuas de tráfico sino valores discretos en un conjunto de puntos o casillas del escenario bajo estudio, se pueden definir ecuaciones análogas en las que los sumatorios sustituirán a las integrales. En cada casilla se consideran condiciones similares tanto en lo relacionado con la demanda de tráfico como en las condiciones de propagación. Sea $D$ el conjunto de casillas del escenario, $\mathcal{D}_{c} \subset \mathcal{D}$ el conjunto de casillas donde la celda $c \in \mathcal{C}$ es best server, $d \in \mathcal{D}$ una casilla cualquiera del escenario y $t_{d}$ la demanda de tráfico en la casilla $d$. El tráfico existente en el área de servicio de la celda $c$ será

$$
T_{c}=\sum_{d \in \mathcal{D}_{c}} t_{d}
$$




\section{CAPÍTULO 4. PLANIFICACIÓN Y OPTIMIZACIÓN DE LA RED DE ACCESO RADIO}

Dado que los recursos no son ilimitados, es posible que una celda no pueda atender todo el tráfico existente en su área de servicio. Sea $\mathcal{D}^{\prime}{ }_{c} \subset \mathcal{D}_{c}$ el conjunto de casillas cuyo tráfico puede ser atendido por la celda $c$. El tráfico cursado por dicha celda será

$$
T^{\prime}{ }_{c}=\sum_{d \in \mathcal{D}^{\prime}{ }_{c}} t_{d}
$$

Tanto para el cálculo del valor de la potencia de señal recibida en cada punto como para la estimación del tráfico cursado se hará uso de las capacidades del simulador estático detallado en la sección 2.2.

El objetivo de la planificación será maximizar el área de cobertura y el tráfico cursado hasta alcanzar los requisitos marcados. Para los casos en que se impongan restricciones adicionales que no permitan alcanzar los requisitos fijados - como, por ejemplo, número máximo de celdas/emplazamientos a implantarel proceso de maximización tratará de proporcionar la mejor solución posible.

Para conseguir este objetivo es necesario definir una función de coste acorde al mismo. Existen distintas definiciones de función de coste para su utilización como objetivo de la planificación y optimización automática. Algunas alternativas se basan en la maximización del área de cobertura o el tráfico cubierto, existiendo en la literatura otras tantas alternativas [83].

Los criterios simples basados en considerar el área o el tráfico cubierto incluyendo quizá algún requisito extra de calidad como un determinado nivel mínimo de SINR para considerar que un punto del escenario queda cubiertopueden llevar a soluciones que una vez trasladadas al sistema implantado no produzcan los resultados esperados, debido a que no se considera la capacidad limitada de cursar tráfico que tienen las celdas desplegadas.

Por esta razón, una función de coste apropiada para la planificación y optimización debe tener en cuenta la capacidad y qué parte del tráfico estimado se va a poder cursar, en lugar de considerar únicamente el hecho de que se disponga de cobertura en la zona donde éste se produzca.

Para ello es necesario estimar la carga de una celda en función de las condiciones radio y del tráfico existente. Esta funcionalidad se encuentra disponible en el simulador estático y ha sido descrita en la sección 2.2.2.4. Básicamente, se utiliza una versión adaptada de la fórmula de la capacidad de Shannon para realizar una estimación de tráfico en cada casilla del escenario en función de la SINR que experimentan los usuarios ubicados en la misma.

Suponiendo que en el proceso de planificación se busque minimizar la función de coste objetivo definida, se ha de invertir el significado de la misma para pasar a representar el porcentaje de tráfico no cursado en lugar del que pueden asumir las celdas planificadas. De esta forma, la función de coste objetivo queda 
definida por la siguiente ecuación:

$$
f_{o b j}=1-\frac{1}{T} \sum_{c \in \mathcal{C}} T_{c}^{\prime} .
$$

A la hora de calcular $T^{\prime}{ }_{c}$ para cada una de las celdas planificadas, se supone que el tráfico de las casillas del escenario donde la celda $c$ es best server se cursan primero, ordenando estas casillas de mayor a menor nivel de SINR experimentado en ellas, pudiendo quedar tráfico de algunas casillas de $D_{c}$ sin atender en caso de agotarse los recursos. Una vez procesadas las casillas donde la celda $c$ es best server, si ésta aún dispone de recursos libres, se considerará que puede cursar tráfico de otras casillas en las que tenga cobertura.

\subsection{Linealización del Sistema LTE}

La planificación y optimización de un sistema LTE requiere disponer de las capacidades necesarias para evaluar las prestaciones del sistema para una configuración dada. En la literatura relacionada con la evaluación de prestaciones de redes móviles es habitual considerar una carga en las celdas del $100 \%$, lo que supone adoptar una posición conservadora al considerar el peor caso con unas condiciones de interferencia extremas. En la planificación de una red de comunicaciones móviles no es aconsejable establecer como objetivo la consecución de la carga completa en las celdas planificadas, siendo recomendable que su nivel de carga no supere un cierto umbral, para permitir que la red pueda gestionar picos de tráfico puntuales.

Considerando que la red final planificada no va a tener todas las celdas a plena carga, con el fin de conseguir la mejor planificación y/o optimización del sistema es necesario estimar la carga que realmente experimentará cada celda en función del tráfico cursado. Esta sección está dedicada al cálculo eficiente de la carga real de una celda LTE.

Para la evaluación de prestaciones de una configuración de la red es imprescindible comenzar con el cálculo de la SINR de la señal recibida desde cada celda en cada casilla del escenario, $\gamma_{c, d}$. Este valor se calculará como

$$
\gamma_{c, d}=\frac{P_{c} g_{c, d}}{\sum_{n \in \mathcal{C} \backslash\{c\}} P_{n} g_{n, d} \rho_{n}+\sigma^{2}},
$$

siendo $P_{c}$ la potencia transmitida por RB por la celda $c, P_{n}$ la correspondiente a las celdas interferentes, $g_{c, d}$ y $g_{n, d}$ la ganancia sufrida por la señal desde su transmisión hasta su recepción para la señal útil e interferente, respectivamente, $\rho_{n}$ la carga de la celda interferente $n$ y $\sigma^{2}$ la potencia de ruido térmico. 


\section{CAPÍTULO 4. PLANIFICACIÓN Y OPTIMIZACIÓN DE LA RED DE ACCESO RADIO}

La carga de una celda determina la cantidad de potencia disponible que se debe utilizar y, por tanto, el nivel de interferencia que provocará a sus vecinas. A efectos de estimar la carga de una celda una vez conocida la zona donde la misma es best server hay que tener en cuenta la demanda de tráfico en su región de servicio y su capacidad de transmisión. El porcentaje de RBs necesarios para cursar la demanda de tráfico en todas las casillas de la zona donde la celda es best server determinará la carga de la celda, tal y como expresa la siguiente ecuación:

$$
\rho_{c}=\frac{1}{N_{c}} \sum_{d \in \mathcal{D}^{\prime}{ }_{c}} \frac{t_{d}}{B_{c, d}},
$$

donde $N_{c}$ es el número de RBs asignables en la celda $c, t_{d}$ es la demanda de tráfico en la casilla $d$ y $B_{c, d}$ representa el throughput conseguido en un RB de la celda $c$ en la casilla $d$. Para estimar el throughput es habitual recurrir a la fórmula de la capacidad de Shannon [57]:

$$
B=W \log _{2}(1+\gamma),
$$

donde $B$ es la capacidad alcanzada en bps, $W$ es el ancho de banda del sistema o canal utilizado en $\mathrm{Hz}$ y $\gamma$ es la SINR en recepción en unidades lineales. Para el caso particular que nos ocupa se utilizará un ecuación similar, modificada a partir de la anterior, de forma que refleje que no se consigue el mismo throughput que en el límite que marca la fórmula de la capacidad Shannon [58], resultando la siguiente ecuación:

$$
B_{c, d}=\eta_{B} W \log _{2}\left(1+\frac{\gamma_{c, d}}{\eta_{\gamma}}\right),
$$

donde $W$ es el ancho de banda de un $\mathrm{RB}$ en $\mathrm{Hz}, \eta_{B}$ es la eficiencia del ancho de banda y $\eta_{\gamma}$ la eficiencia de la SINR. Suponiendo ambas eficiencias constantes para todas las celdas y todas las casillas, la carga de la celda $c$ se calcularía como

$$
\rho_{c}=\sum_{d \in \mathcal{D}^{\prime}{ }_{c}} \frac{t_{d}}{N_{c} \eta_{B} W \log _{2}\left(1+\frac{P_{c} g_{c, d}}{\eta_{\gamma}\left(\sum_{n \in \mathcal{C} \backslash\{c\}} P_{n} g_{n, d} \rho_{n}+\sigma^{2}\right)}\right)} .
$$

Los detalles sobre los valores de eficiencia de ancho de banda y de SINR se pueden consultar en la sección 2.2.2.4.

En la ecuación (4.15) se observa la dependencia de la carga de una celda con la carga de las celdas interferentes. Expresando este hecho para todas las celdas en notación vectorial, resulta que

$$
\rho=f(\rho),
$$


donde $\boldsymbol{\rho}=\left(\rho_{1}, \ldots, \rho_{N}\right)^{T}$ y $\boldsymbol{f}=\left(f_{1}, \ldots, f_{N}\right)^{T}$, con $f_{c}, c=\{1, \ldots, N\}$, definida de la siguiente forma:

$$
f_{c}(\boldsymbol{\rho})=\sum_{d \epsilon \mathcal{D}_{c}} \frac{f_{c}: \mathbb{R}_{+}^{N} \longrightarrow \mathbb{R}_{+}}{N_{c} \eta_{B} W \log _{2}\left(1+\frac{t_{d}}{\eta_{\gamma}\left(\sum_{n \in \mathcal{C} \backslash\{c\}} P_{n} g_{n, d} \rho_{n}+\sigma^{2}\right)}\right)} .
$$

La ecuación (4.16) representa un sistema de ecuaciones de punto fijo, para el que se podrían utilizar métodos iterativos para la búsqueda de la solución de equilibrio. Sin embargo, hay que tener en cuenta la utilidad que se le va a dar a la solución de este sistema de ecuaciones de punto fijo, que es la de evaluar una solución propuesta en el proceso de búsqueda de la solución óptima al problema de planificación utilizando una carga estimada realista. Esta evaluación no debe ser, por tanto, costosa temporalmente lo que invalida la posibilidad de resolver el sistema de ecuaciones mediante métodos iterativos.

Una posibilidad para hacer más rápido este cálculo de la carga real de las celdas parte de la linealización de la función $f_{c}(\boldsymbol{\rho})$, de forma que se simplifique la resolución del sistema de ecuaciones.

Nótese que en la definición del sistema de ecuaciones se ha considerado que la carga de una celda $c$ se calcula incluyendo todas las casillas donde ésta es best server. De esta forma, una celda sobrecargada que cubre mucho tráfico estaría introduciendo una penalización en el sistema al provocar mucha interferencia, con lo que el proceso automático de planificación tenderá a solventar esta situación de alta carga con la reducción del área de servicio de dicha celda.

Utilizando el desarrollo de Taylor de primer orden como aproximación lineal de la función $f_{c}(\boldsymbol{\rho})$, la ecuación (4.16) se aproximaría como:

$$
\rho \approx \boldsymbol{J} \cdot(\boldsymbol{\rho}-\boldsymbol{a})+\boldsymbol{f}(\boldsymbol{a})
$$

donde $\boldsymbol{a}=\left(a_{1}, \ldots, a_{N}\right)^{T}$ es un vector dado de valores de carga y $\boldsymbol{J}$ es el jacobiano de la función $\boldsymbol{f}$ evaluado en $\boldsymbol{a}$, es decir,

$$
\boldsymbol{J}=\left[\begin{array}{rll}
\frac{\delta f_{1}}{\delta \rho_{1}} & \cdots & \frac{\delta f_{1}}{\delta \rho_{N}} \\
\vdots & \ddots & \vdots \\
\frac{\delta f_{N}}{\delta \rho_{1}} & \cdots & \frac{\delta f_{N}}{\delta \rho_{N}}
\end{array}\right]
$$

donde los elementos de los diagonal, $J_{i i}=0, i=\{1, \ldots, N\}$ y los restantes siguen la siguiente expresión:

$$
J_{i j}=\sum_{d \in \mathcal{D}_{i}} \ln (2) \frac{\eta_{\gamma} t_{d}}{N_{i} \eta_{B} W} \frac{P_{j} g_{j, d}}{P_{i} g_{i, d}} \frac{1}{\ln ^{2}\left(1+\frac{P_{i} g_{i, d}}{\eta_{\gamma}\left(\sum_{n \epsilon \mathcal{C} \backslash\{i\}} P_{j} g_{j, d} \rho_{j}+\sigma^{2}\right)}\right)} \times
$$




$$
\times \frac{1}{\left(\frac{\eta_{\gamma}\left(\sum_{n \epsilon \mathcal{C} \backslash\{i\}} P_{j} g_{j, d} \rho_{n}+\sigma^{2}\right)}{P_{i} g_{i, d}}\right)^{2}+\frac{\eta_{\gamma}\left(\sum_{n \in \mathcal{C} \backslash\{i\}} P_{j} g_{j, d} \rho_{n}+\sigma^{2}\right)}{P_{i} g_{i, d}}}
$$

Es importante destacar que cada una de las ecuaciones resultantes de esta aproximación representa el hiperplano tangente a su correspondiente función $f_{c}$ que pasa por $a_{c}$.

En la figura 4.1 se representa un ejemplo de aproximación mediante el desarrollo de Taylor de primer orden de la función $h(x)=\frac{1}{\ln (1+x)}$ en el entorno de $x=0,5$. $h(x)$ tiene una forma similar a la función $\boldsymbol{f}(\rho)$ para el caso de considerar dos celdas.

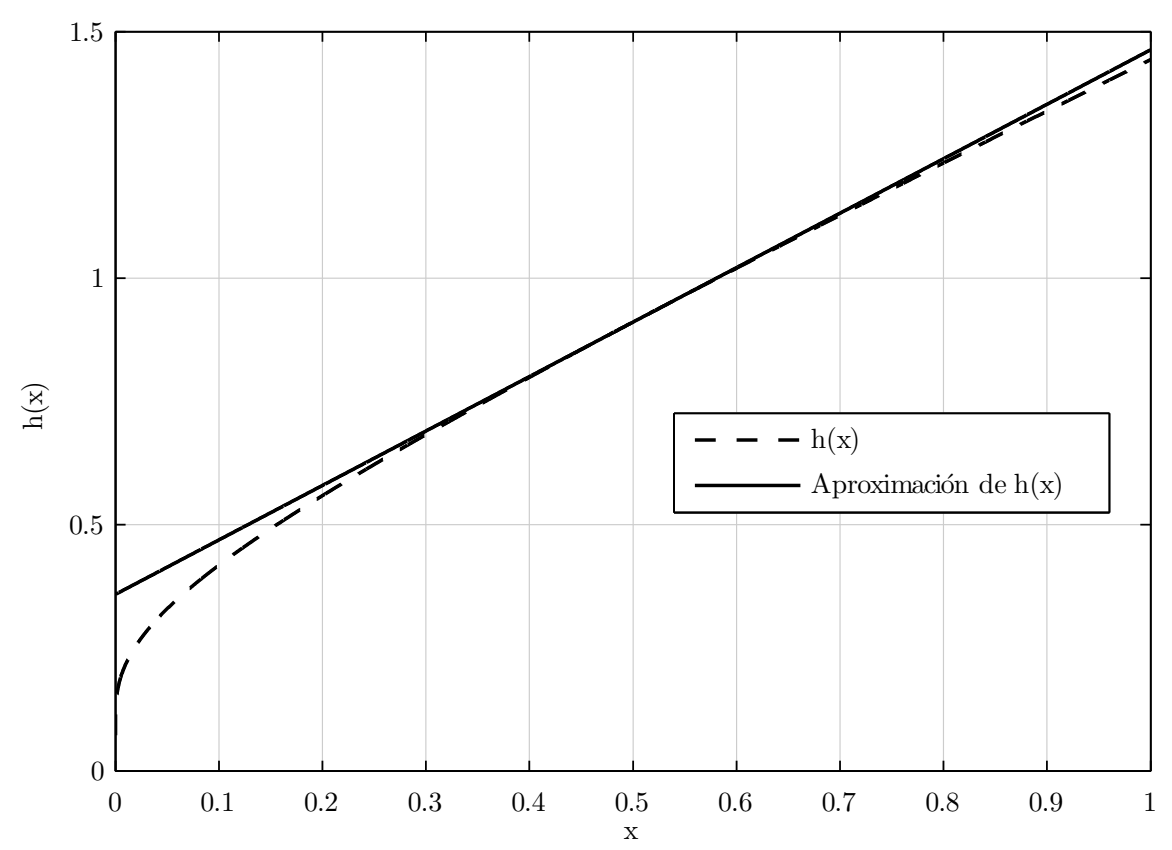

Figura 4.1: Aproximación de $h(x)$ alrededor de $x=0,5$ mediante desarrollo de Taylor de primer orden

Dado que la función $\boldsymbol{f}(\rho)$ es cóncava - como se puede observar en la figura 4.1 y se demuestra de forma general en [33] - y teniendo en cuenta el significado de la aproximación realizada - el desarrollo de Taylor de primer orden se corresponde con el hiperplano tangente a su correspondiente función 
$f_{c}$ que pasa por $a_{c}$ - la solución del sistema de ecuaciones lineales resultante de la aproximación será una cota superior del valor de carga real del sistema.

Además, conforme se puede apreciar también en la figura 4.1, conforme mayor sea la carga de las celdas consideradas y, por tanto, mayor sea el punto $\boldsymbol{a}$ en el entorno del cual se realiza la aproximación, mejor será la aproximación realizada y más próxima estará la cota superior calculada de la carga real de las celdas. Es decir, para valores altos de $x, h(x)$ se parece a una recta que coincidirá con la de la aproximación.

En el límite, la variación de la carga de una celda respecto a la carga de otra celda sigue la siguiente expresión:

$$
\lim _{\rho_{j} \rightarrow \infty} \frac{\partial f_{i}}{\partial \rho_{j}}=\sum_{d \in \mathcal{D}_{i}} \ln (2) \frac{\eta_{\gamma} t_{d}}{N_{i} \eta_{B} W} \frac{P_{j} g_{j, d}}{P_{i} g_{i, d}}
$$

En [33] se demuestra que se puede utilizar la solución del sistema de ecuaciones lineales tomando $\boldsymbol{a}=(0, \ldots, 0)^{T}$ y $J_{i j}=\sum_{d \in \mathcal{D}_{i}} \ln (2) \frac{\eta_{\gamma} t_{d}}{N_{i} \eta_{B} W} \frac{P_{j} g_{j, d}}{P_{i} g_{i, d}}$ para comprobar si el sistema es viable, es decir, capaz de satisfacer la demanda de tráfico existente. Además, la solución para este caso representa una cota inferior de la carga real del sistema. Si la resolución del sistema de ecuaciones lineales proporcionara valores de carga negativos, sería un indicador de que la solución de planificación propuesta no es viable. Lo mismo se puede deducir si los valores de carga resultantes fueran superiores a la unidad, con el valor añadido de que aporta información útil sobre la solución propuesta al indicar el grado de sobrecarga de cada celda.

Por último, el cálculo de esta cota inferior será de gran utilidad para fijar un valor coherente de $\boldsymbol{a}$ y así utilizarlo en el cálculo de la cota superior.

\subsection{Procedimientos de Búsqueda de Solución}

\subsubsection{Introducción}

La planificación y optimización de la red de acceso radio de un sistema de comunicaciones móviles se traduce en un complejo problema combinacional debido al elevado número de variables de decisión y, por lo tanto, a la gran amplitud del espacio de búsqueda de posibles soluciones. Existen distintos métodos matemáticos de optimización global, es decir, que buscan el mínimo o el máximo de una función de coste evitando confundirlo con los mínimos y máximos locales que pudieran existir.

Entre estos métodos se encuentran los de tipo exacto, que son aquellos procedimientos capaces de obtener el óptimo. Dentro de este tipo se encuentran los métodos de búsqueda exhaustiva, que representan la forma más intuitiva de 


\section{CAPÍTULO 4. PLANIFICACIÓN Y OPTIMIZACIÓN DE LA RED DE ACCESO RADIO}

encontrar el óptimo de una función ya que recorren todo el espacio de posibles valores de las variables implicadas. Esto es computacionalmente viable sólo si la función se puede evaluar eficientemente y el conjunto de valores posibles es pequeño y discreto.

Para reducir el coste computacional que supondría la evaluación de todas las posibles soluciones, se recurre a técnicas de optimización heurísticas, conjunto que comprende al resto de métodos que encuentran una buena solución pero que no tiene por qué ser la óptima. Estos métodos son importantes porque a menudo, en la práctica, la eficiencia en tiempo de procesado es prioritaria a la consecución del mejor resultado posible o bien porque son la única opción temporalmente viable. Las técnicas heurísticas tratan de resolver el problema de optimización combinatoria explorando el espacio de búsqueda de manera eficiente. Para ello, de manera iterativa, tratan de mejorar el coste o beneficio de las distintas soluciones candidatas.

\subsubsection{Métodos Heurísticos de Búsqueda}

A continuación se describen tres métodos heurísticos de optimización global frecuentemente tratados en la literatura por el gran interés en su aplicación a la resolución de problemas prácticos debido a los buenos resultados que han demostrado.

\subsubsection{Simulated Annealing}

El SA es una heurística de optimización combinatoria basada en el método de templado utilizado en metalurgia. Su simplicidad y buenos resultados en numerosos problemas de optimización lo han convertido en una herramienta muy popular, con aplicación en una gran variedad de campos. Se definió originalmente [84] como una generalización del método de Montecarlo y ha demostrado ser una herramienta muy potente para resolver una amplia gama de problemas de optimización combinatoria. Es una variante de la búsqueda local, que permite movimientos hacia estados que representan soluciones peores, evitando de esta manera que el proceso quede atrapado prematuramente en un óptimo local.

En la jerga metalúrgica, el templado consiste en calentar el material a muy alta temperatura. En esa situación, los átomos adquieren una distribución aleatoria dentro de la estructura del material y la energía del sistema es máxima. Posteriormente, se hace descender la temperatura muy lentamente por etapas, dejando que en cada una de ellas los átomos queden en equilibrio alcanzando una configuración óptima para esa temperatura. El enfriamiento paulatino aumenta las probabilidades de encontrar configuraciones con una energía interna 
menor que la inicial. Al final del proceso, los átomos forman una estructura cristalina altamente regular gracias a la que la energía del sistema es mínima, lo que permite al material alcanzar su máxima resistencia.

Tratando de imitar este proceso físico, el SA reemplaza en cada iteración la solución actual por una nueva generada aleatoriamente, siendo ésta cercana a la solución anterior. De hecho, en la generación de nuevas soluciones candidatas se suele variar una sola variable de la función de coste respecto a la solución anterior. Una vez generada la nueva solución candidata, si ofrece una mejora en términos de la función de coste se aceptará y si hace que empeore podrá ser aceptada o rechazada con cierta probabilidad que depende de la temperatura actual del proceso y del empeoramiento que produce la nueva solución en la función de coste respecto a la solución anterior. Con esto se trata de resolver el problema de quedarse atascado en un mínimo local al permitir que algunos movimientos se produzcan hacia soluciones peores, controlando este trastorno del proceso normal para tratar de no saltar a soluciones peores cuando el proceso está ya cerca del óptimo global.

Si bien la idea fundamental del proceso es sencilla, la configuración del mismo es compleja ya que existen diversos parámetros que controlan el funcionamiento del algoritmo que tienen una gran influencia en la calidad de las soluciones alcanzadas.

Entre los puntos de configuración críticos se encuentran los relacionados con la temperatura, es decir, las temperaturas inicial y final seleccionadas, así como el método de enfriamiento y número de iteraciones entre cambios de temperatura, que afectarán a la convergencia del algoritmo, en mayor o menor grado, dependiendo del problema. Seleccionar una temperatura inicial demasiado baja puede producir que no se dé la libertad suficiente al algoritmo para saltar a soluciones peores de forma que no quede atrapado en un mínimo local. Si se escoge una temperatura final - la que establece uno de los criterios de parada del algoritmo - muy alta, es posible que no se deje converger al algoritmo, no llegando a la mejor solución que podría alcanzar. Por otro lado, una temperatura final demasiado baja puede ocasionar que se pierda el tiempo en iteraciones finales del algoritmo en las que no se va a producir ya ninguna mejora, cuando podría venir mejor dedicar ese tiempo en temperaturas más altas donde se puede explorar con mayor exhaustividad el espacio de búsqueda. De igual forma, un método de enfriamiento demasiado rápido y un número de iteraciones demasiado bajo puede provocar que el proceso llegue demasiado rápido a la temperatura final, sin dejar tiempo suficiente para alcanzar una buena solución. Por el contrario, un método de enfriamiento lento y un número de iteraciones excesivo puede no ser necesario, pero sí una pérdida de tiempo, en la búsqueda del óptimo. La ecuación (4.22) representa el enfriamiento típico 


\section{CAPÍTULO 4. PLANIFICACIÓN Y OPTIMIZACIÓN DE LA RED DE ACCESO RADIO}

utilizado en el algoritmo de SA, con descenso geométrico de la temperatura entre iteraciones.

$$
T_{i+1}=\alpha \cdot T_{i} .
$$

$i=\{1, \ldots, N\}$ es la iteración actual siendo $N$ el número máximo de iteraciones del algoritmo, que viene determinado por el método de enfriamiento utilizado y las temperatura inicial y final, y $\alpha$ es el factor de enfriamiento, con valores típicos del orden de 0,9 para velocidades de enfriamiento lentas.

En cuanto al número de iteraciones entre cambios de temperatura, es normal que este número no sea fijo sino que vaya variando conforme avanza la temperatura. Interesa que sea más alto conforme más baja sea la temperatura, de forma que se favorezca el alcance del óptimo — global o local, ya que es bastante improbable que salga del mínimo actual debido a la baja temperaturaen las últimas iteraciones del algoritmo.

Otra forma de mantener variable el número de iteraciones entre temperaturas es hacer depender el mismo del número de aceptaciones en cada etapa. De esta forma se hace que el algoritmo de SA se autoadapte y no dedique demasiado tiempo del proceso a etapas donde se acepte casi cualquier solución debido a la alta temperatura.

En lo que respecta la probabilidad de aceptación de soluciones, ésta viene dada por la siguiente ecuación [84]:

$$
P(\Delta E, T)=\left\{\begin{array}{cc}
1, & \Delta E<0 \\
e^{\frac{-\Delta E}{k \cdot T}}, & \Delta E \geq 0
\end{array}\right.
$$

donde $\Delta E$ es la diferencia de energía — valor de la función de coste- entre la solución actual y la nueva solución, $T$ es la temperatura actual y $k$ es la constante de Boltzmann. Esta expresión deriva de la correspondiente al Factor de Boltzmann, que es es un factor de ponderación que determina la probabilidad relativa de un estado en un sistema con múltiples estados en equilibrio termodinámico a una cierta temperatura. La constante de Boltzmann no mantiene un significado físico en la aplicación de la ecuación (4.23) al problema de optimización, por lo que no suele intervenir en las implementaciones del algoritmo de SA $(k=1)$. Sin embargo, es posible darle utilidad a esta constante para tener cierto grado de control sobre la probabilidad de aceptación en función de la temperatura además de poder escalar la diferencia de energía en el caso de que la función de coste no esté normalizada.

\subsubsection{Algoritmos genéticos}

Los algoritmos genéticos son otro tipo de técnica de búsqueda muy utilizada en problemas de optimización. Se basan en la evolución biológica, concretamen- 
te en la ley natural de supervivencia de los más fuertes, de manera que se generan poblaciones de individuos que serán evaluados mediante la función de coste que se haya definido. Aquéllos individuos que presenten mejores prestaciones en términos de esa función de coste tendrán más posibilidades de perpetuar la especie.

Cada individuo, para el que también se suele utilizar el término cromosoma, está constituido por una serie de genes, cada uno de los cuales se corresponde con una de las variables de la solución candidata al problema de optimización que representa el individuo. Tal como ocurre en la naturaleza, la siguiente generación de individuos que surgirá partiendo de la generación actual se obtendrá por reproducción de los individuos de la generación actual y/o mutación de uno o varios de sus genes.

La reproducción consiste en la combinación de los genes de dos individuos, a partir de la cual se generarán dos descendientes. Esta combinación se realiza cogiendo para uno de los descendientes parte de los genes de un padre y parte del otro, y para el segundo descendiente los genes restantes. El punto de cruce entre los de uno y otro se calcula de forma aleatoria. La selección de los padres que formarán nuevos individuos de la siguiente generación se hará también de forma aleatoria, teniendo mayor probabilidad de selección los individuos más fuertes de la población padre. De esta forma, se simula el proceso de selección natural presente en la naturaleza.

Por otro lado, la mutación consiste en la variación de los genes de los descendientes resultantes de la reproducción con una cierta probabilidad. Cuanto mayor sea la probabilidad de mutación menos se parecerán los individuos de la nueva generación a sus padres. Es por esto que el valor de esta probabilidad se suele mantener bajo, del orden de un $5 \%$.

Tras los procesos de reproducción y mutación se obtiene una nueva generación. En un segundo proceso de imitación de la selección natural, la nueva población de individuos del algoritmo genético tendrá el mismo número de individuos que la población original, estando ésta formada por los mejores individuos, aquéllos que mejores prestaciones tienen según la función de coste.

Todo este proceso de evolución y creación de nuevas generaciones se repite iterativamente hasta que se llega a un máximo número de iteraciones o se cumplen los criterios de parada previamente fijados.

Loa algoritmos genéticos se pueden utilizar para resolver problemas con un único o con varios objetivos, habiendo versiones específicas para el caso de optimización multi-objetivo. Ese es el caso del Non-dominated Sorting Genetic Algorithm II (NSGA-II) [85].

El hecho de tratar de optimizar una función de coste multi-objetivo convierte la misión de conseguir la mejor solución en la de conseguir un conjunto de soluciones, presentando cada una de ellas las mejores prestaciones en uno de los 


\section{CAPÍTULO 4. PLANIFICACIÓN Y OPTIMIZACIÓN DE LA RED DE ACCESO RADIO}

objetivos, dado un valor fijo del resto de objetivos. En esto consiste el concepto de dominancia: una solución domina a otra si presenta mejor rendimiento en un objetivo y no presenta peor rendimiento en el resto de objetivos.

Por otra parte, otro concepto importante en este algoritmo es la diversidad, que se estima analizando la separación de cada individuo respecto al resto en el espacio de soluciones, con el objetivo de que la población final se encuentre uniformemente distribuida en el frente óptimo de Pareto.

La diversidad de la población inicial del NSGA-II influye en la solución final alcanzada. Una diversidad reducida de la población inicial afecta tanto a la diversidad de la población final como a la bondad del frente óptimo de Pareto que se obtiene de la misma. Los siguientes resultados muestran la mejora conseguida en las soluciones del frente óptimo de Pareto cuando, en lugar de generar la población inicial de forma totalmente aleatoria, se seleccionan los genes de parte de la misma para garantizar una mayor diversidad.

Para conseguir guiar la generación de la población inicial de forma parcial, es necesario poder controlar el rendimiento de los distintos objetivos a través de los valores de los genes de la población, lo cual no siempre es posible. En el caso contemplado aquí esa tarea es fácil ya que uno de los genes afecta directamente a los dos objetivos, como es el caso de la potencia en cada celda cuando se trata de optimizar el área cubierta con un mínimo de calidad y el consumo medio de potencia respecto a la potencia máxima. De forma intuitiva se sabe cómo deben tener los individuos los genes para formar un frente diverso en la población inicial, con un simple barrido desde la potencia mínima hasta la potencia máxima disponible.

Los resultados de diversidad de población inicial que aquí se describen se han obtenido en el escenario mostrado en la figura 4.2.

Para la obtención del frente diversificado de la población inicial se han seleccionado 10 individuos para los que se ha fijado el mismo valor de potencia para todas las celdas que lo forman. Además, cada individuo tiene para todas sus celdas uno de los 10 valores que se pueden configurar para el CPICH - de 27 a $36 \mathrm{dBm}$ a pasos de $1 \mathrm{~dB}$ - . Como resultado de este forzado de diversidad de la población inicial se obtiene un frente como el mostrado en la figura 4.3.

Llama la atención que la nube de puntos que se concentra alrededor del valor de potencia del $43 \%$ respecto al valor máximo configurable no lo esté alrededor del $50 \%$, que sería el valor medio lógico cuando a cada celda se le asigna un valor de potencia de entre los 10 posibles de forma aleatoria siguiendo una distribución uniforme. El hecho de que no sea así tiene su explicación en que la generación de los valores de potencia de forma aleatoria se hace escogiendo sobre los valores en $\mathrm{dBm}$, mientras que para calcular el valor de potencia medio del sistema resultante relativo a la potencia máxima configurable se utiliza la escala lineal. 


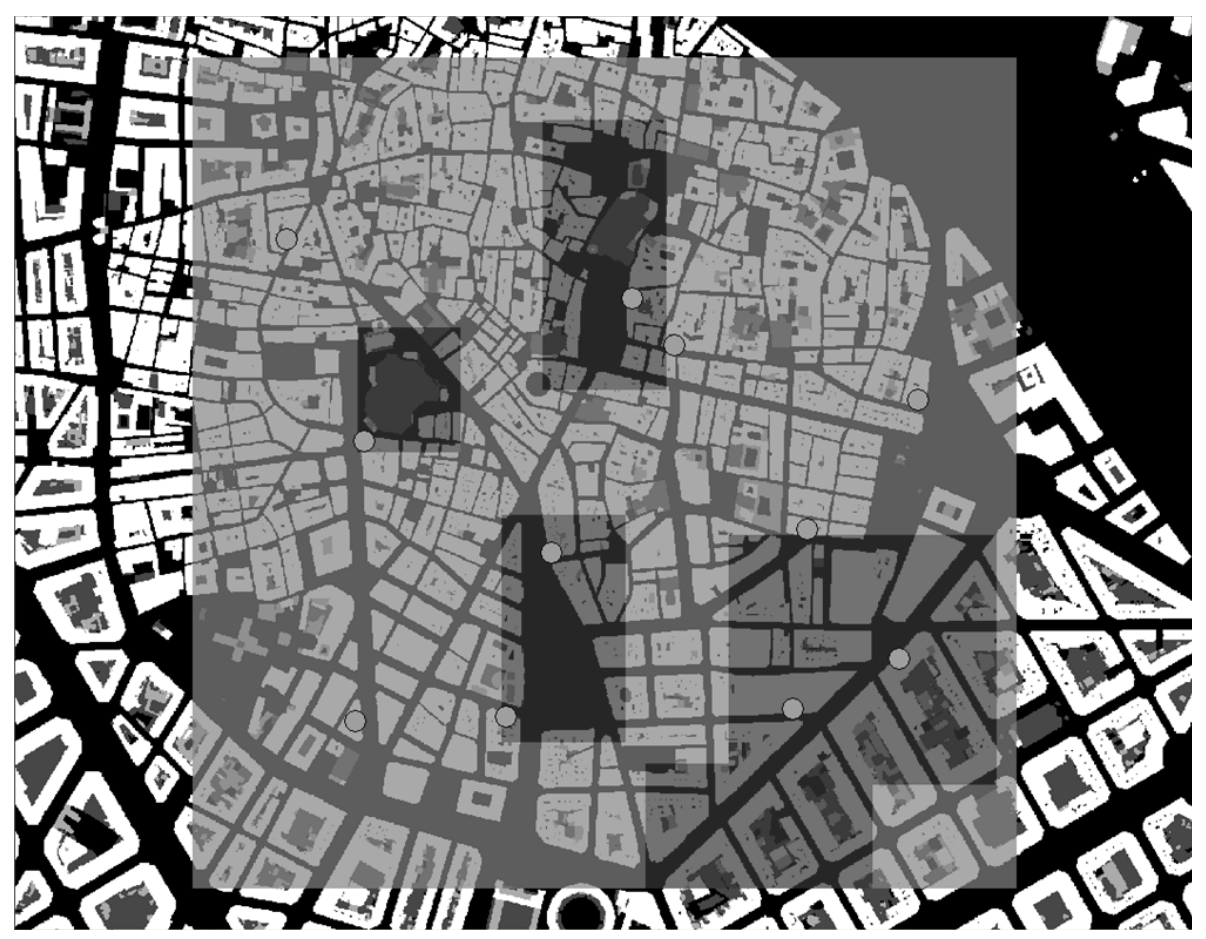

Figura 4.2: Escenario simple con matriz de tráfico sintética

Además de la opción seleccionada para aportar diversidad a la población inicial, sería posible obtener esta diversidad distribuyendo todos los individuos de la población inicial en ese frente diverso, en lugar de solamente un bajo porcentaje de los mismos. El procedimiento sería similar y consistiría en asignar para todos los individuos de una misma población el mismo valor de potencia, que se seleccionaría aleatoriamente de forma uniforme sobre el rango de potencias configurable.

La figura 4.4 compara los resultados conseguidos con y sin forzado de diversidad de la población inicial. Se observa la mejora en la diversidad de la población final que se traduce además en un aumento del número de individuos que forman parte del frente óptimo de Pareto. A pesar de ganar diversidad en el frente de Pareto final se observa como hay puntos del frente de Pareto de la ejecución sin forzado que dominan a los puntos del frente de Pareto con forzado. 


\section{CAPÍTULO 4. PLANIFICACIÓN Y OPTIMIZACIÓN DE LA RED DE ACCESO RADIO}

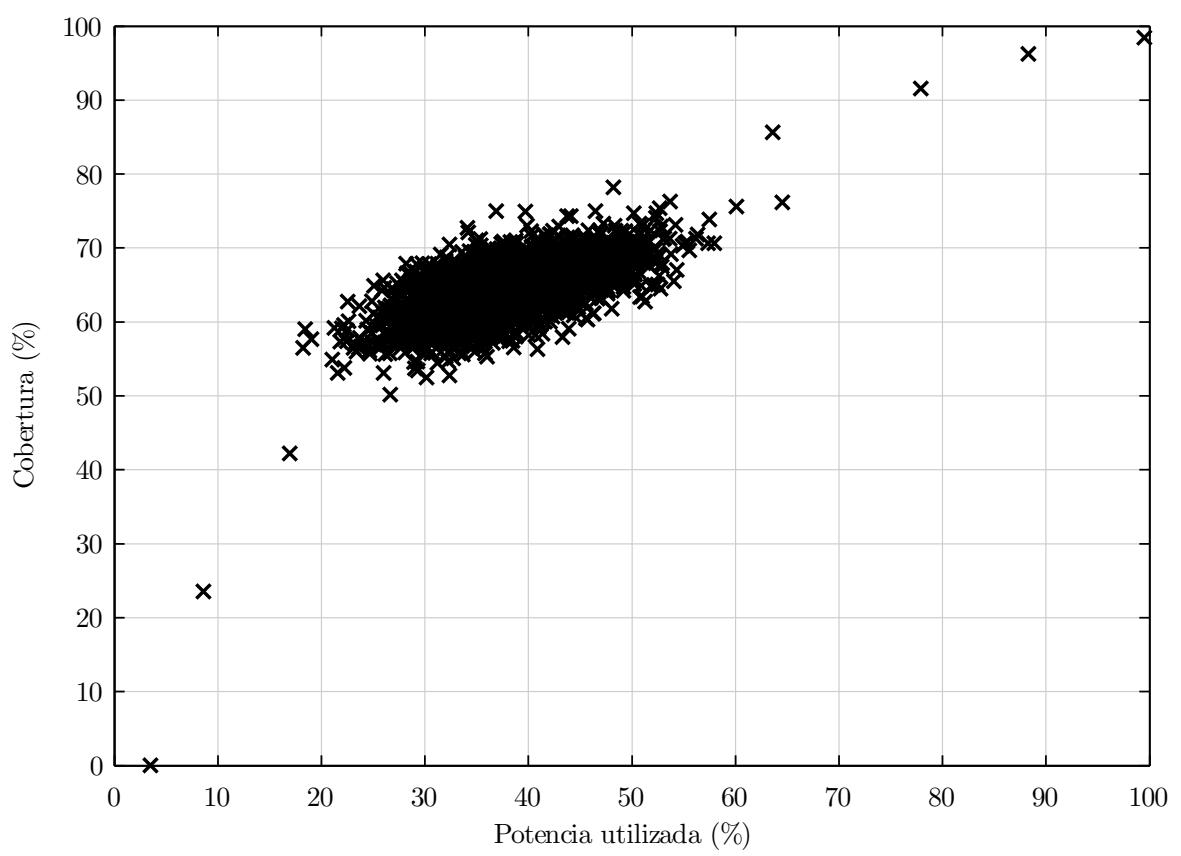

Figura 4.3: Población inicial forzada a estar parcialmente diversificada

La diferencia de grado de madurez entre las poblaciones finales alcanzadas utilizando una población inicial más compacta o más dispersa, se debe a que para el caso de una mayor dispersión inicial, el algoritmo requiere un mayor número de generaciones, y por tanto de tiempo de ejecución, para recombinar de forma adecuada a los distintos individuos que ahora son más distintos entre ellos. La figura 4.5 muestra cómo, con el doble de generaciones, el nuevo frente de Pareto aúna ambas virtudes: madurez en los valores alcanzados proximidad a los mínimos de ambas funciones de coste- y diversidad de las soluciones.

\subsubsection{Particle Swarm Optimisation}

Propuesto en [86] como algoritmo de optimización para funciones no lineales, el Particle Swarm Optimisation (PSO) pretende emular las relaciones sociales entre los diferentes miembros de un grupo, a través de las cuales existe un intercambio de información que permite a los individuos aprovechar la ex- 


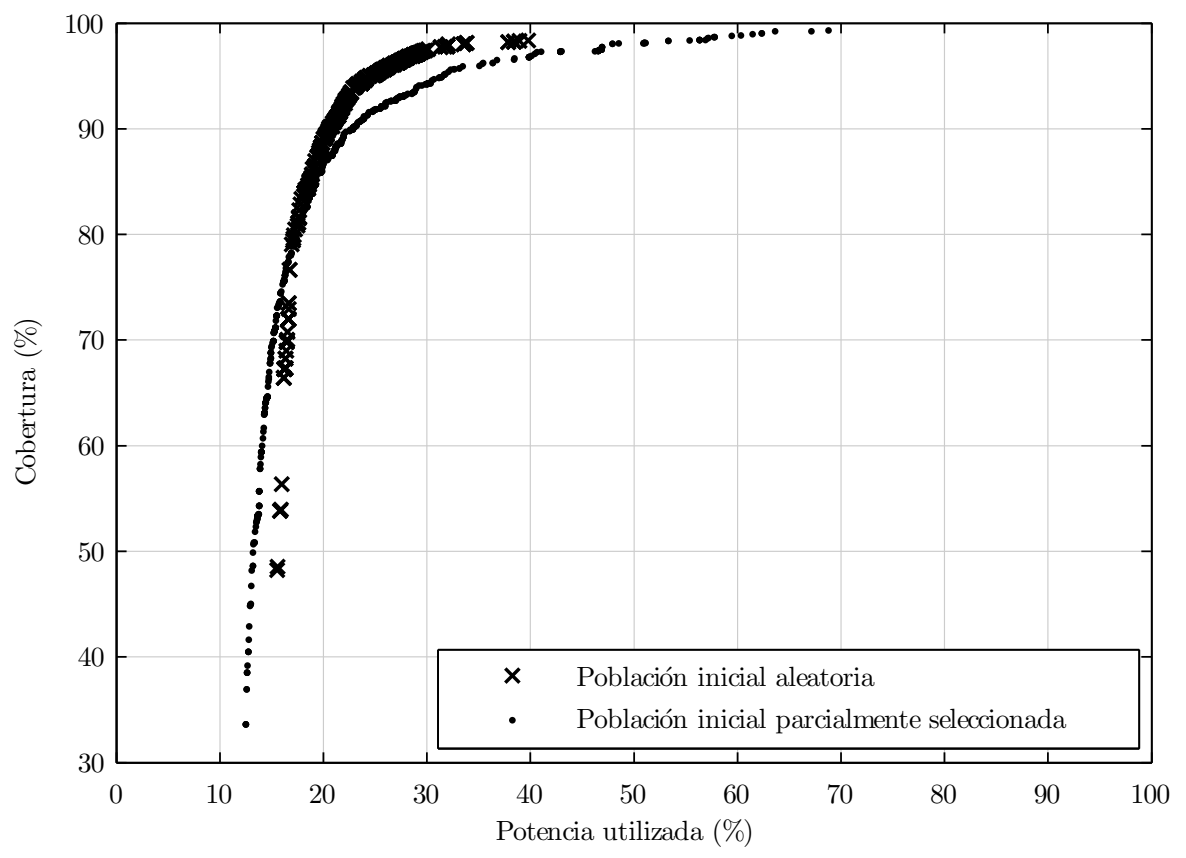

Figura 4.4: Comparación de frente óptimo de Pareto forzando y sin forzar diversidad en la población inicial, para el mismo número de generaciones

periencia de los demás en beneficio propio. Tomando como referencia los GAs se pueden apreciar ciertas similitudes en cuanto a la composición del problema, si bien difieren bastante en cuanto al comportamiento y búsqueda del óptimo.

En el caso del NSGA-II, el sistema parte de una población inicial, donde cada individuo representa una posible solución al problema. Se genera aleatoriamente en todo el espacio de búsqueda de soluciones y durante cierto número de generaciones la búsqueda del óptimo se lleva a cabo modificando estos individuos mediante mecanismos evolutivos, como la combinación entre ellos, o la mutación en parte de la población sobre algunos de sus genes.

En el caso del PSO, se comparte la idea de una composición inicial de soluciones a lo largo del espacio de búsqueda, llamadas partículas — en sustitución de los individuos- - La principal diferencia con los GAs es que las nuevas soluciones no se obtienen aplicando complicados mecanismos de combinación, sino que se hace que las peores partículas, las que peores soluciones aportan, sigan a las que sí presentan buenos resultados, de forma que se aproveche la expe- 


\section{CAPÍTULO 4. PLANIFICACIÓN Y OPTIMIZACIÓN DE LA RED DE ACCESO RADIO}

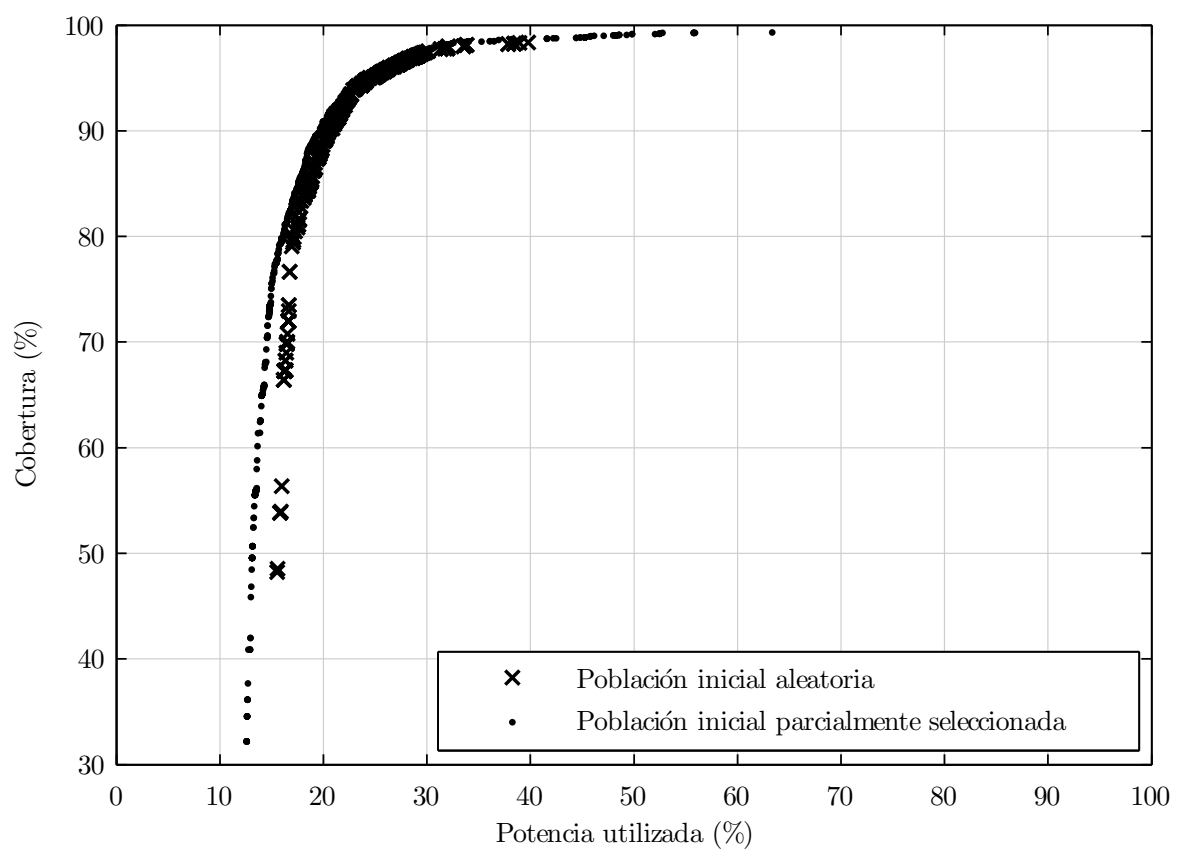

Figura 4.5: Comparación de frente óptimo de Pareto forzando y sin forzar diversidad en la población inicial, con doble número de generaciones en el caso forzado

riencia de esas partículas para mejorar al resto. Este concepto de seguir ciertas soluciones a otras se puede implementar mediante operadores matemáticos elementales — suma, resta, multiplicación y división-, mucho más simples que las operaciones realizadas en los GAs.

Inicialmente cada partícula generada evalúa la función objetivo y la asocia a su posición actual que ocupa en el espacio de soluciones. Posteriormente, para determinar su movimiento, combinará información propia sobre su histórico de posiciones con mejores soluciones e información proveniente de las mejores ubicaciones de los demás miembros del grupo. Cada iteración conlleva el desplazamiento de todas las partículas, de ahí que conceptualmente se relacione el funcionamiento del algoritmo con el movimiento en conjunto de una bandada de pájaros, volando en grupo.

Para llevar a cabo el movimiento anteriormente mencionado, cada partícula tiene cuatro atributos o datos con los que trabaja: 
- Posición actual: el algoritmo asocia el concepto de posición en el espacio a una combinación de los parámetros de entrada, de modo que cada solución tendrá asociada una evaluación de la función de coste objetivo.

- Mejor posición ocupada: cada partícula puede almacenar fácilmente su histórico, teniendo disponible qué combinación le proporcionó la mejor solución hasta ese momento, actualizándose en cada iteración.

- Vecindario: conceptualmente, esta información está asociada a la red social de la partícula. Ésta adquirirá el conocimiento de otras buenas posiciones mediante el intercambio de esa información con otras partículas. Por tanto, se asociará el concepto de vecindario o red social a ese conjunto de partículas con las que podrá haber intercambio de información.

- Velocidad de movimiento: determina el desplazamiento que llevará a cabo a partir de su ubicación actual. A través de unos pesos, dicho movimiento será una combinación entre un desplazamiento hacia su mejor posición histórica y la mejor de sus vecinos, y se recalculará en cada nueva iteración.

La actualización de la posición mediante el cálculo de la velocidad de movimiento viene dado por la siguiente formulación:

$$
x_{i, j}^{t+1}=x_{i, j}^{t}+v_{i, j}^{t+1},
$$

donde $i$ identifica a la partícula, $j$ es la dimensión y representa a la variable $j$-ésima del problema de optimización, $x_{i, j}^{t+1}$ es la nueva posición tras las actualización, $x_{i, j}^{t}$ es la posición anterior y $v_{i, j}^{t+1}$ es la nueva velocidad de la partícula que viene dada por

$$
v_{i, j}^{t+1}=c_{0} \cdot v_{i, j}^{t}+c_{1} \cdot r_{1}\left(x_{i, j}^{N B}-x_{i, j}\right)+c_{2} \cdot r_{2}\left(x_{i, j}^{L B}-x_{i, j}\right),
$$

donde $c_{0}$ representa la inercia del movimiento previo, determinado por la velocidad $v_{i, j}^{t}, x_{i, j}^{N B}$ es la posición de la mejor partícula vecina, $x_{i, j}^{L B}$ es la mejor posición encontrada por la partícula $i$ hasta el momento, $c_{1}$ es el peso que se da al movimiento en la dirección del mejor vecino, $c_{2}$ es el peso que se da al movimiento hacia la mejor posición del histórico local de la partícula y $r_{1}$ y $r_{2}$ son valores aleatorios generados en el intervalo $[0,1]$ conocidos como coeficientes de aceleración.

La ecuación (4.25) se compone de tres términos. El primero se refiere al valor de la velocidad de la iteración anterior. El factor $c_{0}$ fija cuánto del movimiento anterior se conserva para estimar el nuevo. Normalmente, el valor de la inercia se suele modificar a lo largo del proceso, de modo que durante las primeras 


\section{CAPÍTULO 4. PLANIFICACIÓN Y OPTIMIZACIÓN DE LA RED DE ACCESO RADIO}

iteraciones la inercia tendrá mayor importancia — valores entre 0,5 y 1 -, para ir disminuyendo paulatinamente su valor hasta alcanzar valores mucho más pequeños al final del algoritmo. El segundo término está relacionado con la información que el vecindario le aporta a la partícula, en concreto, informándole de la mejor posición, $x_{i, j}^{N B}$, ocupada por todas sus partículas vecinas. Se le suele conocer como el término social. El tercer término se vincula a la experiencia propia adquirida. Estos últimos términos están ponderados por dos coeficientes, $c_{1}$ y $c_{2}$, para controlar cuánto influye en el movimiento la información personal y cuánto la de los demás. Normalmente, se emplea un mismo valor para ambos coeficientes, de modo que se consideran ambas informaciones igualmente válidas e influyentes.

\subsubsection{Resultados comparativos}

Para una evaluación del rendimiento que ofrecen cada uno de los métodos de búsqueda propuestos que permita seleccionar la mejor opción para la consecución del objetivo de planificación y optimización de redes LTE, se parte de resultados disponibles de un estudio preliminar de optimización de una red UMTS operativa.

El escenario de optimización es el mostrado en la figura 4.6, un área rectangular de $8,64 \mathrm{Km}^{2}$. En la figura, las $N=70$ celdas UMTS se marcan con líneas gruesas negras apuntando en la dirección del acimut. El mapa coloreado indicada la densidad de tráfico en cada punto, lo que servirá para dar más peso a tener cobertura en unos puntos que en otros. Los valores extremos del mapa de tráfico son rojo oscuro para tráfico denso y azul oscuro para tráfico poco denso. Esta distribución de tráfico se ha obtenido sobre la red real utilizando el algoritmo de localización de llamadas descrito en la sección 3.2.1 sobre un conjunto de llamadas de monitorizadas durante una semana.

Las variables del problema de optimización son las mostradas en la tabla 4.1 junto con sus posibles valores discretos.

Tabla 4.1: Posibles valores de las variables a optimizar

\begin{tabular}{cccc}
\hline Variable & Valor mínimo & Valor máximo & Paso \\
\hline \hline Potencia de CPICH & $27 \mathrm{dBm}$ & $36 \mathrm{dBm}$ & $1 \mathrm{~dB}$ \\
Acimut relativo al actual & $-20^{\circ}$ & $20^{\circ}$ & $2^{\circ}$ \\
Tilt & $0^{\circ}$ & $15^{\circ}$ & $1^{\circ}$ \\
\hline
\end{tabular}

El objetivo de la optimización es doble. Por un lado, se pretende maximizar el número del puntos de escenario con $\frac{E_{c}}{N_{0}}$ mayor que un determinado umbral, 


\subsection{Procedimientos de Búsqueda de Solución}

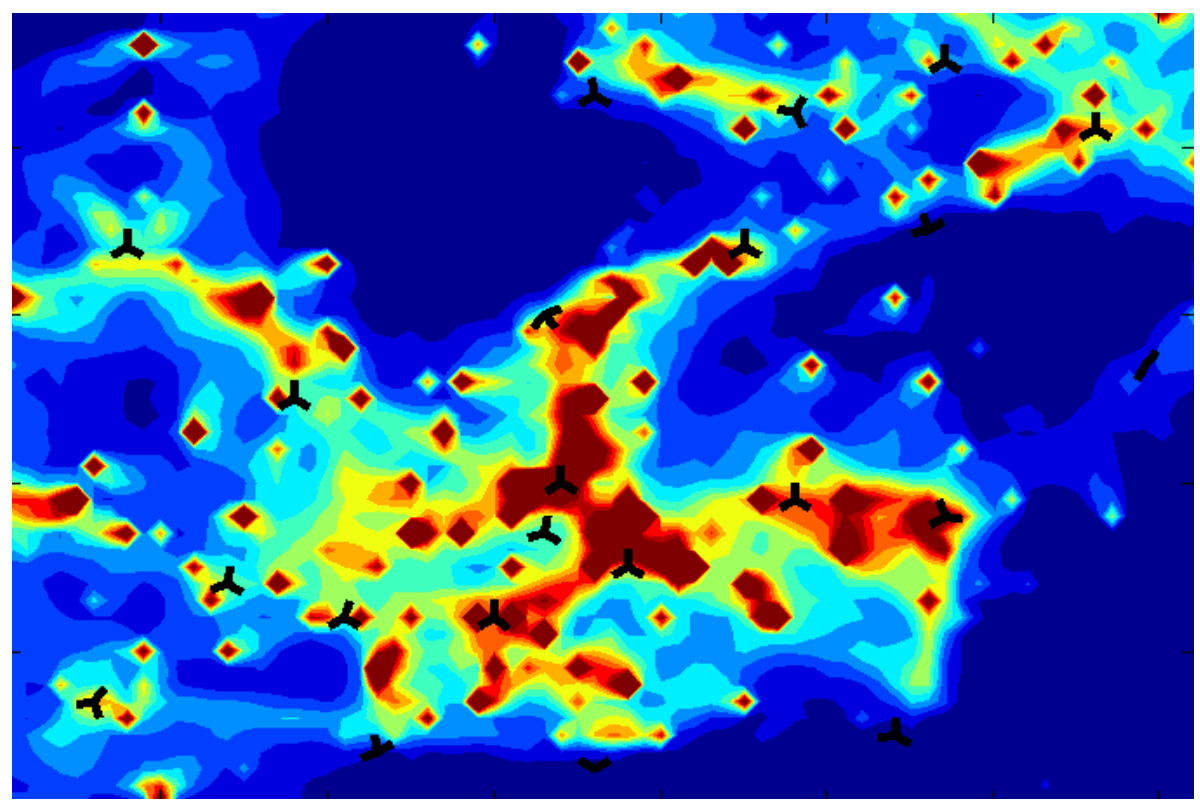

Figura 4.6: Escenario a optimizar y mapa de tráfico sintético

fijado en $-12 \mathrm{~dB}$. Por otro lado, se busca minimizar la potencia media de CPICH, reduciendo así el nivel de interferencia del sistema. Estos dos objetivos se plasman en sendas función de coste, que en el caso de SA y PSO se combinan ponderadas según la ecuación (4.26) y en el caso de NSGA-II se utilizan independientemente ya que este algoritmo es multi-objetivo. En la ponderación se fija un peso para el término de cobertura 10 veces mayor que para el término de la potencia, es decir, $\alpha=0,1$.

$$
f_{o b j}=f_{c o b}-\alpha \cdot f_{p o t},
$$

donde, por un lado, la función de coste asociada a la cobertura viene dada por la siguiente expresión:

$$
f_{c o b}=\frac{1}{A} \sum_{c \in \mathcal{C}} A_{c},
$$

siendo $A$ el área total y $A_{c}$ el área cubierta por la celda $c$, ponderando en ambas cada casilla de la rejilla definida sobre el el escenario según la densidad indicada por el mapa de tráfico. Una localización se considera cubierta si el valor $\frac{E_{c}}{N_{0}}$ medido sobre el canal CPICH es superior al umbral de $-12 \mathrm{~dB}$. 


\section{CAPÍTULO 4. PLANIFICACIÓN Y OPTIMIZACIÓN DE LA RED DE ACCESO RADIO}

Por otro lado, la función de coste asociada a la potencia del $\mathrm{CPICH}$ viene dada por la siguiente expresión:

$$
f_{\text {pot }}=\frac{1}{N} \sum_{c \in \mathcal{C}} \frac{P_{c}-P_{\text {min }}}{P_{\max }-P_{\min }},
$$

donde $P_{c}$ es la potencia de CPICH de la celda $c$ y $P_{\max }$ y $P_{\min }$ los valores máximo y mínimo que se pueden configurar para dicha potencia, respectivamente.

En la tabla 4.2 se muestran los parámetros más relevantes utilizados en la optimización mediante los tres mecanismos evaluados.

Tabla 4.2: Parámetros más relevantes utilizados en los algoritmos de búsqueda

\begin{tabular}{ccc}
\hline Algoritmo & Parámetro & Valor \\
\hline \hline SA & Temperatura inicial & 1 \\
SA & Temperatura final & 0,000285 \\
SA & Factor de enfriamiento & 0,96 \\
SA & Iteraciones por temperatura & 200 \\
NSGA-II & Número de individuos & 4000 \\
NSGA-II & Probabilidad de mutación & $5 \%$ \\
NSGA-II & Número de generaciones & 100 \\
PSO & Número de partículas & 200 \\
PSO & Número de iteraciones & 2000 \\
PSO & Valor inicial de $c_{0}$ & 0,5 \\
PSO & Valor final de $c_{0}$ & 0,1 \\
PSO & Variación de $c_{0}$ entre iteraciones & Lineal \\
PSO & $c_{1}$ & 2 \\
PSO & $c_{2}$ & 2 \\
\hline
\end{tabular}

En la tabla 4.3 se muestran los resultados obtenidos en términos de cobertura y tiempo de ejecución para los tres métodos heurísticos de búsqueda comparados. Los valores temporales se dan en términos relativos al tiempo de ejecución obtenido con SA. En el caso de NSGA-II, cuyo resultado en un conjunto de soluciones formando un frente de Pareto, se ha seleccionado la solución que mejor cobertura proporciona. Para hacer los resultados comparables, las configuraciones para cada uno de los métodos de búsqueda se han seleccionado de forma que el número de configuraciones probadas sea el mismo.

Viendo los resultados se deduce que es posible que el NSGA-II necesite más generaciones y/o individuos en la población para obtener un rendimiento mejor que el SA y, de igual forma, el PSO necesite más iteraciones y/o partículas. Sin embargo, se aprecia que el SA es una buena opción como algoritmo heurístico 
Tabla 4.3: Resultados comparativos de las distintas heurísticas de búsqueda planteadas

\begin{tabular}{ccc}
\hline Algoritmo & Cobertura (\%) & Tiempo de ejecución relativo (\%) \\
\hline \hline SA & 98,53 & 100 \\
NSGA-II & 97,61 & 275 \\
PSO & 92,54 & 216 \\
\hline
\end{tabular}

de búsqueda para su aplicación a planificación y optimización de redes LTE debido a la buena relación entre rendimiento y tiempo de ejecución.

\subsection{Proceso de Planificación}

El esquema general de funcionamiento del proceso de planificación automática propuesto para LTE se representa en la figura 4.7. Mediante call tracing se obtienen datos de los sistemas predecesores para posteriormente procesarlos - bloque de análisis - y generar información de entrada útil para el proceso de planificación. La principal fuente de información son mapas de distribución de tráfico generados a partir de los datos de call tracing, utilizando para ello el algoritmo de localización descrito en la sección 3.2. La planificación automática estará guiada por estos mapas generados a partir de datos reales en lugar de estimaciones.

La solución de la planificación se obtendrá buscando en el espacio de soluciones generado por las distintas combinaciones de emplazamientos candidatos y configuraciones de las celdas que lo constituyen, como potencia, tilt y acimut, los cuales constituyen los parámetros objetivo de la planificación. Esta búsqueda se realiza utilizando técnicas heurísticas de optimización como las descritas en la sección 4.3.2, considerando el algoritmo SA como una buena alternativa. Las posibles configuraciones de los distintos parámetros a optimizar estarán delimitadas por una serie de restricciones impuestas por los criterios y objetivos de la planificación. Para cada una de las soluciones candidatas que se evalúen durante la búsqueda será necesaria la utilización del simulador estático descrito en la sección 2.2. Al final del proceso, los cambios propuestos por la herramienta de planificación automática serán analizados por un ingeniero con el fin de llevar a cabo la implantación de los mismos.

La planificación de una nueva red LTE se puede realizar siguiendo dos estrategias diferentes en cuanto al número de emplazamientos a implantar. Por un lado, el objetivo planteado podría ser implantar un número concreto de emplazamientos, para lo cual se buscan los mejores candidatos y la configura- 


\section{CAPÍTULO 4. PLANIFICACIÓN Y OPTIMIZACIÓN DE LA RED DE ACCESO RADIO}

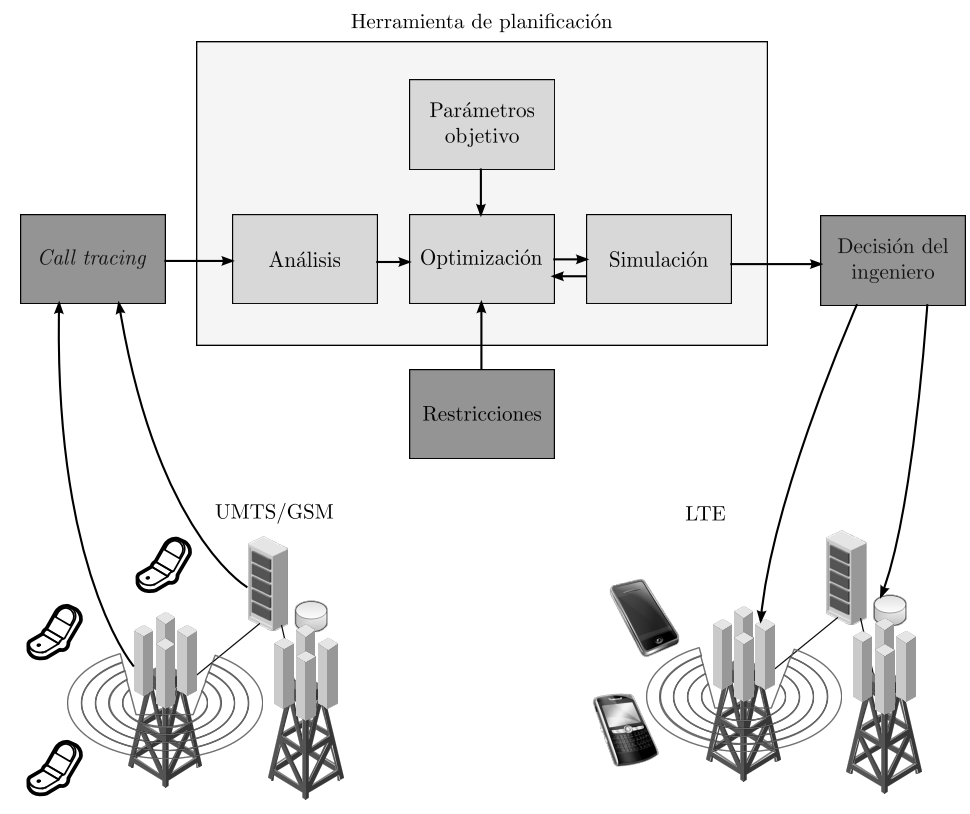

Figura 4.7: Proceso de planificación automática propuesto

ción óptima de sus celdas de forma que se obtengan las máximas prestaciones posibles.

Por otro lado, el objetivo de la planificación puede consistir en cumplir una serie de requisitos de cobertura y/o calidad como los descritos en la sección 4.1. En ese caso lo que se pretende que la planificación obtenga a la salida es, además de la configuración óptima, el número de celdas o de emplazamientos necesarios para cumplir con los requisitos fijados.

El proceso de planificación automática variará ligeramente según cuál de las dos estrategias se utilice. El caso base lo constituye la planificación de un número determinado de emplazamientos, mientras que el caso de buscar el número de emplazamientos necesario hará un barrido variando el número emplazamientos candidatos a implantar.

Dado que el proceso de planificación automática propuesto supone un coste computacional elevado para escenarios grandes, se requiere la utilización de métodos de ejecución eficiente. Por ejemplo, para escenarios grandes el espacio de posibles soluciones es tan extenso que una búsqueda a través de SA requeriría un tiempo de ejecución muy elevado para obtener una solución aceptable. El número de combinaciones distintas de los parámetros objetivo de la 
planificación crece exponencialmente con las dimensiones del escenario, ya que escenarios más grandes incluirán más emplazamientos a contemplar además de más puntos de cálculo en la rejilla definida. Para ese caso se propone dividir la planificación en dos fases.

En la primera fase se seleccionarán los mejores emplazamientos dando únicamente libertad en la variación del acimut de las celdas y fijando un valor para el tilt y la potencia total de cada celda. En la segunda fase, una vez fijados los emplazamientos, se optimiza su configuración con una segunda ejecución del algoritmo SA, permitiendo en este caso variar todos los parámetros de cada una de las celdas de los emplazamientos seleccionados, es decir, potencia total, tilt y acimut. Para escenarios pequeños no hace falta partir de esta forma el espacio de búsqueda y se puede hacer una búsqueda global. En la sección 4.6 se puede encontrar una descripción detallada del resto de métodos propuestos para una ejecución eficiente del proceso de planificación automática.

Durante el proceso de búsqueda de la mejor configuración en la segunda fase, una vez seleccionados los mejores emplazamientos de entre todos los candidatos, la utilización de la experiencia obtenida en los sistemas predecesores puede aportar un valor añadido. Por ejemplo, a la hora de seleccionar los parámetros a variar entre iteraciones del SA, lo cual se realiza aleatoriamente, se puede dar más probabilidad de selección a los parámetros de determinadas celdas, siendo un posible criterio el consistente en dar prioridad a las celdas que más llamadas cursen en UMTS. De esta forma se le da más importancia a esas celdas que se consideran más críticas por la experiencia previa en esa misma ubicación.

Si el despliegue de la red se pretende realizar de manera progresiva, una vez ejecutado el proceso de planificación automática se puede realizar una etapa de post-procesado de la solución de planificación obtenida en la que se determine el orden óptimo de despliegue, fundamentado en la aportación que cada emplazamiento realiza individualmente al sistema global. Para ello se puede evaluar la función de coste objetivo estando presente un único emplazamiento y repetir el proceso para cada uno de los emplazamientos planificados. De esta forma se podría seleccionar cuál es el mejor emplazamiento para comenzar la implantación. Para determinar el orden óptimo de implantación de los restantes emplazamientos se procedería de forma similar, estando presente en cada evaluación de las prestaciones del sistema, además del nuevo emplazamiento, los emplazamientos previamente seleccionados. La configuración de potencia total, tilt y acimut no será la óptima para las soluciones parciales implantadas, pero sí lo será cuando el sistema esté completamente desplegado. En el caso de que el despliegue progresivo se vaya a realizar de forma lenta, convendrá realizar una optimización de la configuración de cada emplazamiento dentro de la solución parcial implantada, que habrá que repetir cada vez que se introduzca un nuevo emplazamiento de la solución final. 


\subsection{Optimización}

El diagrama funcional de un proceso de optimización se muestra en la figura 4.8. Es muy similar al correspondiente al proceso de planificación descrito en la sección 4.4. La principal diferencia es que al optimizar no ha de realizarse ninguna selección de los mejores emplazamientos pues únicamente se trata de obtener la mejor configuración de los parámetros objetivo para los emplazamientos existentes. En otras palabras, sólo se lleva a cabo la segunda fase de las descritas para el proceso de planificación automática.

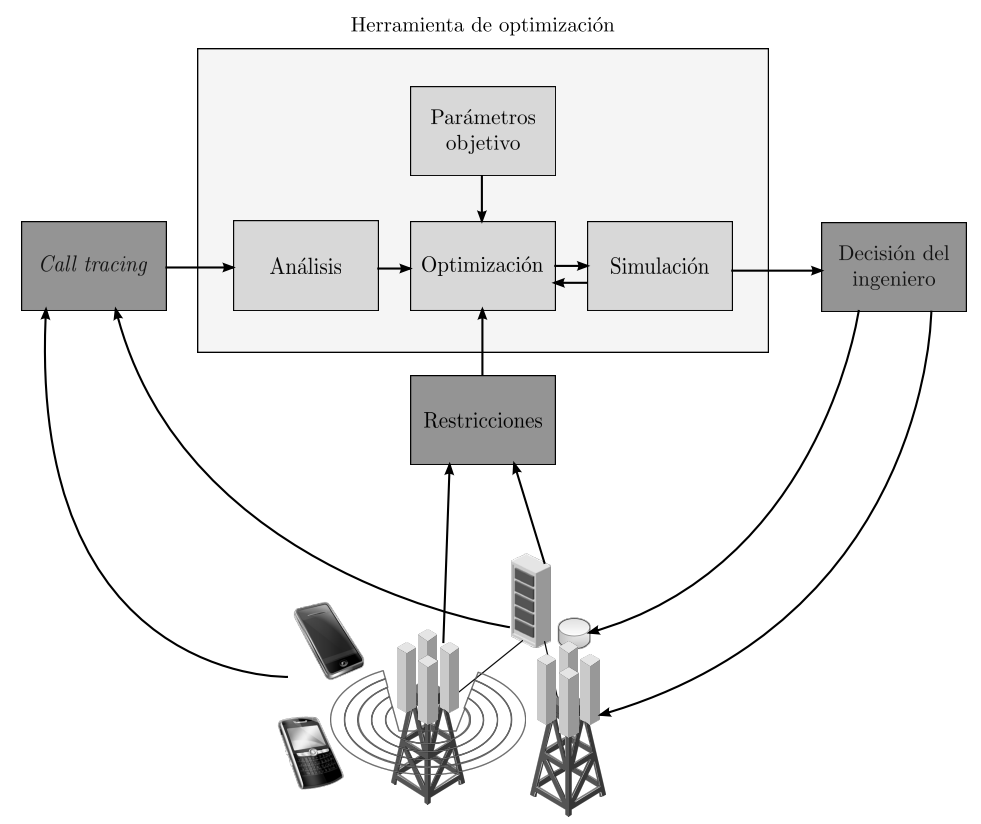

Figura 4.8: Proceso de optimización automática propuesto

Otra diferencia respecto a la planificación es que en este caso sí se dispone de información sobre prestaciones y distribución de tráfico de la misma red que se pretende optimizar, hecho que no ocurre al planificar una nueva red LTE, por lo que no hace falta recurrir a la información generada por los sistemas predecesores.

Dado que se dispone de datos de la propia red a optimizar, resulta de gran utilidad el uso del algoritmo de localización para geo-referenciar KPIs y generar mapas de entrada para el proceso automático de optimización. De esta forma la herramienta automática puede, por un lado, calibrar algunos de los modelos 
utilizados y, por otro lado, identificar dónde se encuentran los desequilibrios de la red para después solventarlos.

Tal como refleja la figura 4.8 la optimización automática es un proceso cíclico, que no termina con una única ejecución y la correspondiente implementación de los cambios propuestos. Los continuos cambios en las condiciones de la red y en la distribución del tráfico exigen que el proceso de optimización automática se ejecute periódicamente, o bajo demanda ante la detección de problemas en la red, para conseguir adaptarse a los cambios producidos y obtener siempre las máximas prestaciones posibles del sistema.

\subsection{Métodos de Ejecución Eficiente}

La planificación y optimización automática es un problema combinacional que requiere la evaluación de un elevado número de posibles soluciones para encontrar la configuración óptima de la nueva red. Para reducir el número requerido de iteraciones, tal y como se describió en la sección 4.3.2, se hace uso de métodos avanzados de búsqueda del óptimo. A pesar de la reducción del número de iteraciones necesarias conseguido de esta forma - a expensas de no garantizar la obtención de la solución óptima - el problema de la elevada carga computacional sigue existiendo, además de empeorar drásticamente cuando crecen las dimensiones del escenario considerado. Por estas razones, es necesario aplicar técnicas que disminuyan esta elevada carga computacional y permitan reducir los tiempos de ejecución, o bien mantenerlos con el fin de conseguir mejores soluciones.

Una opción de fácil implementación con el hardware disponible en la actualidad consiste en aprovechar los procesadores con varios núcleos y con multithreading y las características de los cálculos necesarios en cada evaluación de la función de coste, para dividir el trabajo. La evaluación de la función de coste implica realizar operaciones para cada una de las casillas de la rejilla definida sobre el escenario bajo estudio, por lo que se puede dividir la matriz de casillas en varias partes que se procesen en paralelo en distintos núcleos o threads del procesador, con el consiguiente ahorro en tiempo de ejecución para un mismo número de iteraciones.

Por otra parte, el espacio de búsqueda es muy amplio y aumenta exponencialmente con las dimensiones del escenario. Cuanto mayor es el área del escenario considerado mayores son el número de celdas y emplazamientos candidatos, el número de celdas a seleccionar para conseguir cumplir los requisitos de planificación y el número de puntos de la rejilla definida sobre los que realizar cálculos. Dado que un problema así no es escalable, una opción para facilitar la búsqueda y reducir los tiempos de ejecución consiste en partir el espacio de 


\section{CAPÍTULO 4. PLANIFICACIÓN Y OPTIMIZACIÓN DE LA RED DE ACCESO RADIO}

soluciones. En esta Tesis Doctoral se ha planteado dividir el proceso de planificación y optimización en dos fases conforme a lo descrito en la sección 4.4. Cada una de estas fases dispondrá de un espacio de búsqueda más reducido que el global. En la primera fase de planificación se fijarán los emplazamientos seleccionados de entre todos los candidatos, dando libertad en la búsqueda a cambiar emplazamientos y acimut de cada una de sus celdas. En la segunda fase, dedicada a la optimización de esos emplazamientos ya fijados, se dará libertad para variar todos los parámetros de las celdas seleccionadas.

Debido a las características del algoritmo de búsqueda SA, entre iteraciones consecutivas de este proceso únicamente se varía uno de los parámetros disponibles - emplazamiento candidato seleccionado o variación de potencia, tilt o acimut de una de sus celdas - por lo que no es necesario volver a calcular las matrices de señal que generan las celdas del resto de emplazamientos activos o de las celdas que no han variado su configuración. Esto ahorra número de operaciones requeridas para calcular la SINR que proporciona cada celda en el escenario bajo estudio.

Por último, el proceso de planificación y optimización propuesto requiere ir aumentando progresivamente el número de emplazamientos hasta encontrar la cantidad de unidades mínima y su configuración que permita alcanzar los objetivos marcados. Este proceso iterativo se puede realizar de forma más eficiente de dos maneras. Por un lado, se puede realizar una estimación inicial del número de emplazamientos necesario para cursar el tráfico estimado que se considera, con lo que se consigue reducir el número de iteraciones de prueba. Un método simple para realizar esta estimación inicial consistiría en sumar todo el throughput de todas las casillas del mapa de tráfico disponible y dividir por el throughput medio por celda típico que se puede cursar para el tipo de escenario y ancho de banda contemplados. Cabe destacar que, con esta estimación inicial, es posible que las variaciones a realizar desde este punto de partida consistan en quitar emplazamientos y no sólo añadir. Por otro lado, en lugar de ir añadiendo - o quitando - emplazamientos de uno en uno hasta alcanzar la mejor solución se pueden añadir varios emplazamientos simultáneamente, de forma que se acelere la búsqueda del número mínimo de emplazamientos necesarios. Una vez alcanzado este número se puede retroceder e ir quitando emplazamientos hasta encontrar el número óptimo de emplazamientos, en un ajuste fino final, para cubrir el caso en el que se pudieran cumplir los criterios establecidos con un número de emplazamientos menor. 


\subsection{Aplicación de Sistemas Expertos}

Hasta el momento el proceso de optimización automática propuesto se había centrado en una solución basada en algoritmos de búsqueda y simulaciones con el objetivo de encontrar la mejor combinación posible de los parámetros establecidos como objetivo de la optimización. La figura 4.8 muestra este proceso. Con el propósito de mejorar la optimización automática, resulta interesante la idea de aprovechar el conocimiento adquirido con la experiencia de los ingenieros de optimización. Los sistemas expertos son capaces de emular esa experiencia y, por tanto, la combinación de uno de estos sistemas con la herramienta de auto-optimización aportaría al conjunto del proceso un gran valor añadido y una mayor confianza en los resultados obtenidos.

El diagrama de bloques resultante de la incorporación de esta mejora se muestra en la figura 4.9. Como se puede apreciar, aparecen dos nuevos bloques a la salida de la herramienta de optimización automática. Se introduce, por un lado, el sistema experto que utiliza datos procedentes del bloque de análisis de la herramienta de optimización automática como datos de entrada y su salida se deriva al bloque de decisión de Inteligencia Artificial (IA). Por otro lado, se añade el bloque de decisión de IA, que se alimenta de las soluciones que proporcionan la herramienta de optimización automática y el sistema experto para decidir el cambio a implementar y realizar una medida de la fiabilidad de la solución obtenida.

La salida del bloque de decisión de IA será la salida del proceso de optimización automática a partir de la que el ingeniero de optimización deberá decidir los cambios a implementar en la red. Una selección de estas decisiones, aquéllas tomadas por los ingenieros de confianza con más experiencia, servirán para continuar entrenando el sistema experto. De esta forma, el sistema experto siempre estará evolucionando y mejorando. Será necesario realizar un entrenamiento inicial del sistema experto antes de incluirlo en el proceso de optimización automática. Este entrenamiento inicial se realizará con un histórico de casos resueltos por los ingenieros seleccionados.

El sistema experto propuesto se basa en redes neuronales, las cuales se caracterizan por su habilidad de aprendizaje a través del entrenamiento con un conjunto de muestras de valores de entrada y sus correspondientes salidas esperadas. El conocimiento adquirido por parte de la red neuronal se almacena en las distintas neuronas que la constituyen en forma de pesos, cuyos valores se va ajustando durante el entrenamiento. Estos pesos sirven para ponderar las entradas de cada neurona en la combinación lineal que realiza a partir de ellas. Las neuronas se distribuyen en distintas capas, existiendo diferencias entre la capa de entrada, las capas ocultas y la capa de salida. La capa de entrada simplemente traslada las entradas a la primera capa oculta. Neuronas 


\section{CAPÍTULO 4. PLANIFICACIÓN Y OPTIMIZACIÓN DE LA RED DE ACCESO RADIO}

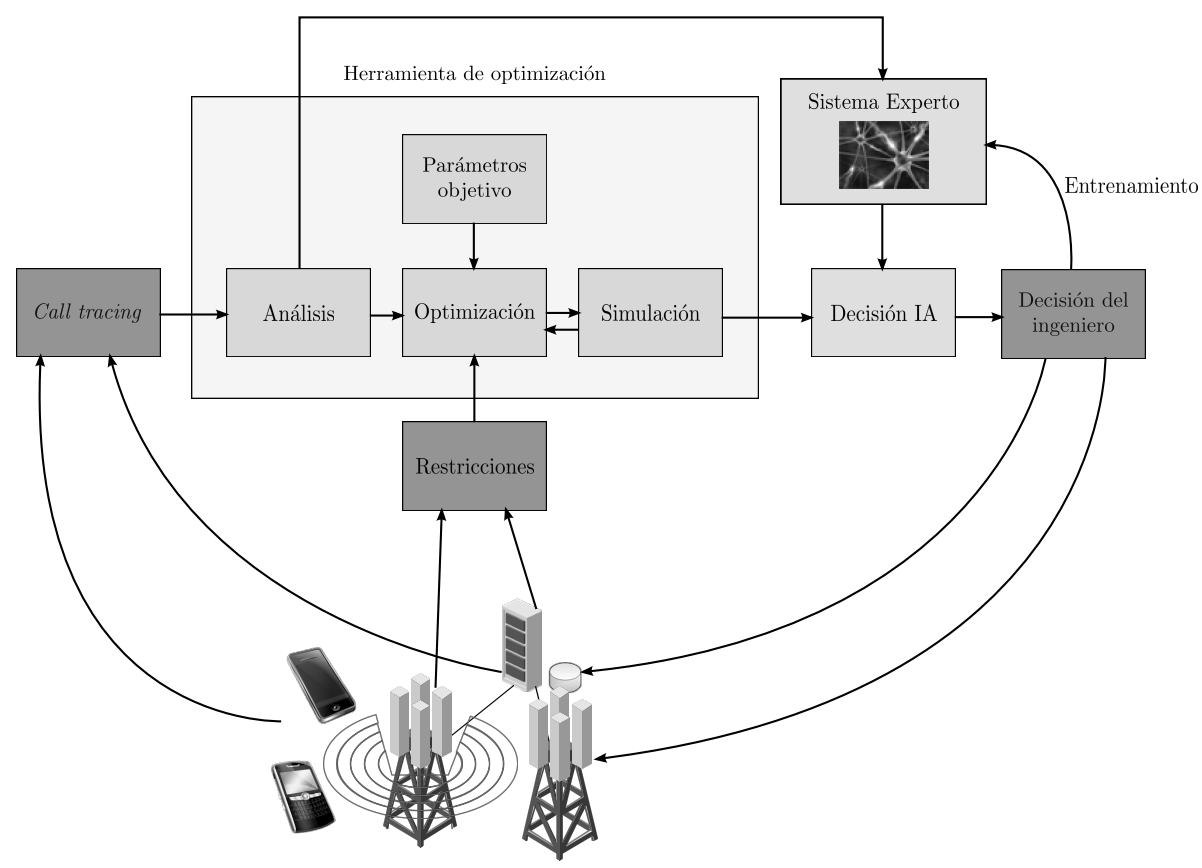

Figura 4.9: Aplicación del sistema experto al proceso de optimización automática

pertenecientes a una misma capa oculta no intercambian información mientras que las neuronas de una capa sí lo hacen con las neuronas de la capa siguiente. La capa de salida combina las entradas procedentes de las neuronas de la última capa oculta aunque no intercambia conocimiento con otras neuronas ya que su salida es directamente la salida de la red neuronal. En la sección 3.4 se pueden encontrar más detalles sobre el sistema experto propuesto.

Además de la elección de la mejor configuración de capas ocultas y número de neuronas en cada una de ellas, la cual afectará en gran medida a los resultados alcanzables, un aspecto muy importante del sistema experto diseñado lo constituye el conjunto de datos de entrada que se utilicen para alimentarlo. Por otro lado, con el fin de obtener las salidas necesarias para conseguir los resultados deseados, el sistema experto tendrá la peculiaridad de estar formado por tantas redes neuronales distintas como parámetros objetivo y sentido de cambio puedan haber. Por ejemplo, si se tienen como parámetros objetivo a optimizar el tilt y el acimut de un conjunto de celdas, deberán existir cuatro redes neuronales distintas que indicarán el grado de certeza en las decisiones subir tilt, 
bajar tilt, incrementar acimut o decrementar acimut. Estas redes neuronales serán las mismas para todas las celdas que se vayan a optimizar.

\subsubsection{Datos de Entrada}

La tabla 4.4 muestra la lista de los datos que se han considerado como entrada de la red neuronal para la optimización del tilt de una Celda Bajo Estudio (CBE) ante la detección de un alcance excesivo. Para el caso de optimización del tilt, y sus dos posibles sentidos de cambio, existirían dos redes neuronales independientes: la que indica si hay que reducir el tilt -alcance insuficiente - y la que indica si hay que incrementarlo - alcance excesivo-. La razón de tener dos redes neuronales independientes para el mismo concepto, aunque en sentidos de cambio contrarios, reside en que las entradas para cada uno de los casos no tienen por qué ser las mismas. Las entradas reflejadas en la tabla 4.4 se corresponden únicamente al caso de detección de alcance excesivo y, por tanto, de necesidad de incrementar el tilt.

Como se puede observar, se consideran hasta 9 celdas interferentes que deberían ser las más cercanas desde el punto de vista de propagación radio. A continuación se detalla el significado de cada una de las entradas consideradas. Todas ellas se utilizan normalizadas respecto a un valor máximo, en los casos en que es posible fijar dicho valor. En caso contrario, se realiza la normalización restando a cada valor la media de todas las muestras y dividiéndolo por la desviación típica de los valores respecto de la media.

- Potencia de señal piloto de la CBE: valor de la potencia de la señal piloto de la celda, como es la potencia de las Reference Signal (RS) en LTE o la del CPICH en UMTS.

- Tilt de la CBE: inclinación de la antena de la CBE.

- RACH PD medio: valor medio del RACH PD de todas las llamadas iniciado en la CBE.

- Percentil 95 del RACH PD: valor del percentil 95 del RACH PD de todas las llamadas iniciadas en la CBE.

- Percentil 98 del RACH PD: valor del percentil 98 del RACH PD de todas las llamadas iniciadas en la CBE.

- Tasa de bloqueo en la CBE: tasa de bloqueo UTRAN de las llamadas atendidas por la CBE.

- Número de celdas reportadas: cantidad de celdas distintas que aparecen en los MRs que se reportan siendo serving cell la CBE. 


\section{CAPÍTULO 4. PLANIFICACIÓN Y OPTIMIZACIÓN DE LA RED DE ACCESO RADIO}

Tabla 4.4: Entradas de la red neuronal para la optimización de tilt

\begin{tabular}{cc}
\hline Identificador & Entrada \\
\hline \hline 1 & Potencia de señal piloto \\
2 & RACH PD medio \\
3 & Percentil 95 del RACH PD \\
4 & Percentil 98 del RACH PD \\
5 & Tasa de bloqueo en la CBE \\
6 & Número de celdas reportadas \\
7 & Número de Missing neighbours detectadas \\
8 & Número de MRs polucionados \\
9 & Número de MRs polucionantes \\
10 & Calidad media de llamadas \\
11 & Distancia a celda interferente 1 \\
12 & Acimut relativo a celda interferente 1 \\
13 & Potencia de señal piloto de interferente 1 \\
14 & Solape con interferente 1 \\
15 & Distancia a celda interferente 2 \\
16 & Azimuth relativo a celda interferente 2 \\
17 & Potencia de señal piloto de interferente 2 \\
18 & Solape con interferente 2 \\
19 & ... \\
$\ldots$ & Dotencia de señal piloto de interferente 9 \\
44 & Solape con interferente 9 \\
45 & Azimuth relativo a celda interferente 9 \\
46 & Poten a celda interferente 9 \\
\hline &
\end{tabular}

- Número de Missing neighbours detectadas: cantidad de celdas que se detecta que deberían añadirse al vecindario de la CBE.

- Número de MRs polucionados: número de MRs recibidos siendo serving cell la CBE y en los que hay más de 3 celdas reportadas.

- Número de MRs polucionantes: número de MRs recibidos en los que aparece la CBE sin ser serving cell y en los que hay más de 3 celdas reportadas.

- Calidad media de llamadas: RSRQ medio de los valores reportados en los MRs siendo serving cell la CBE. En el caso de UMTS se consideraría el $E_{c} / N_{0}$ en lugar del RSRQ. 
- Distancia a celda interferente $i, i=\{1, \ldots, 9\}$ : distancia en metros de la celda interferente $i$ a la CBE.

- Acimut relativo a celda interferente $i$ : ángulo entre la dirección del acimut de la CBE y la dirección entre la CBE y la celda interferente $i$.

- Potencia de señal piloto de interferente $i$ : valor de la potencia de la señal piloto de la celda interferente $i$, como es la potencia de las RS en LTE o la del CPICH en UMTS.

- Solape con interferente $i$ : área de la zona de solape entre las coberturas de la CBE y la celda interferente $i$, calculada utilizando huellas de señal de ambas celdas.

A la salida de la red neuronal se obtendrá un valor entre 0 y 1 , cuya magnitud indicará el grado de certeza en el cambio correspondiente, en este caso el de incrementar el tilt. En la tabla 4.5 se muestran distintos niveles de certeza [87] de la decisión tomada por la red neuronal en función del valor a su salida.

Tabla 4.5: Interpretación de los valores de salida de la red neuronal

\begin{tabular}{cc}
\hline Valor de salida & Nivel de certeza \\
\hline \hline 0 & No \\
0,1 & Casi seguro que no \\
0,2 & Probablemente no \\
0,3 & Quizá no \\
$0,4-0,6$ & Desconocido \\
0,7 & Quizá sí \\
0,8 & Probablemente sí \\
0,9 & Casi seguro que sí \\
1 & Sí \\
\hline
\end{tabular}

\subsubsection{Entrenamiento}

Como ya se introdujo en la sección 3.4, el algoritmo de entrenamiento más comúnmente utilizado para redes neuronales es el back-propagation algorithm, y es el que se ha elegido para la aplicación de sistemas expertos basados en redes neuronales a la optimización de redes de comunicaciones móviles planteada en esta sección. Concretamente, se ha utilizado el algoritmo de LevenbergMarquardt [88], aplicado por primera vez al entrenamiento de redes neuronales 


\section{CAPÍTULO 4. PLANIFICACIÓN Y OPTIMIZACIÓN DE LA RED DE ACCESO RADIO}

en [89], donde se concluyó que este método puede llegar a ser entre 10 y 100 veces más rápido que el método normal de descenso de gradiente.

Para el entrenamiento se dispone de 203 casos de optimización de tilt resueltos por ingenieros expertos para casos detectado de celdas con alcance excesivo y para las que se decidió incrementar el tilt. Del conjunto de muestras se reserva un $15 \%$ para validación del entrenamiento de forma que se introduce un criterio de parada adicional cuando se detecte que la red entrenada está perdiendo generalidad al incrementarse el error cometido con las muestras de validación, a pesar de que con las muestras de entrenamiento se pudieran seguir ajustando los pesos. De esta forma se trata de evitar el sobre-entrenamiento. Otro $15 \%$ se reserva para realizar pruebas del rendimiento de la red entrenada. El restante $70 \%$ de muestras constituye el conjunto destinado al entrenamiento de la red neuronal.

\subsection{Resultados y Discusión}

\subsubsection{Planificación y Optimización}

Los parámetros de configuración del algoritmo de búsqueda SA utilizado por la herramienta de planificación y optimización propuesta se detallan en la tabla 4.6. La búsqueda de la mejor solución finaliza cuando se cumple el criterio de parada fijado para la función de coste objetivo, que en este caso supone cursar todo el tráfico que refleja el mapa disponible, o cuando se supere el máximo de iteraciones. Según la configuración indicada, el máximo número de evaluaciones de la función de coste en cada ejecución del SA será de 26300, aunque el número exacto dependerá de si el proceso en algún momento llega a superar el millar de iteraciones sin conseguir reducir el valor de la función de coste objetivo. A pesar de que el escenario considerado no es muy extenso, se ha

Tabla 4.6: Parámetros de configuración de SA

\begin{tabular}{cc}
\hline Parámetro & Valor \\
\hline \hline Temperatura inicial & 1 \\
Temperatura final & $10^{-12}$ \\
Factor de enfriamiento & 0,9 \\
Iteraciones por temperatura & 100 \\
Máximo número de iteraciones sin mejorar & 1000 \\
Criterio de parada & Tráfico no cursado $=0$ \\
\hline
\end{tabular}

utilizado en la planificación el modo de reducción del espacio de búsqueda para 
poder analizar las prestaciones incluyendo esta funcionalidad. En este modo, la búsqueda mediante SA se ejecuta dos veces. En la primera se seleccionan los mejores emplazamientos dejando únicamente libertad en la variación del acimut de cada celda y en la selección de emplazamientos candidatos, mientras que en la segunda, una vez fijados los emplazamientos, se optimizan los valores de potencia, tilt y acimut de cada celda.

La tabla 4.7 presenta las suposiciones realizadas para configurar el simulador estático utilizado por la herramienta de planificación y optimización. Como se puede deducir por la utilización de pérdidas de penetración en edificios, se ha supuesto que todo el tráfico reflejado en el mapa disponible se genera en el interior de edificios. De esta forma se establece un criterio de planificación conservador al ponerse en el caso peor que consiste en que la señal transmitida por los eNB sufre pérdidas adicionales por tener que atravesar las paredes de los edificios.

Tabla 4.7: Parámetros de configuración del simulador estático

\begin{tabular}{cc}
\hline Parámetro & Valor \\
\hline \hline Frecuencia central & $1800 \mathrm{MHz}$ \\
Ancho de banda & $10 \mathrm{MHz}$ \\
Resolución de rejilla & $50 \mathrm{~m} \mathrm{x} \mathrm{50} \mathrm{m}$ \\
Ganancia de antena en eNB & $17 \mathrm{dBi}$ \\
Pérdidas de cableado hasta antena del eNB & $3 \mathrm{~dB}$ \\
Densidad espectral de ruido & $-174 \mathrm{dBm} / \mathrm{Hz}$ \\
Desviación estándar del shadowing & $6 \mathrm{~dB}$ \\
Ganancia de antena en UE & $0 \mathrm{dBi}$ \\
Body loss & $3 \mathrm{~dB}$ \\
Figura de ruido del UE & $7 \mathrm{~dB}$ \\
Pérdidas de penetración en edificios & $10 \mathrm{~dB}$ \\
\hline
\end{tabular}

La tabla 4.8 muestra los parámetros de configuración de la herramienta de planificación y optimización. La unidad o elemento de planificación considerado en la generación de estos resultados es el emplazamiento tri-sectorial, siendo posible realizar una planificación por celda utilizando otra configuración diferente. En la planificación por emplazamiento se introducen progresivamente nuevas unidades, seleccionando el mejor candidato que se encuentre. Se procede de esta forma hasta encontrar el número de emplazamientos y su configuración óptima que permita cumplir con el objetivo de cobertura buscado. En este caso, el objetivo se fijó en cursar el $98 \%$ de la estimación de demanda de tráfico en la nueva red LTE. 


\section{CAPÍTULO 4. PLANIFICACIÓN Y OPTIMIZACIÓN DE LA RED DE ACCESO RADIO}

Tabla 4.8: Parámetros de configuración de la herramienta de planificación y optimización

\begin{tabular}{cc}
\hline Parámetro & Valor \\
\hline \hline $\mathrm{N}^{\circ}$ de emplazamientos candidatos & 24 \\
$\mathrm{~N}^{\circ}$ de celdas por emplazamiento & 3 \\
Valor de tilt fijado para fase 1 & $4^{\circ}$ \\
Valor de potencia total fijado para fase 1 & $43 \mathrm{dBm}$ \\
Tilt mínimo & $0^{\circ}$ \\
Tilt máximo & $16^{\circ}$ \\
Acimut relativo mínimo & $-30^{\circ}$ \\
Acimut relativo máximo & $30^{\circ}$ \\
Potencia total mínima & $40 \mathrm{dBm}$ \\
Potencia total máxima & $46 \mathrm{dBm}$ \\
Factor de escala sobre mapa de tráfico UMTS & 1,5 \\
\hline
\end{tabular}

Centrando la atención ya en los resultados, la figura 4.10 muestra la evolución del tráfico no cursado conforme aumenta el número de emplazamientos utilizados. En cada una de las iteraciones en las que se va introduciendo un nuevo emplazamiento no se ha realizado una única ejecución del proceso de planificación y optimización sino 20 ejecuciones con semillas diferentes. Por ello, en los resultados mostrados, para cada punto del eje de abcisas correspondiente a un número determinado de emplazamientos planificados y optimizados, se ha promediado el porcentaje de tráfico no cursado de las distintas ejecuciones.

Se presentan los resultados para los dos modos disponibles en relación a la estimación de la carga de las celdas. En el modo sin estimación de carga se supone que en cada celda la utilización de los recursos es del $100 \%$. Es por ello que, al estar introduciendo cada celda el máximo de interferencias posible en el sistema, se necesita un mayor número de emplazamientos para conseguir el mismo objetivo que en el modo con estimación de la carga real de cada celda. Junto con la evolución del tráfico no cursado, conforme se aumenta el número de emplazamientos en ambos modos se representa la evolución de la carga media en las celdas. Se puede observar cómo el método de estimación de la carga basado en la linealización del sistema LTE hace una estimación muy aproximada a la realidad, como demuestra el hecho de que para cargas superiores al $98 \%$ los resultados son idénticos a suponer el sistema saturado.

Los resultados reflejan que el número mínimo de emplazamientos para conseguir, por ejemplo, una cobertura del tráfico del $98 \%$ es de 7 , obteniendo para 


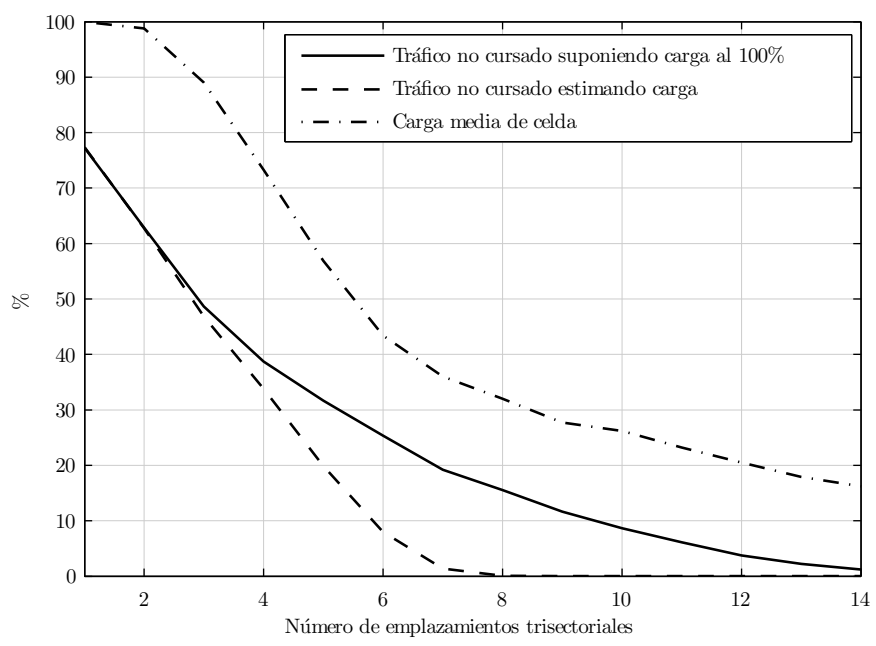

Figura 4.10: Resultados de cobertura y carga obtenidos de la herramienta automática de planificación y optimización en función del número de emplazamientos

ese caso una carga media por celda del 35\%. La figura 4.11 muestra el mapa de serving cell de la solución de planificación obtenida para esta configuración.

En cuanto a la SINR media en el escenario bajo estudio - métrica relacionada con la experiencia de usuario por la posibilidad de alcanzar valores mayores de throughput conforme mayor es su valor - la figura 4.12 recoge los resultados obtenidos. El método de estimación de la carga de cada celda propuesto en esta Tesis Doctoral permite evaluar la ganancia en la SINR media que se experimenta con la implantación de nuevos emplazamientos LTE, cosa que no ocurre cuando se supone una carga por celda del $100 \%$. Esto se debe a que, adoptando una posición conservadora al considerar el caso peor con la suposición de carga al $100 \%$, cada celda que se introduce en el sistema, llegado a cierto punto, introduce interferencias en celdas que ya existían, con lo que la SINR media no mejora con su inclusión. Esto se aprecia en la curva correspondiente al modo sin estimación de carga, la cual se mantiene relativamente constante e incluso llega a bajar al llegar a cierta densidad de emplazamientos. La consiguiente pérdida en el throughput por celda, ocasionada por el empeoramiento de la SINR experimentada por los usuarios, se ve compensada con la aparición de nuevas celdas que incrementan la capacidad global del sistema. Por eso con nuevos emplazamientos se aprecia una disminución del tráfico no 


\section{CAPÍTULO 4. PLANIFICACIÓN Y OPTIMIZACIÓN DE LA RED DE ACCESO RADIO}

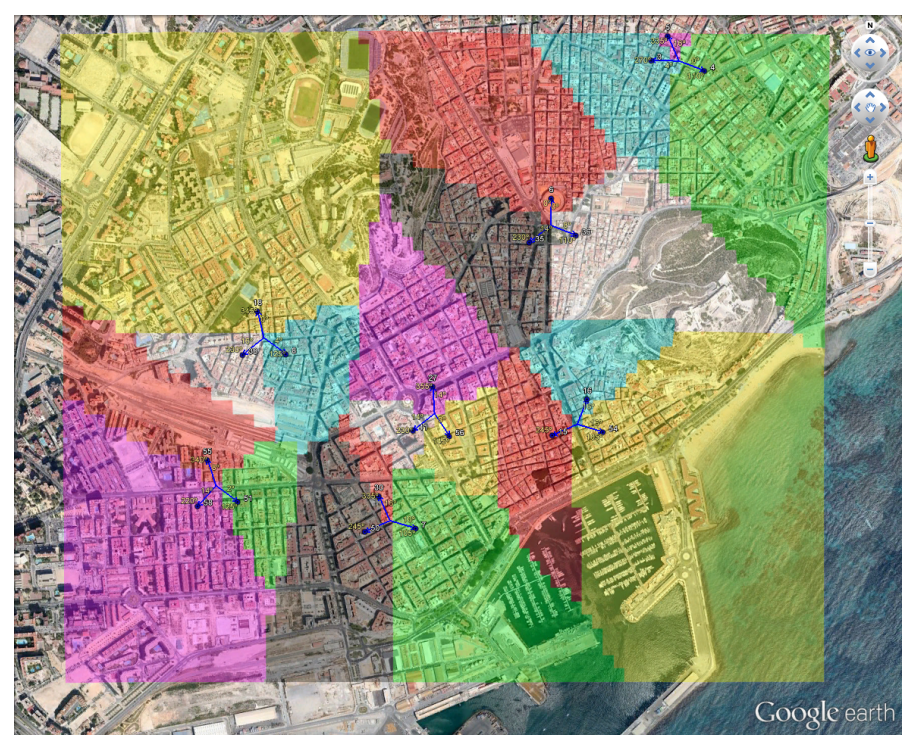

Figura 4.11: Mapa de serving cell de la solución propuesta por la herramienta automática de planificación y optimización

cursado en la figura 4.10 a pesar del empeoramiento de la SINR media. Por otro lado, en el modo con estimación de carga, cada nuevo emplazamiento que se introduce en el sistema libera de carga a las celdas previamente existentes, lo que se tiene su efecto tanto en la SINR experimentada como en la capacidad de cursar tráfico del sistema.

En la figura 4.13 se muestran los mapas de distribución de SINR obtenidos con la herramienta de planificación y optimización comparados con los del modo sin estimación de carga real por celda. Además de apreciarse que se seleccionan emplazamientos diferentes entre todos los candidatos en los dos modos, se observa como la SINR obtenida cuando se supone que las celdas están cargadas al $100 \%$ es mucho menor que en el caso de hacer una estimación de su estado de carga. De nuevo esto es debido a que la suposición pesimista de carga completa evita poder estimar de manera correcta el efecto producido por la no uniformidad del tráfico demandado.

\subsubsection{Impacto del Error de Localización}

La herramienta propuesta de planificación y optimización hace uso de un algoritmo de localización de UEs que permite geo-localizar el tráfico genera- 


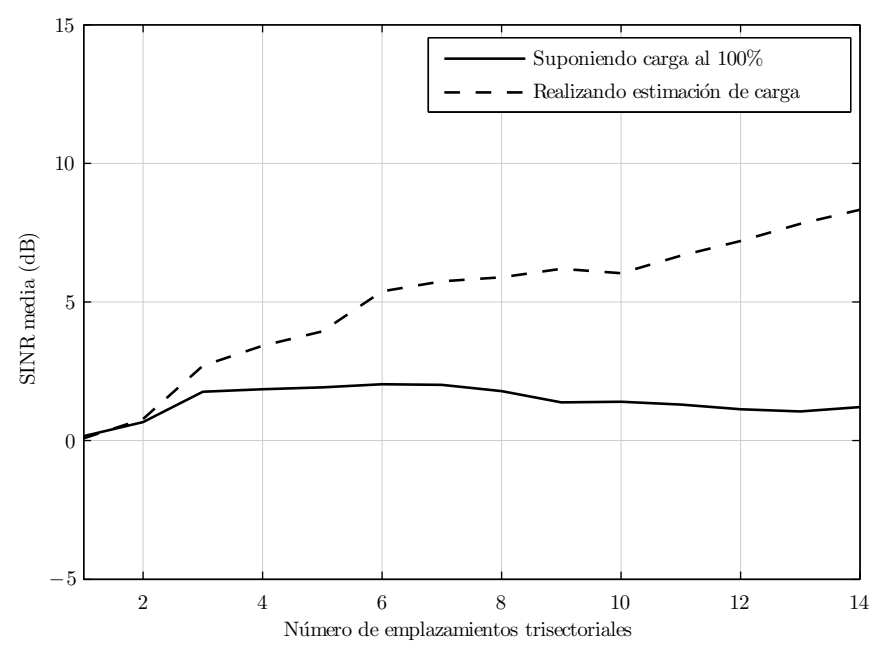

Figura 4.12: Resultados de SINR media obtenidos de la herramienta automática de planificación y optimización en función del número de emplazamientos

do en las redes operativas y, por tanto, habilita el ajuste de la red, ya sea al planificar u optimizar, a las necesidades reales de cobertura. Los errores en la localización de llamadas afectarán previsiblemente a las prestaciones de las soluciones obtenidas. En esta sección se analiza cómo afecta este error de localización a los resultados. Además de analizar el caso concreto del algoritmo de localización diseñado en esta Tesis Doctoral, con la precisión obtenida por el mismo conforme se detalla en la sección 3.2.3.1, se estudiará lo que ocurre para otras precisiones diferentes.

Al no disponer de la distribución de tráfico real, se ha tomado como referencia el mapa de tráfico obtenido mediante localización como si fuera el mapa real. A partir de él, se ha derivado de forma ficticia un mapa de tráfico que refleje el error cometido con la localización. Para ello, se ha introducido una desviación de cada punto de las llamadas localizadas, siguiendo una distribución gaussiana de media 100 metros y desviación típica 87 metros. Estos valores son coherentes con los resultados del algoritmo de localización descrito en la sección 3.2.3.1. El valor aleatorio generado se toma como distancia entre el nuevo punto y el punto de localización considerado como real. La dirección en la que se genera el punto con error se obtiene aleatoriamente siguiendo, en este caso, una distribución uniforme para el ángulo utilizado. 

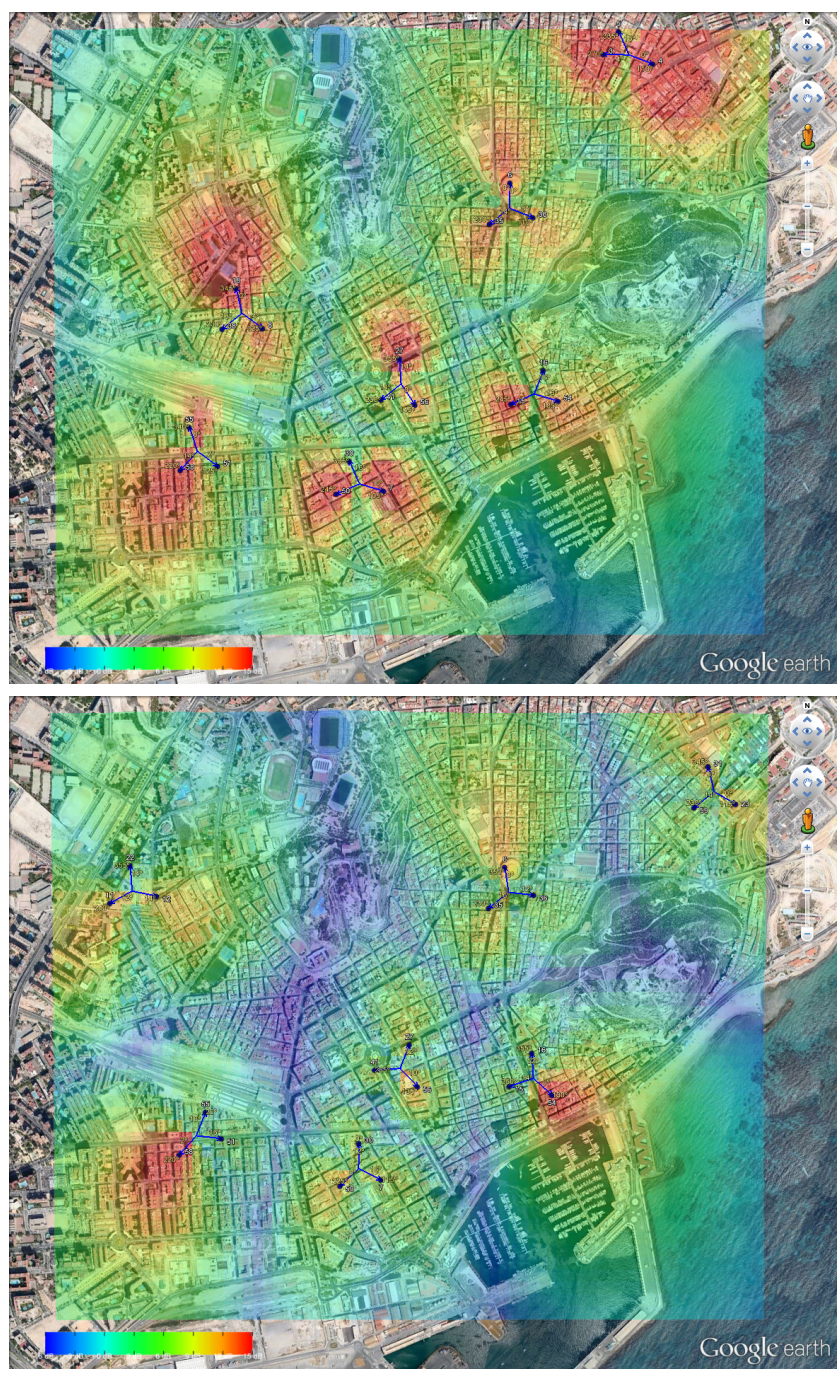

Figura 4.13: Comparación del mapa de SINR para las soluciones obtenidas para 7 emplazamientos en el modo con estimación de carga (arriba) y suponiendo carga al $100 \%$ (abajo)

En la figura 4.14 se muestra la comparación del mapa de tráfico considerado real con el mapa con error sintético. 

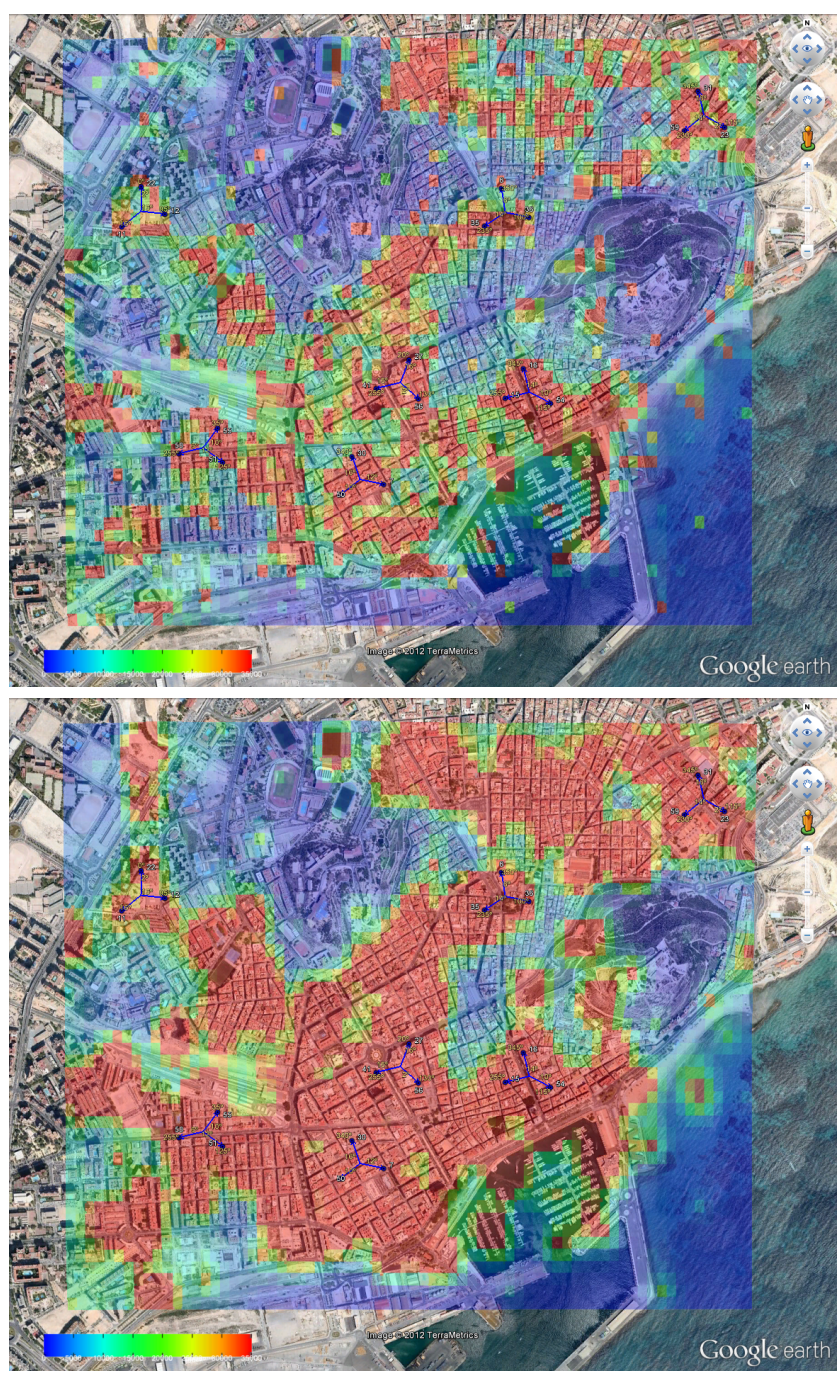

Figura 4.14: Comparación del mapa de tráfico considerado real (arriba) y del afectado por el error de localización (abajo)

Observando ambos mapas puede parecer que haya más tráfico en el mapa con error de localización debido a que hay más área coloreada de rojo, pero en realidad esto no es así y requiere una aclaración. El mapa original refleja muchos 


\section{CAPÍTULO 4. PLANIFICACIÓN Y OPTIMIZACIÓN DE LA RED DE ACCESO RADIO}

hot-spots donde los valores de tráfico son muy elevados. Con el fin de que esos valores altos no expandieran la escala utilizada de forma que se degradara la calidad de la información visualizada en el mapa, se fijó un valor, mucho menor que el máximo de tráfico entre todas las casillas, como máximo de la escala utilizada. En el mapa con error, al diluirse el tráfico de los hot-spots entre las casillas colindantes, como el tráfico repartido sigue siendo muy elevado, estas casillas también aparecen con color rojo.

Independientemente de este efecto causado por las características de la escala utilizada, cabe destacar en el mapa de tráfico con error que la información que contiene se difumina, con el consiguiente peligro de que la solución de planificación u optimización realizada partiendo del mismo no tenga las prestaciones deseadas.

A continuación se muestran los resultados conseguidos al evaluar las prestaciones del sistema cuando se considera que la distribución de tráfico viene dada por el mapa con error de localización pero aplicando una solución de planificación que ha sido obtenida considerando que la distribución de tráfico viene dada por el mapa sin error de localización. Con este resultado se pretende evaluar la degradación de prestaciones que se produce por el desajuste entre la información de entrada relativa a la distribución de tráfico que se utiliza y la real. Los resultados muestran un barrido para distintas precisiones del algoritmo de localización, siendo la correspondiente al algoritmo propuesto en esta Tesis Doctoral de 100 metros de error de media y de 187 metros para el $95 \%$ de las localizaciones.

La figura 4.15 muestra la comparación del tráfico no cursado para distintas precisiones de localización, para la mejor solución de planificación obtenida que consigue una cobertura de tráfico mayor del $98 \%$, lo cual se consigue implantando siete emplazamientos tri-sectoriales. Obviamente, se aprecia cómo la degradación de prestaciones es mayor conforme mayor es el error de localización. Para el caso concreto de un error de 100 metros de media, la degradación de resultados es de tan sólo un 2,25\% de tráfico no cursado respecto al caso sin error de localización.

Para el caso en que el objetivo de la planificación sea cursar el $100 \%$ del tráfico, con el fin de dejar más margen de error al tener en cuenta la precisión del algoritmo de localización, se obtienen los resultados de la figura 4.16. La mejor solución de planificación que consigue cursar todo el tráfico se consigue con nueve emplazamientos tri-sectoriales. En esta ocasión tan sólo se aprecia una degradación del $0,6 \%$ del tráfico no cursado respecto al caso sin error de localización, de lo que se deduce que un ligero sobre-dimensionamiento de la red permite compensar los efectos del error cometido por el algoritmo de localización en la generación de la distribución de tráfico utilizada. 


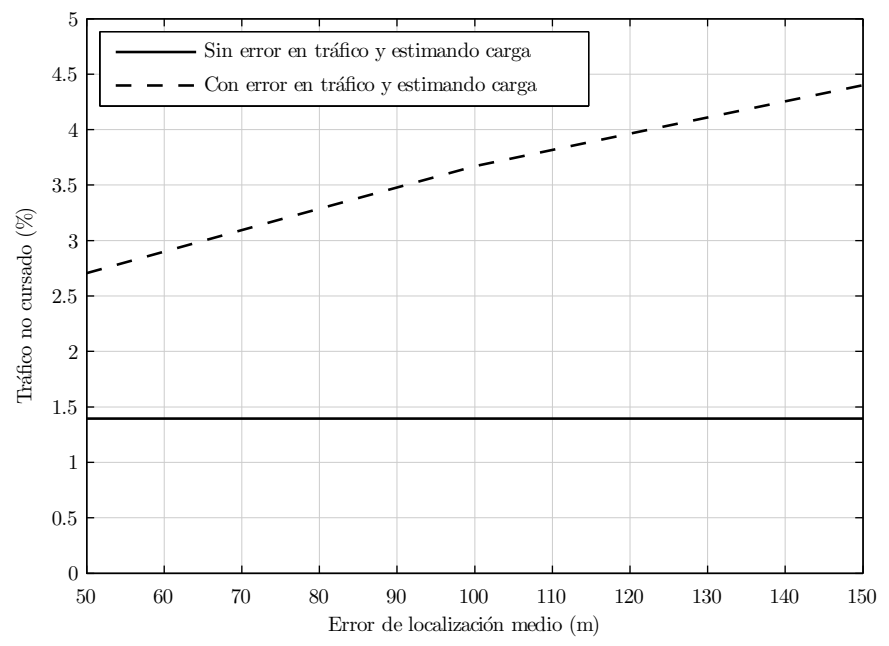

Figura 4.15: Impacto del error de localización sobre el tráfico cursado por la solución obtenida en la planificación de 7 emplazamientos (21 celdas)

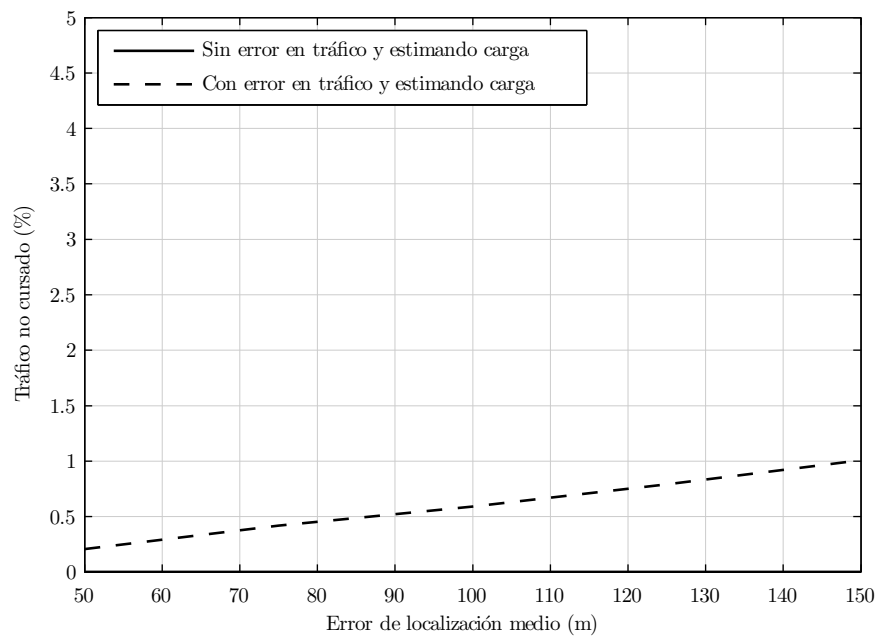

Figura 4.16: Impacto del error de localización sobre el tráfico cursado por la solución obtenida en la planificación de 9 emplazamientos (27 celdas) 


\subsubsection{Sistemas Expertos}

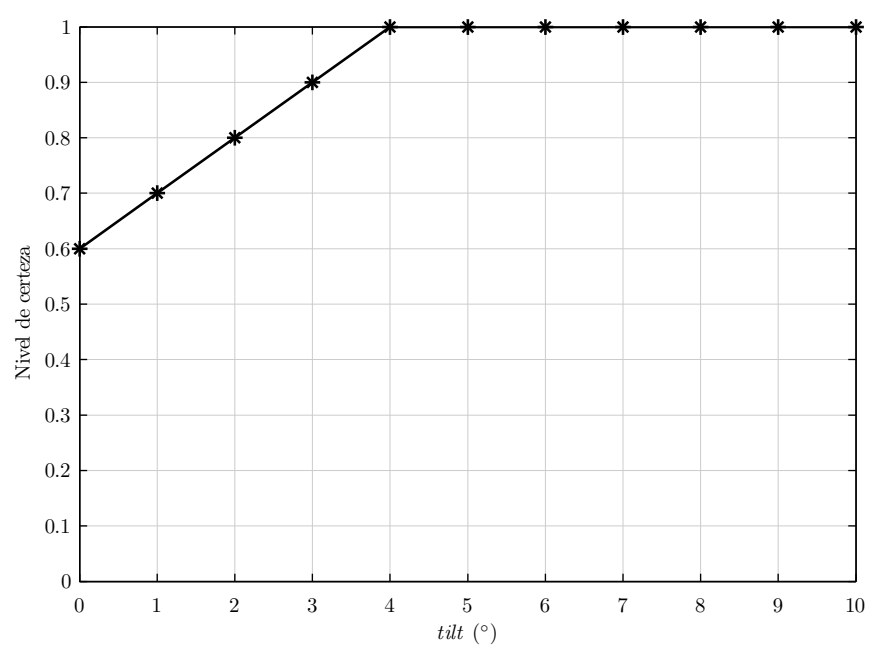

Figura 4.17: Función de transferencia para conversión de niveles de certeza en valores de incrementos de tilt comparables con la salida de la herramienta de optimización

La elección de la topología de la red neuronal — número de capas ocultas y número de neuronas en cada capa - se ha realizado probando un conjunto de alternativas y seleccionando la que mejor resultado final aporta. El mejor rendimiento se obtuvo con tres capas ocultas de 40, 20 y 10 neuronas respectivamente.

Tras la comparación de los resultados obtenidos con las muestras reservadas para pruebas - muestras que no participan de ninguna forma en el entrenamiento de la red neuronal - se observa una alineación de los resultados del $83 \%$.

Comparando los resultados de la herramienta de optimización de la sección 4.5 con la optimización realizada por el sistema experto se aprecia una alineación de los resultados del $77 \%$, incluyendo todas las muestras. Para realizar esta comparación se ha fijado un umbral en 0,6 para la salida de la red neuronal, valor a partir del cual se decide que el sistema experto sugiere un incremento del tilt. Esa sugerencia se compara con el resultado propuesto por la herramienta de optimización y se considera que los resultados están alineados si esta última indica que la mejor configuración también requiere incrementar el tilt. 
También es posible ir más allá de la comparación del sentido de cambio indicado - incrementar tilt o no - traduciendo el valor obtenido a la salida de la red neuronal con una propuesta de incremento de tilt. Para ello se podría utilizar una función de transferencia tal como la mostrada en la figura 4.17. Sin embargo, la alineación de los resultados propuestos tras la aplicación de esta función de transferencia es más baja - menor del 50\%-cuando se compara con las propuestas de cambio realizadas por la herramienta de optimización.

A la vista de los resultados, parece que únicamente tiene sentido la detección de alcance excesivo, ya que la traslación del resultado de la red neuronal a un valor de tilt optimizado no parece muy acertada dada la desalineación que se observa con las soluciones propuestas por la herramienta de optimización. En cambio, sí es viable y proporciona buenos resultados la detección de casos de alcance excesivo.

Adicionalmente, el discreto porcentaje de aciertos conseguido con las muestras de prueba tras el entrenamiento sugiere que la red neuronal no está del todo ajustada, hecho que podría deberse a haber utilizado un número insuficiente de muestras que no permitan un aprendizaje con la suficiente generalidad. Para solucionar este problema sería necesario aumentar el número de casos resueltos por los ingenieros expertos.

Asimismo, convendría realizar un análisis de componentes principales sobre las muestras para poder realizar un descarte de las entradas que menos información aportan, con el fin de conseguir mejorar la generalidad de la red tras el entrenamiento.

Ambos puntos de acción se podrán desarrollar como trabajo futuro en la línea de aplicación de sistemas expertos a la optimización de redes móviles. 
CAPÍTULO 4. PLANIFICACIÓN Y OPTIMIZACIÓN DE LA RED DE ACCESO RADIO 


\section{Capítulo 5}

\section{Optimización del Uso del Espectro}

El ancho del banda disponible para un sistema de comunicaciones inalámbrico determina el número de recursos asignables a los usuarios y, por tanto, condiciona las prestaciones globales del sistema. Ante un elemento tan crítico, es obvio que es de vital importancia el uso que se haga de él, teniendo en cuenta las distintas alternativas existentes.

En primer lugar, dado el limitado ancho de banda asignado por las autoridades competentes a los operadores de sistemas de comunicaciones móviles, no es posible evitar las interferencias intra-sistema producidas por la reutilización de frecuencias entre celdas distintas y distantes, necesaria para conseguir un uso eficiente de los recursos disponibles. Es importante, pues, determinar el patrón de reutilización de frecuencias que mejores prestaciones aporte a un sistema LTE.

Por otro lado, con la evolución de las tecnologías de comunicaciones móviles, los nuevos sistemas como LTE realizan un uso más eficiente del ancho de banda disponible en comparación con las tecnologías preexistentes. Es por esto que, sin dejar de lado la continuidad necesaria de los sistemas predecesores como GSM y UMTS, es necesario realizar un estudio de la posible ganancia que se conseguiría con el reemplazo de estas tecnologías por LTE.

Otra estrategia ideada para combatir la escasez de recursos consiste en el uso oportunista de bandas de frecuencia licenciadas a otro sistema pero con escaso uso. Dentro de estos sistemas oportunistas, serán importantes tanto los mecanismos de detección y de decisión del uso oportunista como los de coordinación entre transmisores operando de forma oportunista. 


\section{CAPÍTULO 5. OPTIMIZACIÓN DEL USO DEL ESPECTRO}

En este capítulo se tratan cada uno de estos puntos que afectan a la utilización del ancho de banda disponible y se estudia su influencia en las prestaciones globales del sistema.

\subsection{Reutilización de Frecuencias}

\subsubsection{Introducción}

El esquema de acceso radio de LTE proporciona ortogonalidad entre los usuarios de una misma celda, tanto en UL como en DL. Sin embargo, no evita la interferencia entre usuarios de distintas celdas. Por ese motivo, las prestaciones de LTE en términos de eficiencia espectral y tasas de transmisión de pico están limitadas principalmente por las interferencias producidas por celdas vecinas, en comparación con lo que sucedía en las tecnologías 3G. Cualquier técnica que permita reducir las interferencias entre celdas será, por tanto, una mejora en las prestaciones de LTE, sobre todo en términos de calidad de servicio ofrecida a los usuarios en los bordes de las celdas. Existen varias técnicas para lograr este objetivo que se pueden catalogar en tres tipos: técnicas de cancelación de interferencias, técnicas de promediado de interferencias y técnicas de evasión de interferencias.

Las técnicas de cancelación de interferencias se basan en estimar la interferencia de la señal recibida y restar su valor a la componente de la señal deseada. En cambio, las técnicas de promediado de interferencias se basan en organizar la transmisión de manera que las interferencias se distribuyan equitativamente entre todos los usuarios. Por último, las técnicas de evasión de interferencias se basan en encontrar un factor de reutilización óptimo, restringiendo ciertas frecuencias y realizando un control de potencia para conseguir el objetivo, como sucede con las técnicas ICIC, en las que se centra esta sección.

Las redes $4 \mathrm{G}$ buscan la reutilización universal de frecuencias, es decir, utilizar todo el ancho de banda en todas las celdas para maximizar la eficiencia espectral del sistema. Sin embargo, en redes celulares basadas en OFDMA esto supone una degradación significativa de las tasas de transmisión de los usuarios situados en el borde de la celda. Esto es debido a que las pérdidas de propagación son proporcionales a la distancia entre el receptor y el transmisor, de modo que a medida que el usuario se aleja de su estación base servidora, no sólo experimenta un decremento en la potencia de la señal útil sino también un incremento en la potencia de las señales interferentes producidas por celdas vecinas.

En [90] se ilustra la necesidad de las técnicas ICIC. En el caso analizado en este estudio se llega a la conclusión de que la capacidad de un sistema LTE es una función de las ganancias de canal de cada usuario y de las potencias 
transmitidas por cada eNB. En general, si un recurso común es utilizado simultáneamente por un grupo de eNBs, la capacidad se maximiza si dicho recurso se asigna exclusivamente a un único usuario en cada celda o bien si al menos un eNB transmite a potencia máxima. Si las SINR de los usuarios es elevada, es decir, si los usuarios están cerca de sus estaciones bases servidoras, entonces la capacidad se maximiza si todos los eNBs transmiten a la potencia mínima requerida para obtener la tasa de transmisión más alta que el sistema puede proporcionar. De esto se entiende que los usuarios con buenas condiciones de canal deben optar por utilizar factores de reutilización bajos, mientras que los usuarios en los bordes deben optar por esquemas que incorporen factores de reutilización más elevados. Esta conclusión es la base del estudio de varias estrategias ICIC que se describirán a continuación.

La motivación del análisis realizado a continuación reside en conocer la mejor alternativa para la realización de la planificación de frecuencias en LTE, ya que ésta afecta de forma importante a los procesos de planificación de una red móvil. Es posible planificar el despliegue celular con reutilización universal de frecuencias. Sin embargo, hay que tener en cuenta que los usuarios en el borde de la celda - o Cell-Edge Users (CEUs) - son los que van a sufrir niveles de interferencia más elevados si no se adoptan estrategias de compensación o reducción de interferencias. Por tanto, el objetivo es encontrar la opción que mejore las prestaciones obtenidas por los CEUs sin degradar las prestaciones globales del sistema, al menos más allá de lo asumible.

\subsubsection{Técnicas ICIC}

El objetivo de las técnicas ICIC es decidir un conjunto de restricciones y preferencias sobre el uso y la potencia de transmisión por bloque de recurso de un determinado eNB para mitigar la interferencia intercelular, especialmente la que reciben los usuarios cercanos a los bordes de las celdas, y así mejorar la calidad de servicio, en particular su tasa de transmisión. Esta funcionalidad debe ir integrada con el scheduler, el cual podrá tomar las acciones necesarias durante la asignación de recursos para conseguir el equivalente a esquemas de reutilización de frecuencias distintos para el interior y exterior de las celdas.

El mínimo recurso que un eNB puede asignar a un UE es un Resource Block, es decir, un conjunto de 12 subportadoras durante una subtrama, es decir, dos slots consecutivos. Asignar recursos consiste en repartir RBs y niveles de potencia para cada subtrama entre los usuarios seleccionados para asignarles recursos para el siguiente TTI. En cuanto al control de potencia, éste tiene una doble funcionalidad. Por una parte, reduce la interferencia entre celdas, minimizando el consumo de potencia tanto en el eNB como en el UE. Por otro lado, asegura un nivel de QoS suficiente. En LTE, el control de potencia se 


\section{CAPÍTULO 5. OPTIMIZACIÓN DEL USO DEL ESPECTRO}

orienta a servicios de transmisión de paquetes y se combina con la elección del mejor esquema de Adaptive Modulation and Coding (AMC), a fin de maximizar la eficiencia espectral, y con técnicas de HARQ en la gestión de retardos y colas.

Las técnicas ICIC parten del supuesto de que los usuarios más afectados por las interferencias producidas por otras celdas son aquéllos situados cerca del borde de la celda en la que se encuentran. Para minimizar estas interferencias, se propone dividir el espectro disponible en bloques y reservar uno de ellos para uso exclusivo de los usuarios situados en el borde de dicha celda. Las celdas adyacentes ubicarán a sus CEUs en bloques del espectro distintos, por lo que se consigue evitar la interferencia entre usuarios geográficamente cercanos pero servidos por celdas distintas.

Esta restricción o limitación de los recursos radio disponibles en las celdas puede darse o bien indefinidamente o por periodos de tiempo específicos. Así, se pueden clasificar las estrategias ICIC de diversas maneras:

- Atendiendo a las temporalidad con la cual se asignan los recursos

- Estáticos: Se realizan normalmente en la etapa de scheduling e incluyen esquemas como reutilización fija, FFR y SFR.

- Auto-configurables: Son esquemas esencialmente estáticos que pueden tomar en consideración los niveles medios de interferencia procedente de las celdas vecinas en periodos de tiempo del orden de días. Se les considera esquemas semi-estáticos.

- Celda-adaptables: Igual que los esquemas auto-configurables, estos también se consideran esquemas semi-estáticos. En este caso la reutilización de frecuencias se puede adaptar de acuerdo a los niveles de carga de cada celda, con un periodo de cambio del orden de minutos $\mathrm{u}$ horas.

- Usuario-adaptables: Son conocidos como dinámicos y en estos esquemas la asignación de recursos en las diferentes celdas toma en consideración elementos como la carga, tipo de tráfico de cada usuario y la interferencia intercelular. Sin embargo, estos esquemas requieren demasiada señalización para coordinar la asignación de recursos.

- Sincronizados: Son esquemas en los que la coordinación de los recursos se realiza a nivel de TTI.

- Atendiendo a la ubicación lógica de la unidad responsable de realizar la coordinación de recursos

- Distribuidos: Son esquemas donde las decisiones se toman de manera autónoma en cada eNB, normalmente basándose en la interferencia media recibida de las celdas vecinas. 
- Semi-distribuidos: En estos esquemas las decisiones se toman localmente en cada celda pero se utiliza en información de celdas vecinas que ha sido previamente procesada por una entidad central.

- Centralizados: La coordinación se realiza totalmente por una unidad lógica central que procesa convenientemente la información asociada a un grupo de celdas vecinas, quedando sólo el proceso de scheduling por cuenta de cada celda.

En los esquemas estáticos, los recursos disponibles - conjunto de subportadoras y niveles de potencia asignados - son fijos para cada celda y no cambian a lo largo del tiempo sino que se calculan y evalúan durante el proceso de planificación. Es por ello que son los esquemas que se van evaluar en esta Tesis Doctoral, para poder concretar los detalles al respecto en el proceso de planificación de una red móvil LTE. Además, estos esquemas son atractivos para los operadores puesto que su complejidad de desarrollo es muy baja y no existe la necesidad de utilizar señalización extra. A continuación se describen los principios tecnológicos de la reutilización de frecuencias de factor 3 , FFR y SFR.

\subsubsection{Reutilización de frecuencias de factor 3}

En este patrón de reutilización cada celda utiliza un tercio de todo el espectro disponible, siendo cada bloque del espectro ortogonal al bloque de las celdas adyacentes para que éstas no usen el mismo bloque de frecuencias. Esto se puede observar en la parte derecha de la figura 5.1. Nótese que se ha representado como nivel máximo de potencia un valor $P$. Para cada uno de los esquemas analizados el valor de $P$ se escogerá de forma que la potencia total de la celda se mantenga constante en los distintos casos planteados, independientemente del número de subportadoras utilizadas, consiguiendo de esta forma una comparación justa entre los distintos esquemas.

Con este esquema de reutilización de frecuencias la interferencia en los bordes de las celdas se reduce drásticamente. Sin embargo, la eficiencia se reduce en un factor 3 respecto a la eficiencia obtenida utilizando la reutilización universal de frecuencias.

\subsubsection{FFR}

Este esquema consiste en la combinación de los patrones de reutilización de frecuencias de factor 3 y de reutilización universal. A diferencia del caso anterior, el FFR se basa en clasificar a los usuarios en dos grupos: Cell-Center Users (CCUs) y CEUs, que utilizarán un patrón de reutilización de frecuencias distinto y cuya potencia disponible puede ser diferente. 


\section{CAPÍTULO 5. OPTIMIZACIÓN DEL USO DEL ESPECTRO}
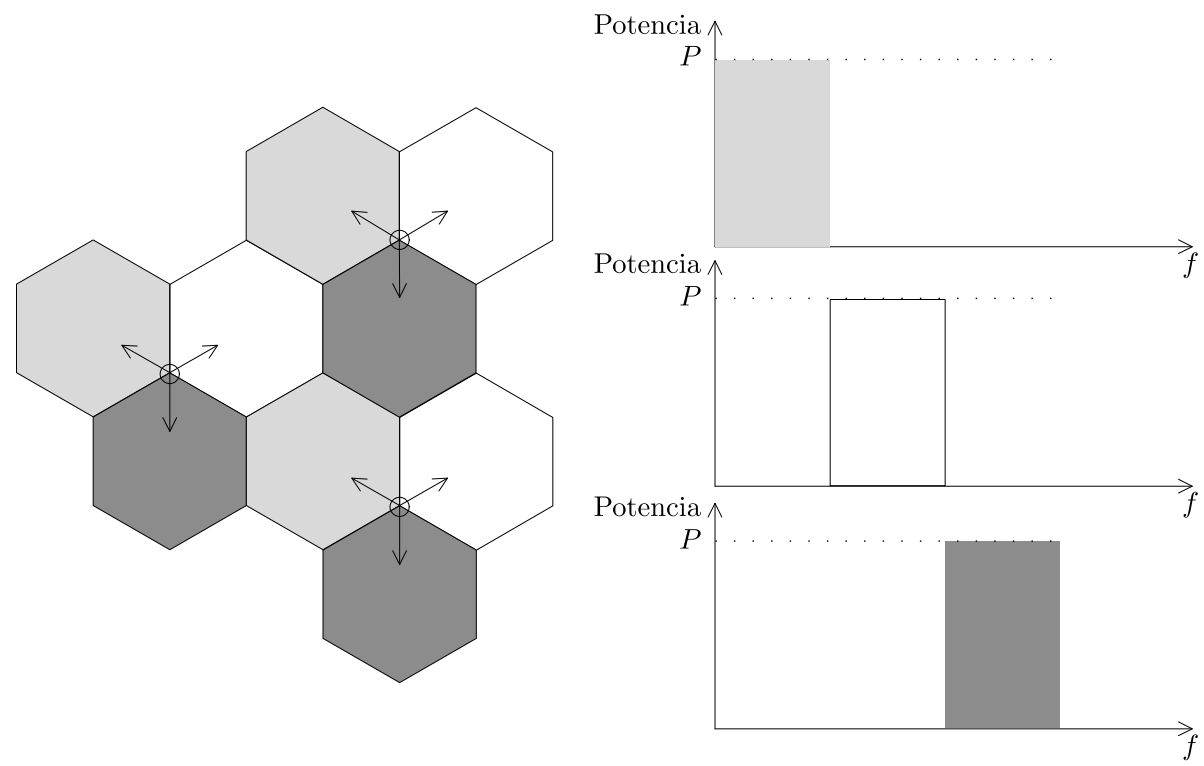

Figura 5.1: Reutilización de factor 3

En este esquema los usuarios clasificados como CCU reutilizan todas las frecuencias de una porción del ancho de banda total de la celda. Esta porción del espectro viene determinada por el parámetro $\beta \in[0,1]$. El ancho de banda restante se distribuye entre los usuarios clasificados como CEU, pero en este caso utilizando un patrón de reutilización de factor 3. En cuanto al criterio por el que se va a regir la clasificación de usuarios, existen distintas formas de realizar esta clasificación y se hablará de ello más adelante. El esquema FFR se puede observar en la figura 5.2.

Además de combinar distintos esquemas, a los RBs se les puede asignar una potencia diferente según si se transmite a un CCU o a un CEU. La potencia viene determinada por el parámetro $\alpha \in[0,1]$ que controla la reducción de potencia en la banda común a todas las celdas. Como se puede observar en la figura 5.2, la potencia máxima corresponderá a los RBs de los usuarios cercanos al borde de la celda, mientras que la de los RBs de los usuarios del centro se verá reducida por un factor $\alpha$, siempre que $\alpha$ sea menor que 1 . 


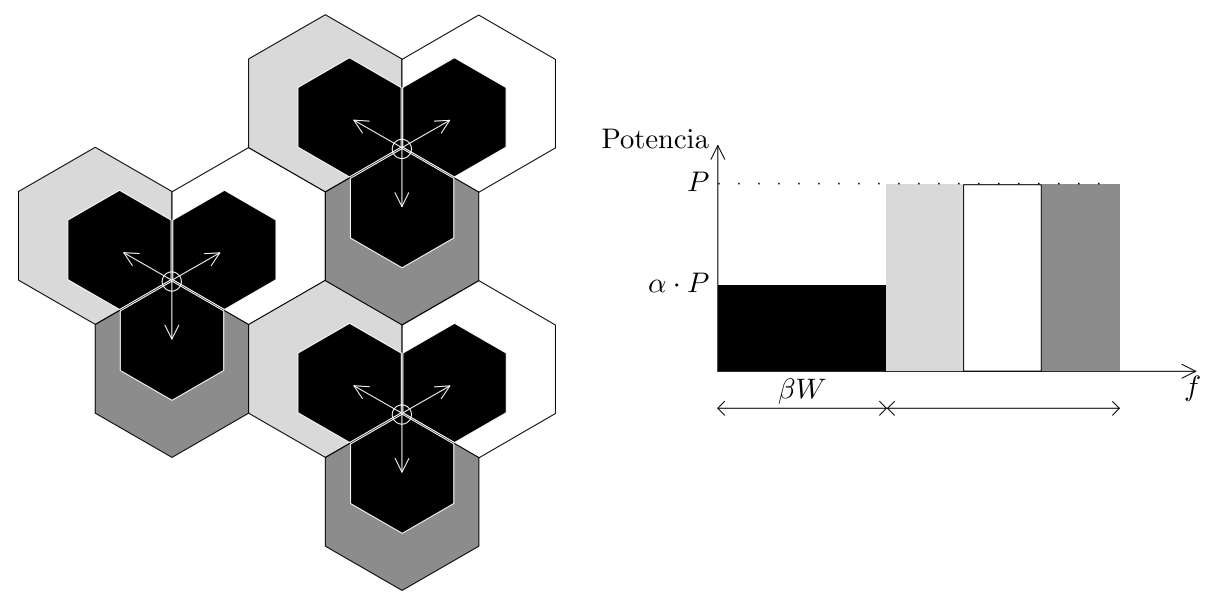

Figura 5.2: Esquema FFR

\subsubsection{SFR}

En este esquema se utiliza toda la banda disponible en todas las celdas usando una máscara de potencia no uniforme para disponer de patrones diferentes para los CCUs y los CEU.

Según el esquema SFR todas las celdas reservan una parte del espectro para los CCUs y otra parte para los CEUs. La zona del espectro disponible para los CEUs de una celda es distinta de la porción del espectro asignada a los CEUs de las celdas adyacentes, como se puede observar en la figura 5.3.

Además, en este esquema se realiza control de potencia al igual que en FFR. Es decir, a los RBs se les asigna una potencia diferente según si han sido asignados a CCU o a CEU. Esta potencia, también viene determinada por el parámetro $\alpha \in[0,1]$. Sin embargo, en este caso no existe el parámetro $\beta$ que determine la división del espectro sino que éste se divide en tres bloques del mismo tamaño. Nótese que en el caso extremo de que $\alpha=0$, SFR es equivalente al esquema de reutilización de frecuencias de factor 3 , mientras que en el extremo opuesto en el que $\alpha=1 \mathrm{SFR}$ es equivalente al patrón de reutilización universal.

\subsubsection{Resultados y Discusión}

Con el fin de evaluar las prestaciones de las distintas técnicas de reutilización de frecuencias analizadas para determinar la mejor opción a considerar en el proceso de planificación de una red LTE, se han realizado simulaciones 


\section{CAPÍTULO 5. OPTIMIZACIÓN DEL USO DEL ESPECTRO}
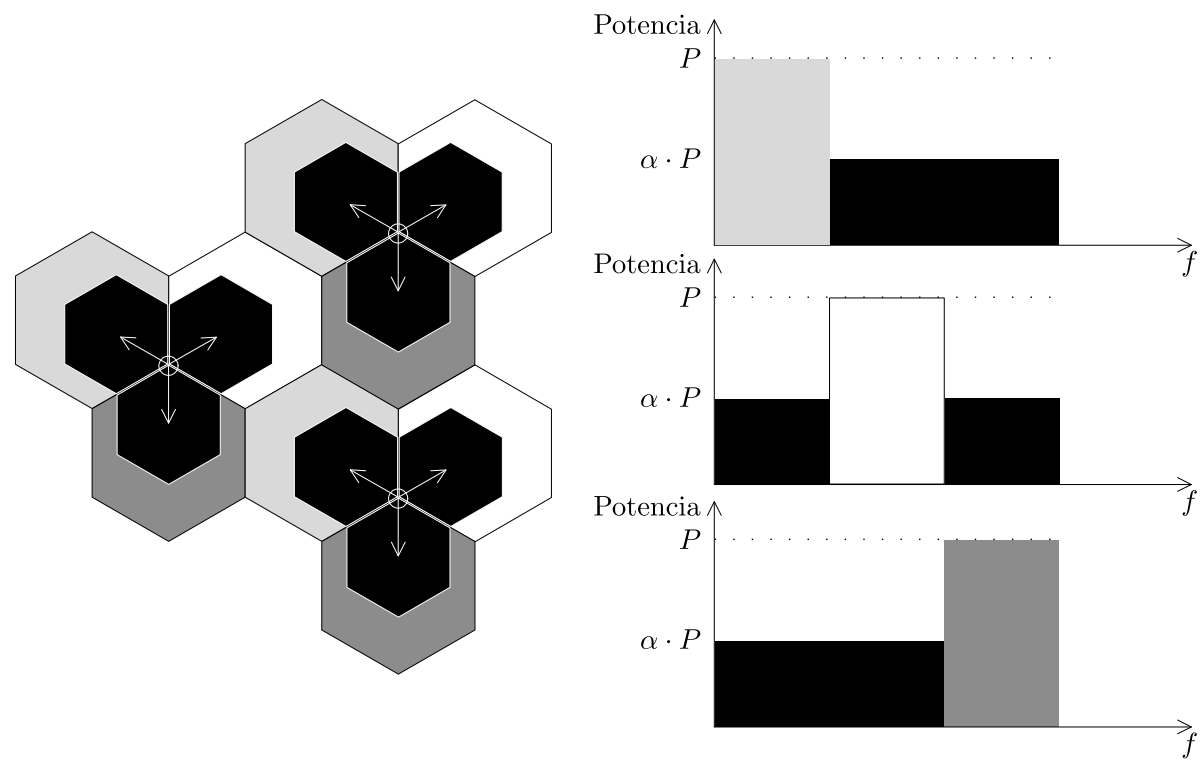

Figura 5.3: Esquema SFR

utilizando el simulador dinámico descrito en 2.3. A continuación se detallan los parámetros de las simulaciones realizadas, se presentan los resultados conseguidos en términos de eficiencia espectral, throughput de los CEUs y fairness en el reparto de recursos para distintas configuraciones de las alternativas planteadas y se extraen las conclusiones alcanzadas. En la métrica de fairness se ha utilizado el Jain's index [91].

Para cada uno de los resultados obtenidos se fijará un valor que se tomará como base de configuración para la obtención de los resultados restantes.

\subsubsection{Escenario y parámetros de simulación}

Las simulaciones de los diferentes mecanismos de reutilización de frecuencias evaluadas, para distintas configuraciones, se han llevado a cabo sobre un escenario sintético de 57 celdas repartidas en 19 emplazamientos trisectoriales, siendo los principales parámetros utilizados en las simulaciones los reflejados en la tabla 5.1. En cada una de las secciones de resultados siguientes se irán detallando los parámetros adicionales específicos para cada caso. 


\subsection{Reutilización de Frecuencias}

Tabla 5.1: Parámetros de las simulaciones de reutilización de frecuencias

\begin{tabular}{cc}
\hline Parámetro & Valor \\
\hline \hline $\mathrm{N}^{\mathrm{O}}$ celdas & 57 \\
$\mathrm{~N}^{\circ}$ interferentes & $56($ wrap-around $)$ \\
$\mathrm{N}^{\mathrm{O}}$ usuarios por celda & 10 \\
Distribución de usuarios & Uniforme \\
Frecuencia central & $2 \mathrm{GHz}$ \\
Modelo de pérdidas de propagación & Okumura-Hata $\left(128,1+37,6 \cdot \log _{10}\left(d_{k m}\right)\right)$ \\
Ancho de banda & $10 \mathrm{MHz}$ \\
$\mathrm{N}^{\circ}$ RBs & 54 \\
Potencia de celda & $43 \mathrm{dBm}$ \\
DEP de ruido térmico & $-174 \mathrm{dBm} / \mathrm{Hz}$ \\
Figura de ruido en el UE & $7 \mathrm{~dB}$ \\
Ganancia de antena del eNB & $14 \mathrm{dBi}$ \\
Ganancia de antena del UE & $0 \mathrm{dBi}$ \\
Movilidad & Usuarios estáticos \\
Modelo de tráfico & Full-buffer \\
Algoritmo de scheduling & $\mathrm{PF}$ \\
$\mathrm{N}^{\circ}$ entidades HARQ en scheduling & 3 \\
$\mathrm{~N}^{\circ}$ máx. retransmisiones & 3 \\
$\mathrm{~N}^{\circ}$ seeds & 10 \\
\hline
\end{tabular}

\subsubsection{Clasificación de usuarios}

Para controlar la disponibilidad de los recursos reservados para los CEUs existen distintas alternativas basadas en las condiciones experimentadas por cada usuario. Para evaluar la mejor configuración de asignación de frecuencias, entre estas alternativas se ha seleccionado la clasificación según la wideband SINR utilizando dos estrategias diferentes. Por un lado se encuentra el modo de clasificación de usuarios según un determinado umbral de wideband SINR. Por otro, una clasificación relativa de usuarios, donde una cierta proporción de los mismos, los que peor wideband SINR miden, se consideran CEUs.

Para evaluar el efecto de esta clasificación de usuarios se ha seleccionado un escenario donde la distancia entre emplazamientos es de $500 \mathrm{~m}$. Los umbrales de wideband SINR simulados son $-1 \mathrm{~dB},-2 \mathrm{~dB}$ y $-3 \mathrm{~dB}$ y el porcentaje de usuarios que se clasifican como CEU en el modo relativo es del $10 \%$.

En la figura 5.4 se muestra la Cumulative Distribution Function (CDF) del throughput de usuario para el caso de FFR con $\beta=0,66$ y $\alpha=0,5$, lo que supone que en un tercio del ancho de banda disponible se hace reutilización 


\section{CAPÍTULO 5. OPTIMIZACIÓN DEL USO DEL ESPECTRO}

de factor 3 , teniendo en esa porción del espectro $3 \mathrm{~dB}$ más de potencia que en la parte en la que se hace reutilización universal de frecuencias. Por otro lado, en la figura 5.5 se muestran los resultados comparativos para la misma configuración pero analizando en este caso la equidad del reparto - o fairness y la eficiencia espectral de celda y de CEU.

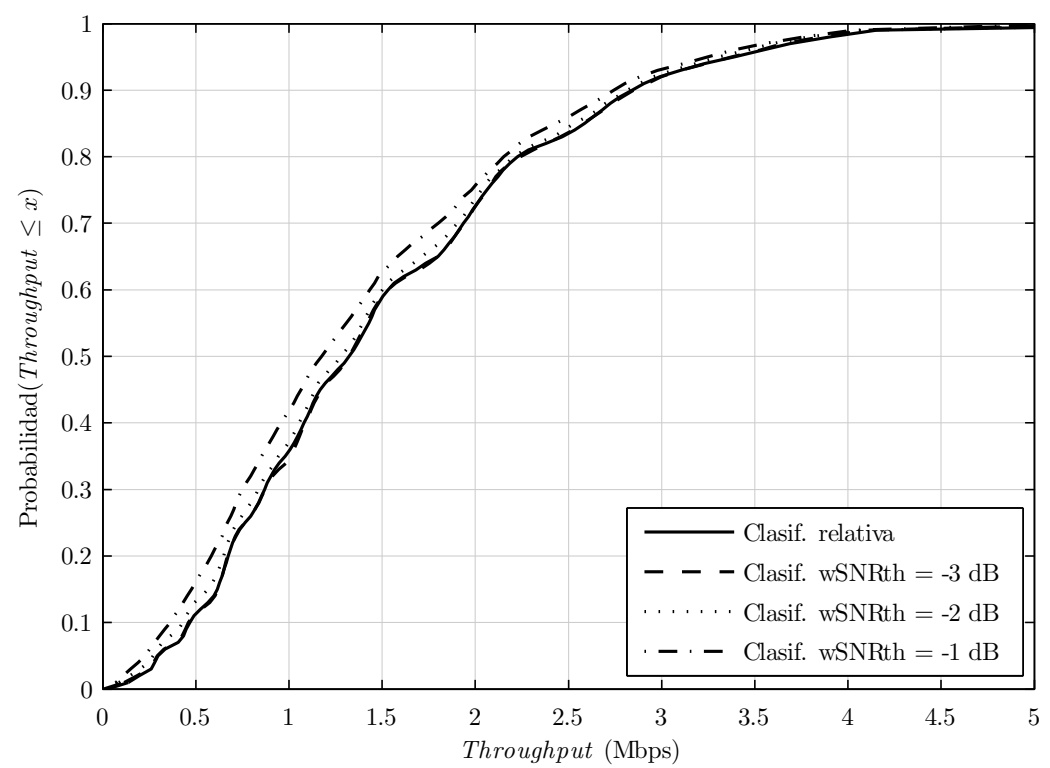

Figura 5.4: CDF del throughput de usuarios para SFR según modo de clasificación de usuarios

Como se puede apreciar en estos resultados, en el modo de clasificación por umbral se obtiene que la mejor configuración se corresponde con el umbral de -3 dB. Además, para esta configuración se obtienen resultados muy similares al modo de clasificación relativo. Por otro lado, el modo relativo permite tener una solución adaptable a cualquier situación de la celda, sin los problemas que supone el hecho de tener que seleccionar un determinado umbral, que según la celda considerada puede provocar que haya demasiados o pocos usuarios para utilizar los recursos de la banda reservada para los CEUs. Es previsible que, para cada celda, hubiera que configurar un umbral específico para las condiciones de la celda, por lo que es mucho más recomendable el modo relativo.

Para el caso de FFR los resultados son los mostrados en las figuras 5.6 y 5.7. De nuevo, se obtienen los mejores resultados para clasificación con umbral fijo 


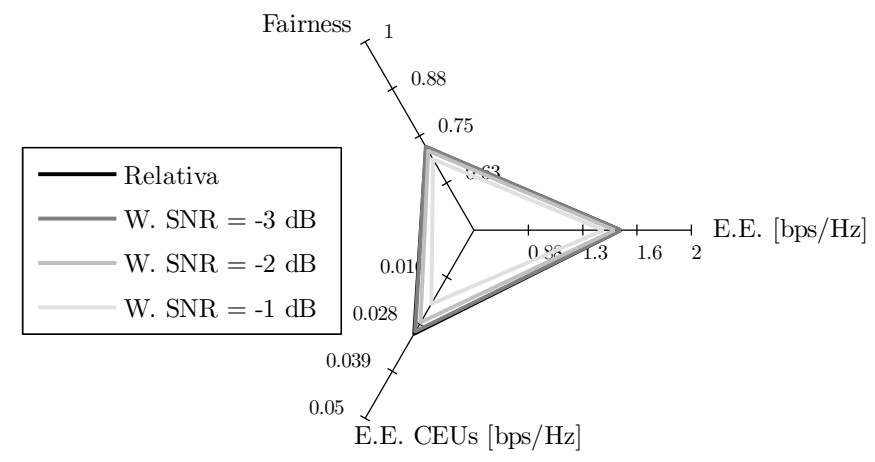

Figura 5.5: Fairness, eficiencia espectral por celda y eficiencia espectral de CEUs para SFR según modo de clasificación de usuarios

de $-3 \mathrm{~dB}$ y para clasificación relativa, visto lo cual se selecciona como estrategia de clasificación de CEUs para reparto de recursos el modo relativo, por las razones expuestas anteriormente.

\subsubsection{Barrido de parámetros}

Una vez fijado el criterio de clasificación de usuarios, conviene analizar las posibles configuraciones de los mecanismos FFR y SFR que mejores prestaciones tienen. Para realizar este estudio se ha realizado, sobre cada uno de los mecanismos, un barrido de los parámetros que controlan su comportamiento.

En el caso del FFR, el barrido de sus parámetros se va a realizar con los valores, y posibles combinaciones entre ellos, mostrados en la tabla 5.2.

Tabla 5.2: Valores del barrido de parámetros $\alpha$ y $\beta$ para FFR

\begin{tabular}{|c|c|}
\hline Parámetro & Posibles valores \\
\hline$\alpha$ & 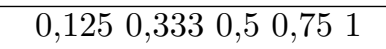 \\
\hline$\beta$ & $\begin{array}{llllllll}0,2 & 0,3 & 0,4 & 0,5 & 0,6 & 0,7 & 0,8\end{array}$ \\
\hline
\end{tabular}




\section{CAPÍTULO 5. OPTIMIZACIÓN DEL USO DEL ESPECTRO}

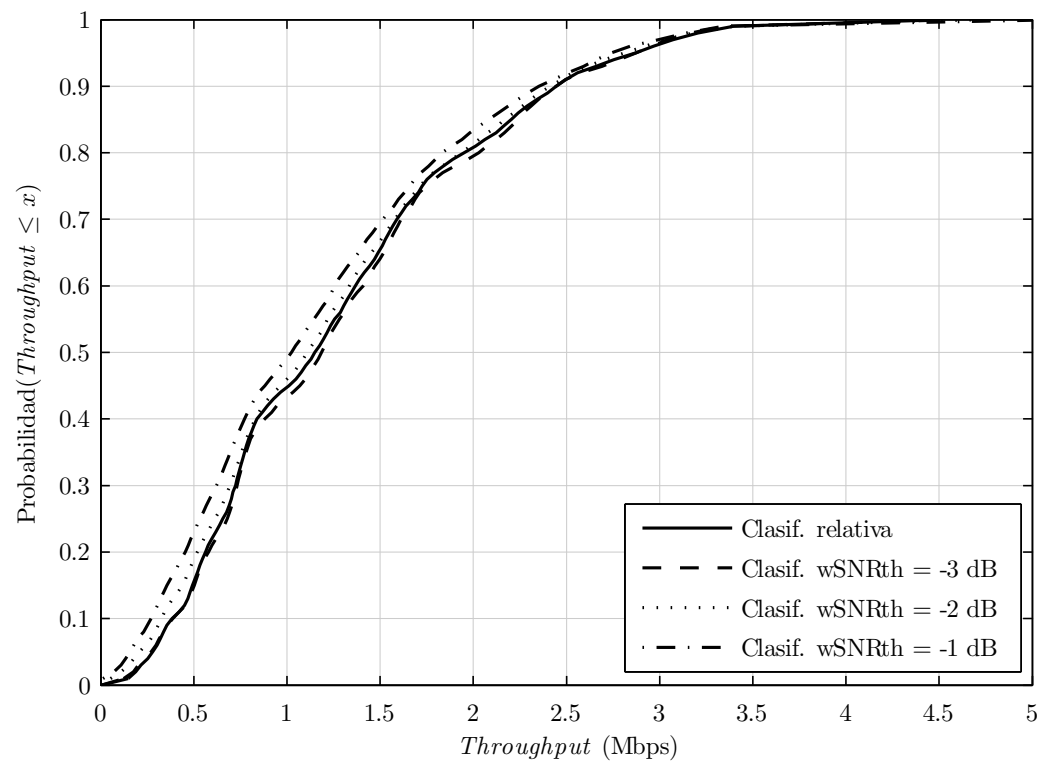

Figura 5.6: CDF del throughput de usuario para FFR según modo de clasificación de usuarios

En la figura 5.8 se muestran los valores de throughput experimentados por los CEUs para las distintas combinaciones de parámetros. Cada curva se corresponde con un valor de $\beta$ diferente mientras que la abscisa representa el barrido realizado sobre el parámetro $\alpha$. Por otro lado, las prestaciones globales del sistema en términos de throughput se representan en la figura 5.9.

Los resultados obtenidos en el barrido del parámetro $\beta$ son como cabría esperar. Conforme disminuye $\beta$-proporción del ancho de banda total disponible que se destina a reutilización universal - mejor es el throughput de los CEUs. Nótese que el valor extremo $\beta=0$ se corresponde con la reutilización de factor 3 mientras que el valor extremo opuesto, $\beta=1$, se corresponde con la reutilización universal de frecuencias. En lo que respecta al throughput global del sistema, se cumple la relación inversa pronosticada ya que las prestaciones del sistema se degradan cuando el valor de $\beta$ disminuye.

Por otro lado, el barrido del parámetro $\alpha$ no produce los resultados esperados y coherentes con el objetivo buscado por el FFR. A menor valor de $\alpha$ - relación entre la potencia de la banda sobre la que se realiza reutilización universal de frecuencias y la banda correspondiente a reutilización de frecuen- 


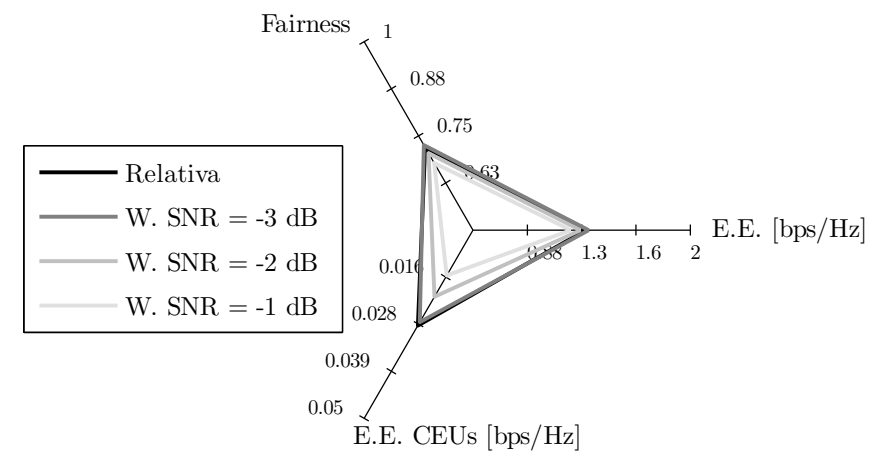

Figura 5.7: Fairness, eficiencia espectral por celda y eficiencia espectral de CEUs para FFR según modo de clasificación de usuarios

cias de factor 3- no se obtiene una mejora en el throughput experimentado por los CEUs.

Para el caso de SFR, sólo se dispone de un parámetro sobre el que realizar el barrido. Los valores seleccionados para el parámetro $\alpha$ son los representados en la tabla 5.3.

Tabla 5.3: Valores del barrido de parámetros $\alpha$ para SFR

\begin{tabular}{cc}
\hline Parámetro & Posibles valores \\
\hline \hline$\alpha$ & $0,125,0,333,0,5,0,75,1$ \\
\hline
\end{tabular}

La figura 5.10 muestra distintas curvas representando la CDF del throughput de usuario para los distintos valores analizados.

Nótese que, de forma análoga a como ocurría en el caso de FFR, los valores extremos de $\alpha$ dan lugar a las configuraciones de reutilización universal de frecuencias, con $\alpha=1$ y a la reutilización de frecuencias de factor 3 , con $\alpha=0$. A partir de los resultados obtenidos se desprende que, conforme más parecida es la configuración del SFR a la reutilización universal de frecuencias, mejores prestaciones del sistema se obtienen, tanto las globales como las particulares de 


\section{CAPÍTULO 5. OPTIMIZACIÓN DEL USO DEL ESPECTRO}

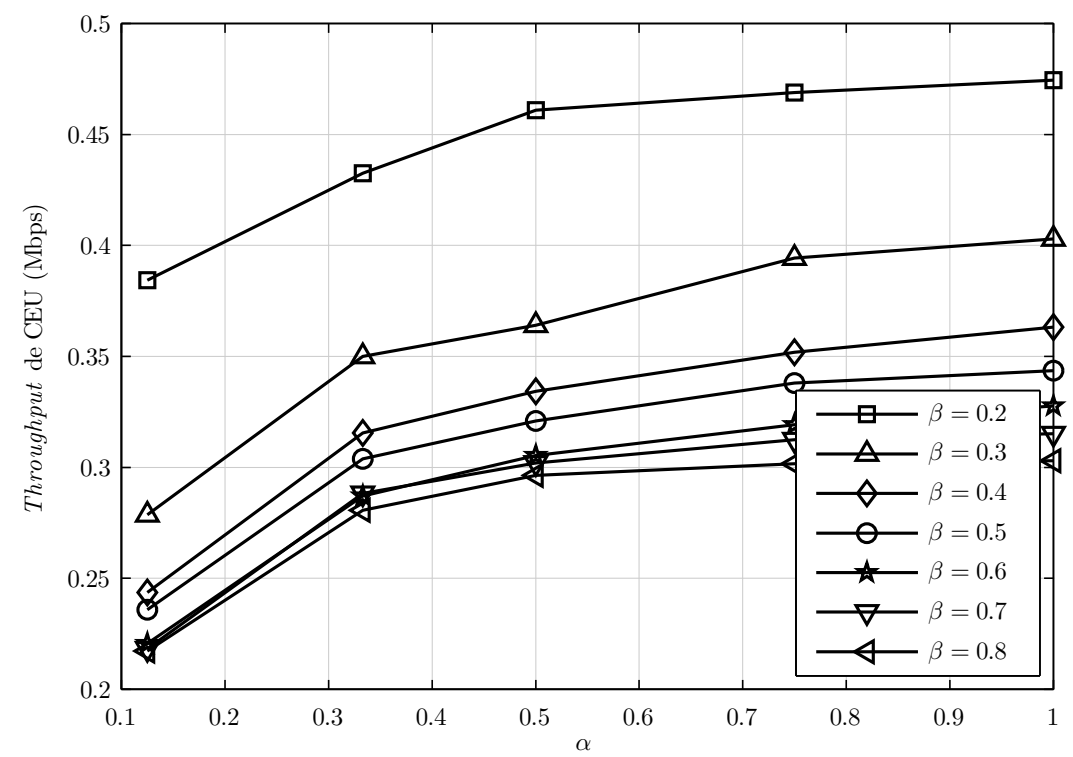

Figura 5.8: Throughput medio de usuario CEU para FFR y varios valores de $\alpha$ y $\beta$

los CEUs. A partir de esta conclusión se hace necesario profundizar en este análisis - como se hará en secciones sucesivas - para discernir sobre los escenarios en los que la reutilización universal no ofrezca las mejores prestaciones.

Para el resto de secciones en las que se realizan otros barridos sobre los que evaluar las prestaciones de los distintos mecanismos de reutilización de frecuencias planteados, se considerará que la configuración del FFR será $\alpha=$ 0,75 y $\beta=0,6$, suponiendo un posible caso de uso de este mecanismo, ya que no se ha encontrado una combinación de $\alpha$ y $\beta$, con $\alpha$ menor que la unidad, que mejore las prestaciones de la reutilización universal. Para $\beta$ se supondrá que un $60 \%$ del ancho de banda total disponible se reutiliza universalmente, de forma que no se degraden exageradamente las prestaciones globales del sistema y que dé margen para que se pueda apreciar alguna ganancia para los CEUs gracias a la porción de ancho de banda reutilizada con factor 3. Por su parte, para SFR se supondrá $\alpha=0,75$. 


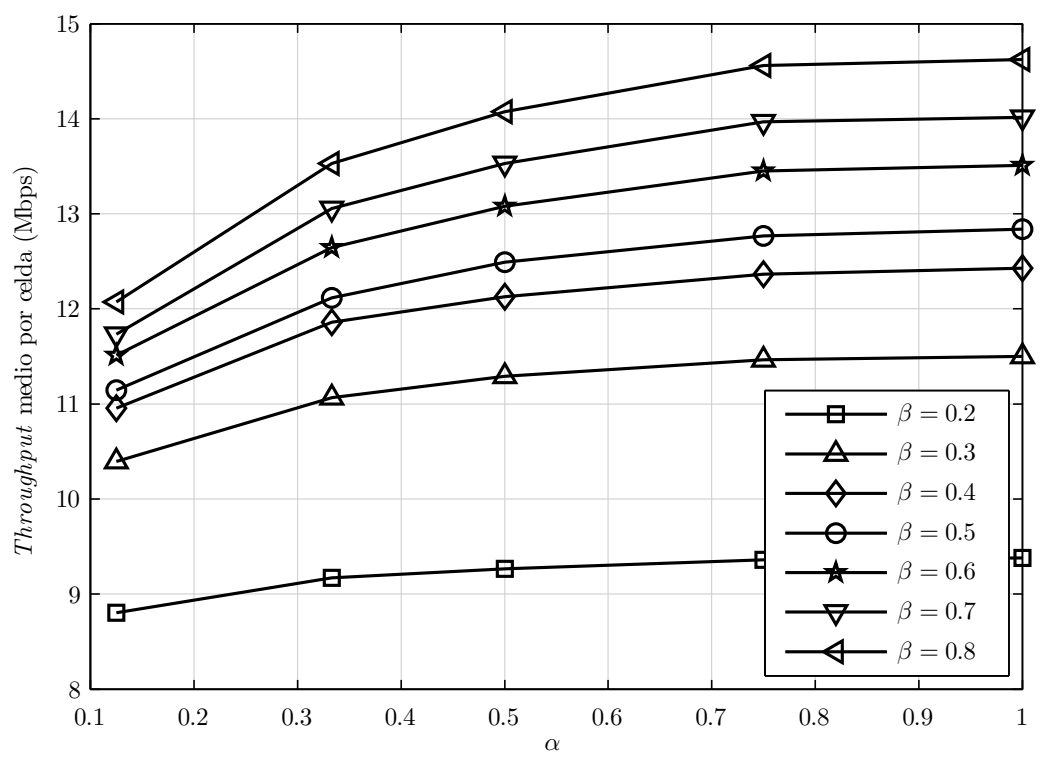

Figura 5.9: Throughput medio de celda para FFR y varios valores de $\alpha$ y $\beta$

\subsubsection{Distancia entre emplazamientos}

El barrido de la distancia entre emplazamientos se ha realizado entre $200 \mathrm{~m}$ y $1000 \mathrm{~m}$, a saltos de $100 \mathrm{~m}$. La figura 5.11 muestra la eficiencia espectral media del sistema en función de la distancia entre emplazamientos para los distintos mecanismos de reutilizacion de frecuencias considerados. Como es lógico, la eficiencia espectral media del sistema disminuye conforme más alejados están los emplazamientos entre sí debido a que los UEs cada vez están más alejados de los eNBs y, por tanto, disminuye la SINR experimentada por los mismos al recibir cada vez menos potencia de su serving cell.

No ocurre lo mismo en el caso del valor más bajo de distancia entre emplazamientos que se ha evaluado, donde se aprecia que la eficiencia espectral del sistema es menor que para algunos valores de distancia mayores. En esta ocasión, cuando las celdas están muy próximas entre sí, el alto nivel de interferencia degrada las prestaciones del sistema a pesar de tener usuarios más próximos a su serving cell.

En lo que respecta al throughput de los CEUs, que son los que deberían experimentar alguna ganancia por la utilización de algún mecanismo de reuti- 


\section{CAPÍTULO 5. OPTIMIZACIÓN DEL USO DEL ESPECTRO}

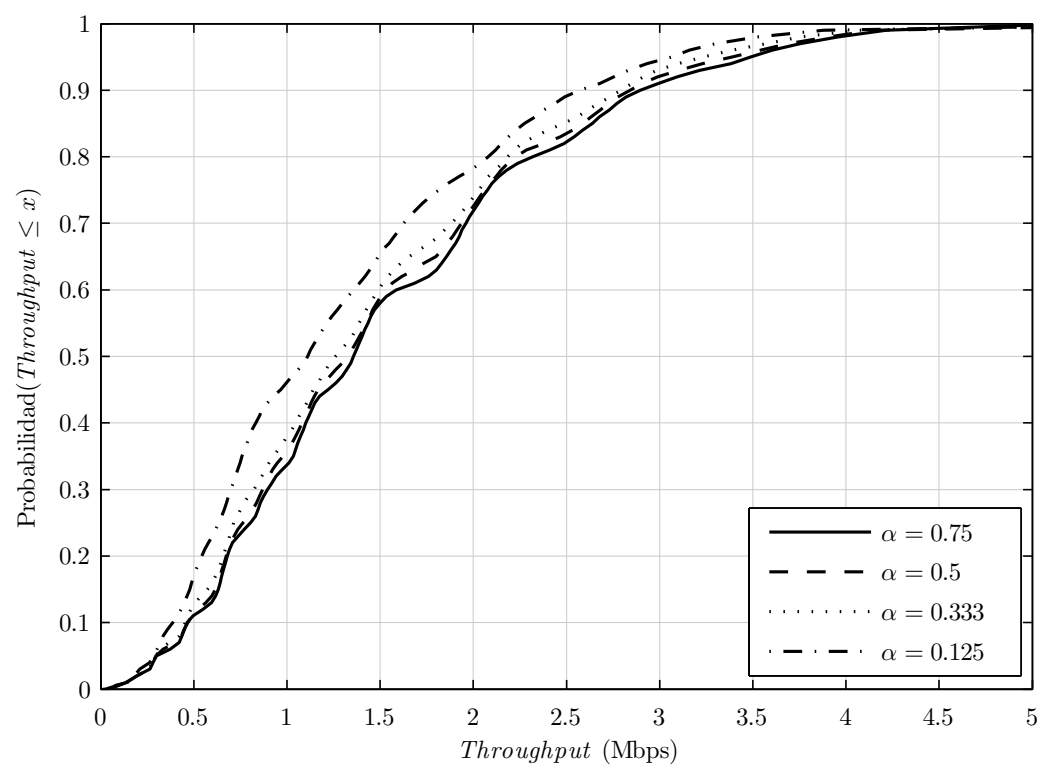

Figura 5.10: CDF del throughput de usuario para SFR y varios valores de $\alpha$

lización de frecuencias, se observa en la figura 5.12 que para distancias entre emplazamientos menores que 600 metros se obtiene una ligera ganancia en el caso de utilizar FFR respecto al caso de reutilización universal de frecuencias, la cual desaparece a partir de ese umbral. El SFR no consigue aportar mejora alguna para ninguno de los valores de distancia.

Por último, la figura 5.13 representa la equidad en el reparto de recursos para los distintos mecanismos de reutilización de frecuencias y todas las distancias entre emplazamientos evaluadas. Por un lado, se observa que el fairness disminuye conforme aumenta la distancia entre emplazamientos. Esto es debido a que cuanto más amplia es la zona de cobertura de una celda mayor diferencia habrá en términos de señal recibida entre los distintos usuarios al haber más diferencia entre los valores de distancia entre UE y eNB. Por otro lado, comparando los valores de fairness entre los distintos mecanismos, la reutilización de frecuencias de factor 3 es la que proporciona mayor equidad en el reparto de recursos, mientras que para las otras tres alternativas los valores son muy similares, siendo el FFR el segundo que mejor comportamiento tiene. 


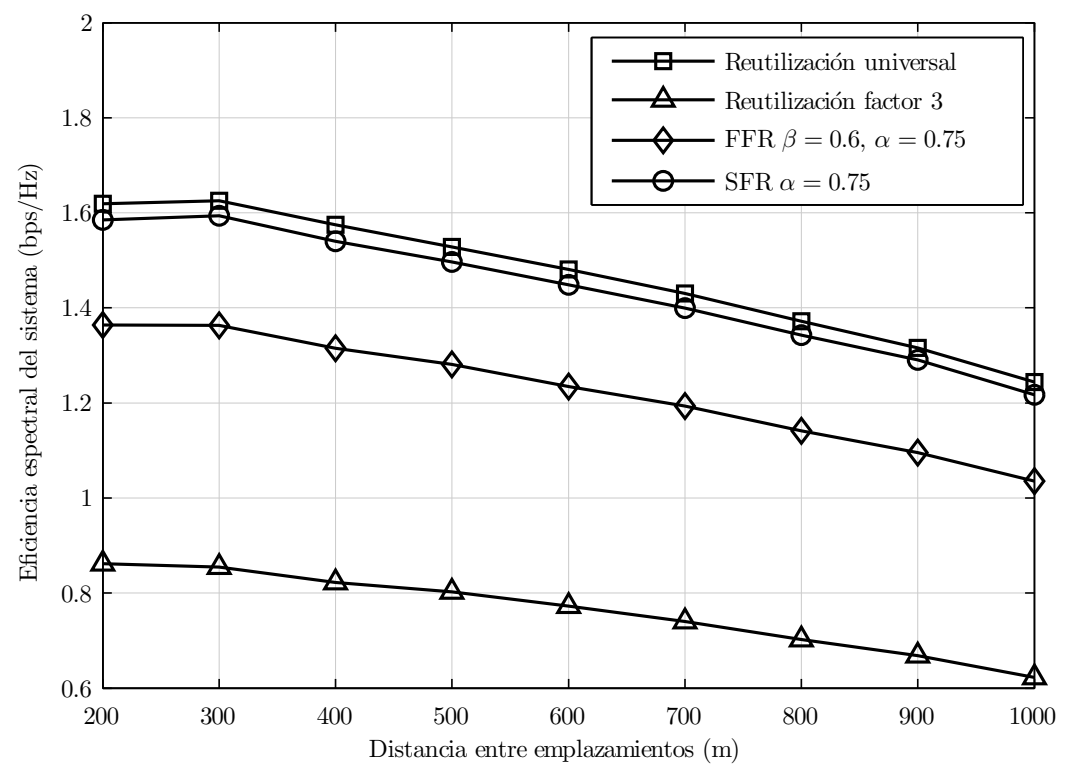

Figura 5.11: Eficiencia espectral del sistema para los distintos modos en función de la distancia entre emplazamientos

\subsubsection{Comparativa entre alternativas}

La figura 5.14 muestra la comparación de las CDFs del throughput medio de usuario obtenidas por las distintas alternativas de reutilización de frecuencias para valores concretos de los parámetros analizados anteriormente. Concretamente se fija una distancia entre emplazamientos de 500 metros, clasificación relativa de usuarios en FFR y SFR y se utilizan valores $\alpha=0,75$ y $\beta=0,6$ para FFR y $\alpha=0,75$ para SFR.

Como era de esperar, la reutilización de frecuencias de factor 3 proporciona cierta mejora en los resultados de los CEUs. Por el contrario, ninguna de las otras dos alternativas de reutilización de frecuencias distintas de la reutilización universal aporta una mejora respecto a la misma, al menos de forma apreciable. En la figura 5.15 se muestra de forma más clara que no se consigue una mejora palpable en el throughput de CEU ni para FFR ni para SFR. En cambio, sí se aprecia una degradación considerable de las prestaciones del sistema para el caso de FFR que no compensa la ligerísima ganancia que se produce en el throughput de CEU. 


\section{CAPÍTULO 5. OPTIMIZACIÓN DEL USO DEL ESPECTRO}

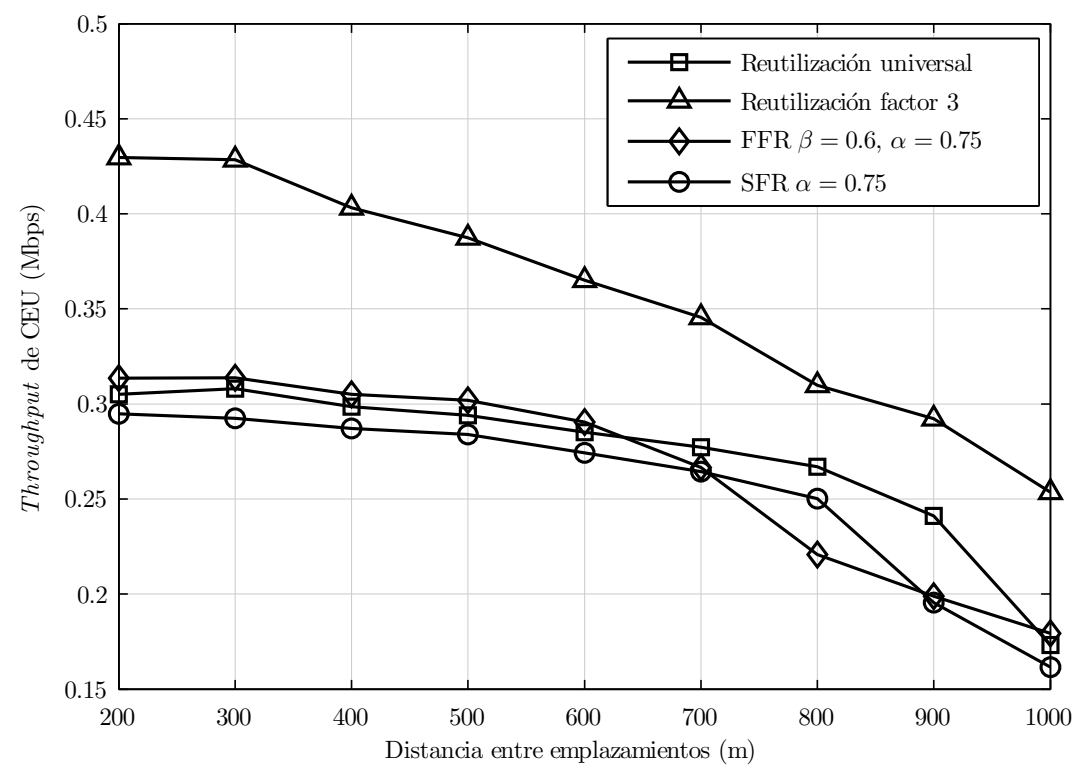

Figura 5.12: Throughput medio de usuario CEU para los distintos modos en función de la distancia entre emplazamientos

En lo que respecta al fairness, el reparto más equitativo de recursos se consigue reutilizando las frecuencias con factor 3. Sin embargo, esta prestación tan deseable viene acompañada de una tremenda degradación de la eficiencia espectral del sistema, haciendo perder toda posibilidad de ser considerado un mecanismo de reutilización de frecuencias viable en LTE. El resto de alternativas de reutilización de frecuencias presentan un fairness muy similar.

El buen comportamiento de la reutilización universal de frecuencias se atribuye a los mecanismos disponibles en LTE para combatir la interferencia intercelular. El soft combining realizado con las retransmisiones, el uso de schedulers que saquen provecho de las variaciones del canal en frecuencia para los distintos UEs y la modulacion y codificación adaptativas a las condiciones del canal entre eNB y UE parecen estar detrás de este resultado no esperado a priori.

A continuación se presentan los resultados de pruebas realizadas en determinadas condiciones extremas y sin alguna de las ayudas citadas para confirmar que son estos mecanismos disponibles en LTE los que provocan que no se observe ganancia alguna con la utilización de FFR y SFR. 


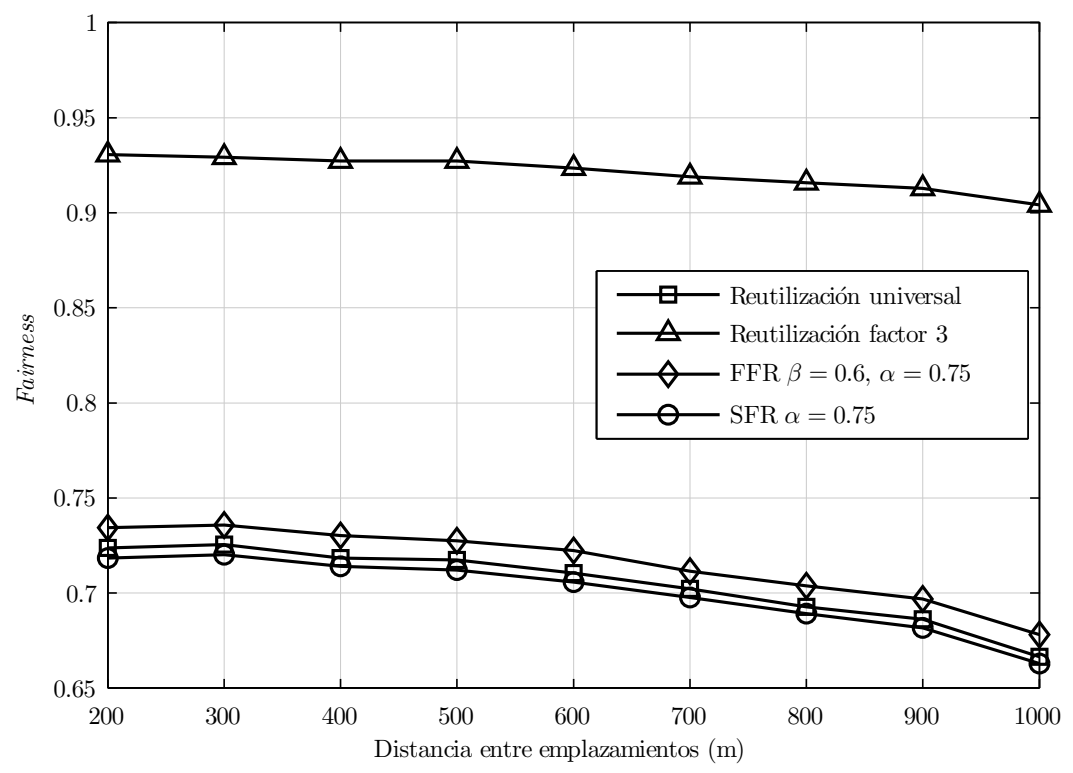

Figura 5.13: Fairness para los distintos modos en función de la distancia entre emplazamientos

\subsubsection{Condiciones extremas}

Con el fin de intentar magnificar las ganancias de los mecanismos de reutilización de frecuencias, a continuación se muestran los resultados de unas simulaciones realizadas en condiciones distintas a las anteriores, en las que se trata de reproducir un escenario en el que se aprecie alguna ganancia al utilizar una estrategia de reutilización de frecuencias distinta de reutilización universal con máscara de potencia plana.

El punto más diferenciador es la distribución no uniforme de usuarios y su concentración en el borde de las celdas. Se ha considerado un caso extremo de $50 \%$ de los usuarios a una distancia del eNB mayor del $85 \%$ del radio de la celda. Un ejemplo se muestra en la figura 5.16. Por otro lado, se elimina una de las herramientas mencionadas que actúa como protección frente a interferencias: el scheduling en el dominio de la frecuencia, de forma que no se puede seleccionar los mejores RBs a asignar a un usuario en un determinado TTI. Además, con el fin de observar lo que ocurre en un situación más realista, se ha sustituido el 


\section{CAPÍTULO 5. OPTIMIZACIÓN DEL USO DEL ESPECTRO}

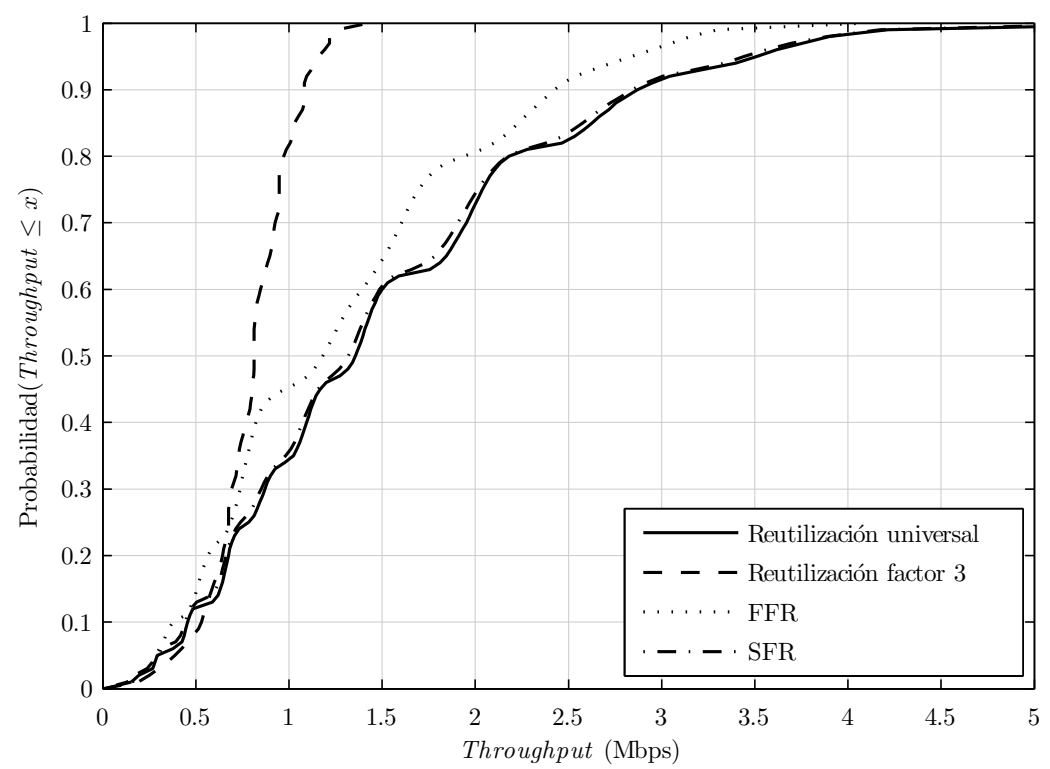

Figura 5.14: Comparación de la CDF del throughput de usuarios para los distintos métodos de reutilización de frecuencias

modelo de tráfico utilizado previamente, el full-buffer, por un modelo de tráfico web.

Respecto a los parámetros utilizados en las simulaciones anteriores, las simulaciones realizadas en condiciones extremas contemplan las variaciones mostradas en la tabla 5.4. El resto de parámetros, no mencionados en dicha tabla, mantienen sus valores previos.

A continuación se muestran los resultados obtenidos para este caso extremo con los dos tipos de scheduling considerados. Para el caso de utilizar PF, los resultados se recogen en la figura 5.17 donde se muestra la CDF del throughput medio de usuario, mientras que la figura 5.18 muestra un zoom para poder visualizar el valor en el percentil 5, considerado como el throughput medio de los usuarios del borde de la celda.

Se puede observar cómo el hecho de utilizar mecanismos de reutilización de frecuencias no aporta una ganancia apreciable. En la tabla 5.5 se muestran los valores medios obtenidos del throughput de celda y de usuario, donde se puede ver la reutilización universal de frecuencias sigue siendo la mejor opción. 


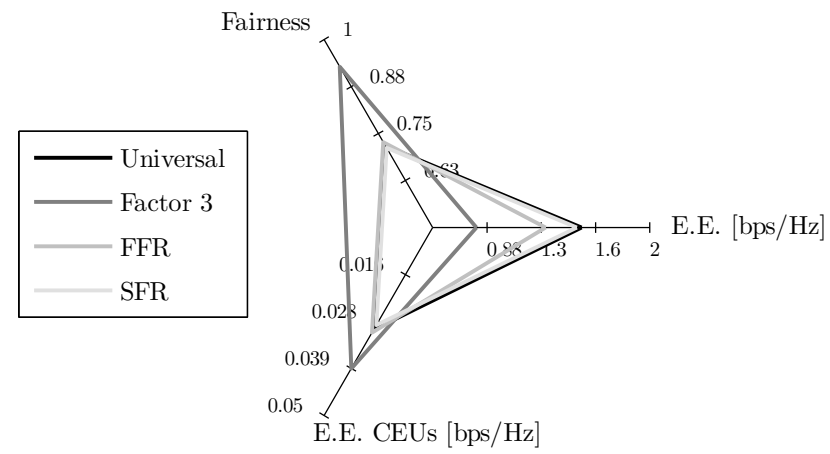

Figura 5.15: Comparación del fairness, eficiencia espectral del sistema y eficiencia espectral de CEUs para los distintos métodos de reutilización de frecuencias

Tabla 5.4: Parámetros alterados para las simulaciones de reutilización de frecuencias en condiciones extremas

\begin{tabular}{cc}
\hline Parámetro & Valor \\
\hline \hline $\mathrm{N}^{\circ}$ usuarios por celda & 100 \\
Distribución de usuarios & $50 \%$ en el borde, $50 \%$ uniforme \\
Frecuencia central & $2 \mathrm{GHz}$ \\
Ancho de banda & $3 \times 1,4 \mathrm{MHz}$ \\
$\mathrm{N}^{\circ}$ RBs & 18 \\
Potencia de celda & $38,57 \mathrm{dBm}$ \\
Modelo de tráfico & Web $(50$ sesiones $/ \mathrm{s} /$ celda $)$ \\
Algoritmo de scheduling & $\mathrm{RR} / \mathrm{PF}$ \\
$\mathrm{N}^{\circ}$ seeds & 20 \\
\hline
\end{tabular}

Por otro lado, se observa que la reutilización de frecuencias de factor 3 deja de presentar una mejora en lo que respecta al throughput medio de CEU y tan sólo muestra ganancia respecto a la reutilización universal de frecuencias en una baja proporción de los usuarios. 


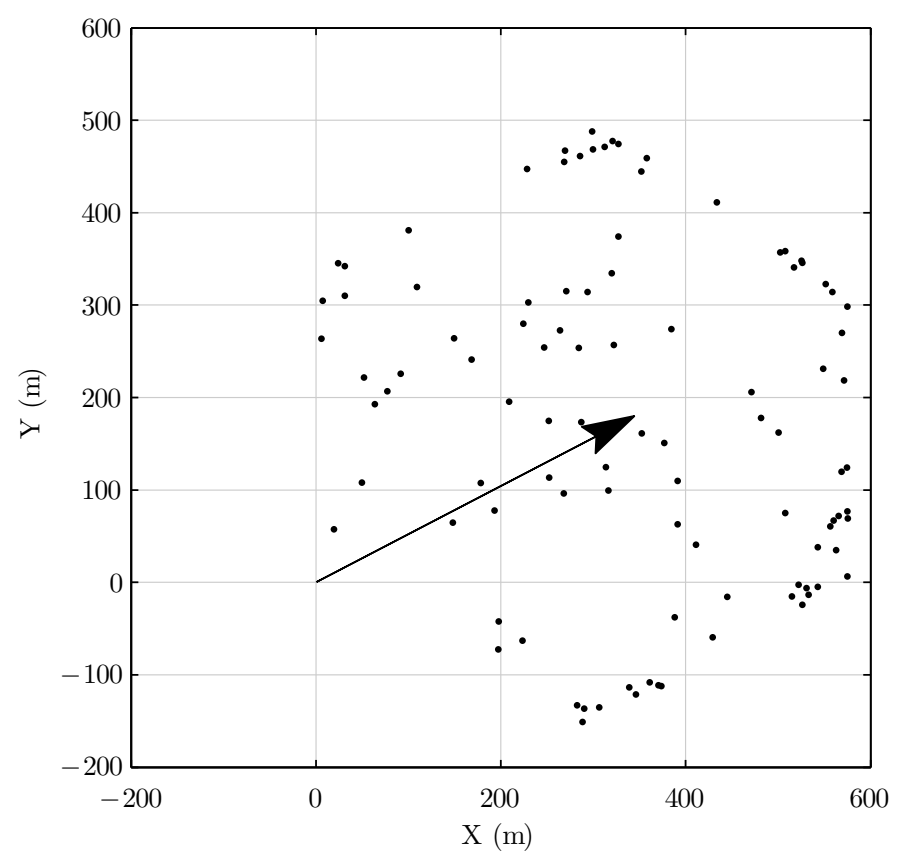

Figura 5.16: Distribución de usuarios no uniforme en el caso extremo de concentración del $50 \%$ en el borde de la celda

Tabla 5.5: Resumen de valores medios para el caso extremo y scheduling PF

\begin{tabular}{ccccc}
\hline & Universal & Factor 3 & FFR & SFR \\
\hline \hline Throughput de celda (Mbps) & 10,11 & 4,14 & 9,55 & 10,04 \\
Throughput de usuario (kbps) & 215,98 & 70,74 & 196,43 & 215,81 \\
Throughput de CEU (kbps) & 67,26 & 56,39 & 71,28 & 66,57 \\
\hline
\end{tabular}

En el caso de utilizar scheduling RR los resultados son ligeramente distintos. De forma análoga tenemos, las figuras 5.19 y 5.20 y el resumen de resultados medios en la tabla 5.6. En esta ocasión sí se aprecia una ganancia significativa tanto en el throughput de los usuarios de borde como en el throughput medio de celda y de usuario, conforme se esperaba al forzar la concentración de usuarios en el borde de la celda. 


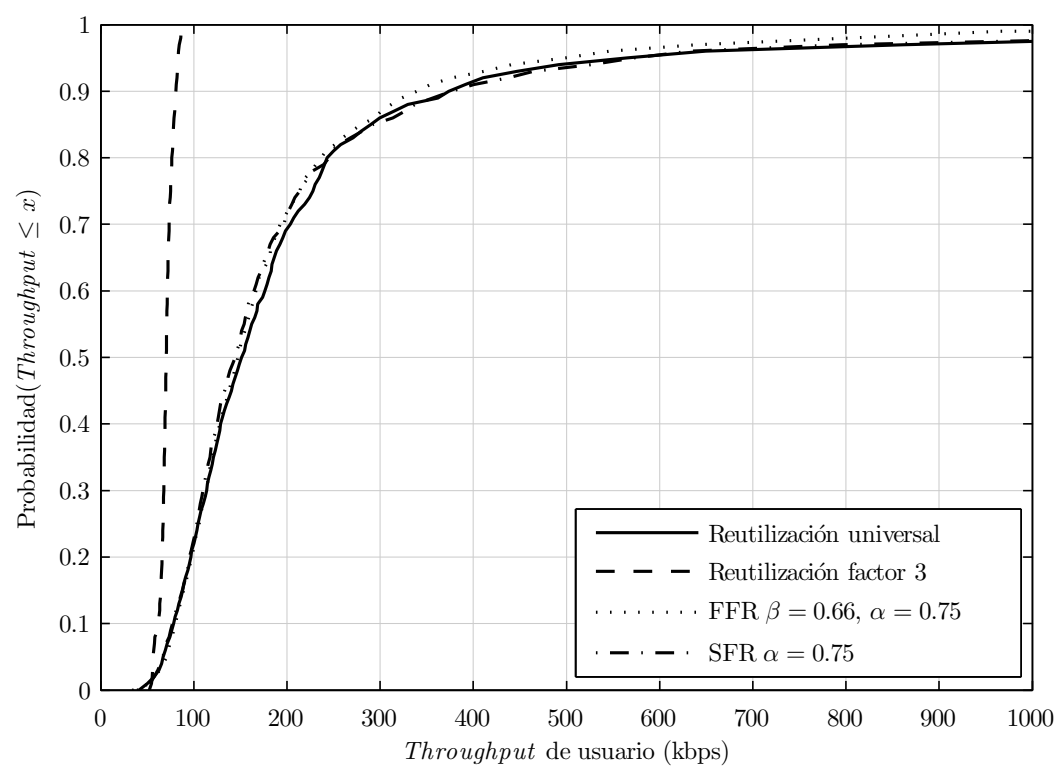

Figura 5.17: CDF del throughput de usuario para distintos modos de reutilización de frecuencias en el caso extremo planteado y scheduling $\mathrm{PF}$

Tabla 5.6: Resumen de valores medios para el caso extremo y scheduling RR

\begin{tabular}{ccccc}
\hline & Universal & Factor 3 & FFR & SFR \\
\hline \hline Throughput de celda (Mbps) & 9,07 & 4,15 & 9,32 & 10,17 \\
Throughput de usuario (kbps) & 196,15 & 74,00 & 185,34 & 221,91 \\
Throughput de CEU (kbps) & 68,69 & 60,77 & 70,17 & 73,33 \\
\hline
\end{tabular}

\subsubsection{Conclusiones}

El hecho de no observar ganancia alguna en la reutilización de frecuencias en algunos casos es coherente con el resultado conseguido en el barrido del parámetro $\alpha$, donde se obtenía que la mejor configuración era la que menos diferencia tenía con respecto al esquema de reutilización universal de frecuencias con mascara de potencias plana.

No resulta rentable ninguna alternativa de las analizadas respecto al caso de reutilizar todas las frecuencias en todas las celdas. Tanto por los resultados 


\section{CAPÍTULO 5. OPTIMIZACIÓN DEL USO DEL ESPECTRO}



Figura 5.18: Zoom de la CDF del throughput de usuario para distintos modos de reutilización de frecuencias en el caso extremo planteado y scheduling PF

que se han obtenido, donde la ganancia en cell-edge, si existe, es muy escasa, como por la complejidad que introduciría en la planificación, la cual no se vería recompensada por una mejora en las prestaciones de la red.

El sistema LTE demuestra tener una gran resistencia a las interferencias que se producen por la reutilización universal de las bandas de frecuencia disponibles. La posibilidad de realizar scheduling en el dominio de la frecuencia permite al eNB, dependiendo de la política seguida, seleccionar los recursos que mejor rendimiento van a proporcionar a cada usuario, como sucede en el caso de utilizar un scheduler de tipo Proportional Fair. Los esquemas de modulación y codificación adaptativos según las condiciones del canal, junto con el HARQ y el soft combining permite una protección extra del sistema frente a interferencias. Esto favorece que los usuarios del borde de la celda experimenten un rendimiento por parte de la red muy similar al caso de implementar algún tipo de reutilización de frecuencias de bajo orden, como por ejemplo reutilización de factor 3 .

Se concluye, pues, que la mejor estrategia en los procesos de planificación de una red LTE es no realizar planificación de frecuencias alguna y reutilizar 


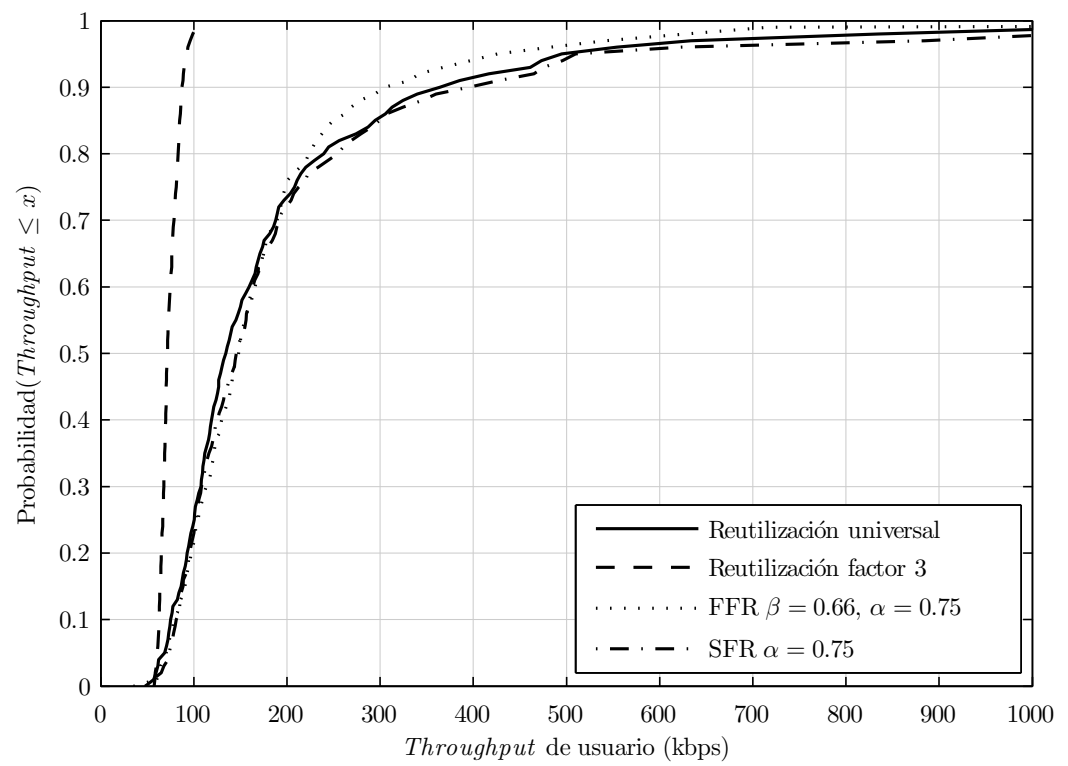

Figura 5.19: CDF del throughput de usuario para distintos modos de reutilización de frecuencias en el caso extremo planteado y scheduling RR

universalmente el ancho de banda disponible. Únicamente será recomendable utilizar mecanismos como FFR y SFR si los esquemas antes mencionados, es decir, scheduling inteligente, HARQ y adaptación al canal, no estuvieran disponibles.

\subsection{Refarming}

\subsubsection{Introducción}

Durante las primeras fases de despliegue de la tecnología LTE, existe la posibilidad de que la nueva red se implante utilizando parte de las frecuencias que actualmente utilizan los sistemas GSM y UMTS. Esto es debido a la actual indisponibilidad de bandas de frecuencia específicas para esta tecnología, como puede comprobarse en la lista de concesiones para telefonía móvil disponible en [92], donde sólo aparecen concesiones de ámbito autonómico en la banda de 2600 $\mathrm{MHz}$, la banda específica de LTE, para operadores de cable. En los próximos meses se concederán licencias para operar en la banda de $2600 \mathrm{MHz}$ a la que se 


\section{CAPÍTULO 5. OPTIMIZACIÓN DEL USO DEL ESPECTRO}

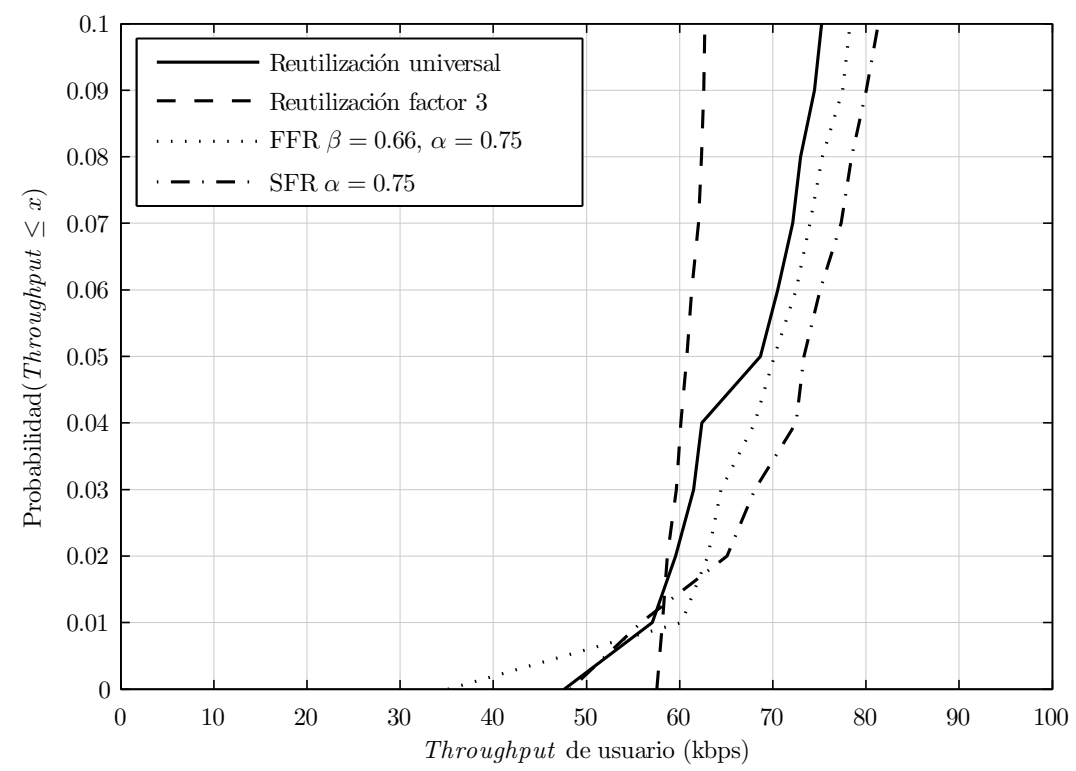

Figura 5.20: Zoom de la CDF del throughput de usuario para distintos modos de reutilización de frecuencias en el caso extremo planteado y scheduling RR

sumará la banda de $800 \mathrm{MHz}$ del dividendo digital a partir del año 2015. Sin embargo, mientras tanto los operadores podrán ir migrando gradualmente sus estaciones base de tecnologías predecesoras a la nueva tecnología, sin dejar de garantizar suficientes recursos en las redes GSM y UMTS, con el fin de ampliar la capacidad de sus redes de acuerdo a la creciente demanda de tráfico, ya sea como complemento o alternativa a un despliegue en la banda propia de LTE.

Aunque no se prevé comenzar la implantación de LTE sobre la banda de UMTS, sí es previsible que tarde o temprano comiencen a migrarse celdas de GSM a LTE. Se hace pues necesario el estudio de la coexistencia de la nueva tecnología con las redes pre-existentes, para garantizar que su introducción no produzca una degradación de las prestaciones, tanto de las redes móviles activas como de la nueva red que se pretende desplegar.

La migración tecnológica debe realizarse de forma que LTE opere en portadoras diferentes a las de estaciones base GSM y UMTS existentes, con el fin de que se eviten interferencias inter-sistema inaceptables. Lo mismo ocurre con las portadoras dedicadas al enlace ascendente, para las transmisiones desde el equipo de usuario a la estación base. Para conseguir ese objetivo, será necesaria 
una reestructuración de los recursos en frecuencia, conocido con el término refarming, de forma que parte del ancho de banda de una o varias redes existentes sea cedido para su uso exclusivo por parte de la nueva red LTE.

Como se ha comentado antes, por el momento los operadores móviles únicamente contemplan la posibilidad de coger prestados recursos en frecuencia de sus redes GSM, al ser la tecnología más antigua y a la que mejor margen de mejora se le puede sacar con el cambio. Por esta razón, el trabajo desarrollado a continuación se centra en el caso de coexistencia de LTE con GSM.

La utilización de las diferentes bandas de frecuencia por parte de las distintas tecnologías móviles celulares, y de igual forma los procesos de refarming, vienen reglamentados por la Unión Europea y, por extensión, por los gobiernos de cada país miembro.

En el caso concreto de España, de acuerdo con la Decisión 2009/766/CE, el Ministerio de Industria, Turismo y Comercio aprobó la Orden Ministerial ITC/332/2010 en la que se publicaba el nuevo Cuadro Nacional de Atribución de Frecuencias. En él se reflejaba la apertura de la banda de $900 \mathrm{MHz}$ para su utilización por parte de la tecnología UMTS, dejando de estar autorizada para uso exclusivo por parte de la tecnología GSM.

Este primer paso hacia el uso flexible de bandas de frecuencia aprobado por el Gobierno abrió la veda para que los operadores y fabricantes puedan explotar al máximo esta posibilidad con el fin de mejorar los servicios que ofrecen.

Tras el análisis realizado en [93] se concluye que la ganancia es significativa en el caso de refarming de GSM a UMTS en la banda de $900 \mathrm{MHz}$. Sin embargo, lo que no queda claro es que la apertura de esta posibilidad no perjudique a los operadores que no tengan frecuencias asignadas en esta banda. A pesar de ello, como se ha indicado anteriormente, el uso de dicha banda por la tecnología UMTS acabó aprobándose. Sobre el refarming de GSM a UMTS en la banda de $1800 \mathrm{MHz}$, no se da tal situación de enfrentamiento entre operadores pues no se aprecia un ventaja significativa en el uso de la banda de $1800 \mathrm{MHz}$ en lugar de la de $2100 \mathrm{MHz}$ en relación a las condiciones de propagación, ya que éstas son muy similares en ambas bandas. Con la introducción de LTE volverá a plantearse el problema y surgirán de nuevo opiniones enfrentadas respecto al refarming de la banda de $1800 \mathrm{MHz}$, en este caso de GSM (o UMTS si ya hubo un refarming previo) a LTE, ya que sí existen diferencias sustanciales en las condiciones de propagación respecto a la banda propia de LTE en $2600 \mathrm{MHz}$.

El despliegue de LTE en la banda de $1800 \mathrm{MHz}$ tiene sus ventajas e inconvenientes, los cuales se enumeran a continuación.

$\oplus$ Alcance sustancialmente mayor que en la banda de $2600 \mathrm{MHz}$. Este hecho puede suponer un ahorro económico muy interesante para los operadores, 


\section{CAPÍTULO 5. OPTIMIZACIÓN DEL USO DEL ESPECTRO}

sobre todo en entornos rurales donde la capacidad requerida de la red normalmente no condiciona una densidad alta de eNBs.

$\oplus$ Aumento del ancho de banda total disponible para LTE. Esto permitirá aumentar el throughput de usuario con el consiguiente aumento de la Quality of Experience (QoE).

๑ Posibilidad de reutilizar antenas de UMTS 2100 MHz y GSM 1800 MHz.

๑ Posibilidad de desarrollar Base station Transceiver Subsystems (BTSs) Multi-RAB con GSM y LTE con el consiguiente beneficio para los fabricantes de equipo y para los operadores por el coste reducido y uniformidad de equipamiento.

$\ominus$ Generación de interferencias inter-sistema. La ejecución incorrecta o incompleta del proceso de refarming de frecuencias de GSM a LTE puede producir una degradación del servicio ofrecido en ambos sistemas.

$\ominus$ Reducción de la calidad de servicio de los usuarios con terminales GSM. Esto es debido a la reducción del ancho de banda disponible para dicha tecnología, si bien la mejora de la tecnología de la red debería incentivar por sí misma la renovación de los terminales por parte de los usuarios, compensando este efecto.

\subsubsection{Resultados y Discusión}

En esta sección se describe un ejemplo de caso de refarming de GSM a LTE. En este caso de uso se dispone de $10 \mathrm{MHz}$ en la banda de $1800 \mathrm{MHz}$ de GSM y se quieren evaluar las prestaciones de distintas posibilidades de refarming. Las diferentes alternativas que se contemplan son las mostradas en la tabla 5.7.

Tabla 5.7: Distintas posibilidades de refarming contempladas

\begin{tabular}{ccc}
\hline Caso & Recursos en GSM & Recursos en LTE \\
\hline \hline Todo GSM & 49 portadoras & N.A. \\
$1,4 \mathrm{LTE}$ & 42 portadoras & $1,4 \mathrm{MHz}(6 \mathrm{RBs})$ \\
$5 \mathrm{LTE}$ & 24 portadoras & $5 \mathrm{MHz}(25 \mathrm{RBs})$ \\
Todo LTE & N.A. & $10 \mathrm{MHz}(50 \mathrm{RBs})$ \\
\hline
\end{tabular}

En este estudio se supuso caso coordinado - los emplazamientos para los eNBs del nuevo sistema LTE coinciden con emplazamientos de BTSs GSMque requiere menos banda de guarda entre sistemas al haber menos diferencia 
entre las potencias recibidas de ambos sistemas para la misma ubicación donde se mida.

Los parámetros más relevantes de las simulaciones realizadas se muestran en la tabla 5.8 (parámetros comunes), en la tabla 5.9 (parámetros de las simulaciones GSM) y en la tabla 5.10 (parámetros de las simulaciones LTE).

Tabla 5.8: Parámetros comunes de simulación

\begin{tabular}{|c|c|}
\hline Parámetro & Valor \\
\hline Escenario & 21 celdas omnidireccionales \\
\hline Distancia entre emplazamientos & $500 \mathrm{~m}$ \\
\hline Banda & $1800 \mathrm{MHz}$ \\
\hline Ganancia de antena & BS: $14 \mathrm{dBi}, \mathrm{UE}: 0 \mathrm{dBi}$ \\
\hline Modelo pérdidas de propagación & Okumura-hata \\
\hline Modelos de tráfico & Full-buffer, WWW \\
\hline $\mathrm{N}^{\mathrm{o}}$ de usuarios & 16 por celda $(\mathrm{GSM}+\mathrm{LTE})$ \\
\hline Movilidad & UEs estáticos \\
\hline
\end{tabular}

Tabla 5.9: Parámetros de simulación de GSM

\begin{tabular}{cc}
\hline Parámetro & Valor \\
\hline \hline $\mathrm{N}^{\circ}$ máx. de TS por usuario & 8 \\
Potencia por TRX & $30 \mathrm{dBm}$ \\
Potencia de ruido térmico por TRX & $-121 \mathrm{dBm}$ \\
Algoritmo de scheduling & FCFS \\
Factor de reutilización de frecuencias & 3 \\
\hline
\end{tabular}

Tabla 5.10: Parámetros de simulación de LTE

\begin{tabular}{cc}
\hline Parámetro & Valor \\
\hline \hline $\mathrm{N}^{\mathrm{o}}$ máx. de retransmisiones & 3 \\
Configuración de antena & MIMO $1 \mathrm{x} 2$ \\
Potencia por RB & $26 \mathrm{dBm}$ \\
Potencia de ruido térmico por RB & $-121 \mathrm{dBm}$ \\
Algoritmo de scheduling & $\mathrm{PF}$ \\
Factor de reutilización de frecuencias & 1 (reutilización universal) \\
\hline
\end{tabular}




\section{CAPÍTULO 5. OPTIMIZACIÓN DEL USO DEL ESPECTRO}

En LTE se supuso reutilización universal de las frecuencias en todos los eNB mientras que en GSM se aplicó un factor 3 de reutilización de frecuencias. Del análisis en detalle realizado en la sección 5.1 respecto a la reutilización de frecuencias se concluyó que la reutilización de todas las frecuencias disponibles en todas las celdas LTE proporciona buenas prestaciones gracias a los distintos mecanismos de protección frente a interferencias y errores.

Se han realizado simulaciones contemplando dos modelos de tráfico distintos. Por un lado se realizaron simulaciones con tráfico full-buffer que permiten obtener resultados de eficiencia espectral de cada sistema. Por otro lado, se ejecutaron simulaciones con tráfico web que permiten obtener resultados vinculados directamente con la experiencia de usuario como es el retardo en la recepción de los datos. De esta manera, las métricas monitorizadas son el tráfico medio por celda (Mbps) y el retardo medio normalizado $(\mathrm{ms} / \mathrm{kb})$.

Conviene aclarar también que el número de usuarios se mantuvo constante para cada caso contemplado. Es decir, para cada emplazamiento la suma de usuarios de las celdas de GSM y de LTE siempre será la misma.

En la figura 5.21 se muestran las CDFs del throughput medio por celda para las distintas tecnologías en los diferentes casos. Aquí se aprecia claramente la gran ganancia conseguida con la migración de GSM a LTE. Para observar algunos valores en detalle, la tabla 5.11 muestra los valores medios de throughput por celda.

Tabla 5.11: Throughput medio por celda

\begin{tabular}{ccc}
\hline Caso & Throughput GSM (Mbps) & Throughput LTE (Mbps) \\
\hline \hline Todo GSM & 1,286 & N.A. \\
1,4 LTE & 1,201 & 1,363 \\
5 LTE & 0,687 & 5,722 \\
Todo LTE & N.A. & 11,793 \\
\hline
\end{tabular}

A la vista de los resultados, la elección de un caso u otro de entre todas las posibilidades analizadas dependerá de las estimaciones de tráfico GSM que se hagan y de la previsión de la evolución del mismo. Además, la flexibilidad espectral de LTE permite comenzar el despliegue con anchos de banda de 1,4, 3 o $5 \mathrm{MHz}$, para posteriormente introducir anchos de banda mayores cuando el tráfico GSM haya disminuido en la evolución natural del sistema y tras la migración de los usuarios hacia la nueva tecnología. 


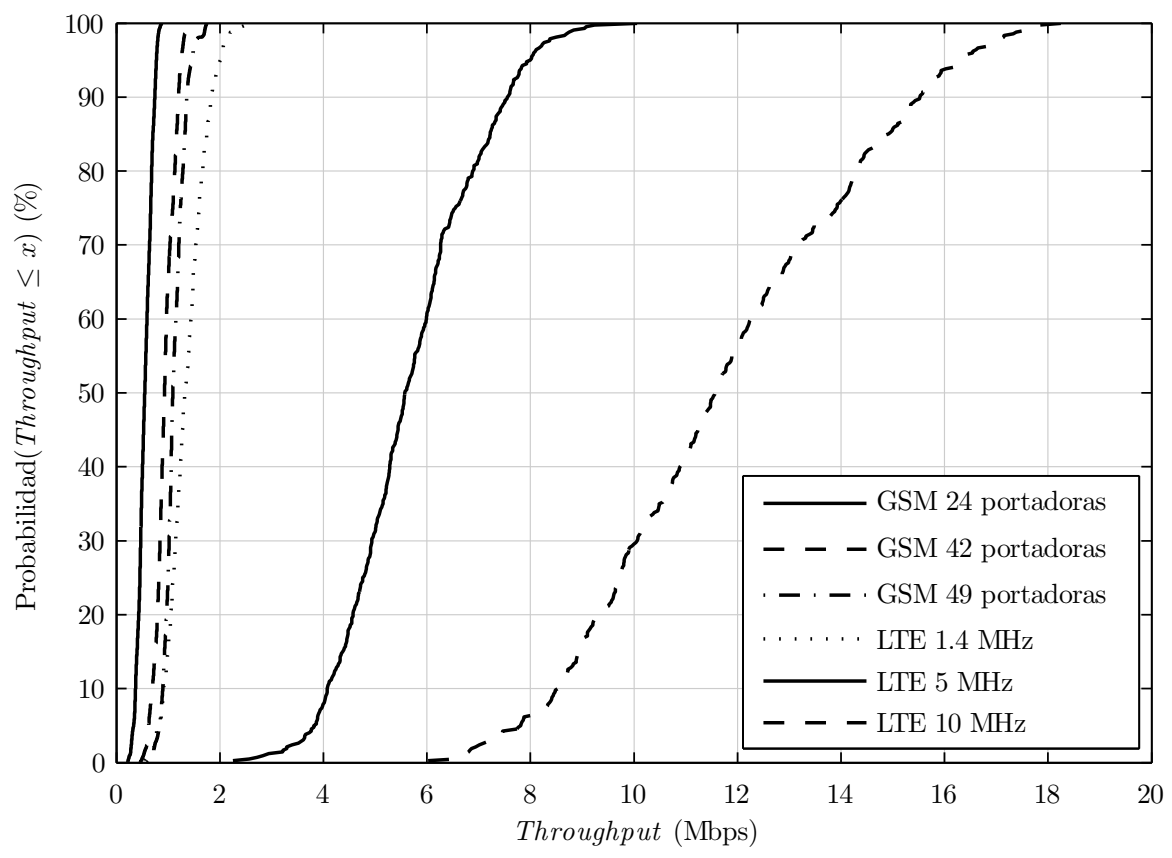

Figura 5.21: CDF del Throughput medio por celda para GSM y LTE en los casos de refarming contemplados

\subsection{Planificación Automática de Frecuencias}

Una vez realizada la reestructuración de recursos a través del refarming, es probable que la distribución de frecuencias en la red no sea la más adecuada. El hecho de haber eliminado frecuencias de una red existente puede haber dejado desequilibrios entre los recursos disponibles y la demanda de tráfico en dicha red. Estos desequilibrios, que dependen de la planificación de frecuencias original y de las características del refarming, obligan a rellenar los huecos de cobertura creados con frecuencias que ahora introducirán mayores interferencias.

Por todo esto, será necesario realizar una replanificación de frecuencias tras el refarming con el objetivo de minimizar las interferencias creadas con la redistribución de recursos. A continuación se proporcionan detalles sobre la implementación de procesos de planificación automática de frecuencias para el caso concreto de refarming sobre GSM. 


\section{CAPÍTULO 5. OPTIMIZACIÓN DEL USO DEL ESPECTRO}

\subsubsection{Restricciones del Problema}

El estándar de GSM define unos niveles de interferencia de referencia [94] para los cuales se cumplen los requisitos de calidad establecidos. Se contempla tanto el caso de interferencia co-canal - celda interferente e interferida operando en el mismo canal de $200 \mathrm{kHz}$ - como el de interferencia de canal adyacente - celda interferente e interferida operando en canales adyacentes - incluyendo los casos con varios canales de separación. Según estos niveles de interferencia de referencia, y centrando la atención en las dos contribuciones de interferencia más importantes que son la interferencia co-canal y la de canal adyacente de primer orden, por un lado habrá demasiada interferencia co-canal entre dos celdas en un punto si la diferencia de potencia recibida entre la serving cell y la interferente es inferior a $9 \mathrm{~dB}$, es decir, $R x \operatorname{Lev}_{S C}-R x L e v_{I}<9 \mathrm{~dB}$. Por otro lado, habrá demasiada interferencia de canal adyacente si la potencia recibida de la celda interferente supera en más de $9 \mathrm{~dB}$ la potencia de la serving cell, es decir, $R x L e v_{S C}-R x L e v_{I}>-9 \mathrm{~dB}$. En la práctica se suelen establecer restricciones de interferencias más exigentes que las definidas por estos niveles de interferencia de referencia [95].

Adicionalmente, se pueden imponer otras restricciones a la hora de de realizar la planificación de frecuencias, estando éstas relacionadas con la separación mínima entre canales Traffic Channel (TCH) y Broadcast Control Channel $(\mathrm{BCCH})$ para celdas en las que exista posibilidad de que se realice un hand-over entre ellas y entre TRXs del mismo emplazamiento o de la misma celda [96]. La tabla 5.12 refleja todas estas restricciones extra.

Tabla 5.12: Restricciones de separación de canales.

\begin{tabular}{|l|l|c|c|}
\cline { 3 - 4 } \multicolumn{2}{c|}{} & BCCH & TCH \\
\hline \multirow{3}{*}{ BCCH } & Misma celda & 3 & 3 \\
\cline { 2 - 4 } & Mismo emplazamiento & 2 & 2 \\
\cline { 2 - 4 } & Vecina & 2 & 1 \\
\hline \multirow{3}{*}{ TCH } & Misma celda & 3 & 3 \\
\cline { 2 - 4 } & Mismo emplazamiento & 2 & 2 \\
\cline { 2 - 4 } & Vecina & 2 & 1 \\
\hline
\end{tabular}

\subsubsection{Fases del Proceso}

El proceso automático de planificación de frecuencias consta de cuatro fases: definición de escenario y restricciones, cálculo de matriz de interferencias, búsqueda de solución de planificación de frecuencias y planificación de Base Station Identity Codes (BSICs). A continuación se describe cada una de ellas. 


\subsubsection{Definición de escenario y restricciones}

El primer paso en el proceso de planificación de frecuencias es definir el escenario bajo estudio, concretar las frecuencias disponibles, las celdas en las que está permitido el cambio de la frecuencia que utilizan actualmente y el número de frecuencias a asignar en cada celda. Además, es necesario recopilar todos los datos necesarios para poder realizar las fases siguientes, como la topología de la red - posición de las celdas, parámetros y configuración de las antenas-, potencia de transmisión, número de Transceivers (TRXs), frecuencias actuales asignadas y listas de vecinas.

Además, se definen en esta primera fase la lista de restricciones a cumplir con la asignación de frecuencias, como las de la tabla 5.12, y se fijan los umbrales para determinar cuando una celda co-canal o de canal adyacente a otra celda está produciendo interferencias en una determinada ubicación del escenario. Concretando posibles valores, es habitual fijar un umbral de $12 \mathrm{~dB}$ - en lugar de $9 \mathrm{~dB}$ que especifica el estándar - para la interferencia co-canal y de $-3 \mathrm{~dB}$ - en lugar de -9 dB que especifica el estándar - para la interferencia de canal adyacente.

\subsubsection{Cálculo de matriz de interferencias}

Para el cálculo de la matriz de interferencias que determinará las posibles asignaciones de frecuencias a las distintas celdas, será necesario utilizar el simulador estático descrito en la sección 2.2. Se obtendrá el mapa de señal de cada una de las celdas calculando el nivel de solape en cuanto a co-canalidad y adyacencia entre pares de celdas, según los umbrales fijados en la primera fase. Precisamente ese nivel de solape será el valor que se almacene en la matriz de interferencias.

La matriz de interferencias es cuadrada y tiene tantas filas y columnas como celdas tenga el escenario bajo estudio, tengan o no posibilidad de cambiar su frecuencia actual. Eso es así porque, aunque no puedan sufrir un cambio de frecuencia, sí afectan a las posibles frecuencias asignables del resto de celdas. La matriz de interferencias será una matriz dispersa que sólo tendrá valores en las posiciones donde fila y columna corresponden a sendas celdas que tienen relación de vecindad o comparten emplazamiento. El valor almacenado en cada posición corresponderá al área de solape entre las áreas de influencia de ambas celdas donde se sobrepasen los umbrales de co-canalidad y adyacencia fijados. Como sobre el escenario se habrá definido una rejilla de casillas sobre la que se calculen los mapas de señal de las celdas, el área de solape se calculará como el número de casillas en las que hay solape dividido por el número de casillas que cubre el área de influencia de la celda correspondiente a la fila. El área de influencia de una celda se define como el conjunto de casillas donde se recibe de 


\section{CAPÍTULO 5. OPTIMIZACIÓN DEL USO DEL ESPECTRO}

dicha celda un nivel de señal superior a un determinado umbral, normalmente el umbral de sensibilidad del UE.

En realidad, el proceso trabajará con varias matrices de interferencias independientes: una para las relaciones de co-canalidad y el resto para las de adyacencia, según los niveles de separación que se contemplen. En este caso, las restricciones impuestas definen separaciones de hasta tres canales, por lo que se necesitarán tres matrices de adyacencia. En las posiciones de las matrices de interferencia que correspondan a relaciones entre celdas que incumplan las restricciones de separación impuestas (tabla 5.12) se almacenará un valor muy alto de forma que se penalice el incumplimiento de las restricciones. El valor asignado para cada caso de restricción incumplida podrá ajustarse para dar prioridad al cumplimiento de unas restricciones sobre otras.

La matriz de co-canalidad, dado que el umbral fijado es más estricto para la diferencia de señal entre la serving cell y la celda interferente, reflejará áreas de solape mayores que la matriz de adyacencia para el mismo par de celdas. Las matrices de interferencia servirán para evaluar el grado de cumplimiento de las restricciones impuestas, dada una cierta asignación de frecuencias, con la simple suma de los elementos correspondientes a las relaciones de co-canalidad y adyacencia entre celdas que aparezcan debido a esa asignación.

\subsubsection{Búsqueda de la solución de planificación de frecuencias}

La planificación de frecuencias es un problema de optimización combinatoria para el que se puede utilizar una heurística de búsqueda como SA, tal y como se propuso para el problema de planificación y optimización de redes móviles en la sección 4.3.

Aunque la selección de celda a modificar se realice de forma aleatoria, una técnica que puede ayudar a encontrar mejores soluciones consiste en proporcionar mayor probabilidad de selección a las celdas que más dificultades puedan tener a la hora de encontrar una frecuencia adecuada, pre-procesando la matriz de interferencias calculada en la fase anterior para confeccionar una lista ordenada de celdas.

La función de coste objetivo a minimizar mediante SA procesará las matrices de interferencia según la asignación de frecuencias de la iteración actual. Concretamente, se sumarán los valores almacenados en dichas matrices en las posiciones donde se cumplan las relaciones de co-canalidad y adyacencia correspondientes a dicha asignación.

Es posible que la solución final, aunque realmente consiga alcanzar el mínimo absoluto de la función de coste, no cumpla todas las restricciones establecidas. La correcta configuración de los valores almacenados en las matrices 
de interferencia para los casos de incumplimiento de restricciones permitirá obtener la mejor solución posible dentro de las posibilidades existentes.

A continuación se muestra un ejemplo de resultados de un caso real de replanificación de frecuencias, cortesía de la empresa Ingenia Telecom S.L. En las siguientes figuras los mapas de colores superpuestos sobre el escenario bajo estudio reflejan los distintos niveles de $C / I$ - relación de la potencia media de señal portadora respecto a potencia media de interferencia co-canal- medidos sobre canales TCH en cada punto del escenario. En la leyenda utilizada en dichas figuras, el color rojo indica baja $C / I$ mientras que el color azul indica alta $C / I$.

En este caso concreto de planificación de frecuencias se han limitado las posibilidades de cambio a las celdas de las zonas donde se tiene un nivel deficiente de $C / I$. Estas zonas se pueden apreciar claramente en las figura 5.22. Tras la replanificación de frecuencias se consigue mejorar en gran medida el $C / I$ de los canales $\mathrm{TCH}$, como se puede apreciar en la figura 5.23. A pesar de conseguir una mejora en general, existen ciertos puntos donde se empeoran, de forma muy limitada, las condiciones experimentadas en determinadas ubicaciones. Esto se puede apreciar en la figura 5.24 donde se representan las zonas de mejora (azul), las que empeoran (rojo) y las que se mantienen igual (cian).

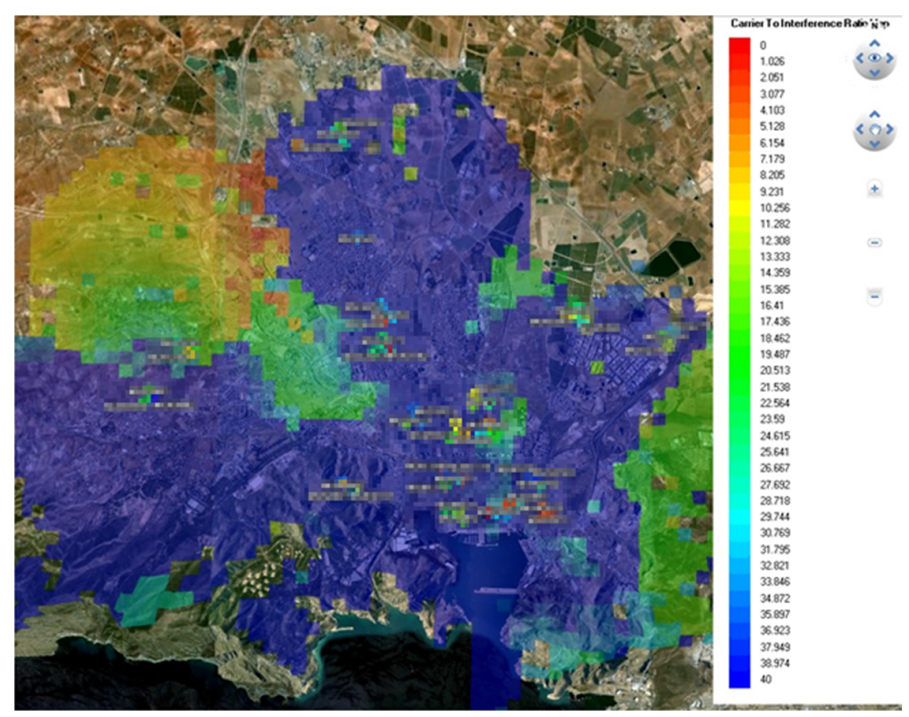

Figura 5.22: $C / I$ en canales TCH antes de la replanificación de frecuencias 


\section{CAPÍTULO 5. OPTIMIZACIÓN DEL USO DEL ESPECTRO}

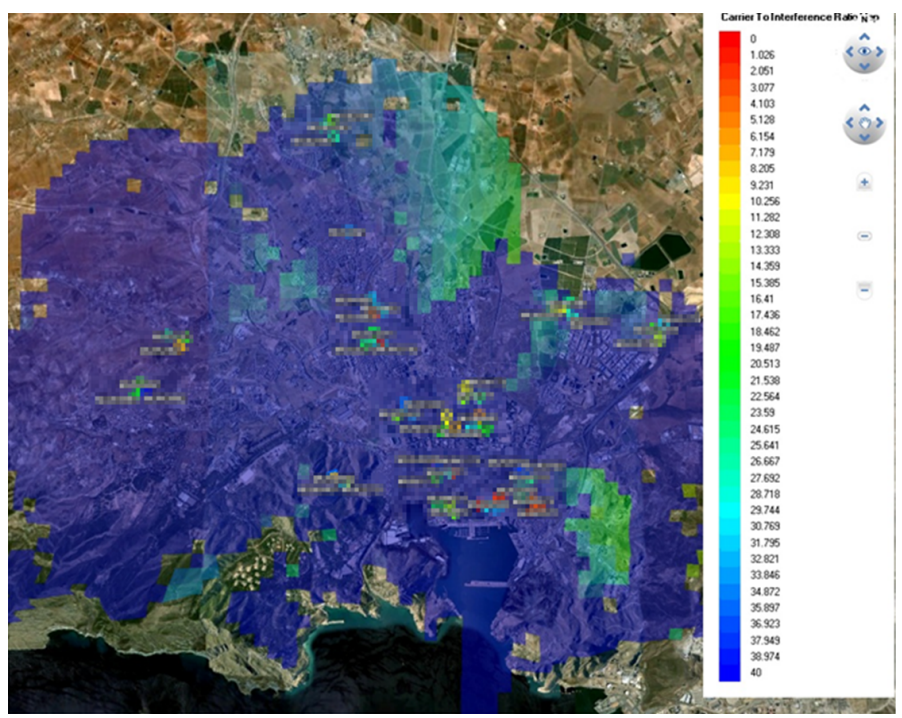

Figura 5.23: $C / I$ en canales TCH después de la replanificación de frecuencias

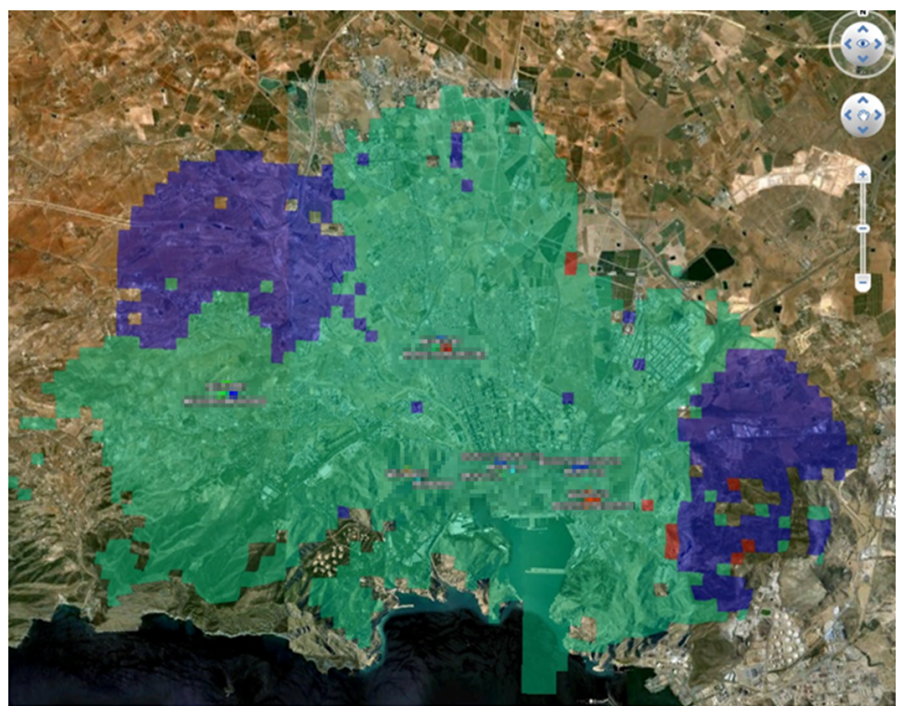

Figura 5.24: Zonas de mejora y empeoramiento de $C / I$ tras las replanificación 


\subsubsection{Planificación de BSICs}

El BSIC se compone de dos códigos de tres bits cada uno, el Network Color Code (NCC) y el Base station Color Code (BCC). El NCC permite distinguir entre operadores, pero dado que los operadores de un mismo país suelen tener asignadas bandas de frecuencia distintas para operar, normalmente se hace uso de todos los códigos disponibles. Por otro lado el BCC se ideó para distinguir las Base Stations (BSs) de un mismo operador.

Se dispone, por tanto, de 64 valores distintos para el BSIC y el objetivo es conseguir la asignación de estos valores de forma que cada celda tenga un par de valores formados por la frecuencia del BCCH y el BSIC que no se repita en ninguna de sus vecinas ni vecinas de segundo orden - vecinas de vecinas-. Por lo tanto, se dispone de bastantes grados de libertad - salvo en las fronteras entre países, donde sí podrá darse el caso de que otro operador esté utilizando la misma frecuencia y haya conflictos con los BSICs - y es relativamente fácil encontrar una solución. Bastará con ir recorriendo la lista de celdas con necesidad de asignación de BSIC, por orden de mayor a menor dificultad estimada de asignación de un identificador no problemático, es decir, por orden decreciente del número de frecuencias distintas en las vecinas y vecinas de segundo orden de una celda. De esta forma se pretende dejar para el final las asignaciones en las que se dispone de mayor libertad de elección.

La problemática de repetir el mismo par frecuencia-BSIC en el vecindario es obvia, pues si no se cumpliera esta restricción un UE en zona de cobertura de ambas celdas no sabría distinguir entre ambas celdas y se reportarían medidas que podrían no corresponderse con la realidad, además de que sería imposible realizar hand-over entre ellas. El caso de la repetición del mismo par frecuencia-BSIC en las vecinas de segundo orden no es tan directo pero sí igualmente problemático. Este caso queda representado en la figura 5.25. En este caso, se puede llegar a caer una llamada debido a una confusión entre la celda de la que el UE reporta medidas y la celda configurada como vecina en la serving cell. Cierto es que esta situación sólo se puede dar cuando las listas de vecinas configuradas no son recíprocas ${ }^{1}$, pues con listas de vecinas recíprocas el problema habría aparecido al proceder a configurar dos celdas distintas con el mismo par frecuencia-BSIC como vecinas de la misma celda. Indicar también que el caso es inevitable cuando ocurre debido al sobre-alcance de una celda en una zona donde se supone que no tiene cobertura, ya que si no existe relación alguna de vecindad no será posible determinar las restricciones de asignación de BSIC correspondientes a ese caso.

\footnotetext{
${ }^{1}$ La reciprocidad de las listas de vecinas consiste en que la celda A configurada como vecina en otra celda B debe contener en su lista de vecinas a la celda B
} 


\section{CAPÍTULO 5. OPTIMIZACIÓN DEL USO DEL ESPECTRO}

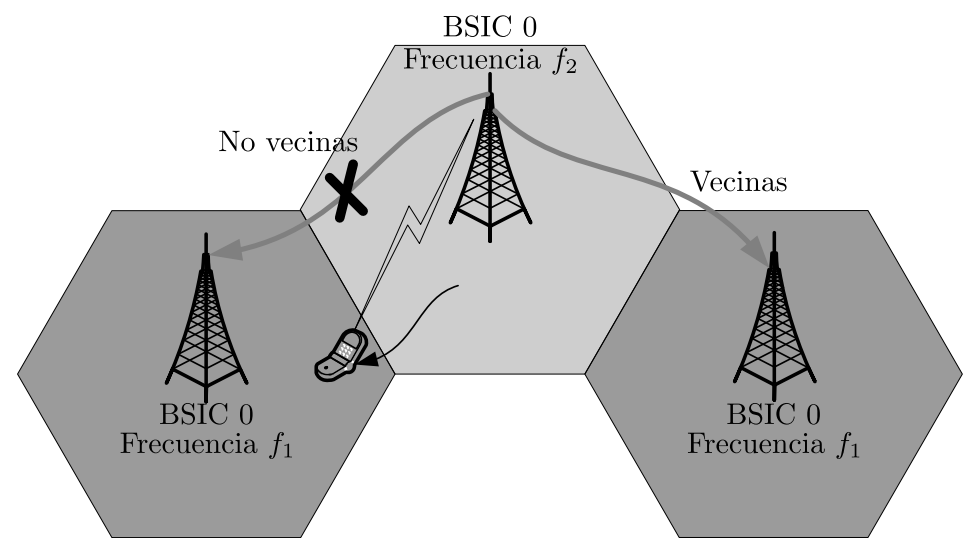

Figura 5.25: Problema de coincidencia de par frecuencia-BSIC en vecindario de segundo orden

\subsection{Acceso Oportunista al Espectro}

LTE fue diseñado para mejorar la banda ancha móvil y así soportar servicios que requieran mayores tasas de transmisión [97]. Sin embargo, el camino hacia los sistemas IMT-Advanced, tales como LTE-A, imponen requisitos más ambiciosos y por eso actualmente aún se discuten en el 3GPP algunas técnicas innovadoras que permitan alcanzar o superar estos requisitos. Una de las características que se prevé clave para todas las tecnologías IMT-Advanced consiste en la posibilidad de agregar porciones de espectro, continuas o discontinuas, tanto en UL como en DL, de forma que el ancho de banda de transmisión se amplíe, conteniendo varias portadoras, con el objetivo de incrementar la tasas de transmisión de datos [98]. Este concepto se conoce con el nombre de Carrier Aggregation (CA) [99]. Varios estudios — véase por ejemplo [100] - revelan que gracias al CA se puede conseguir un importante incremento de la tasa media de transmisión de los usuarios sin afectar a los usuarios del borde de la celda. Sin embargo, a pesar del potencial y las ventajas del CA, existe el gran problema del reducido ancho de banda disponible útil para las futuras tecnologías móviles inalámbricas.

El ancho de banda disponible para comunicaciones móviles es un recurso escaso cuyo uso está estrictamente controlado y licenciado por las entidades gubernamentales propias de cada país, como por ejemplo, la Secretaría de Estado de Telecomunicaciones y para la Sociedad de la Información (SETSI) en España, la Federal Communications Commission (FCC) en Estados Unidos de América o la Office of Communications (OFCOM) en Reino Unido. 
Además, actualmente el uso del espectro no es uniforme en cuanto a su explotación. Mientras que unas bandas son muy utilizadas otras no lo son, tanto en el dominio temporal como en el espacial. En la literatura se hace referencia a estas porciones del espectro infra-utilizadas como agujeros en el espectro o espacios en blanco [101]. La técnica conocida como Cognitive Radio (CR) ha surgido como una solución muy factible contra este uso ineficiente del espectro $[102,103]$ proporcionando un conjunto de metodologías y funcionalidades que permiten atajar el problema. De entre las funcionalidades que ofrece la CR, el Acceso Oportunista al Espectro (AOE) se divisa como un método dinámico que permite incrementar la eficiencia total del sistema permitiendo a usuarios no licenciados - también conocidos como usuarios secundarios o cognitivosutilizar espectro licenciado - o primario - no utilizado. Para conseguirlo se requieren técnicas que permitan una correcta identificación del estado del canal ${ }^{2}$. Concretamente, por un lado es necesario asegurarse de que el canal está libre cuando un usuario secundario se dispone a utilizarlo de forma oportunista para no colisionar con un usuario licenciado. Por otro lado, se necesita la capacidad de detectar cuándo aparece un usuario primario para que el usuario secundario pueda liberar el canal que estaba aprovechando mientras estaba libre. De lo contrario, el AOE podría causar interferencias perjudiciales para la actividad del sistema primario.

La Televisión Digital Terrestre (TDT) es un claro ejemplo en el que se puede aprovechar espectro que está infra-utilizado. Dependiendo del área geográfica, sólo ciertos canales están ocupados. Los organismos de estandarización se percataron de este hecho y a día de hoy continúan trabajando para permitir el uso compartido del espectro sin causar interferencias perjudiciales a los receptores de TDT [104-106]. En [107] se estudia el uso de canales de televisión libres para tecnologías inalámbricas, mostrando que hay una clara oportunidad de mejorar el rendimiento de los sistemas IMT-Advanced aprovechando, por ejemplo, las bandas de frecuencia que se han liberado gracias a la migración de television analógica a digital, lo que se conoce como dividendo digital [108]. En [109] se estudian distintos esquemas de uso compartido del espectro basados en detección cognitiva para la coexistencia de LTE-A y la TDT. Sin embargo, no se presta atención en este estudio a los aspectos relacionados con la implementación práctica de la solución propuesta.

El estado del canal, piedra angular de la CR, se puede monitorizar fácilmente con la estimación de canal que normalmente realizan los usuarios móviles, los cuales reportan al sistema las medidas realizadas sobre el espectro en cuestión. Un aspecto fundamental en la detección de espectro es la fiabilidad de las medidas realizadas por un único usuario. Estas medidas se pueden considerar

\footnotetext{
2Se utilizarán indistintamente los términos "canal" y "banda" para hacer referencia a una porción de espectro potencialmente disponible para el AOE.
} 


\section{CAPÍTULO 5. OPTIMIZACIÓN DEL USO DEL ESPECTRO}

parciales e inducir a errores de detección ya que los sistemas inalámbricos se ven afectados por desvanecimiento multicamino y desvanecimiento por ocultamiento y, por tanto, la medida de un único usuario en un momento determinado y en un punto de localización concreto puede realizarse sobre una señal muy degradada debido a estos dos tipos de desvanecimiento. De este modo, se puede dar el caso indeseado en el que un usuario secundario no detecte actividad del sistema primario por esta razón [110], como es el caso del problema del nodo oculto, representado en la figura 5.26. Un usuario secundario - A en la figurapuede estar en una zona en la que no recibe suficiente señal del sistema primario como para detectarlo, pero el uso oportunista del espectro por parte del sistema secundario, al no haber detectado la presencia del primario de forma correcta, puede afectar a usuarios primarios — B en la figura - que estén cerca del usuario secundario.

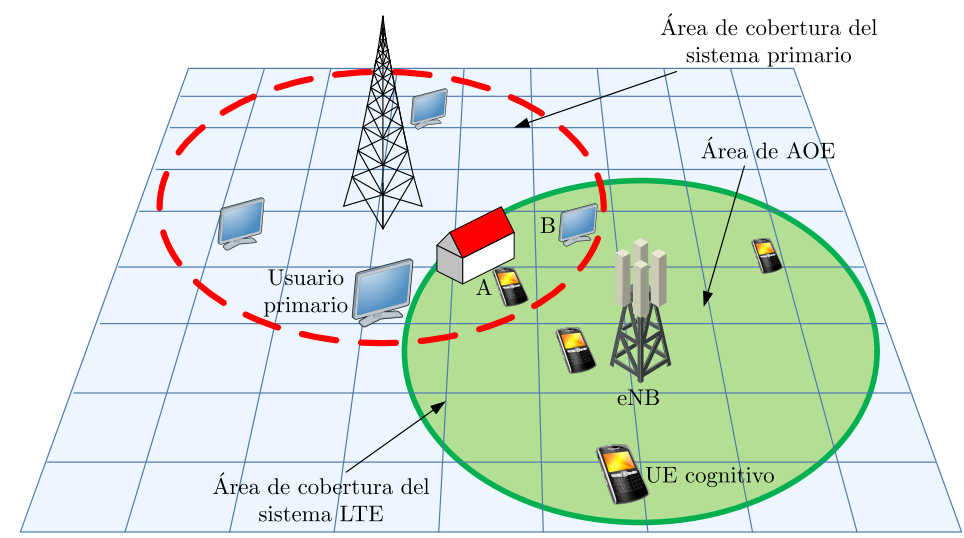

Figura 5.26: Problema del nodo oculto en DL

Para hacer frente a estos inconvenientes, en la literatura se propone aumentar el tiempo de detección. Así, en [111] se optimizan los tiempos de detección y de transmisión en CRs limitadas por consumo de energía. En este sentido, cabe indicar que no se pueden extender los tiempos de detección sine die ya que en la práctica se requiere la detección rápida de oportunidades en redes basadas en CR [48]. Además, el incremento del tiempo de detección disminuye el tiempo de transmisión de datos en la misma proporción, por lo que afecta directamente al throughput. En [112] se trata en detalle la implementación de la detección de espectro y se proporciona una visión general de todos estos problemas, proponiendo como solución para el problema de la incertidumbre en la detección de espectro realizada por un único usuario el uso de detección de espectro cooperativa. En el contexto de AOE, un sistema se considera coopera- 
tivo si las decisiones que se toman no se basan en las medidas reportadas por un único usuario sino que se tiene en consideración la información proporcionada por otros usuarios cognitivos. Por contra, en los esquemas no cooperativos, se toman las decisiones teniendo en cuenta únicamente las medidas reportadas por el usuario secundario que solicita acceso a la banda primaria. Se ha demostrado que la detección de espectro cooperativa proporciona resultados fiables cuando el número de usuarios cooperando es lo suficientemente elevado [113]. Además, la detección cooperativa acorta los tiempos de detección necesarios a la vez que mejora la capacidad global de detección [114]. Sin embargo, la literatura relacionada no clarifica sustancialmente el criterio óptimo de decisión a emplear. En [115] se realiza una comparación entre criterios de decisión hard — decisión basada únicamente en umbrales - y criterios de decisión soft - todas las medidas tienen un peso en la decisión final-, concluyendo que las decisiones soft son mejores para su aplicación en AOE. En la misma dirección, [116] sugiere un mecanismo soft de detección de espectro cooperativa basado en reportes de medidas de SINR que proporciona buenos resultados.

Una vez analizado el espectro, las medidas realizadas han de ser reportadas a la entidad que decide si dar o no acceso oportunista al recurso. En relación con el intercambio de información para detección cooperativa en redes basadas en CR, en [117] se destaca que no se requiere ningún gran esfuerzo para conseguirlo ya que la detección de espectro se realiza en las estaciones base y, por tanto, se puede utilizar la red troncal de la propia red móvil para transmitir esta información. En cambio, en el caso de estudio analizado en [118] si existe la necesidad de que los usuarios cognitivos transmitan la información con las medidas realizadas a una entidad central, proponiendo una solución que consiste en transmitir información con una baja tasa de transmisión utilizando espectro ensanchado, evitando así la interferencia con el sistema primario. La propuesta proporcionada en [119] contempla la implementación de un canal de control común utilizando Ultra-Wideband (UWB). Sin embargo, entre la literatura existente no se encuentran implementaciones prácticas y factibles de mecanismos de intercambio de mensajes entre las entidades correspondientes en una red basada en $\mathrm{CR}$.

Una vez que el estado del canal ya es conocido, la geo-localización de las medidas proporciona un gran valor a la red basada en CR en muchos sentidos [120], especialmente en el caso de AOE dinámico. En la literatura se pueden encontrar distintos esquemas que introducen la información de localización en los procesos de AOE. Concretamente, la FCC ha sugerido dos alternativas para un escenario estático $[121,122]$. La primera consiste en comprobar en una base de datos centralizada si existen espacios en blanco para el usuario cuya localización se conoce. La segunda consiste en la difusión, de forma local, de información de disponibilidad de canales de TV libres. A pesar de la existencia 


\section{CAPÍTULO 5. OPTIMIZACIÓN DEL USO DEL ESPECTRO}

de estas propuestas, la inclusión de la información de localización en escenarios de AOE dinámico es un tema de investigación relativamente reciente que merece una especial atención. En [123], se propone un reparto de recursos basado en la distancia entre los usuarios primarios y secundarios a partir de predicciones de propagación y extrayendo de esa información la máxima potencia asignable para evitar interferencias. La principal desventaja de esta propuesta, sin embargo, es que no se incluyen mecanismos de detección de espectro y los modelos de predicción de pérdidas de propagación puede que no tengan la precisión suficiente para que este planteamiento sea factible.

Teniendo en mente el estado del arte analizado en la sección 1.2, a continuación se proporcionan reglas específicas para la implementación práctica de mecanismos de detección cooperativa de espectro en LTE-A. Además, se evalúa la idoneidad del uso del AOE dinámico en términos de rendimiento del sistema en tales redes. La propuesta contempla la introducción en el sistema de una Base de Datos Geo-localizados (BD-Geo) que contenga los espacios en blanco disponibles en una cierta banda de frecuencias en cada instante de tiempo. Con el fin de mantener y actualizar la BD-Geo, los usuarios cognitivos monitorizarán la banda del sistema primario y reportarán las medidas realizadas utilizando el estándar IEEE 802.21 Multimedia Independent Handover (MIH) [104]. La red recopilará todas las medidas reportadas por los usuarios cognitivos juntos con sus posiciones geográficas para decidir sobre la disponibilidad del canal primario, en una cierta localización, actualizando la BD-Geo consecuentemente. Esta decisión debe ser realizada no sólo teniendo en cuenta las medidas reportadas sino también la fiabilidad de las mismas y la distancia del usuario a la estación base, entre otras cosas. Además, el AOE se permitirá únicamente a los usuarios ubicados en zonas libres de actividad del sistema primario. Por otra parte, la propuesta incluye un mecanismo de reparto de recursos sencillo combinado con un mecanismo de Control de Potencia (CP) adecuado para el acceso oportunista a la banda primaria. Este mecanismo, basado en la información de la BD-Geo, está orientado a minimizar la interferencia producida a los usuarios del sistema primario y a otros usuarios del secundario, utilizando la localización como elemento clave.

\subsubsection{Características y Herramientas de CR en LTE-A}

El objetivo de esta sección es identificar el conjunto de herramientas disponibles en LTE-A que permiten la implementación del AOE en esta tecnología. El sistema LTE-A tendrá el papel de sistema secundario y lo que se persigue es utilizar capacidades ya existentes y contempladas en el estándar para elaborar una BD-Geo con la localización de los espacios en blanco de la banda de frecuencias utilizada por el sistema primario. Este análisis se centra en resaltar 
las restricciones operacionales y en identificar las variables y parámetros que se pueden ajustar. Los resultados numéricos que se presentarán en la sección 5.4.3 proporcionan valores de referencia para estas variables.

\subsubsection{Posible escenario de despliegue}

Antes de entrar en detalle en los mecanismos que permiten la implementación del AOE en LTE-A, es esencial describir el posible escenario donde la utilización del AOE puede resultar de utilidad. En tal escenario, una red LTE puede coexistir con otros sistemas inalámbricos licenciados que implementen distintas tecnologías, como por ejemplo TDT, GSM, UMTS, Terrestrial Trunked Radio (TETRA), etc. Es posible que algunos de estos sistemas licenciados no estén transmitiendo en la banda licenciada continuamente y, por tanto, estén infrautilizando sus correspondientes recursos, como es el caso de TETRA que se utiliza principalmente en emergencias. Por otro lado, es posible que otros sistemas no utilicen toda la banda de frecuencias que tienen asignada, como ocurre con los espacios en blanco de la banda de TDT. El esquema propuesto contempla un sistema LTE que, como complemento a su actividad intrínseca en la banda que tiene asignada, actúa como sistema secundario al acecho de oportunidades de transmisión en los huecos, temporales, frecuenciales y/o espaciales, de un sistema primario y las aprovecha al máximo mientras duren. Es decir, la transmisión oportunista debe cesar en cuanto se detecte de nuevo actividad en el sistema primario. Tal como se expone en la sección 5.4, se utilizará la detección de espectro como mecanismo para poder descubrir esas oportunidades. La información sobre el estado de la banda del sistema primario se obtendrá desde distintas localizaciones gracias a la monitorización que realizarán los propios usuarios del sistema secundario. Con el fin de prevenir posibles errores a la hora de definir el estado del canal como libre u ocupado, se plantea la utilización de un esquema colaborativo de detección del espectro, en el cual los UEs reportan su percepción de la banda licenciada y, posteriormente, se toma una decisión final sobre el estado del canal en base a todas las medidas disponibles. Esta información junto con la localización de los distintos UEs se empleará para crear la BD-Geo.

\subsubsection{Detección del espectro}

El éxito del AOE depende en gran medida de la correcta detección del estado del canal. Los usuarios cognitivos deben transmitir única y exclusivamente cuando la banda licenciada está en desuso de forma que no se interfiera al sistema primario. Con el objetivo de evitar las interferencias y de maximizar las oportunidades de los usuarios secundarios, se aprovecharán las capacidades de análisis del espectro disponibles en LTE-A. 


\section{CAPÍTULO 5. OPTIMIZACIÓN DEL USO DEL ESPECTRO}

En general, la tarea de detección de espectro se caracteriza por el tiempo de detección $T_{d}$ y el periodo de detección $P_{d}$. El tiempo de detección se refiere al tiempo utilizado para determinar el nivel de señal de una determinada banda de frecuencia mientras que el periodo de detección se refiere a la frecuencia con la que el usuario cognitivo monitoriza una determinada banda de frecuencias. Algunas de las capacidades de medida de los UE contempladas en el estándar de LTE-A para los procesos de handover pueden utilizarse en la detección del estado del canal primario. Claramente, el tiempo y el periodo de detección se pueden relacionar directamente con los parámetros del patrón de huecos definido en el estándar para los procedimientos de medida en estado RRC_CONNECTED [124]: Measurement Gap Length (MGL) y Measurement Gap Repetition Period (MGRP). Ambos parámetros se muestran en la figura 5.27 .

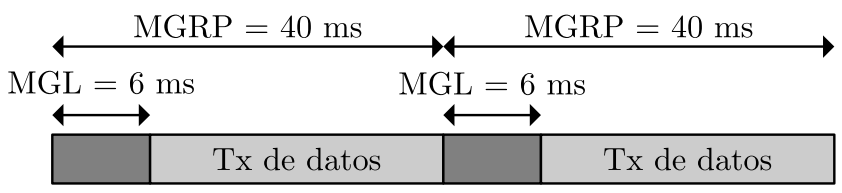

Figura 5.27: Parámetros del patrón de huecos para los procedimientos de medida en LTE-A

Mientras el usuario mide el canal no es capaz de transmitir o recibir datos, por lo que puede sintonizar su receptor en otras frecuencias portadoras. De acuerdo con el estándar, el MGL es fijo mientras que el MGRP es configurable en múltiplos de la longitud de trama - es decir, $10 \mathrm{~ms}$ - Esto permite cierta libertad de elección en el compromiso entre información de base de datos actualizada y rendimiento del sistema, ya que cuanto menor es el MGRP menor es el tiempo que dedica el usuario a recibir datos en DL. La configuración del MGRP y el conjunto de frecuencias a monitorizar puede realizarse a través de señalización de RRC, que al mismo tiempo garantiza la sincronización entre la asignación de recursos en el eNB y la monitorización en el UE.

Además de utilizarse para realizar la detección de espectro, el patrón de huecos debe seguir sirviendo para la operación normal del UE en cuestión de medidas de celdas vecinas monitorizadas o detectadas, intra e inter-sistema, para los procesos de handover ajenos a la banda cognitiva. A tal efecto, se reservará un hueco de medida cada cierto número de ellos que vendrá determinado por el MGRP escogido, de forma que resultará un valor de MGRP efectivo para la funcionalidad original del patrón de huecos. Este MGRP efectivo deberá cumplir con las configuraciones de patrón de huecos que se contemplan en el estándar y que cumplen con los requisitos de monitorización de vecinas fijados 
[124]. Se ha establecido el valor de MGRP efectivo en $80 \mathrm{~ms}$ que se corresponde con el patrón de huecos con identificador 1 descrito en el citado estándar.

La elección del valor de configuración del MGRP no se debe tomar a la ligera ya que el rendimiento del sistema depende considerablemente de este parámetro. Por un lado, cuanto mayor es el MGRP menor es la frecuencia con la que se monitoriza el estado del canal primario y, por tanto, con mayor probabilidad los valores de la BD-Geo estarán obsoletos. Como resultado, la probabilidad de asignar un $\mathrm{RB}^{3}$ ocupado en la banda primaria a un usuario secundario, es decir, la probabilidad de colisión o interferencia, se incrementa. Pero por otro lado, cuanto menor es el MGRP mayor será la carga de señalización introducida y menor será el throughput en DL para el usuario en cuestión. Los efectos de cambiar este parámetro se estudian en la sección 5.4.3, en la que se proporcionará un valor óptimo para el escenario de evaluación considerado.

Además, los UEs de LTE-A tienen la capacidad de medir la RSSI. Esta medida permite detectar actividad o inactividad en la banda primaria. Teniendo en cuenta el tiempo de sintonización necesario al principio y al final del hueco de medida, es posible monitorizar un determinado ancho de banda durante un tiempo efectivo de 5,166 ms [125, pp. 313-314]. El planteamiento propuesto considera que la detección de espectro se realiza sobre trozos del tamaño de un $\mathrm{RB}$ en la banda primaria, esto es, $180 \mathrm{kHz}$. Las medidas de RSSI se obtienen calculando la potencia total recibida en el puerto de antena del terminal tras aplicar un filtro de forma específico. Sin embargo, debido a la compatibilidad con los sistemas predecesores, los UE de LTE disponen de un filtro de $200 \mathrm{kHz}$ específico para GSM, que puede utilizarse para medir la señal en un RB [126]. Durante cada hueco de medidas se mide un $\mathrm{RB}$ distinto de la banda primaria. Poniendo por caso una hipotética banda primaria de $10 \mathrm{MHz}-50 \mathrm{RBs}-\mathrm{y}$ un MGRP de 40 ms, se podrá monitorizar toda la banda primaria cada 4 segundos, suponiendo que uno de cada dos huecos de medidas se dedican a medir vecinas intra e inter-sistema. Todas estas medidas deben ser reportadas a una entidad lógica que gestiona y actualiza la BD-Geo. En la sección 5.4.1.3 se proporciona una propuesta para este procedimiento.

Durante el AOE, es posible que en algún momento el sistema primario vuelva a necesitar su banda licenciada si es un sistema caracterizado por tener periodos de actividad e inactividad, como por ejemplo un sistema TETRA. En este caso, es necesario que los usuarios del sistema secundario sean capaces de detectar esta actividad aún cuando el propio sistema secundario está realizando transmisiones oportunistas en la misma banda. En el presente estudio, se ha supuesto que es posible tener esta capacidad de detección si se seleccionan

\footnotetext{
${ }^{3}$ Un RB, siguiendo la terminología del 3GPP, es la mínima porción de espectro que puede asignarse a un usuario $(180 \mathrm{kHz})$. Se utilizará en el mismo contexto que el término "canal".
} 


\section{CAPÍTULO 5. OPTIMIZACIÓN DEL USO DEL ESPECTRO}

umbrales de RSSI adecuados y se detectan valores anormales de esta medida que indiquen la reaparición del sistema primario.

En general, la inevitable imprecisión de la detección de espectro puede resultar en información errónea sobre la ocupación del canal primario. La figura 5.28 muestra todos los posibles resultados que puede proporcionar el mecanismo de detección de espectro según la presencia o no de actividad en la banda de frecuencias licenciada del sistema primario. En general, los errores de detección - las áreas en gris oscuro- se clasifican en dos grupos: error de falso positivo o False Alarm (FA) y error de falso negativo o Missed Detection (MD). La FA ocurre cuando se detecta la presencia de una actividad inexistente en el primario mientras que la MD sucede cuando el usuario cognitivo es incapaz de detectar la actividad en el primario.

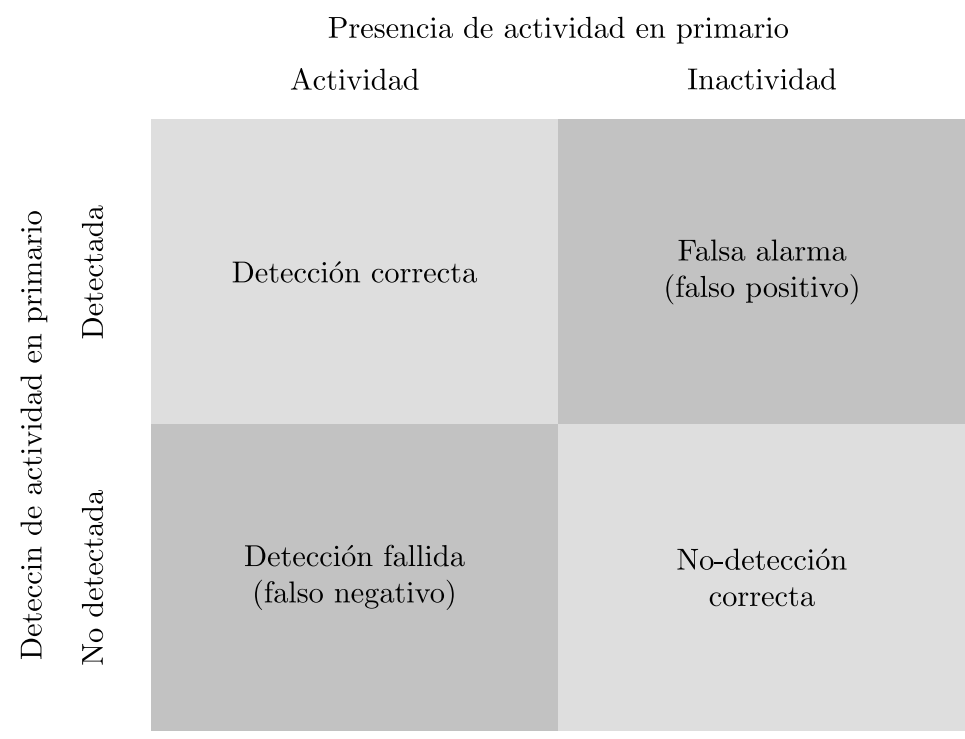

Figura 5.28: Detección de actividad en el sistema primario

Los errores de FA y MD tienen consecuencias diferentes. Un error de MD provocará que se asigne a un usuario secundario un RB ocupado por un usuario primario, con la consecuente interferencia - o colisión - entre los sistemas primario y secundario. Por contra, un error de FA llevará a una infra-utilización del espectro disponible en el primario, ya que no se aprovechará la oportunidad de transmitir en el hueco existente. En el esquema propuesto se modela el rendimiento del detector de espectro a través de curvas Características de Operación del Receptor (COR) para el detector de espectro como las calculadas 
en $[127,128]$. Los modelos para curvas COR representan la probabilidad de FA $(\varepsilon)$ como función de la probabilidad de $\mathrm{MD}(\delta)$ dadas ciertas condiciones de canal y parámetros de diseño. Concretamente, las expresiones para las probabilidades de FA y MD se pueden encontrar en la literatura para canales AWGN con desvanecimiento Rayleigh, Nakagami y Ricean. En esta Tesis Doctoral, se supone un canal Rayleigh para el cual, según [127], la probabilidad de FA para el detector de espectro viene dada por

$$
\varepsilon(\lambda)=\frac{\Gamma(m, \lambda / 2)}{\Gamma(m)},
$$

donde $\lambda$ es el umbral de detección de energía y donde $\Gamma(\cdot)$ y $\Gamma(\cdot, \cdot)$ son las funciones gamma y gamma-incompleta, respectivamente. El parámetro $m$ es el llamado producto tiempo-ancho de banda y está relacionado con el tiempo dedicado a detectar espectro en un ancho de banda concreto. En general, cuanto mayor es $m$ mejores serán las medidas realizadas. En el caso de ejemplo que se ha planteado anteriormente, $m$ está completamente definido por el tiempo de detección para un RB $-5,166 \mathrm{~ms}$ - y el ancho de banda de un RB - 180 $\mathrm{kHz}$ - Por lo tanto, $m=930$.

De forma similar, [127] proporciona la probabilidad de MD como

$\delta(\lambda)=e^{-\frac{\lambda}{2}} \sum_{k=0}^{m-2} \frac{1}{k !}\left(\frac{\lambda}{2}\right)^{k}+\left(\frac{1+\bar{\gamma}_{p}}{\bar{\gamma}_{p}}\right)^{m-1}\left[e^{-\frac{\lambda}{2\left(1+\bar{\gamma}_{p}\right)}}-e^{-\frac{\lambda}{2}} \sum_{k=0}^{m-2} \frac{1}{k !} \frac{\lambda \bar{\gamma}_{p}}{2\left(1+\bar{\gamma}_{p}\right)}\right]$

donde $\bar{\gamma}_{p}$ es la SINR recibida del primario la cual se considerará un parámetro de entrada.

Analizando las ecuaciones (5.1) y (5.2) se aprecia que el umbral de decisión $\lambda$ se puede seleccionar de forma que se encuentre un equilibrio óptimo entre las probabilidades de FA y MD. Sin embargo, en la práctica el umbral se selecciona de forma que se obtenga un determinado valor de probabilidad de MD [129].

\subsubsection{Reporte de medidas}

Toda la información de detección de espectro obtenida por los usuarios cognitivos debe ser transmitida a la red para su procesamiento. Sin embargo, este procedimiento de reporte de información necesario para el proceso de AOE no está especificado. Una posible solución podría ser la utilización de un protocolo de comunicación propietario, pero esta posibilidad reduciría la posibilidad de implementar el AOE en LTE-A. En cambio, esta Tesis propone el uso del protocolo incluido en el estándar IEEE 802.21 dada su popularidad y la disponibilidad de implementaciones de código abierto. El estándar IEEE 802.21, 


\section{CAPÍTULO 5. OPTIMIZACIÓN DEL USO DEL ESPECTRO}

conocido como MIH, especifica un protocolo de nivel de aplicación cuyo objetivo es permitir la realización de soft handover entre diferentes tecnologías 802.xx [104]. MIH se basa en el intercambio de mensajes que sirven para reportar un conjunto de eventos que se producen a nivel de la capa física. Las funcionalidades MIH las proporciona una entidad llamada Multimedia Independent Handover Function (MIHF), y consisten en Media Independent Event Services (MIES), Media Independent Command Services (MICS) y Media Independent Information Services (MIIS). De éstas, la única funcionalidad que resulta de interés para la implementación propuesta de AOE es MIES, en la que una MIHF local, en el núcleo de la red móvil, recibe notificaciones de eventos de un conjunto de MIHFs remotas adecuadamente configuradas y que se ejecutarían en el terminal de los usuarios cognitivos.

Resulta necesaria la inclusión de una nueva entidad en la red LTE-A, el Gestor de Recursos Cognitivos (GRC), el cual coordina el AOE en la banda licenciada basándose en las notificaciones que reportan el estado del canal según lo perciben los usuarios cognitivos. En base a lo anterior, el GRC debe incluir una entidad MIHF que gestione las suscripciones a notificaciones de eventos y que reciba y procese todas las notificaciones relativas a la detección de espectro, con el fin de construir y actualizar la BD-Geo. El GRC necesita saber cuándo la RSSI medida por el UE en la banda licenciada supera un determinado umbral. Por lo tanto, tras el procedimiento de attach, el GRC tiene que enviar al usuario activo un mensaje MIH_Event_Suscribe con la lista de los RBs a monitorizar. Además, con la primitiva MIH_Link_Configure_Thresholds el GRC especifica los umbrales asociados con esta lista.

Tal como se explicó en la sección 5.4.1.2, a través de la señalización de RRC es posible pedir a los UEs LTE-A que realicen detección de espectro de manera periódica. La entidad MIHF del UE puede, a través del punto adecuado de acceso al servicio, acceder a los valores de señal medidos y generar notificaciones de acuerdo a dicha información. Cuando el nivel de potencia en la banda licenciada supera el umbral definido, se envía un mensaje MIH_Link_Parameters_Report.indication a la MIHF del GRC, la cual a su vez lo notificará a las capas superiores a través de la interfaz de usuario MIH. El usuario MIH especifica una interfaz entre la MIHF y la aplicación que ejecuta el GRC [130]. El usuario MIH envía comandos directamente a la entidad MIHF local utilizando primitivas disponibles en el estándar IEEE 802.21, el cual soporta mecanismos de suscripción de eventos y notificaciones. La figura 5.29 describe el flujo de datos desde un usuario cognitivo que percibe una alteración del estado de disponibilidad de un recurso y envía la correspondiente notificación de evento al GRC.

$\mathrm{El}$ intercambio de notificaciones de eventos entre los usuarios cognitivos y el GRC es posible utilizando el Default EPS Bearer disponible en LTE-A para 


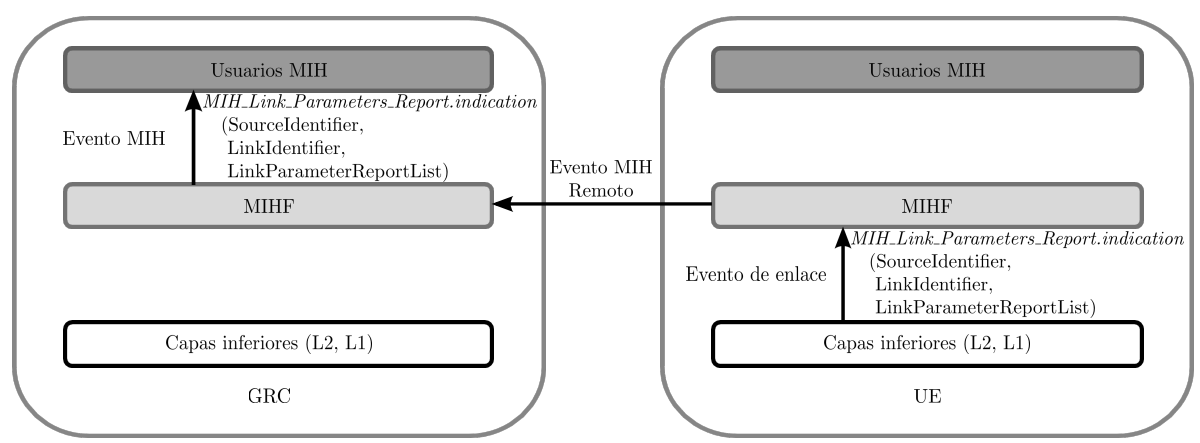

Figura 5.29: Flujo de eventos para $M I H \_L i n k \_$Parameters_Report.indication

cualquier usuario activo. El Default EPS Bearer asigna una dirección IP única a los usuarios LTE-A y proporciona conectividad, al menos, con todos los nodos dentro de la red LTE-A.

\subsubsection{Localización de usuarios}

En la solución de AOE propuesta, el principal objetivo de la localización de usuarios es la recopilación dinámica de información geo-localizada sobre los espacios en blanco presentes en la banda del sistema primario. Esta información ayudará al scheduler a realizar una asignación oportunista de recursos que incluso podría funcionar aunque se detectase actividad en el primario, si ésta se produce lejos del eNB. En la sección 5.4.2 se describe este procedimiento de AOE en detalle.

Como se describió en la sección 3.2.4, la localización de usuarios en LTE es posible procesando medidas obtenidas de la red. En el esquema propuesto, el GRC y el E-SMLC se interconectan a través del MME, tal como se muestra en la figura 5.30. El GRC es la entidad que solicita el servicio de localización al MME, quien a su vez activará el servicio del E-SMLC. La localización resultante calculada por el E-SMLC se envía a través del MME, quien finalmente reenvía esta información al GRC. Con la información obtenida, el GRC dispone de la correspondencia entre los reportes con información de detección y la localización de los usuarios que los han obtenido, permitiendo la construcción y actualización de la BD-Geo.

\subsubsection{Base de datos geo-localizados}

Gracias a la capacidad de localizar usuarios, la BD-Geo contendrá información valiosa sobre qué partes del espectro primario pueden ser utilizadas de 


\section{CAPÍTULO 5. OPTIMIZACIÓN DEL USO DEL ESPECTRO}

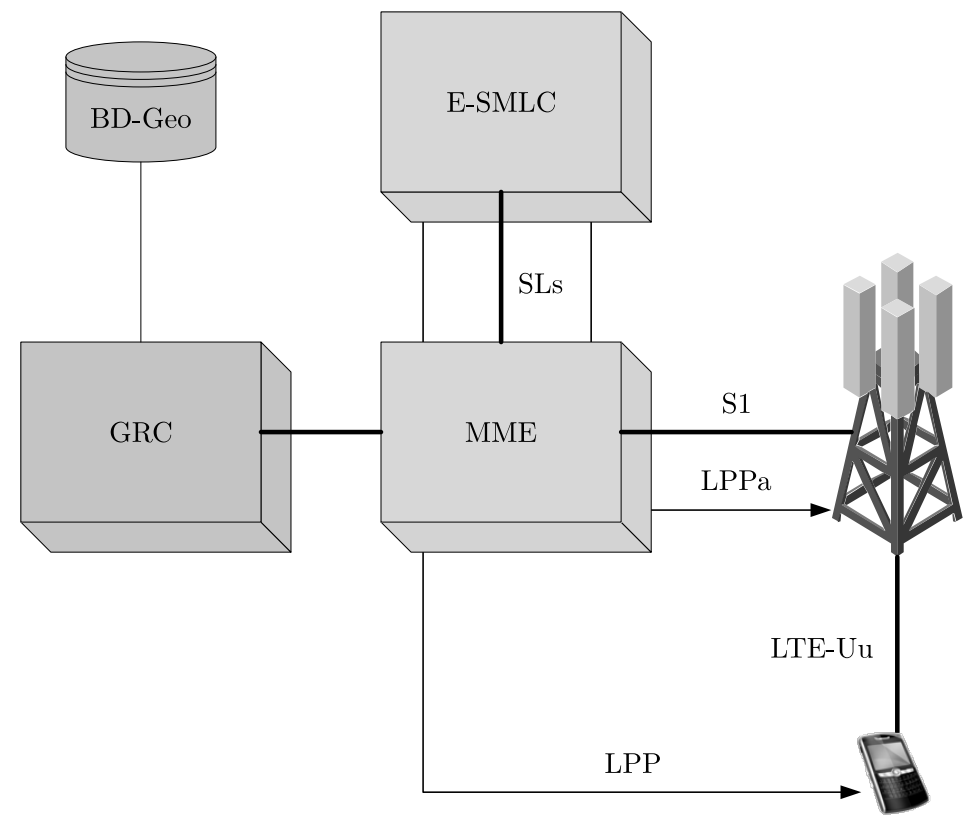

Figura 5.30: Esquema de los nodos implicados en el mantenimiento de la BD-Geo

forma oportunista por un determinado eNB y la máxima cobertura que debería tener en ese recurso para no interferir con el sistema primario. La figura 5.31 ilustra el proceso de cálculo de la BD-Geo. El GRC recopila la información de detección de los UEs y la localización de los mismos haciendo uso del servicio de localización que proporciona el MME y actualiza la base de datos tras la toma de decisión cooperativa, la cual se explicará en la sección 5.4.2.1. Una vez este proceso ha finalizado, el GRC tiene en su poder la información de localización de cada UE oportunista y qué RBs se pueden utilizar — verde en la figura 5.31- y cuáles no — rojo en la figura 5.31-.

La BD-Geo contendrá la información relativa a la disponibilidad de los RBs en la banda primaria para cada eNB, indicando también la máxima distancia de cobertura tal y como muestra la tabla 5.13. De esta forma, un eNB, identificado en la tabla por su Cell Identifier (Cell-ID), es capaz de utilizar de forma oportunista esos RBs, marcados como disponibles, con una potencia de transmisión reducida en el caso de que el alcance máximo venga especificado en la entrada correspondiente de la base de datos. En otro caso, el campo que indica el máximo alcance vendrá informado con el valor No Aplicable (N.A.) 


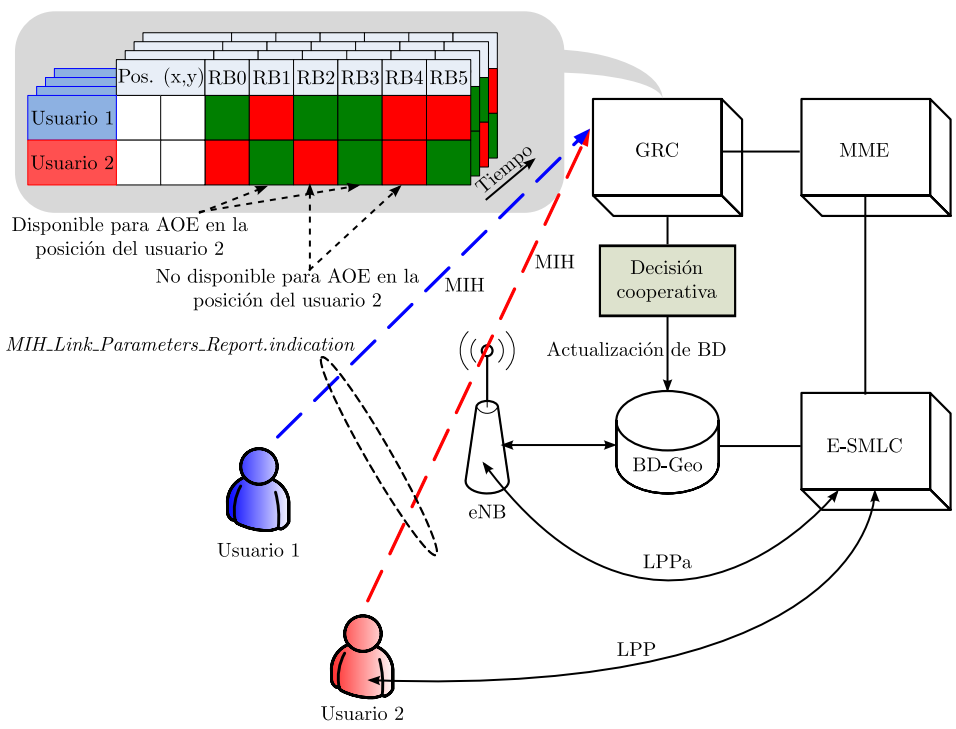

Figura 5.31: Acceso Oportunista al Espectro basado en datos geo-localizados

y los recursos correspondientes podrán utilizarse sin restricciones en cuanto a la potencia transmitida. El campo de alcance máximo está expresado en términos de la la resolución en distancia que permite el TA en el algoritmo de localización, el cual define rangos de 10 metros de ancho, y representa la máxima distancia entre el eNB y cualquier usuario cognitivo candidato a utilizar el recurso correspondiente.

Tabla 5.13: Contenido de la base de datos geolocalizados

\begin{tabular}{ccc}
\hline Cell-ID & RB & Alcance Máximo \\
\hline \hline$\ldots$ & $\ldots$ & $\ldots$ \\
$10001 \mathrm{AX}$ & 0 & $10 \times$ Distancia_TA \\
$10001 \mathrm{AX}$ & 1 & $12 \times$ Distancia_TA \\
$\ldots$ & $\ldots$ & $\ldots$ \\
$10002 \mathrm{AX}$ & 0 & N.A. \\
$10002 \mathrm{AX}$ & 1 & $9 \times$ Distancia_TA \\
$\ldots$ & $\ldots$ & $\ldots$ \\
\hline
\end{tabular}




\section{CAPÍTULO 5. OPTIMIZACIÓN DEL USO DEL ESPECTRO}

La información contenida en la BD-Geo debe actualizarse periódicamente para tener en cuenta las posible variaciones en la actividad del primario. Como se indicó en la sección 5.4.1.2 se necesitan 4 segundos para monitorizar un ancho de banda de $10 \mathrm{MHz}$. Una decisión cooperativa que tenga en cuenta toda la información proporcionada por todos los usuarios que se encuentran dentro de un cierto rango permitirá incrementar la precisión de la detección. El hecho de tener la BD-Geo actualizada reducirá la probabilidad de colisiones con el sistema primario, que podrían producirse por una falta de sincronización entre el estado real del espectro primario y la información almacenada disponible.

\subsubsection{Procedimiento de Acceso Oportunista al Espectro}

El procedimiento de AOE propuesto depende de las herramientas de CR descritas en la sección 5.4.1 e implica ejecutar los procesos descritos en esta sección. Específicamente, a continuación se va a tratar la decisión cooperativa sobre la actividad del sistema primario en los diferentes canales monitorizados así como la forma en la que los recursos libres son asignados entre los usuarios. Además, se concluirá esta sección con la descripción de la metodología adoptada para la transmisión de información de control enviada a los usuarios en relación a los recursos utilizados de forma oportunista.

\subsubsection{Toma de decisiones cooperativa}

Afectado por factores del canal móvil como el ruido, desvanecimiento por ocultamiento y desvanecimiento multicamino, las medidas de un único detector son propensas a errores. Con el objetivo de solventar este problema, se sugiere la utilización de detección de espectro cooperativa en la que colaboren múltiples usuarios en ubicaciones diferentes. Como ya se mencionó en la sección 5.4.1.3, en esta Tesis Doctoral se propone la implementación de un mecanismo centralizado de detección cooperativa para mejorar la identificación del estado del canal. Este mecanismo cooperativo de toma de decisiones estará implementado en el GRC. Con el fin de hacer un uso más eficiente del espectro disponible y para explotar al máximo la naturaleza oportunista del esquema propuesto, se plantea la monitorización y toma de decisiones por RB en lugar de por banda de frecuencias completa. Los datos de entrada considerados por el mecanismo de decisión incluyen todos los reportes sobre el estado del canal enviado por los UEs conectados a un mismo eNB y la posición geográfica de los mismos, obtenida a partir de los servicios de localización que se han mencionado anteriormente. Cada una de las notificaciones sobre el estado del canal crea una entrada en el GRC que contiene el identificador del UE, su posición geográfica estimada, el canal o recurso monitorizado, el estado del mismo en cuanto a 
actividad del sistema primario y una marca temporal indicando cuándo fue recibido el reporte. Una vez se ha recopilado toda esta información procedente de diferentes usuarios, el GRC puede tomar una decisión sobre la disponibilidad de los distintos recursos en distintas localizaciones. Los reportes recopilados se agrupan según la distancia del UE al eNB en diferentes rangos, cuya anchura es un múltiplo de la resolución de la localización que proporciona el TA -Distancia_TA $=10 \mathrm{~m}$ - . Por cada uno de estos rangos y por cada RB se realizará una decisión cooperativa independiente del resto. Para el mismo UE y recurso, solamente se considerarán los últimos datos de detección recibidos - en esta Tesis Doctoral, sólo se considerarán los reportes recibidos desde 2 segundos antes de la toma de decisión-.

Las decisiones tomadas por el GRC para cada recurso y rango se utilizan para actualizar la BD-Geo. El pre-procesado realizado por el GRC para realizar esta actualización se describe en el algoritmo 1.

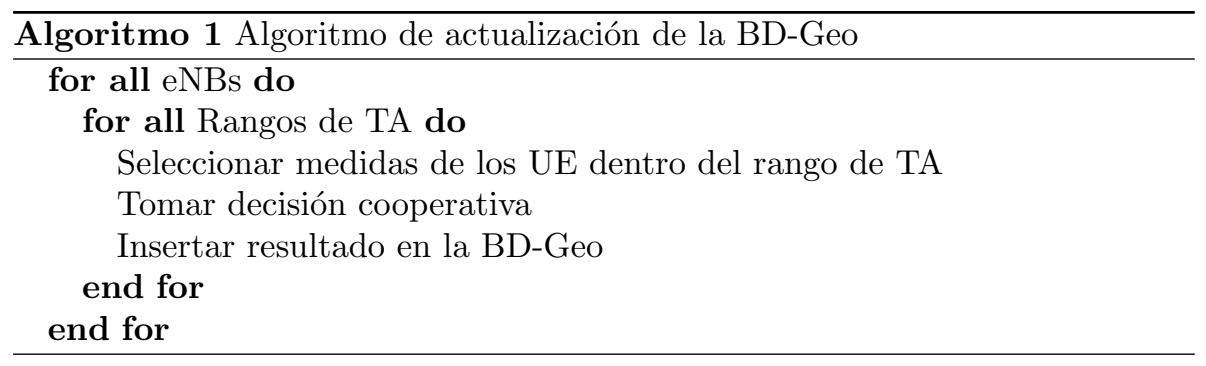

En [115] se proponen dos técnicas simples de fusión de las medidas para la toma cooperativa de decisiones. La técnica basada en regla $O R$ marca un recurso como ocupado con que un único usuario haya detectado actividad en el sistema primario. De forma complementaria, la basada en regla $A N D$ decide que un recurso está ocupado si todos y cada uno de los usuarios que han monitorizado ese recursos detectan actividad del primario en el mismo.

Inspirados en [115], esta Tesis Doctoral introduce dos reglas de decisión similares a las anteriores. La regla conservadora decide que el recurso está libre si todos los UEs que han reportado medidas sobre el mismo dicen que no hay actividad en el primario. En otro caso, el recurso se considera ocupado. Por otro lado, la estrategia más agresiva decide que un recurso está libre si al menos un UE indica que no ha detectado actividad en el primario. Sin embargo, debido a la incertidumbre de las medidas aisladas a la que se hacía referencia anteriormente, se han de considerar las diferentes medidas reportadas a lo largo del tiempo en la decisión final. Eso sí, no se puede dar el mismo valor a una medida recién tomada que a una medida anterior, debido a la diferente probabilidad de que haya cambiado el estado del canal desde que fueron tomadas. 


\section{CAPÍTULO 5. OPTIMIZACIÓN DEL USO DEL ESPECTRO}

Las decisiones basadas en reglas laxas van en esa dirección y, al igual que las decisiones basadas en reglas estrictas que se han comentado anteriormente, se contemplan en este estudio.

En las decisiones cooperativas basadas en reglas laxas, cada medida reportada tiene asociada un peso. En línea con la detección de espectro cooperativa y ponderada que se propone en [116], en lugar de ponderar por la SINR del sistema primario es posible ponderar las notificaciones de eventos de acuerdo al tiempo transcurrido desde que las medidas fueron tomadas y a la coherencia de las mismas con el resto de medidas del mismo rango de TA. El GRC combinará la información del estado del recurso con los correspondientes pesos y tomará una decisión tras comparar el resultado con un umbral predefinido. Cada notificación de estado de un recurso se pondera de acuerdo al tiempo transcurrido entre el instante de recepción de la notificación por parte del GRC y el instante en que se realiza la toma de decisión, representados por $t_{i}$ y $t_{\text {now }}$ respectivamente en la ecuación (5.3). $T_{M A X}$ es el tiempo entre dos medidas consecutivas realizadas sobre el mismo recurso por un mismo UE, es decir, $P_{d}$ veces el número de recursos a monitorizar en la banda primaria. Además de esta versión lineal del peso, en la sección 5.4.3 se evaluarán también los resultados para las versiones cuadrática, representada en la ecuación (5.4), y raíz cuadrada, representada en la ecuación (5.5), de la misma fórmula, para optimizar las prestaciones del algoritmo de decisión.

$$
\begin{gathered}
\omega_{i}=\frac{T_{M A X}-\left(t_{\text {now }}-t_{i}\right)}{T_{M A X}} \\
\omega_{i}=\left(\frac{T_{M A X}-\left(t_{\text {now }}-t_{i}\right)}{T_{M A X}}\right)^{2} \\
\omega_{i}=\sqrt{\frac{T_{M A X}-\left(t_{\text {now }}-t_{i}\right)}{T_{M A X}}}
\end{gathered}
$$

La decisión sobre la disponibilidad de un determinado recurso para el acceso oportunista al mismo se tomará de acuerdo al valor de la métrica de decisión que se define como:

$$
U=\sum_{i=0}^{N-1} \frac{(-1)^{d_{i}} \cdot N_{d_{i}} \cdot \omega_{i}}{N^{2}}
$$

donde $d_{i}$ es el estado del recurso monitorizado definido como:

$$
d_{i}=\left\{\begin{array}{ll}
0 & \text { si se detecta que el recurso está libre } \\
1 & \text { si se detecta que el recurso está ocupado }
\end{array},\right.
$$


$N$ es el número de notificaciones de evento consideradas en el mecanismo de toma de decisiones, incluyendo notificaciones de recurso libre, $N_{0}$, y notificaciones de de recurso ocupado, $N_{1}$. Por su parte, $N_{d_{i}}$ es el número de medidas que coinciden en la detección del estado $d$ del recurso al que se refiere la notificación $i$-ésima: $N_{0}$ si el recurso está libre y $N_{1}$ si el recurso está ocupado.

Tal como refleja la ecuación (5.6), la métrica de decisión $U$ dependerá del número de medidas que se tengan en cuenta, del peso de cada medida y del valor de la mayoría de medidas que se estén considerando. Si la mayoría de las medidas coinciden en que el recurso está libre, se obtendrá un valor positivo de $U$. Por contra, si la mayoría de las medidas coinciden en que el recurso está ocupado, se obtendrá un valor negativo. Nótese que, con el fin de normalizar el valor de $U$, es necesario dividir por el cuadrado de $N$, de forma que se cumpla $-1 \leq U \leq 1$.

Dependiendo del valor de $U$ se toma la decisión $D$, que declara el recurso en cuestión como candidato a asignar $\left(H_{0}\right)$ si el valor es mayor que un determinado umbral, $\gamma$, tal y como expresa la ecuación (5.8). En otro caso, el recurso no está disponible para hacer uso oportunista de él $\left(H_{1}\right)$. El umbral de decisión $\gamma$ debe ajustarse para obtener el máximo provecho del AOE sin interferir al sistema primario.

$$
D=\left\{\begin{array}{ll}
H_{0}, & U \geq \gamma \\
H_{1}, & U<\gamma
\end{array},\right.
$$

\subsubsection{Reparto de recursos para la minimización de interferencias}

Como ya se ha mencionado anteriormente, una de las mayores preocupaciones del AOE es la minimización de la interferencia sobre el sistema primario. El uso oportunista de un recurso debe limitarse a las zonas donde se ha declarado el mismo como libre. Con este objetivo en mente, la potencia transmitida en los recursos utilizados de forma oportunista debe ser controlada dinámicamente por el sistema secundario. Esta filosofía es generalmente conocida en la literatura como Control de Potencia (CP) [131].

Una vez que la BD-Geo está actualizada y se conoce qué recursos del primario pueden ser utilizados, es posible asignarlos a usuarios del sistema secundario - en forma de RBs - para incrementar los recursos existentes en el sistema LTE-A. El comportamiento dinámico e impredecible del sistema primario fuerza la utilización de un perfil irregular de potencias de transmisión para los recursos oportunistas asignados a cada usuario en función de la distancia con el sistema primario, ya que la potencia debe ser lo suficientemente baja como para no interferir en la banda primaria. Puede ocurrir que no se detecte actividad del sistema primario en toda la zona servida por un determinado eNB. 


\section{CAPÍTULO 5. OPTIMIZACIÓN DEL USO DEL ESPECTRO}

En ese caso, el sistema LTE puede utilizar toda la banda licenciada de forma oportunista sin restricciones de potencia. Por el contrario, si en ciertas zonas dentro del área de cobertura del eNB se ha decidido que existe actividad por parte del sistema primario, la potencia de trasmisión debe limitarse para que no llegue suficiente señal como para interferir en las zonas donde se ha detectado actividad, intentando minimizar las interferencias ocasionadas al mismo. Esta restricción define un límite espacial en cuanto a la aplicación del AOE, que se puede representar como el radio de una circunferencia en la cual el AOE está disponible. La figura 5.32 explica este concepto mostrando un escenario simplificado donde se representan una estación base para el sistema primario y un eNB con capacidades de AOE. En este ejemplo, las áreas de cobertura del sistema primario y del eNB, que se representan con elipses de trazo discontinuo, se solapan parcialmente, siendo el AOE únicamente aplicable dentro del área definida por la elipse de trazo continuo. Por ello, la señal LTE transmitida en la banda primaria no debe exceder los límites de dicha zona, siendo necesario transmitir con potencia reducida.



Figura 5.32: Escenario de AOE simplificado

Cada eNB tiene una potencia máxima de transmisión que tiene que distribuir entre todos los RBs disponibles. Esto significa que los recursos que se utilizan de forma oportunista y que van a ser asignados a algún usuario se deben tener en cuenta en esta distribución de potencia. El sistema propuesto solicitará información de la BD-Geo para conocer qué recursos de la banda primaria pueden ser utilizados y, eventualmente, decidirá cuándo utilizarlos. Una vez el sistema sabe cuántos recursos va a asignar el eNB, la obtención de la 
potencia por recursos es inmediata. Sin embargo, es posible que existan restricciones de potencia para los RBs oportunistas, especificadas en la BD-Geo, y que haya que ajustar la potencia asignada a los mismos de acuerdo a la máxima distancia que la señal LTE debe alcanzar. El procedimiento de ajuste consiste en reducir la potencia de transmisión considerando la diferencia en pérdidas de propagación estimadas entre la máxima distancia del área de cobertura de la celda LTE — dada por el percentil $95 \%$ de las distancias de usuarios localizados, extraída de estadísticas off-line - y la máxima distancia donde el recurso puede ser utilizado.

Con el fin de investigar las ventajas de esta estrategia de CP, en la sección 5.4.3 se comparará con la versión sin CP, en la que no se realiza el ajuste de la potencia de transmisión y siempre se transmite con la potencia máxima disponible para todos los recursos que se haya decidido que son utilizables de forma oportunista.

Cabe destacar que la reducción de la potencia de transmisión ha de venir acompañada por una corrección del CQI reportado por el UE con el fin de utilizar un MCS apropiado y acorde a esa reducción de potencia. De acuerdo a las especificaciones de LTE-A, un decremento de la potencia de transmisión en $2 \mathrm{~dB}$ se corresponde con un decremento del CQI en 1 [125].

Tras la asignación de recursos a los usuarios oportunistas, la movilidad de los usuarios aumenta la complejidad debido al incremento de la dinámica del sistema. Además, el servicio de localización puede reportar la posición del usuario con cierta imprecisión que tendrá efectos sobre la consistencia de los datos de las BD-Geo. Ambos aspectos pueden llevar a la generación de interferencias en el sistema primario. El impacto de la precisión de la localización en las prestaciones del sistema se analizará también en la sección 5.4.3.

\subsubsection{Procedimiento de acceso}

En LTE-A la cantidad de recursos disponibles puede incrementarse con el agregado de porciones de espectro continuas o discontinuas, lo que se conoce como CA, hasta llegar a un total de $100 \mathrm{MHz}$ [132], repartidos en dos o más Component Carrier (CC), siempre que el UE tenga la capacidad de recibir en más de una portadora simultáneamente. En el contexto de CR, el concepto de CA puede extenderse para permitir que se puedan añadir al espectro disponible los espacios en blanco de la banda de un sistema primario, para utilizarlos de forma oportunista y sin causar interferencia en el mismo. Éste es el principal concepto en el cual se basa el AOE, proporcionando capacidades ampliadas y una flexibilidad mejorada en la agregación de recursos espectrales para mejorar el throughput y la eficiencia espectral. 


\section{CAPÍTULO 5. OPTIMIZACIÓN DEL USO DEL ESPECTRO}

En cada CC se necesita ajustar una serie de parámetros de transmisión oportunista — por ejemplo, potencia de transmisión, MCS, etc. - para los espacios en blanco disponibles. Como consecuencia, para cada CC se necesita un tratamiento independiente de los procesos HARQ y la señalización de control asociada a los mismos. En esta situación, el correcto diseño del canal de señalización de control es crucial. En general, de acuerdo a las discusiones internas del 3GPP hay tres posibles implementaciones del canal de control en CA [133]:

a) Cada CC tiene su propio canal de control codificado y se requieren modificaciones menores de la estructura de control del sistema LTE — figura 5.33, a) -

b) Los canales de control de CCs diferentes se puede codificar y transmitir conjuntamente en un canal de control dedicado - figura 5.33, b) - .

c) Se codifican y transmiten los canales de control de múltiples CCs sobre toda la banda de frecuencia formada por la banda LTE y la banda agregada - figura 5.33, c)-.

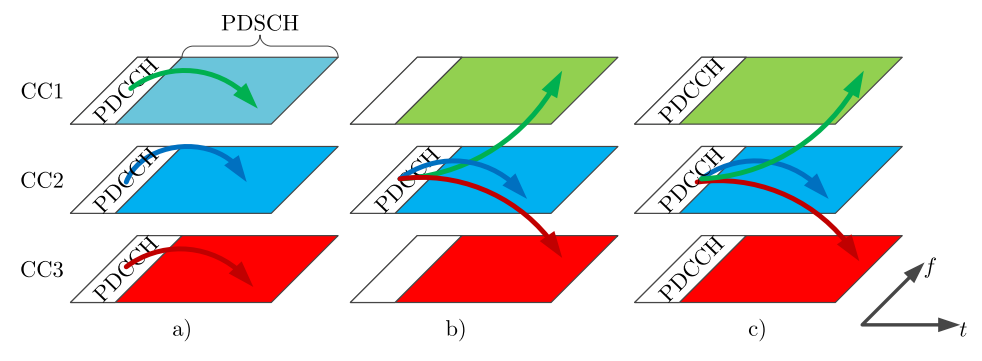

Figura 5.33: Posibilidades de señalización en LTE-A con CA habilitado

Las propuestas a) y c) son incompatibles con el AOE ya que se necesita transmitir información de control sobre la banda primaria antes de saber si está banda se puede utilizar de forma oportunista, dando lugar a colisiones con el sistema primario. Por lo tanto, el sistema de AOE propuesto requiere la implementación del esquema de señalización de control b), en el cual la señalización de todas las CC agregadas se transmite por el canal de control del sistema LTE. Los usuarios oportunistas leerán la información de control en la banda LTE y a continuación, de acuerdo a esa información, transmitirán o recibirán datos en las CCs indicadas. Este procedimiento debe realizarse periódicamente con el fin de dejar de hacer uso de los recursos oportunistas tan pronto se detecte actividad en el sistema primario. Los UEs de LTE pueden 
realizar esta operación cuando todas las CCs son contiguas, incluyendo la banda LTE [98]. Sin embargo, en el caso de que las CCs no sean contiguas y suponiendo que los UEs tienen únicamente un interfaz radio, una vez que el UE lee el canal de control y averigua los recursos que le han sido asignados tiene que sintonizar su frecuencia de trabajo a la CC asignada, sincronizarse con el sistema LTE para comenzar la transmisión o recepción de datos y, tras un intervalo de tiempo determinado, volver a la banda LTE para leer el canal de control. Esta situación es impracticable en el ámbito del AOE ya que el tiempo entre resintonizaciones debe ser muy corto para poder proporcionar información actualizada de la disponibilidad de recursos en la banda primaria y, incluso si el terminal es capaz de realizar una resintonización muy rápida, el tiempo efectivo para sacar provecho de esos recursos se vería muy reducido. Una solución factible a este problema es la asignación de recursos de forma semi-persistente [134], de forma que se alargue la periodicidad con la que se lee el canal de control (hasta varios segundos). Durante el tiempo que el UE tiene asignados los mismos recursos de forma semi-persistente, no se está teniendo en cuenta el estado real del canal primario, ya que no se está recibiendo la información de control tan frecuentemente. Por esta razón, cuando más tiempo esté el UE sin leer el canal de control, mayor es la probabilidad de provocar interferencia en el sistema primario.

Por último, es importante aclarar que la utilización de un sistema oportunista basado en Orthogonal Frequency-Division Multiplexing (OFDM) en el que se pueden utilizar de forma oportunista canales no contiguos, no acarrea ninguna complicación ya que se pueden introducir ceros en las entradas correspondientes a determinadas subportadoras del bloque que realiza la Fast Fourier Transform (FFT) inversa en el transmisor para no provocar interferencias en el sistema primario. En el receptor la FFT a realizar para recuperar los datos transmitidos tampoco supondrá un problema para el modo de operación de AOE. En [135] se propone una implementación eficiente de un transceptor NonContiguous Orthogonal Frequency-Division Multiple Access (NC-OFDMA) para aplicaciones de CR.

\subsubsection{Resultados y Discusión}

\subsubsection{Escenario de simulación y configuración de parámetros}

Para el análisis del AOE se ha considerado un escenario ficticio donde un único eNB LTE-A y una estación base de otro sistema - el sistema primariocoexisten. El sistema primario trabaja en la banda de 2,3 GHz mientras que la frecuencia portadora del sistema LTE-A es 2 GHz. Las áreas de cobertura de ambos sistemas se solapan parcialmente tal como se representa en la figura 5.32. 


\section{CAPÍTULO 5. OPTIMIZACIÓN DEL USO DEL ESPECTRO}

El grado de solape puede variarse con el fin de estudiar hasta qué punto el AOE proporciona mejoras significativas en la capacidad dependiendo de la distancia entre el sistema primario y el secundario. Los usuarios LTE-A se distribuyen aleatoriamente dentro del área de cobertura del sistema LTE-A. La actividad del sistema primario se produce de forma intermitente con periodos de actividad e inactividad aleatorios siguiendo una distribución de Pareto de procesos ONOFF [136] con la siguiente función de distribución de probabilidad:

$$
f(x)=k \frac{x_{m}^{k}}{x^{k+1}}, \quad x \geq x_{m}
$$

donde $k$ es el parámetro de forma y $x_{m}$ el parámetro de escala de la distribución de Pareto. Diferentes combinaciones de estos dos parámetros resultan en diferentes periodos de la actividad del sistema primario, $T_{A P}$, es decir, diferentes intervalos medios $\mathrm{ON}-\mathrm{OFF}$ en el sistema primario. En el simulador, la actividad del sistema primario se modela con un factor de actividad, $F_{A P}$, que se corresponde con el $T_{A P}$ normalizado. La tabla 5.14 muestra los parámetros de simulación más relevantes utilizados.

En este estudio se han utilizado dos métricas diferentes. Por un lado, el máximo throughput servido por el eNB con UEs full-buffer. Por otro lado, la tasa de colisiones, que modela la probabilidad de que la actividad del sistema primario interfiera con el sistema LTE-A. La tasa de colisiones se calcula como la relación entre el número de veces que un usuario ubicado en zona de solape entre ambos sistemas realiza AOE cuando el primario está activo y el número total de veces que se realiza AOE. Esta colisión puede ocurrir tanto porque la información disponible en la BD-Geo tarde en actualizarse cuando se produce un cambio en la actividad del primario como por errores cometidos por el algoritmo de localización, los cuales pueden llegar a dejar la BD-Geo en un estado inconsistente que afecte a los usuarios que estén en la zona límite de uso del AOE. Nótese que con esta forma de definir las colisiones únicamente se están considerando las colisiones que afectan al sistema LTE, que es sobre el que se están evaluando las prestaciones, y no al sistema primario. Se establece un objetivo del $10 \%$ o menos para esta tasa de colisiones.

\subsubsection{Calibración de la detección}

Antes de obtener los resultados de las prestaciones de las herramientas oportunistas implementadas en el sistema LTE-A, primero es necesario optimizar el mecanismo de detección de espectro cooperativa para obtener el mayor rendimiento posible del AOE. Esta optimización consiste en establecer el valor más apropiado del umbral de decisión descrito en la sección 5.4.2.1 y, de acuerdo a este umbral, establecer un valor adecuado para la periodicidad de la detección, es decir, el MGRP. 
Tabla 5.14: Parámetros de simulación

\begin{tabular}{cc}
\hline Parámetro & Valor \\
\hline \hline Distribución de celdas & 1 eNB omni-direccional $/$ \\
$N^{\circ}$ usuarios & 1 transmisor primario \\
Frecuencia LTE-A & 100 \\
Ancho de banda LTE-A & $2 \mathrm{GHz}$ \\
Frecuencia primario & $5 \mathrm{MHz}(25 \mathrm{RBs})$ \\
Ancho de banda primario & $2,3 \mathrm{GHz}$ \\
Scheduling & $5 \mathrm{MHz}$ \\
Modelo de propagación & Round Robin $($ banda LTE-A $) /$ \\
Modelo de shadowing & MaxCIR $[137]($ banda primaria $)$ \\
$k$ & UMa $[50]$ \\
$x_{m}$ & Log-normal, $\sigma=4 \mathrm{~dB}$ \\
$T_{A P}$ & 60 \\
Movilidad & $50 \mathrm{~s}$ \\
No máximo de usuarios en scheduling & 10 \\
Probabilidades FA/MD & Usuarios estáticos \\
Producto tiempo-ancho de banda $(m)$ & $0,028 / 0,01($ objetivo $)$ \\
SINR recibida del primario $\left(\bar{\gamma}_{p}\right)$ & 930 \\
Tiempo de simulación & $8 \mathrm{~dB}$ \\
& $1000 \mathrm{~s}$ \\
\hline
\end{tabular}

En la figura 5.34 se muestran las prestaciones del sistema LTE-A en términos de throughput y tasa de colisiones para un umbral de decisión $\gamma$, con valores entre -1 y 1. Se comparan también las tres alternativas propuestas para el peso de cada una de las muestras tenidas en cuenta en la decisión cooperativa: lineal — ecuación (5.3) — , cuadrático — ecuación (5.4) - y raíz cuadrada - ecuación (5.5) — . En este análisis, la periodicidad de la detección se ha establecido en $40 \mathrm{~ms}$, siendo el solape entre los sistemas primario y secundario del $40 \%$. Umbrales con valores pequeños implican necesitar menos muestras indicando la disponibilidad del canal antes de utilizar los recursos de forma oportunista, lo que incrementa la probabilidad de colisión. Por contra, umbrales con valores grandes implican menos colisiones pero también una reducción de incremento de capacidad conseguido con el AOE. Como puede apreciarse, una buena elección que proporciona tanto máximo throughput como baja probabilidad de colisión es tomar $\gamma$ igual a cero, por lo que de aquí en adelante se usará este valor. También se puede observar que se obtienen resultados simila- 


\section{CAPÍTULO 5. OPTIMIZACIÓN DEL USO DEL ESPECTRO}

res en las versiones linear y cuadrática para $\gamma=0$, por lo que se sugiere usar la versión lineal ya que es la de menor complejidad.
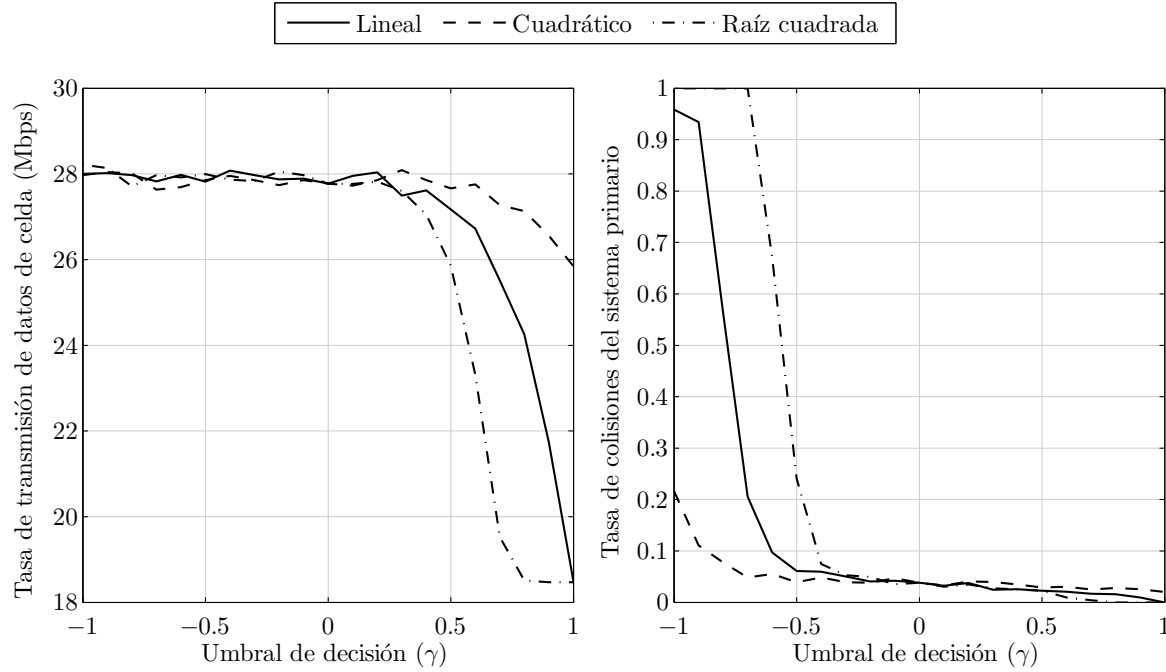

Figura 5.34: Rendimiento del sistema en función del umbral de decisión

Una vez se ha establecido el valor óptimo del umbral de decisión, es necesario comprobar los beneficios de las decisiones soft en comparación con las decisiones hard. Con este propósito, la figura 5.35 muestra las prestaciones del sistema para distintos periodos de detección de espectro, para los tres algoritmos de decisión descritos en la sección 5.4.2.1. La linea continua corresponde al algoritmo de decisión soft propuesto, mientras que las líneas discontinuas se corresponden con las estrategias conservadora - rayas - y agresiva - rayas y puntos - La figura 5.35 muestra que el algoritmo de decisión propuesto proporciona un throughput similar al conseguido por la estrategia agresiva, pero con una probabilidad de colisión mucho más baja. Esto es debido al algoritmo de decisión de scheduling utilizado y al solape parcial de los sistemas primario y secundario en el escenario simulado. Como la estrategia de reparto de recursos trata de alcanzar el máximo throughput, siempre selecciona a los usuarios que están más cerca del eNB, que, debido al solape parcial del $40 \%$ con el sistema primario, no estarán en zona de cobertura del sistema primario y, por tanto, no tendrán interferencias. La diferencia se encuentra en la interferencia causada en el primario, que viene determinada por el control de potencia y que pondrá límites de potencia de transmisión distintos en el algoritmo agresivo y el propuesto. 

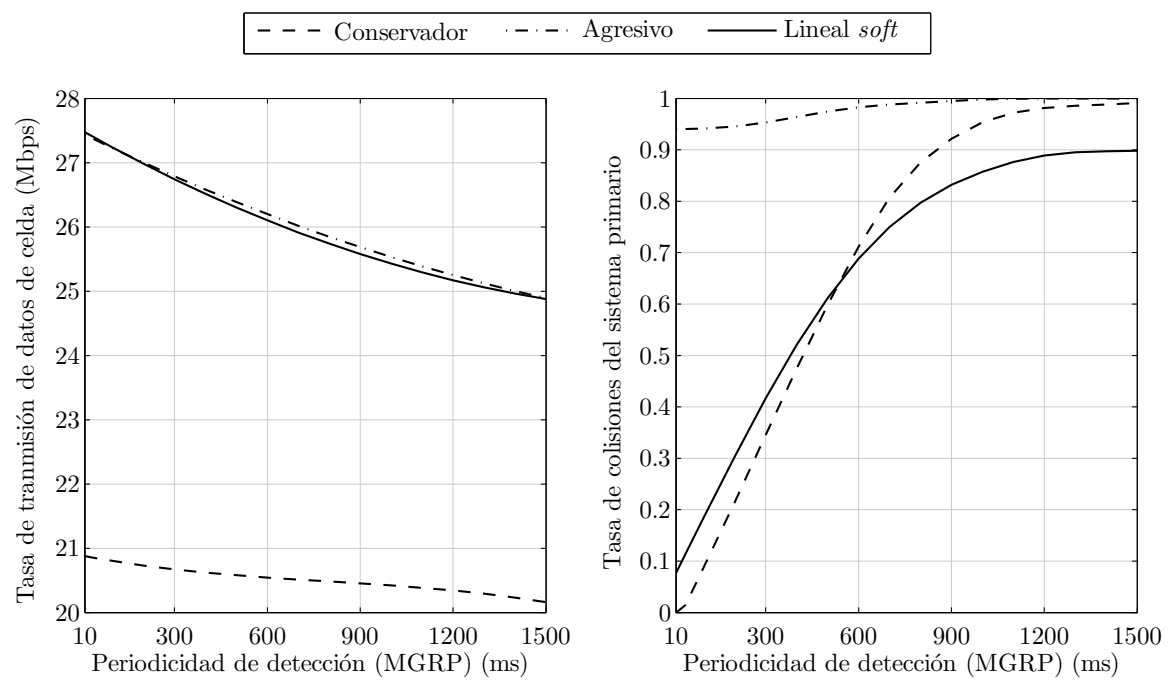

Figura 5.35: Rendimiento del sistema en función del mecanismo de decisión y el periodo de detección

También se puede apreciar en la figura 5.35 qué valores de MGRP provocan incertidumbre en el conocimiento del estado de la banda primaria y hacen que las transmisiones oportunistas colisionen con el sistema primario. Asimismo, se observa que el incremento del periodo de la detección no incrementa el throughput como se podría esperar hasta cierto punto. Con valores del MGRP mayores del mínimo, ya comienza a tener efecto el hecho de que se disponga de información desactualizada sobre el estado del canal y no llegar a compensar en ningún momento el hecho de tener más tiempo para transmitir o recibir datos respecto al tiempo dedicado a la detección de espectro. Se establece, por tanto, el valor del MGRP en el mínimo posible - 10 ms de acuerdo con el estándar [124] que especifica que el MGRP es configurable en múltiplos de la longitud de trama - ya que con este valor se consigue la mínima probabilidad de colisión junto con el máximo throughput.

Tal y como se desprende del valor de MGRP establecido en 10 ms y dado el valor de MGRP efectivo fijado previamente en la sección 5.4.1.2, será necesario reservar uno de cada ocho huecos de medida para la realización de medidas de vecinas intra e inter-sistema para permitir la operación normal de los procesos de handover ajenos a la banda cognitiva. 


\section{CAPÍTULO 5. OPTIMIZACIÓN DEL USO DEL ESPECTRO}

\subsubsection{Evaluación del algoritmo cooperativo}

Otro aspecto crítico de las técnicas de AOE basadas en BD-Geo es la precisión del método de localización utilizado. Si un UE se localiza incorrectamente en un área donde se permite el AOE pero su ubicación real está en una zona donde no se permite, se asignarán recursos al UE en la banda primaria pero recibirá mucha interferencia del sistema primario. Además, el error de localización puede producir otros problemas cuando debe limitarse la potencia de transmisión en función de la distancia a la que se detecta el sistema primario. En caso de que la distancia de alcance máximo de la señal oportunista esté sobre-dimensionada, se incrementará el número de colisiones. Como resultado, los resultado conseguidos por el mecanismo de CP y, por tanto, las prestaciones del AOE se pueden ver comprometidas. Con el objetivo de estudiar el impacto de la precisión del método de localización, se ha modelado el error de localización con una distribución Gaussiana. De esta forma, la figura 5.36 muestra la diferencia entre implementar - linea continua - o no - linea discontinua el mecanismo de CP propuesto para diferentes errores de localización — de 10 a 150 metros - . Tal como podía esperarse, la ausencia de un mecanismo que controle la potencia con la que sea transmite de forma oportunista en la banda primaria causa un incremento de las colisiones con el sistema primario. En la figura 5.36 se puede observar que, para el caso de utilizar el mecanismo de CP, el máximo error de localización que permite tener una tasa de colisiones por debajo del $10 \%$ es de 25 metros.

Por otro lado, los resultados de simulación obtenidos muestran que el throughput por celda apenas se ve afectado por la precisión de localización de los UEs. Esta precisión afecta principalmente a la probabilidad de colisión de los usuarios más cercanos al límite de uso del AOE, que son los que por un error de localización puede determinarse que están dentro del límite sin que lo estén en realidad, ocasionando que la transmisión del primario les interfiera y provocando que los recursos que les son asignados de forma oportunista no contribuyan a aumentar el throughput. Dado que se utiliza un scheduling MaxCIR, esos usuarios del borde de la zona de AOE tienen pocas probabilidades de obtener recursos en la banda primaria y, en caso de conseguirlos, se utilizará un MCS muy robusto por lo que el throughput será reducido. Por estas razones, el throughput apenas varía cuando se producen interferencias del sistema primario sobre las señales recibidas por estos usuarios.

\subsubsection{Impacto del solape y actividad del sistema primario}

En un escenario real las estaciones base se distribuyen de forma que se cubra todo el área de servicio. Por esta razón, la distancia entre eNBs y el sistema primario puede variar de un emplazamiento a otro. Esto puede derivar en mayores 

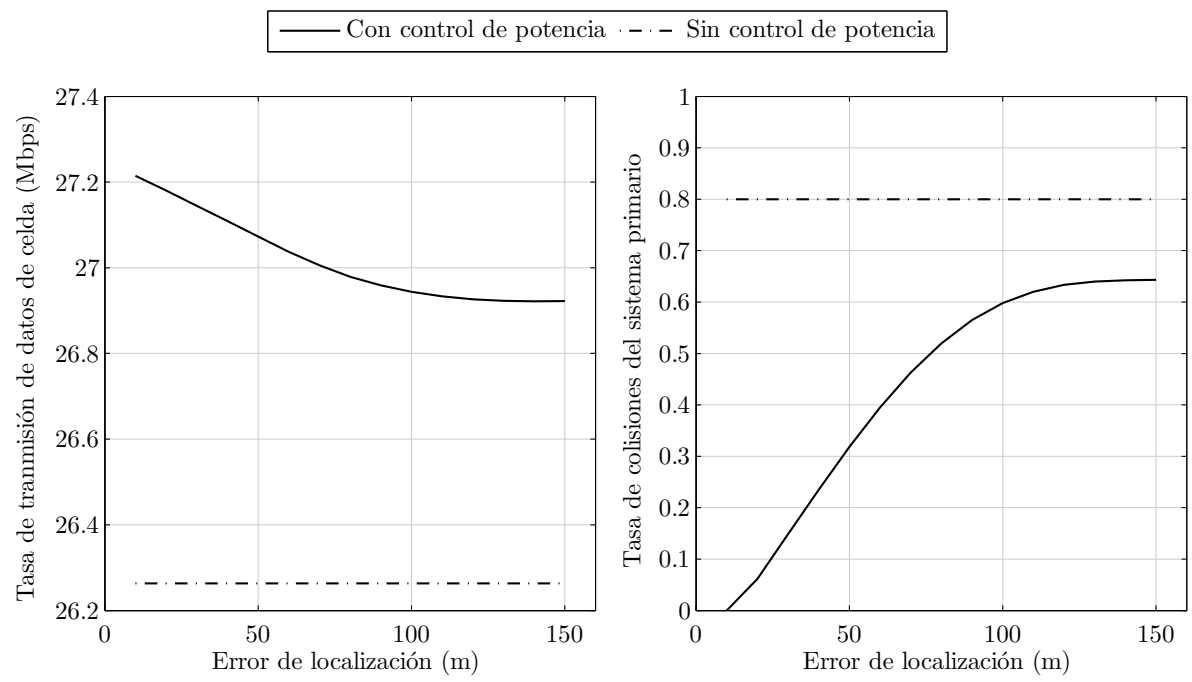

Figura 5.36: Impacto de la precisión del mecanismo de localización

o menores grados de solape entre los sistemas primario y oportunista, en caso de que lleguen a solaparse. Por lo tanto, es necesario evaluar el rendimiento de las herramientas oportunistas descritas en este estudio bajo diferentes situaciones de solape. Se define el factor de solape, $F_{S}$, como el porcentaje de usuarios bajo cobertura del sistema LTE-A que están en situación de detectar actividad en el primario cuando éste está activo. Además, la actividad del sistema primario en un cierto periodo de tiempo depende del sistema primario en sí y su tipo de tráfico específico. Esta sección trata la dependencia del sistema propuesto con respecto a estos dos parámetros.

La figura 5.37 representa el throughput del eNB del sistema LTE-A respecto al $F_{S}$ para diferentes factores de actividad del sistema primario - ver definición del $F_{A P}$ en la sección 5.4.3.1- . Los resultados muestran, como es obvio, que cuanto mayor es la actividad del primario menor es el número de recursos disponibles para el AOE y, por tanto, el throughput conseguido. El $F_{S}$ también afecta a las capacidad, especialmente para tiempos de actividad del sistema primario mayores que el $40 \%$ del tiempo de simulación total. Sin embargo, la probabilidad de colisión no se ve afectada por la variación del $F_{S}$, aunque sí por el $F_{A P}$, como muestra la figura 5.38. La probabilidad de colisión aumenta cuando disminuye la actividad en el primario, debido a que la principal causa de las colisiones es la inconsistencia de la BD-Geo respecto al estado real de la banda del sistema primario. Cuando la banda del sistema primario deja de 


\section{CAPÍTULO 5. OPTIMIZACIÓN DEL USO DEL ESPECTRO}

estar disponible pero el sistema oportunista sigue utilizando los recursos porque la BD-Geo indica que están disponibles, las colisiones producidas por esta desactualización quedan diluidas en un mayor número de usos oportunistas del espectro primario cuando el $F_{A P}$ es mayor, dando una menor tasa de colisiones.

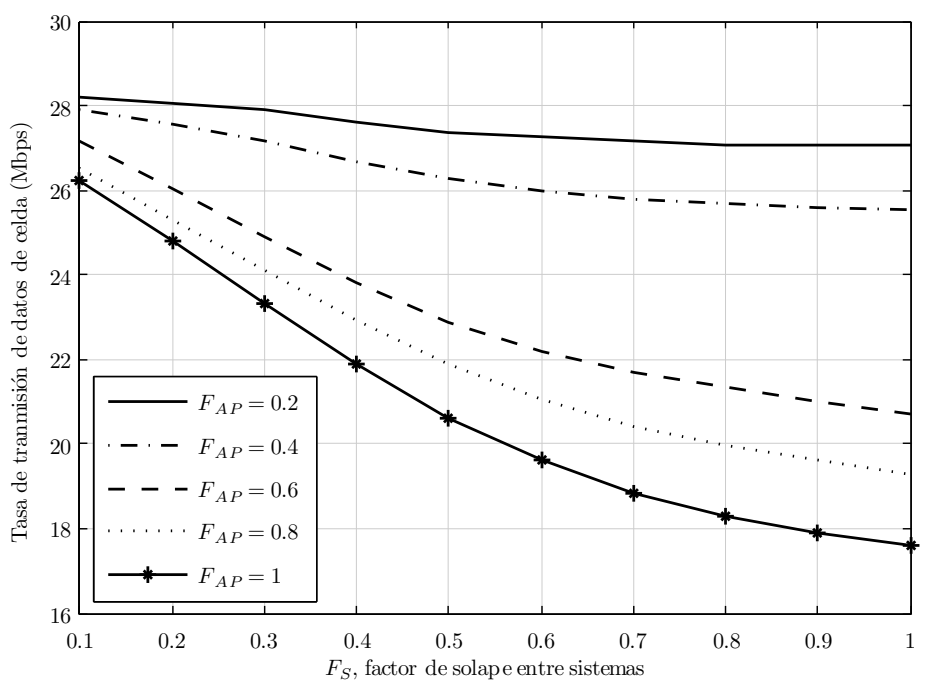

Figura 5.37: Impacto sobre el throughput del factor de actividad del sistema primario y el solape con el secundario

\subsection{Auto-organización de Femtoceldas}

El desarrollo actual de LTE es un paso importante hacia la consecución de un sistema de banda ancha inalámbrico real. LTE promete alcanzar tasas de transmisión de datos de 300 Mbps en DL y 75 Mbps en UL para anchos de banda de $20 \mathrm{MHz}$. Además, los últimos esfuerzos de investigadores y organismos de estandarización se han centrado en mejorar la eficiencia espectral de LTE con el fin de cumplir, incluso de sobrepasar, los requisitos de IMT-Advanced [138]. Algunas de estas innovaciones están siendo consideradas por el 3GPP como parte de LTE-A. Entre las propuestas adoptadas para su adopción en LTE-A se encuentran tres elementos clave:

- Gestión optimizada de despliegues celulares heterogéneos - combinando macro-/micro-/pico-/femtoceldas-. 


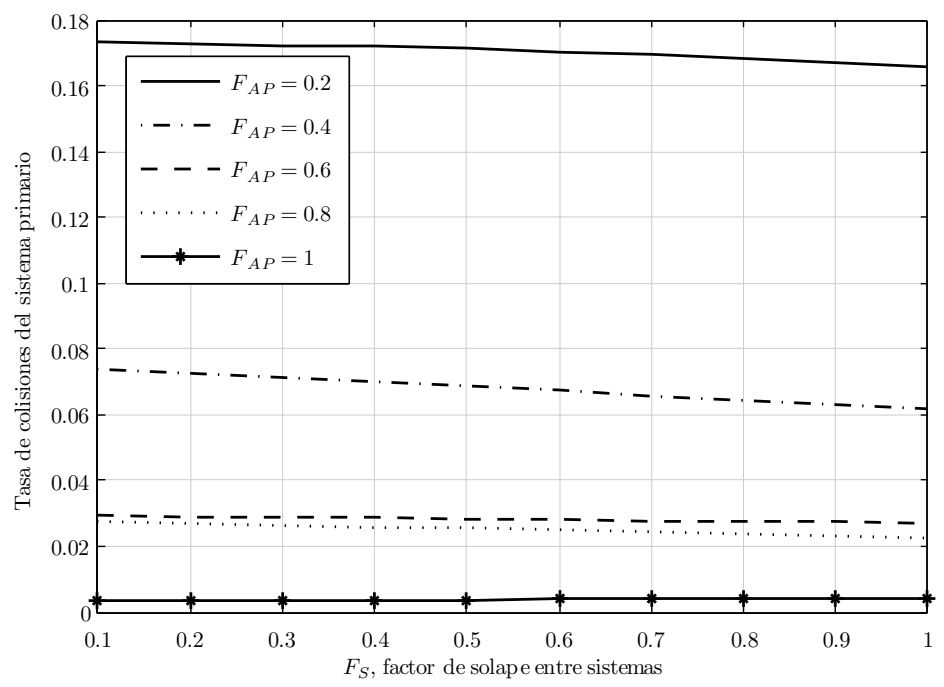

Figura 5.38: Impacto sobre la tasa de colisiones del factor de actividad del sistema primario y el solape con el secundario

- Agregación de espectro tanto continuo como discontinuo mediante CA.

- Uso dinámico y eficiente de los recursos espectrales disponibles a través de técnicas de CR.

Estos dos últimos elementos ya se han considerado en la sección 5.4 como herramientas disponibles para el AOE y serán también clave para la propuesta de auto-organización de femtoceldas que se propone a continuación.

Las femtoceldas, o Home evolved Node Bs (HeNBs) siguiendo la nomenclatura del 3GPP, proporcionan una solución de bajo coste para el operador de comunicaciones móviles inalámbricas, permitiendo proporcionar servicios que requieren altas tasas de transmisión de datos en aquellos lugares donde la señal macrocelular es débil. En general, el nivel de señal de las redes móviles se reduce drásticamente en el interior de edificios debido a las pérdidas de penetración provocadas, por ejemplo, por los muros. No obstante, se puede sacar provecho de esta situación con despliegues femtocelulares si este aislamiento percibido en interiores se acompaña de potencias de transmisión reducidas - normalmente entre 10 y $20 \mathrm{dBm}$ - . De este modo, es posible reutilizar los recursos espectrales macrocelulares con el consiguiente incremento de capacidad. Sin embargo, si el aislamiento no es suficientemente elevado para prevenir las interferencias 


\section{CAPÍTULO 5. OPTIMIZACIÓN DEL USO DEL ESPECTRO}

con la actividad macrocelular, las femtoceldas deben trabajar en otras bandas de frecuencia. Alternativamente, y teniendo en mente la bien conocida escasez de recursos frecuenciales y el hecho de que algunas bandas no se aprovechan al máximo, la femtocelda podría buscar bandas de frecuencia pertenecientes a otras tecnologías y que estén desocupadas. En este caso, las características y funcionalidades de las técnicas de CR pueden ser utilizadas para identificar bandas de frecuencia libres y hacer uso oportunista de las mismas, sin producir ni recibir interferencias del sistema primario licenciado en esa banda, a través de mecanismos de AOE como los vistos en la sección 5.4.

El estudio que se presenta a continuación se centra en el uso oportunista de espacios en blanco en la banda de televisión por parte de femtoceldas dentro de un sistema LTE-A. Se ha seleccionado este sistema primario debido a que es bien conocido que utiliza un esquema de asignación de espectro un tanto ineficiente, en el que algunos canales de televisión no se ocupan nunca en determinadas áreas geográficas porque la actividad en dichos canales causaría interferencias co-canal o de canal adyacente en estaciones vecinas [139]. En esta situación, un transmisor de baja potencia, como una femtocelda, operando en la banda de frecuencia de canales de televisión localmente desocupados, no interferiría en los canales de televisión activos en esa localización. De hecho, los reguladores de Europa y Norteamérica están empezando a promover el AOE en los espacios en blanco de la banda de televisión. Además, cabe destacar que estos espacios en blanco pueden ser mejor aprovechados si se desarrolla la actividad de AOE en interiores en lugar de en exteriores ya que el aislamiento proporcionado por los edificios permite una mayor reutilización de frecuencias y reduce las interferencias.

El problema de la coordinación de interferencias entre macro y femtoceldas, o entre celdas en general, es un tema de exhaustiva investigación [140, 141]. Las soluciones propuestas se basan en el preprocesado de medidas de celda y el intercambio de información entre entidades para ajustar los parámetros de transmisión con el fin de evitar interferencias. Sin embargo, el éxito de los despliegues de femtoceldas LTE depende de la baja complejidad y, por tanto, del bajo precio del equipamiento necesario, por lo que deben diseñarse soluciones simples que permitan el desarrollo práctico del AOE en estos entornos.

De forma similar a la solución de AOE propuesta en la sección 5.4, en esta Tesis Doctoral se propone el uso de IEEE 802.21 MIH para la comunicación de información sobre interferencias a un controlador central encargado de la coordinación entre distintas femtoceldas oportunistas. La principal aportación de esta propuesta procede de su inmediata aplicabilidad en LTE-A, ya que toda la señalización necesaria está actualmente disponible en la red y el modelo de sistema sigue fielmente las especificaciones. Además, esta propuesta no implica 
un incremento del coste computacional en las femtoceldas, por lo que es muy interesante desde el punto de vista de la reducción de costes.

\subsubsection{Coordinación de Interferencias entre HeNBs LTE-A}

Las especificaciones de LTE destacan la importancia de la señalización para control de interferencias entre HeNBs [142]. Como consecuencia, se ha incluido recientemente en el estándar el intercambio directo de mensajes entre femtoceldas a través de la interfaz X2 [143], si bien el flujo de información y los mecanismos concretos de reducción de interferencias no se especifican. La comunicación directa requiere conocer la lista de celdas vecinas de antemano. Esto no es un problema ya que los HeNBs están conectados a través de la interfaz S1 al Home evolved Node B Gateway (HeNB-GW), el cual puede proporcionarles una lista de femtoceldas vecinas.

Una vez conectados, los HeNBs pueden coordinarse ellos mismos de forma autónoma utilizando el procedimiento LOAD INDICATION del X2 Application Protocol (X2-AP) [144]. Este procedimiento permite a los HeNBs informar a HeNBs vecinos acerca de sus condiciones de carga e interferencia. Por lo que respecta al estado de interferencias en DL, los HeNB pueden intercambiar un mapa de bits conocido como indicador Relative Narrowband Transmit Power (RNTP) para informar a sus vecinos sobre sus intenciones de transmitir en un determinado RB por encima de un cierto umbral o no - un bit por RB-, siendo el nivel umbral y el periodo de envío completamente configurables. En relación al enlace ascendente se pueden intercambiar dos mensajes: el Interference Overload Indication (IOI), que indica el nivel de interferencia monitorizado por el HeNB en todos los RBs, y el High Interference Indication (HII), el cual sirve para informar sobre próximas transmisiones en UL. El uso de estos mensajes permite a los HeNBs decidir cuál es la mejor asignación de recursos para los usuarios a los que sirven, de acuerdo a los niveles de interferencia introducidos por sus vecinos.

El principal problema de un mecanismo de coordinación de interferencias distribuido, como éste basado en la comunicación por la interfaz X2, es que consumiría una parte significativa de la capacidad computacional en el HeNB. Además, la carga extra de señalización colapsaría también la femtocelda en el caso de estar ésta diseñada para conseguir un bajo coste. Por esta razón, a continuación se propone un paradigma alternativo que busca reducir al máximo la carga computacional extra en la femtocelda debido a la coordinación de interferencias, a la vez que se consiguen minimizar las mismas. 


\section{CAPÍTULO 5. OPTIMIZACIÓN DEL USO DEL ESPECTRO}

\subsubsection{Procedimiento de Auto-organización}

Una alternativa al mecanismo de decisión cooperativa basado en la información intercambiada a través de la interfaz X2 consiste en la centralización de la toma de decisiones en una nueva entidad, el Coordinador de Espectro (CE), asociada con el HeNB-GW tal y como se muestra en la figura 5.39. La misión del CE es notificar a cada femtocelda qué recursos puede utilizar de forma oportunista en la banda cognitiva, de acuerdo a la actividad de las femtoceldas que tiene a su alrededor. La introducción de este nuevo elemento central presenta dos nuevos retos: el mecanismo para detectar todas las vecinas alrededor de una femtocelda y la forma en que se reparten los recursos de forma que no se produzcan interferencias graves entre femtoceldas.

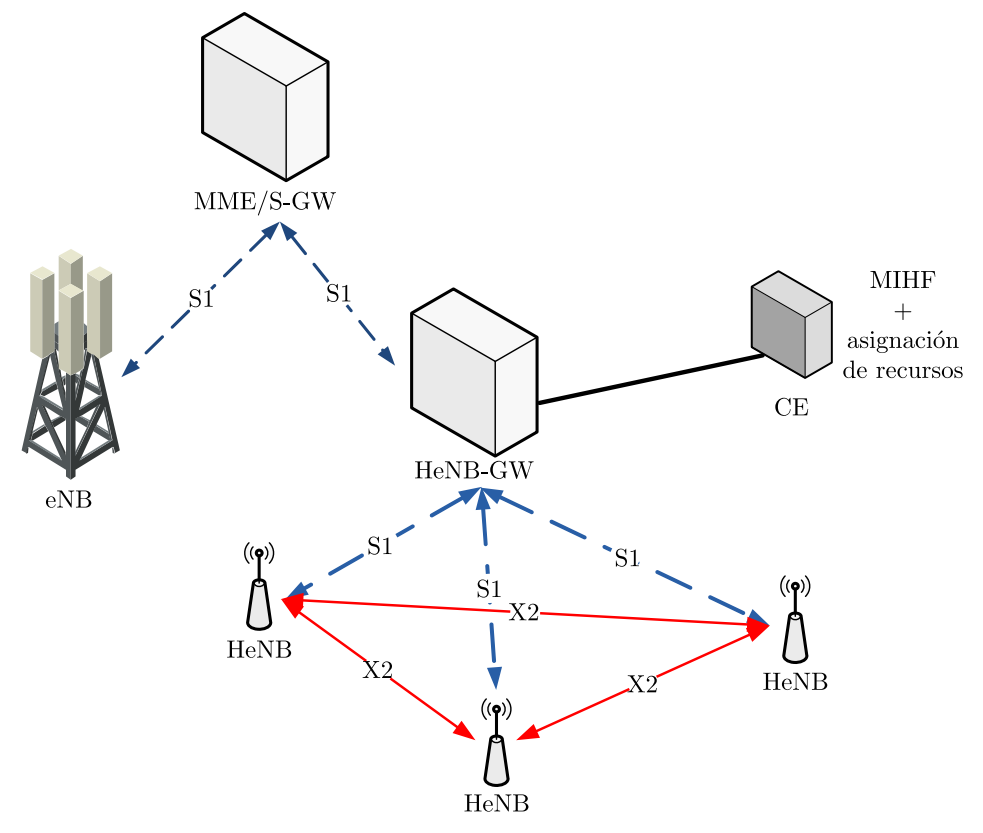

Figura 5.39: Arquitectura de sistema LTE-A con CE

Durante la gestión del espectro cognitivo, el CE elabora una lista dinámica que contiene todas las femtoceldas activas y sus correspondientes vecinas que son potencialmente interferentes. Para poder desempeñar esta función, el CE requiere que las femtoceldas reporten medidas de la banda cognitiva utilizando una señalización específica. Dado que el estándar LTE-A no contempla esta posibilidad, se propone la utilización de señalización MIH [104]. Concretamente, 
la solución propuesta hará uso de la funcionalidad MIES, que ya fue introducida en la sección 5.4.1.3 y que consiste, básicamente, en la notificación de eventos de capa física. El CE implementa una entidad MIHF y es el encargado de realizar la asignación de recursos que evite, en la medida de lo posible, las interferencias entre femtoceldas.

El procedimiento completo de asignación de recursos a Femtocelda Cognitivas (FCs) basado en MIH incluye las siguientes cuatro fases:

- Fase de asociación.

Cuando se instala la FC en una determinada localización y se enciende se conecta al HeNB-GW local a través de la interfaz S1. Una vez se ha establecido este enlace, el CE se suscribe a la notificación de eventos de la FC recién incorporada, la cual también implementa una entidad MIHF. Por lo tanto, el CE envía a la FC un mensaje MIH_Event_Suscribe con la lista de los RBs a monitorizar y el tipo de notificaciones a generar.

- Fase de detección.

A continuación, la FC pasa a monitorizar la actividad en la banda de frecuencias de televisión que el $\mathrm{CE}$ le ha indicado. La FC tiene en esta fase un comportamiento similar al de un UE en modo de escucha. La FC utilizará su capacidad de escuchar redes para sincronizarse con la red del operador y decodificar los canales de broadcast y control de las celdas vecinas. Además, la información recopilada en modo de escucha de red se puede utilizar para identificar celdas vecinas y a qué operador pertenecen, distinguir si son macro o femtoceldas y estimar las pérdidas de propagación hasta ellas. En caso de detectar actividad en el espacio en blanco de la banda de televisión - del sistema primario o de otras celdas oportunistas - la FC envía al CE un mensaje MIH_Link_Detected.indication que contiene información del RB activo, su SINR medida y qué sistemas o Cell-IDs están utilizando el recurso. El mensaje MIH_Link_Parameters_Report.indication permite a su vez que el CE esté al corriente de la desaparición de las interferencias que en algún momento se detectaron. Esta información se envía cuando el nivel de potencia medido supera un determinado umbral establecido por el CE a través de la primitiva $M I H_{-} L i n k_{-}$Configure_Thresholds. Este umbral determina el nivel de solape entre las áreas de cobertura de las FCs que desencadena la puesta en marcha del mecanismo de coordinación de interferencias en el CE. Los resultados obtenidos que se detallan en la sección 5.5.3 permitirán fijar un valor para este umbral. La fase de detección de actividad en la banda oportunista no cesa con la actividad de la propia FC. De toda la información recopilada de todas las FCs, el CE es capaz de crear y actualizar una base de datos que contiene las 


\section{CAPÍTULO 5. OPTIMIZACIÓN DEL USO DEL ESPECTRO}

FCs activas, qué recursos utilizan y cuál es su estado de interferencias, es decir, la lista de vecinas que le interfieren ${ }^{4}$.

- Fase de gestión de recursos.

La FC pasará a estado activo y comenzará a operar únicamente cuando detecte un UE en su área de cobertura. Antes de asignar recursos al UE, la FC debe solicitar información al CE sobre los recursos de la banda cognitiva de los que puede hacer uso oportunista. Básicamente, si dos o más FCs están cercanas entre sí y se interfieren el CE distribuirá los RBs disponibles entre ellas intentando evitar las interferencias. En esta Tesis Doctoral se propone la utilización de un esquema de Hard Frequency Reuse (HFR) [145] en el que se divida el ancho de banda disponible en subbandas de 6 RBs, ya que es el mínimo ancho de banda que puede utilizar una celda LTE. Cada subbanda se asignará a una FC teniendo en cuenta que FCs interferentes deben utilizar subbandas diferentes.

Cuando el CE recibe una notificación que implica un cambio en las condiciones de interferencia de alguna de las FCs que él coordina, comenzará el proceso de gestión de recursos. En primer lugar, el CE identificará la fuente de la notificación y las FCs vecinas cuya área de cobertura solapa con la fuente o alguna de sus vecinas. Se ha denominado a este grupo de celdas como Cluster de Femtoceldas Cognitivas (CFC). Posteriormente, el $\mathrm{CE}$ ordena las FCs del CFC de acuerdo al número de vecinas que tiene cada una. Siguiendo esta lista en orden descendente, el CE asignará subbandas de recursos asegurándose de que no haya solapes entre celdas vecinas. Si es imposible asignar una subbanda a la FC sin producir interferencia co-canal, se asignará la que menores interferencias introduzca. En caso de que el CE recorra toda la lista de FCs y queden recursos por asignar, el proceso comenzara de nuevo desde el principio de la lista.

- Fase de operación.

La asignación de recursos resultante de la fase anterior no tiene por qué permanecer estática. El CE está directamente conectado al HeNB-GW y, por tanto, puede monitorizar el volumen de tráfico de cada FC. El CE también puede controlar el esquema de modulación y codificación que utiliza cada FC para poder detectar si está utilizando los recursos asignados

\footnotetext{
${ }^{4}$ Para ayudar en la solución del problema del nodo oculto, por el cual una FC puede no detectar una celda vecina como interferente debido a ocultamiento pero que la interferencia de la vecina afecte a los UEs servidos por esa FC, será necesario que los UE tengan capacidades cognitivas para detectar la actividad de celdas vecinas en la banda cognitiva, de forma similar a la descrita en la sección 5.4.1.2, y que la información reportada al respecto sea tenida en cuenta por el CE
} 
de forma eficiente. En el caso de que no lo esté haciendo, el CE puede administrar dinámicamente los recursos y "robar" algunos RBs que no estén siendo utilizados eficientemente para asignarlos a otra FC que esté más cargada. Por otro lado, para solventar el problema del nodo oculto, la FC cruza su información de detección con la que reportan los UEs. En el caso de que un UE detecte alguna FC vecina que no esté contemplada en la lista de la FC que le sirve, ésta enviará al CE un mensaje MIH_Link_Detected.indication con la información capturada para que se realice una reasignación de recursos si fuera necesario.

\subsubsection{Resultados y Discusión}

\subsubsection{Escenario y parámetros de simulación}

El análisis de prestaciones de la solución propuesta se basa en la realización de simulaciones a nivel de sistema siguiendo las pautas especificadas por la ITU-R para la evaluación de prestaciones de tecnologías IMT-Advanced [50]. Los detalles acerca del simulador utilizado se han descrito en la sección 2.3.

El escenario simulado consta de un eNB LTE-A operando en una banda de $10 \mathrm{MHz}$ licenciada para LTE-A en $2 \mathrm{GHz}$, coexistiendo con un conjunto de FCs que utilizan de forma oportunista un hueco de $5 \mathrm{MHz}$ en la banda UHF de televisión - $600 \mathrm{MHz}$ - Se ha supuesto que los usuarios conectados a las FCs están en el interior de edificios y los conectados a la macrocelda en el exterior. En la tabla 5.15 se listan los parámetros más relevantes utilizados en las simulaciones.

Dado que en un escenario real el operador no puede controlar el número y localización de las femtoceldas, se ha supuesto un número fijo de ellas distribuidas aleatoriamente por todo el área de cobertura de la macrocelda.

\subsubsection{Prestaciones del sistema}

La evaluación del escenario seleccionado se ha realizado a través de un gran número de simulaciones, utilizando instancias diferentes del escenario en cada una de ellas. Con la ejecución de simulaciones con distintas semillas se ha conseguido la diversidad suficiente de situaciones de solape e interferencia. Los indicadores utilizados se han representado en términos de interferencia más ruido, medida que debería ser utilizada por el CE para determinar en qué situaciones es necesario repartir los recursos disponibles entre celdas interferentes entre sí. El análisis de los resultados de este estudio se ha centrado en la parte de alta interferencia de los mismos.

El primer indicador de prestaciones analizado es el porcentaje de usuarios sin servicio conectados a una FC. Como se puede apreciar en la figura 5.40, el 


\section{CAPÍTULO 5. OPTIMIZACIÓN DEL USO DEL ESPECTRO}

Tabla 5.15: Parámetros de simulación

\begin{tabular}{cc}
\hline Parámetro & Valor \\
\hline \hline $\mathrm{N}^{\mathrm{o}}$ macroceldas & 1 \\
Frecuencia macrocelda & $2 \mathrm{GHz}$ \\
Ancho de banda macrocelda & $10 \mathrm{MHz}$ \\
Potencia total macrocelda & $43 \mathrm{dBm}$ \\
Radio de macrocelda & $166 \mathrm{~m}$ \\
Antena macrocelda & Omnidireccional \\
$\mathrm{N}^{\circ}$ usuarios en macrocelda & 32 \\
Algoritmo de scheduling macrocelda & $\mathrm{PF}$ \\
$\mathrm{N}^{\circ}$ FCs & 8 \\
Frecuencia FCs & $600 \mathrm{MHz}$ \\
Ancho de banda FCs & $5 \mathrm{MHz}$ \\
Potencia total FCs & $18 \mathrm{dBm}$ \\
Radio FCs & $30 \mathrm{~m}$ \\
Antena FCs & Omnidireccional \\
$\mathrm{N}^{\circ}$ usuarios por FC & 4 \\
Algoritmo de scheduling FCs & $\mathrm{PF}$ \\
$\mathrm{N}^{\circ}$ de semillas & 1000 \\
\hline
\end{tabular}

umbral de interferencia más ruido por encima del cual vale la pena activar las funciones de coordinación del $\mathrm{CE}$, proporcionando una mejora en la probabilidad de servicio, es $-12 \mathrm{dBm}$. Este resultado está respaldado por el hecho de que el throughput de los usuarios del borde de la celda es más del $100 \%$ mejor - en media - que el del caso sin coordinación, para niveles de interferencia más ruido por debajo del umbral.

Por otro lado, el análisis del throughput medio en las FCs, como se puede apreciar en la figura 5.41, confirma la necesidad de coordinación en escenarios de alta interferencia. El throughput es más de un $100 \%$ mejor con coordinación que sin ella para los casos entre $-6 \mathrm{dBm}$ y $-12 \mathrm{dBm}$ de nivel de interferencia más ruido. Esta coordinación proporciona tanto mayor probabilidad de servicio como mejores tasas de transmisión de datos, mejorando la experiencia de usuario. Conforme aumentan los niveles de interferencia más ruido, la ganancia obtenida por la coordinación se va reduciendo paulatinamente hasta que las dos curvas llegan a solaparse prácticamente para niveles de $-2 \mathrm{dBm}$ y superiores, donde la situación de interferencia se vuelve inabordable a pesar de la utilización del CE. 


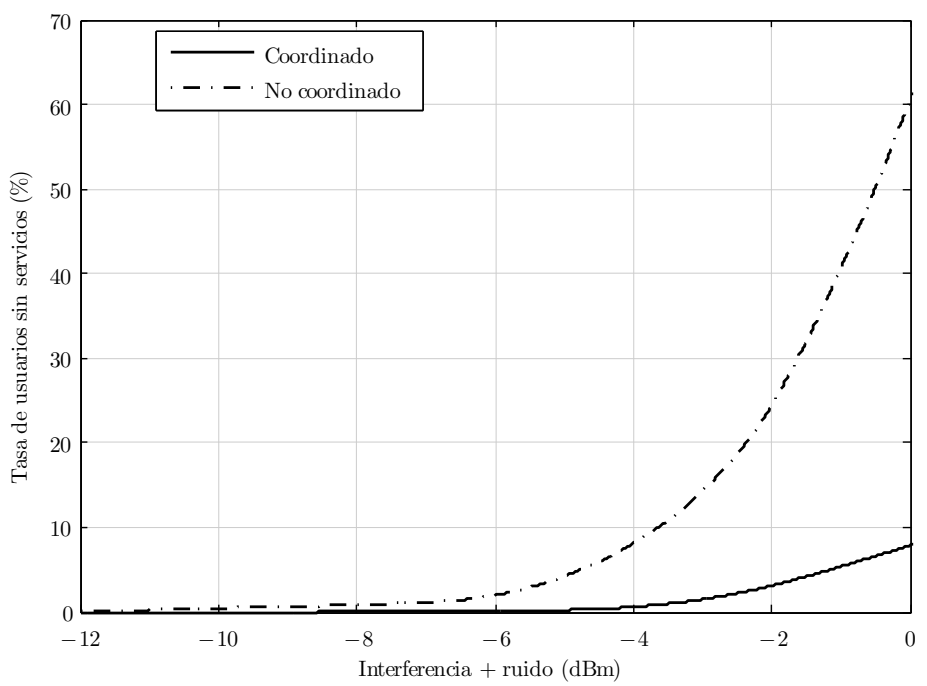

Figura 5.40: Comparación de porcentaje de usuarios sin servicio

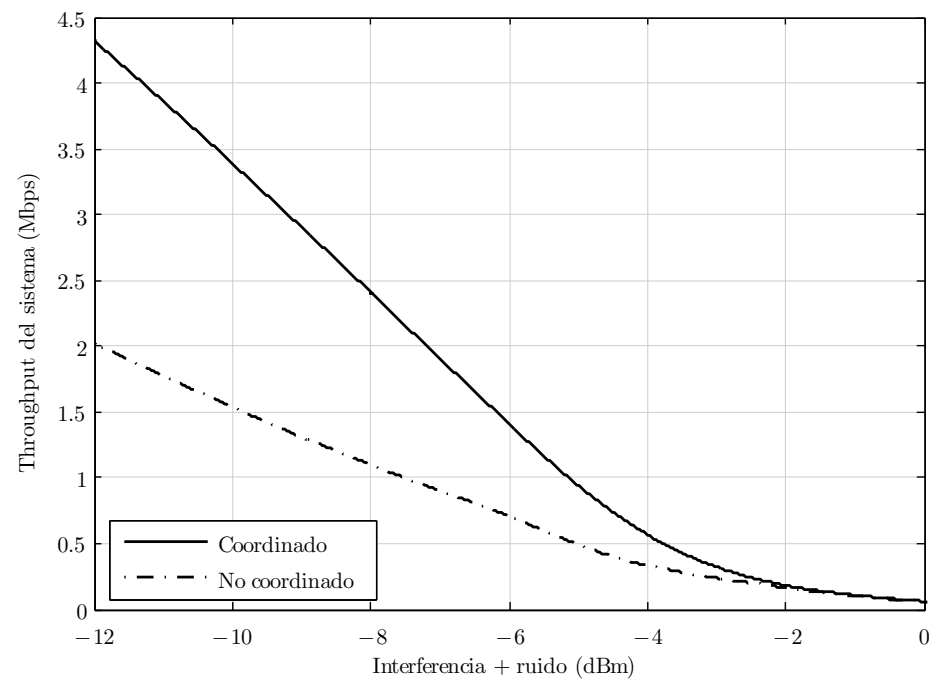

Figura 5.41: Comparación de throughput medio por FC 


\section{Capítulo 6}

\section{Conclusiones y Trabajo Futuro}

\subsection{Conclusiones}

Esta Tesis Doctoral ha tratado de validar las hipótesis formuladas al comienzo de la investigación relativa a la planificación y optimización automática de redes LTE. Se han cumplido todos los objetivos propuestos en el anteproyecto de Tesis, tal y como reflejan los resultados conseguidos. Estos resultados están basados fundamentalmente en comprobaciones empíricas y simulaciones. La colaboración con la empresa Ingenia Telecom ha permitido disponer del contexto idóneo para el desarrollo de esta Tesis Doctoral y el trabajo realizado ha repercutido directamente en la calidad de sus procesos y en la ampliación de su portafolio de productos.

Un elemento básico para el conjunto del trabajo realizado en esta Tesis Doctoral es el algoritmo de localización diseñado. Este algoritmo utiliza un método geométrico que intenta llevar la intuición que tendría un ingeniero por inspección detallada de las medidas disponibles. Los resultados de este algoritmo han sido comprobados empíricamente mediante una campaña de medidas, la cual ha permitido también la calibración de un conjunto de parámetros. La gran ventaja de este algoritmo es que alcanza una buena precision basándose únicamente en medidas disponibles en la red, sin necesidad de incorporar ningún elemento adicional ni en el terminal ni en la estación base. Además, se ha podido comprobar que el mecanismo propuesto mejora la precisión de localización basada en fingerprinting, incluso utilizando modelos de predicción de pérdidas calibrados con drive-test y considerando la ubicación y altura de edificios. 


\section{CAPÍTULO 6. CONCLUSIONES Y TRABAJO FUTURO}

Respecto a la planificación y optimización automática, se ha demostrado cómo la utilización de distribuciones de tráfico realistas, extraídas tras la aplicación del algoritmo de localización sobre un histórico de llamadas, permite obtener soluciones de planificación y optimización ajustadas a la realidad en lugar de a predicciones o estimaciones. El error cometido en el cálculo del mapa de tráfico, debido a la precisión limitada de la localización, afecta ligeramente a las prestaciones de la solución de planificación y optimización obtenida, evaluadas a través de la función de coste objetivo empleada. Además, esta degradación de prestaciones de la solución obtenida se ha demostrado que se puede reducir introduciendo un ligero sobre-dimensionamiento en el sistema. Por otro lado, la utilización de modelos adecuados permite la realización de estimaciones de la carga soportada por cada una de las celdas, sin suponer un sobre-coste computacional excesivo que impida su ejecución en cada iteración del proceso de búsqueda de la mejor solución de planificación y optimización. Esta ejecución eficiente de la estimación de carga se consigue gracias a la linealización realizada sobre el modelo utilizado. Se ha comprobado que la estimación de carga permite obtener unas prestaciones del sistema ampliamente superiores a las conseguidas realizando la suposición conservadora de que las celdas están completamente cargadas. Respecto al mecanismo de búsqueda de la mejor solución de planificación y optimización, se ha comprobado que el algoritmo de búsqueda meta-heurística SA obtiene buenos resultados en su aplicación a este problema, a la vez que mantiene reducidos tiempos de ejecución al compararlos con otras alternativas como PSO o NSGA-II.

La optimización de la red móvil, a través del ajuste de los parámetros considerados de configuración de cada celda — potencia, tilt y acimut-, puede complementarse con la ayuda de sistemas de inteligencia artificial que adquieran el conocimiento a través del entrenamiento por parte de expertos ingenieros de optimización. Los resultados obtenidos de la aplicación de un sistema experto a la optimización de redes móviles dependen en gran medida de los datos utilizados para el entrenamiento, del "ruido" que contengan y del propio procedimiento de entrenamiento que se realice, ya que es de vital importancia evitar el sobre-ajuste de la red neuronal para que no se pierda la generalidad del sistema.

En cuanto a la forma en que se ha de realizar la planificación de frecuencias en LTE, este sistema ha demostrado tener una gran resistencia a las interferencias que se producen por la reutilización universal de las frecuencias disponibles. La posibilidad de realizar scheduling en el dominio de la frecuencia permite al eNB, dependiendo de la política seguida, seleccionar los recursos que mejor rendimiento van a proporcionar a cada usuario, como sucede en el caso de utilizar un scheduler de tipo Proportional Fair. Los esquemas de modulación y codificación asignados según las condiciones del canal, junto con el HARQ y el soft 
combining, permiten una protección extra del sistema frente a interferencias que a su vez posibilita que los usuarios del borde de la celda experimenten un rendimiento muy similar al caso de implementar algún tipo de reutilización de frecuencias de bajo orden, como por ejemplo reutilización de factor 3. Por ello, se ha concluido que la reutilización universal de frecuencias es la mejor opción a considerar en la planificación de una nueva red LTE, salvo que algunos de los esquemas de protección que incorpora el estándar no estén habilitados.

Con el fin de realizar un uso más eficiente de los recursos en frecuencia, esta Tesis Doctoral propone un conjunto de herramientas y procedimientos para incluir el AOE en un sistema LTE-A. La implementación de este acceso oportunista en LTE-A mejora las prestaciones globales del sistema al agregar de manera inteligente los recursos espectrales que de otra forma quedarían infrautilizados. Sin embargo, los mecanismos implicados deben configurarse adecuadamente teniendo en cuenta la viabilidad de implementación que ofrecen los estándares adoptados. En primer lugar, la periodicidad de la detección debe ser tan pequeña como sea posible para incrementar la precisión de la detección. Únicamente con la utilización de mecanismos de decisión cooperativa es posible incrementar el periodo de detección. Además, se han comparado varios mecanismos de decisión cooperativa, concluyendo que el mecanismo de decisión propuesto proporciona mejores resultados que los mecanismos de decisión hard encontrados en la literatura. Se consiguen tasas de transmisión de datos similares a las conseguidas con la estrategia más agresiva pero con una evidente reducción del número de colisiones con el sistema primario, que son incluso menores que las conseguidas con la estrategia más conservadora. Por lo tanto, el algoritmo de decisión soft sugerido toma lo bueno de ambos mecanismos hard si se utiliza el umbral de decisión apropiado. Con el fin de aprovechar al máximo los recursos espectrales fuera de la banda licenciada, se propone utilizar el algoritmo de localización para delimitar zonas de uso de los recursos utilizados de forma oportunista. Se ha comprobado que el mecanismo de localización debe ser lo suficientemente preciso para no interferir excesivamente en el sistema primario. El método de AOE descrito mejora de forma clara las prestaciones del sistema LTE-A. Además, el sistema propuesto es una solución de bajo coste, porque no exige ninguna modificación sustancial de la arquitectura de sistema LTE-A. Únicamente se ha de agregar una nueva entidad funcional al sistema, junto con un conjunto de nuevos servicios de nivel de aplicación. Esta nueva entidad, el GRC, debería ubicarse preferiblemente junto a la entidad MME, con el fin de reducir la carga de señalización adicional.

Por último, al igual que en el caso de AOE en entornos macrocelulares, se ha mostrado una implementación factible de AOE en entornos femtocelulares. Para ello se han utilizando mecanismos disponibles y especificados en el estándar, con excepción de la señalización específica entre FCs y el CE, que se ha solucionado 


\section{CAPÍTULO 6. CONCLUSIONES Y TRABAJO FUTURO}

mediante MIH. De los resultados proporcionados, se puede concluir que se necesita la coordinación de recursos oportunistas a utilizar por las distintas FCs cuando el aislamiento entre las mismas no es suficientemente alto. Es de vital importancia determinar las condiciones bajo las que la coordinación comienza a tener una ganancia respecto al caso de no tenerla. Con este fin, se ha proporcionado un umbral en términos de interferencia más ruido que permitirá ejecutar las tareas de coordinación convenientemente a partir de las medidas de RSSI y la identificación de celdas vecinas interferentes que reporta cada FC.

\subsection{Líneas Futuras de Investigación}

A continuación se exponen algunas cuestiones que han quedado sin explorar o que han surgido como nuevos retos detectados durante la realización de esta Tesis Doctoral. Dado su elevado interés se presentan como actuaciones futuras para dar continuidad al trabajo realizado.

- Localización

Ante la falta de datos reales, no se han podido evaluar las prestaciones del algoritmo de localización LTE. La disponibilidad de datos de TA será crítica para determinar la precision del algoritmo y el grado de utilidad en su aplicación a planificación y optimización de la red móvil. La experiencia previa para el caso de UMTS hace pensar que los fabricantes incluirán este dato en los logs de la mensajera generada y capturada por sus equipos, pero a día de hoy todavía es una incógnita.

Tampoco ha sido posible contemplar la posibilidad de utilizar las PRS para incluir funcionalidades de OTDoA — basadas en medidas de RSTD en el algoritmo de localización. Su inclusión o utilización de forma independiente supondrá, previsiblemente, una considerable mejora en la precisión del mismo.

- Sistemas expertos basados en redes neuronales

Los resultados obtenidos no han cumplidos con las expectativas de las prestaciones del sistema experto basado en redes neuronales. Es necesario comprobar si es posible obtener mejores resultados con la consideración de un mayor número de muestras para el entrenamiento. Además, resulta necesario evaluar la red entrenada en escenarios distintos a los utilizados para el entrenamiento con el fin de comprobar la generalidad de la red, que quizá requiera ser entrenada con una mayor diversidad de escenarios.

Asimismo, convendría realizar un análisis de componentes principales sobre las muestras para poder descartar las entradas que menos información 
aportan, con el fin de conseguir mejorar la generalidad de la red tras el entrenamiento al haber eliminado entradas que solo aportan "ruido".

- Planificación y optimización

La consideración del UL en la herramienta de planificación y optimización automática es necesaria para evitar situaciones de desequilibrio entre UL y DL. Las soluciones que cumplan con los objetivos fijados para el DL pueden no cumplir con objetivos que pudieran existir para el UL, por lo que se requiere una planificación y optimización conjunta para ambos enlaces.

En cuanto a la distribución de tráfico utilizada, se ha considerado un único mapa de tráfico global para todos los tipos de servicios. Una herramienta de planificación y optimización automática completa requiere que se contemplen distintos objetivos y criterios según el tipo de servicio, para lo cual será necesario disponer de mapas de tráfico independientes para cada tipo de servicio.

Un ejemplo claro de esta necesidad lo tenemos en el servicio de VoIP, en el que los paquetes transmitidos son de pequeño tamaño. En esta situación, un usuario que reporte un CQI, — salvo en los casos en que se apliquen técnicas para hacer un uso más eficiente de los recursos, como el packet bundling - es probable que esté infrautilizando los recursos asignados, ya que podría estar transmitiendo tamaños de bloque más grandes sin aumentar el BLER. Esto afecta de forma importante a la estimación de consumo de recursos que se realiza en el proceso de planificación y optimización, ya que en esta Tesis Doctoral se han considerado que los recursos asignados se exprimen al máximo.

- Reutilización de recursos espectrales

El hecho de que la reutilización universal de frecuencias sea la opción más favorable como esquema de planificación de frecuencias se atribuye, en otras cosas, a la capacidad de LTE a adaptarse al canal disponible entre UE y eNB, seleccionando los mejores recursos para cada usuario y los esquemas apropiados de modulación y codificación. Esto ocurre bajo la suposición de que el scheduling se realiza cada TTI pero, ¿qué ocurre cuando se realiza scheduling semi-persistente y la misma asignación de recursos se mantiene a lo largo de varios TTIs?

Tampoco se han tratado los mecanismos dinámicos de ICIC, los cuales previsiblemente aportarán una ganancia considerable respecto a la reutilización universal de frecuencias cuando la carga de las celdas no sea del 


\section{CAPÍTULO 6. CONCLUSIONES Y TRABAJO FUTURO}

$100 \%$. El estudio de estos mecanismos dinámicos puede ser de gran utilidad para entornos femtocelulares en los que se requiera la funcionalidad de auto-organización de las celdas.

\section{- $\mathrm{AOE}$}

Una de las debilidades del sistema de AOE propuesto se encuentra cuando se intenta utilizar de forma oportunista la banda licenciada de un sistema caracterizado por periodos de actividad e inactividad. Esta debilidad guarda relación con la forma en la que se realiza la detección de la actividad del primario cuando están en curso transmisiones oportunistas debido a un periodo previo de inactividad del sistema primario y que ahora finaliza. En este caso, la detección de espectro se realiza monitorizando valores de RSSI anormales que hagan presuponer una vuelta a la actividad del sistema primario, con la dificultad que entraña el establecimiento de umbrales apropiados para la consecución de este objetivo.

De forma alternativa a la propuesta de detección de espectro planteada, sería posible aprovechar otra característica disponible en el estándar LTE-A para producir silencios de transmisión, funcionalidad utilizada en el estándar para Enhanced Multimedia Broadcast Multicast Services (E-MBMS) [146]. Consiste en forzar un silencio en 1 de cada 10 subtramas, ya que durante esos silencios se indica a los usuarios la disponibilidad de contenidos multimedia. Si durante esa subtrama no se indica nada en relación a los contenidos E-MBMS y no se transmite nada durante la misma ya que estaba reservada para ello, los UEs pueden aprovechar la ausencia de transmisiones por parte de la red LTE para realizar la detección de espectro del sistema primario. Los silencios afectarían a las prestaciones del sistema ya que el throughput por celda se vería mermado, por lo que resulta necesario realizar un estudio basado en simulaciones.

Un requisito para la aplicación de esta idea consistiría en la sincronización de la detección de espectro realizada por parte de los UEs con los silencios generados. Durante los periodos de silencio, todos los UEs intentan detectar el espectro del sistema primario con el fin de detectar la señal del primario y no la señal del propio eNB utilizando la banda primaria de forma oportunista. Esta sincronización es de vital importancia para la capacidad del sistema oportunista de detectar la actividad del primario en el momento en que ésta vuelva tras un periodo de inactividad y evitar de este modo que se produzcan colisiones entre ambos sistemas.

Otra cuestión pendiente de analizar reside en el impacto sobre las prestaciones de la propia red LTE de la utilización de parte de los measurement 
gaps para monitorizar la banda no licenciada, ya que reduce el tiempo dedicado a medir la actividad normal en la banda licenciada.

Por último, el impacto del error cometido mediante el algoritmo de localización refleja que no se tiene mucho margen y se requiere una precisión muy elevada. Ante la previsión de que una precisión así no sea posible, si bien está pendiente concretar la precisión alcanzada con la consideración de las PRS, se requiere el estudio de variantes más conservadoras en el acceso oportunista al espectro que eviten perjudicar al sistema primario con un elevado número de colisiones.

- Auto-organización de femto-celdas

Tan solo se ha hecho un estudio previo que analiza los niveles de interferencia que se han de vigilar antes de pasar a ejecutar algún tipo de algoritmo de reparto de recursos entre celdas que se estén molestando. Queda mucho por hacer en esta línea con el objetivo de obtener algoritmos concretos que aporten una ganancia en la coordinación del reparto de recursos entre femtoceldas mutuamente interferentes, considerándose muy relevante el estudio de mecanismos dinámicos de ICIC tal como se ha indicado previamente. 


\section{Anexo A}

\section{Datos Disponibles para las Herramientas de Procesamiento de Información}

El proceso de planificación y optimización automática propuesto en esta Tesis Doctoral hace uso de herramientas que procesan información obtenida de la red desde distintas fuentes.

Topología Información generada y mantenida por el operador con los datos de la red implantada.

MRs La información contenida en los MRs que envía el UE a la red se utiliza principalmente en los procesos de hand-over aunque también se puede utilizar para otras funciones como el control de potencia. Se ha incluido aquí la información contenida en los MRs de GSM ya que el algoritmo de localización propuesto, que aprovecha la información reportada por el UE, también es válido para GSM con algunas variaciones.

Señalización Para UMTS y LTE, al no disponer de información temporal como el TA en los MRs, interesa obtener algún equivalente.

En UMTS es posible disponer de información temporal similar gracias al RACH PD, que es el retardo de propagación en un único sentido medido durante el acceso al canal PRACH. 


\section{CAPÍTULO A. DATOS DISPONIBLES PARA LAS HERRAMIENTAS DE PROCESAMIENTO DE INFORMACIÓN}

En LTE el UE transmite un Random Access Preamble (RAP) antes de establecer una conexión RRC. El eNB aprovecha la transmisión del RAP para realizar una estimación del retardo. Acorde con el mismo, el eNB envía un comando de TA que contiene el valor temporal con el que el UE tiene que ajustar sus transmisiones.

Contadores Existen infinidad de contadores que almacenan información de lo que ocurre en la red. La variedad, cantidad y definición de los mismos depende del fabricante. El sistema experto de optimización basado en redes neuronales propuesto en esta Tesis Doctoral utiliza uno de estos contadores.

La siguiente tabla contiene una lista de los datos considerados en las herramientas descritas en el capítulo 3. Además de proporcionar el nombre, la fuente, la tecnología en la que se utiliza el dato y una breve descripción del mismo, se indica la función en la que se utiliza. 


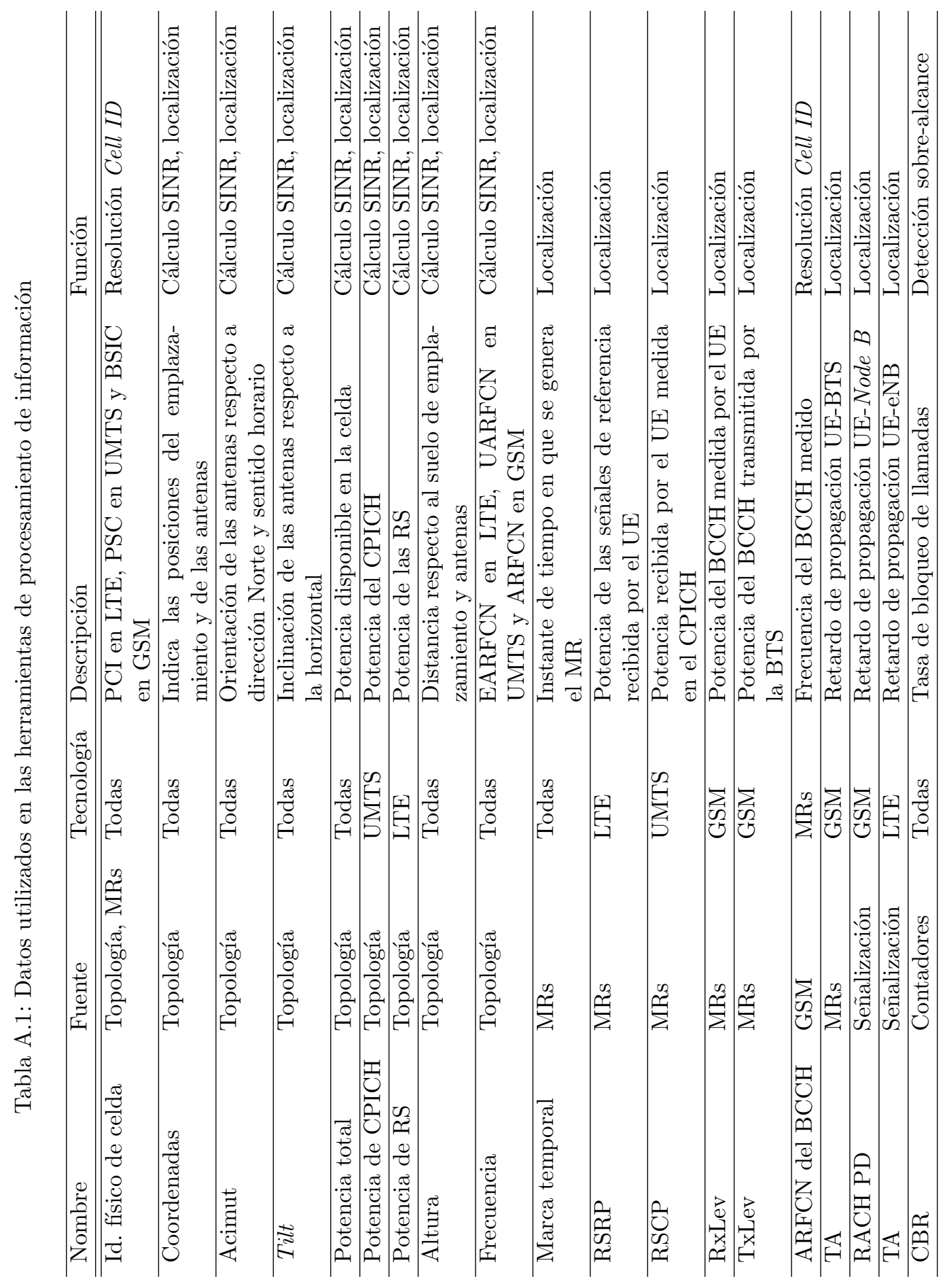


CAPÍTULO A. DATOS DISPONIBLES PARA LAS HERRAMIENTAS DE PROCESAMIENTO DE INFORMACIÓN 


\section{Referencias}

[1] Telia Sonera. Página web: http://www.teliasonera.com/

[2] H. Holma y A. Toskala, WCDMA for UMTS: HSPA Evolution and LTE. John Wiley \& Sons, Septiembre 2010.

[3] A. R. Mishra, Advanced Cellular Network Planning and Optimisation: 2G/2.5G/3G - Evolution to $4 G$. John Wiley, 2007.

[4] O. Stabler, R. Hoppe, G. Wolfle, T. Hager, y T. Herrmann, "Consideration of MIMO in the Planning of LTE Networks in Urban and Indoor Scenarios", en Antennas and Propagation (EUCAP), Proceedings of the 5th European Conference on, Abril 2011, pp. 2187 -2191.

[5] O. Sallent, J. Pérez-Romero, J. Sánchez-González, R. Agustí, M. Díazguerra, D. Henche, y D. Paul, "A Roadmap from UMTS Optimization to LTE Self-Optimization", Communications Magazine, IEEE, vol. 49, no. 6, pp. $172-182$, Junio 2011.

[6] L. Song y J. Shen, Evolved Cellular Network Planning and Optimization for UMTS and LTE. Taylor \& Francis, 2010.

[7] M. Neuland, T. Kurner, y M. Amirijoo, "Influence of Positioning Error on X-Map Estimation in LTE", en Vehicular Technology Conference (VTC Spring), 2011 IEEE 73rd, Mayo 2011, pp. $1-5$.

[8] _ , "Influence of Different Dactors on X-Map Estimation in LTE", en Vehicular Technology Conference (VTC Spring), 2011 IEEE 73rd, Mayo 2011, pp. $1-5$.

[9] TS 37.320 Universal Terrestrial Radio Access (UTRA) and Evolved Universal Terrestrial Radio Access (E-UTRA); Radio Measurement Collection for Minimization of Drive Tests (MDT); Overall Description, 3GPP Std. 


\section{REFERENCIAS}

[10] L. Mihaylova, D. Angelova, D. Bull, y N. Canagarajah, "Localization of Mobile Nodes in Wireless Networks with Correlated in Time Measurement Noise", Mobile Computing, IEEE Transactions on, vol. 10, no. 1, pp. $44-53$, Enero 2011.

[11] S. Fang, Y. Hsu, y W. Kuo, "Dynamic Fingerprinting Combination for Improved Mobile Localization", Wireless Communications, IEEE Transactions on, vol. 10, no. 12, pp. 4018 -4022, Diciembre 2011.

[12] I. Bilik, K. Adhikari, y J. Buck, "Shannon Capacity Bound on Mobile Station Localization Accuracy in Urban Environments", Signal Processing, IEEE Transactions on, vol. 59, no. 12, pp. 6206 -6216, Diciembre 2011.

[13] F. Gustafsson y F. Gunnarsson, "Mobile Positioning Using Wireless Networks: Possibilities and Fundamental Limitations Based on Available Wireless Network Measurements", Signal Processing Magazine, IEEE, vol. 22 , no. 4 , pp. $41-53$, Julio 2005.

[14] S. Gezici, Z. Tian, G. Giannakis, H. Kobayashi, A. Molisch, H. Poor, y Z. Sahinoglu, "Localization via Ultra-Wideband Radios: a Look at Positioning Aspects for Future Sensor Networks", Signal Processing Magazine, IEEE, vol. 22, no. 4, pp. $70-84$, Julio 2005.

[15] Y. Qi, H. Kobayashi, y H. Suda, "Analysis of Wireless Geolocation in a Non-Line-of-Sight Environment", Wireless Communications, IEEE Transactions on, vol. 5, no. 3, pp. 672 -681, Marzo 2006.

[16] S. Gezici, "A Survey on Wireless Position Estimation", Wireless Personal Communications, vol. 44, no. 3, pp. 263 -282, Febrero 2008.

[17] M. Bshara, U. Orguner, F. Gustafsson, y L. Van Biesen, "Fingerprinting Localization in Wireless Networks Based on Received-Signal-Strength Measurements: A Case Study on WiMAX Networks", Vehicular Technology, IEEE Transactions on, vol. 59, no. 1, pp. 283 -294, Enero 2010.

[18] T. Öktem y D. Slock, "Power Delay Doppler Profile Fingerprinting for Mobile Localization in NLOS", en Personal Indoor and Mobile Radio Communications (PIMRC), 2010 IEEE 21st International Symposium on, Septiembre 2010, pp. $876-881$.

[19] T. Wigren, "Adaptive Enhanced Cell-ID Fingerprinting Localization by Clustering of Precise Position Measurements", Vehicular Technology, IEEE Transactions on, vol. 56, no. 5, pp. 3199 -3209, Septiembre 2007. 
[20] — "Clustering and Polygon Merging Algorithms for Fingerprinting Positioning in LTE", en Signal Processing and Communication Systems (ICSPCS), 2011 5th International Conference on, Diciembre 2011, pp. 1 -10 .

[21] F. Benedetto, G. Giunta, y E. Guzzon, "Enhanced TOA-based IndoorPositioning Algorithm for Mobile LTE Cellular Systems", en Positioning Navigation and Communication (WPNC), 2011 8th Workshop on, Abril 2011, pp. $137-142$.

[22] J. Medbo, I. Siomina, A. Kangas, y J. Furuskog, "Propagation Channel Impact on LTE Positioning Accuracy: A Study Based on Real Measurements of Observed Time Difference of Arrival", en Personal, Indoor and Mobile Radio Communications, 2009 IEEE 20th International Symposium on, Septiembre 2009, pp. 2213 -2217.

[23] Ericsson, "White Paper, 284 23-3155 Uen", Ericsson, Tech. Rep., 2011.

[24] M. St-Hilaire y S. Liu, "Comparison of Different Meta-Heuristics to Solve the Global Planning Problem of UMTS Networks", Comput. Netw., vol. 55, no. 12, pp. 2705 -2716, Agosto 2011.

[25] I. Siomina, P. Varbrand, y D. Yuan, "Automated Optimization of Service Coverage and Base Station Antenna Configuration in UMTS Networks", Wireless Communications, IEEE, vol. 13, no. 6, pp. $16-25$, Diciembre 2006.

[26] A. Temesvary, "Self-Configuration of Antenna Tilt and Power for Plug \& Play Deployed Cellular Networks", en Wireless Communications and Networking Conference, 2009. WCNC 2009. IEEE, Abril 2009, pp. 1 -6.

[27] A. Awada, B. Wegmann, I. Viering, y A. Klein, "Optimizing the Radio Network Parameters of the Long Term Evolution System Using Taguchi's Method", Vehicular Technology, IEEE Transactions on, vol. 60, no. 8, pp. $3825-3839$, Octubre 2011.

[28] —_, "A Joint Optimization of Antenna Parameters in a Cellular Network Using Taguchi's Method", en Vehicular Technology Conference (VTC Spring), 2011 IEEE 73rd, Mayo 2011, pp. 1 -5.

[29] Z. Li y S. Li, "LTE Network Planning Based on Game Theory", en Computer Science and Service System (CSSS), 2011 International Conference on, Junio 2011, pp. 3963 -3966. 
[30] A. Khalek, L. Al-Kanj, Z. Dawy, y G. Turkiyyah, "Site Placement and Site Selection Algorithms for UMTS Radio Planning with Quality Constraints", en Telecommunications (ICT), 2010 IEEE 17th International Conference on, Abril 2010, pp. 375 -381.

[31] A. Eisenblätter, A. Fügenschuh, H. Geerdes, D. Junglas, T. Koch, y A. Martin, "Integer Programming Methods for UMTS Radio Network Planning", en WIOPT'04, Proceedings of, 2004.

[32] Eisenblätter, Andreas and Geerdes, Hans-Florian, "Wireless Network Design: Solution-Oriented Modeling and Mathematical Optimization", Wireless Communications, IEEE, vol. 13, no. 6, pp. 8 -14, Diciembre 2006.

[33] I. Siomina y D. Yuan, "Analysis of Cell Load Coupling for LTE Network Planning and Optimization", IEEE Transactions on Wireless Communications, vol. 11, no. 6, pp. 2287 -2297, Junio 2012.

[34] K. Majewski y M. Koonert, "Conservative Cell Load Approximation for Radio Networks with Shannon Channels and its Application to LTE Network Planning", en Telecommunications (AICT), 2010 Sixth Advanced International Conference on, Mayo 2010, pp. 219 -225.

[35] O. Yilmaz, J. Hämäläinen, y S. Hämäläinen, "Self-Optimization of Remote Electrical Tilt", en Personal Indoor and Mobile Radio Communications (PIMRC), 2010 IEEE 21st International Symposium on, Septiembre 2010, pp. $1128-1132$.

[36] M. Amirijoo, P. Frenger, F. Gunnarsson, H. Kallin, J. Moe, y K. Zetterberg, "Neighbor Cell Relation List and Measured Cell Identity Management in LTE", en Network Operations and Management Symposium, 2008. NOMS 2008. IEEE, Abril 2008, pp. 152 -159.

[37] S. Razavi, D. Yuan, F. Gunnarsson, y J. Moe, "Exploiting Tracking Area List for Improving Signaling Overhead in LTE", en Vehicular Technology Conference (VTC 2010-Spring), 2010 IEEE 71st, Mayo 2010, pp. 1 -5.

[38] —_, "Dynamic Tracking Area List configuration and performance evaluation in LTE", en GLOBECOM Workshops (GC Wkshps), 2010 IEEE, Diciembre 2010, pp. $49-53$.

[39] H. Wang, C. Rosa, y K. Pedersen, "Performance Analysis of Downlink Inter-Band Carrier Aggregation in LTE-Advanced", en Vehicular Technology Conference (VTC Fall), 2011 IEEE, Septiembre 2011, pp. 1 -5. 
[40] S. Gao, H. Tian, J. Zhu, L. Chen, y X. She, "A Throughput-Optimized Component Carrier Selection Algorithm for LTE-advanced Systems", en Communication Technology and Application (ICCTA 2011), IET International Conference on, Octubre 2011, pp. 218 -222.

[41] S. Elayoubi, O. Ben Haddada, y B. Fourestie, "Performance Evaluation of Frequency Planning Schemes in OFDMA-based Networks", Wireless Communications, IEEE Transactions on, vol. 7, no. 5, pp. $1623-1633$, Mayo 2008.

[42] N. Himayat, S. Talwar, A. Rao, y R. Soni, "Interference Management for 4G Cellular Standards [WIMAX/LTE UPDATE]", Communications Magazine, IEEE, vol. 48, no. 8, pp. 86 -92, Agosto 2010.

[43] M. Qian, W. Hardjawana, Y. Li, B. Vucetic, J. Shi, y X. Yang, "InterCell Interference Coordination through Adaptive Soft Frequency Reuse in LTE Networks", en 2012 IEEE Wireless Communications and Networking Conference (WCNC), Abril 2012, pp. 1618 -1623.

[44] M. Rahman y H. Yanikomeroglu, "Enhancing Cell-Edge Performance: a Downlink Dynamic Interference Avoidance Scheme with Inter-Cell Coordination", Wireless Communications, IEEE Transactions on, vol. 9, no. 4, pp. $1414-1425$, Abril 2010.

[45] V. Chandrasekhar, J. Andrews, y A. Gatherer, "Femtocell Networks: a Survey", Communications Magazine, IEEE, vol. 46, no. 9, pp. 59 -67, Septiembre 2008.

[46] R. Lau y T. Zhang, "Planning and Control of LTE Femto Networks", en Modeling and Optimization in Mobile, Ad Hoc and Wireless Networks (WiOpt), 2011 International Symposium on, Mayo 2011, pp. 423 -427.

[47] G. de la Roche, A. Ladányi, D. López-Pérez, C. Chong, y J. Zhang, "SelfOrganization for LTE Enterprise Femtocells", en GLOBECOM Workshops (GC Wkshps), 2010 IEEE, Diciembre 2010, pp. 674-678.

[48] T. Yucek y H. Arslan, "A Survey of Spectrum Sensing Algorithms for Cognitive Radio Applications", Communications Surveys Tutorials, IEEE, vol. 11, no. 1, pp. $116-130,2009$.

[49] S. Stotas y A. Nallanathan, "On the Throughput and Spectrum Sensing Enhancement of Opportunistic Spectrum Access Cognitive Radio Networks", Wireless Communications, IEEE Transactions on, vol. 11, no. 1, pp. $97-107$, Enero 2012. 
[50] ITU-R, "M2135: Guidelines for Evaluation of Radio Interface Technologies for IMT-Advanced", ITU-R, Tech. Rep., 2008.

[51] M. Hata, "Empirical Formula for Propagation Loss in Land Mobile Radio Services", IEEE Trans. on Vehicular Technology, vol. 29, pp. 317-325, 1980.

[52] Y. Okumura, E. Ohmori, T. Kawano, y K. Fukuda, "Field Strength and its Variability in VHF and UHF Land-Mobile Service", Review of the Electrical Communication Laboratory, vol. 16, pp. 825-873, 1968.

[53] C. A. 231, "Digital Mobile Radio Towards Future Generation Systems, Final Report", COST Action 231, Tech. Rep., 1999. Página web: http://www.lx.it.pt/cost231/final_report.htm

[54] J. Seybold, Introduction to RF Propagation. John Wiley \& Sons, 2005.

[55] L. Barklay y L. Barclay, Propagation of Radiowaves, 2nd Edition, ser. Electromagnetic Waves. The Institution of Engineering and Technology, 2003.

[56] Página web: http://projects.celtic-initiative.org/winner+/index.html

[57] C. E. Shannon, "A Mathematical Theory of Communication", The Bell System Technical Journal, vol. 27, pp. 379-423, 623-656, 1948.

[58] P. Mogensen, W. Na, I. Kovacs, F. Frederiksen, A. Pokhariyal, K. Pedersen, T. Kolding, K. Hugl, y M. Kuusela, "LTE Capacity Compared to the Shannon Bound", en Vehicular Technology Conference, 200\%. VTC200\%Spring. IEEE 65th, Abril 2007, pp. $1234-1238$.

[59] K. Safjan, V. D'Amico, D. Bultmann, D. Martin-Sacristan, A. Saadani, y H. Schoneich, "Assessing 3GPP LTE-advanced as IMT-advanced Technology: the WINNER+ Evaluation Group Approach", IEEE Communications Magazine, vol. 49, no. 2, pp. 92 -100, Febrero 2011.

[60] W. Jakes, Microwave Mobile Communications, ser. IEEE Press classic reissue. Wiley, 1974.

[61] Ingenia Telecom. Página web: http://www.ingenia-telecom.com

[62] Optimi. Página web: http://www.optimi.com

[63] Actix. Página web: www.actix.com

[64] Tektronix. Página web: http://www.tektronixcommunications.com 
[65] Telenity. Página web: http://www.telenity.com

[66] Celcite. Página web: http://www.celcite.com

[67] Ascom. Página web: http://www.ascom.com

[68] Z. Yang y Y. Liu, "Quality of Trilateration: Confidence Based Iterative Localization", en Distributed Computing Systems, 2008. ICDCS '08. The 28th International Conference on, Junio 2008, pp. 446 -453.

[69] D. Zimmermann, J. Baumann, A. Layh, F. Landstorfer, R. Hoppe, y G. Wolfle, "Database Correlation for Positioning of Mobile Terminals in Cellular Networks Using Wave Propagation Models", en Vehicular Technology Conference, 2004. VTC2004-Fall. 2004 IEEE 60th, vol. 7, Sep 2004, pp. $4682-4686$.

[70] J. Caffery y G. Stuber, "Overview of Radiolocation in CDMA Cellular Systems", Communications Magazine, IEEE, vol. 36, no. 4, pp. $38-45$, Abril 1998.

[71] H. Kaaranen, UMTS Networks: Architecture, Mobility And Services. John Wiley \& Sons, 2005.

[72] TS 25.331 Technical Specification Group Radio Access Network; Radio Resource Control (RRC); Protocol Specification, 3GPP Std.

[73] TS 25.133 Technical Specification Group Radio Access Network; Requirements for Support of Radio Resource Management (FDD), 3GPP Std.

[74] T. G. Farr et al., "The Shuttle Radar Topography Mission", Reviews of geophysics, vol. 45, p. 33, 2007.

[75] B. Lakmali, W. Wijesinghe, K. De Silva, K. Liyanagama, y S. Dias, "Design, Implementation \& Testing of Positioning Techniques in Mobile Networks", en Information and Automation for Sustainability, 200\%. ICIAFS 200\%. Third International Conference on, Diciembre 2007, pp. 94 -99.

[76] M. Layh, U. Reiser, D. Zimmermann, y F. Landstorfer, "Positioning of Mobile Terminals based on Feature Extraction from Channel Impulse Responses", en Vehicular Technology Conference, 2006. VTC 2006Spring. IEEE 63rd, vol. 3, Mayo 2006, pp. 1078 -1081.

[77] C. Takenga, Q. Wen, y K. Kyamakya, "On the Accuracy Improvement Issues in GSM Location Fingerprinting", en Vehicular Technology Conference, 2006. VTC-2006 Fall. 2006 IEEE 64th, Septiembre 2006, pp. 1 -5 . 


\section{REFERENCIAS}

[78] M. Al Hallak, M. Safadi, y R. Kouatly, "Mobile Positioning Technique using Signal Strength Measurement Method with the Aid of Passive Mobile Listener Grid", en Information and Communication Technologies, 2006. ICTTA '06. 2nd, vol. 1, 2006, pp. $105-110$.

[79] E. Hepsaydir, "Analysis of Mobile Positioning Measurements in CDMA Cellular Networks", en Radio and Wireless Conference, 1999. RAWCON 99. 1999 IEEE, 1999, pp. $73-76$.

[80] E. Villebrun, A. Ben Hadj Alaya, Y. Boursier, y N. Noisette, "Indoor Outdoor User Discrimination in Mobile Wireless Networks", en Vehicular Technology Conference, 2006. VTC-2006 Fall. 2006 IEEE 64th, Septiembre 2006, pp. $1-5$.

[81] TS 36.355 Evolved Universal Terrestrial Radio Access (E-UTRA); LTE Positioning Protocol (LPP), 3GPP Std.

[82] TS 36.455 Evolved Universal Terrestrial Radio Access (E-UTRA); LTE Positioning Protocol A (LPPa), 3GPP Std.

[83] M. Nawrocki, H. Aghvami, y M. Dohler, Understanding UMTS Radio Network Modelling, Planning and Automated Optimisation: Theory and Practice. Wiley, 2006.

[84] S. Kirkpatrick, C. D. Gelatt, y M. P. Vecchi, "Optimization by Simulated Annealing", Science, vol. 220, pp. $671-680,1983$.

[85] K. Deb, A. Pratap, S. Agarwal, y T. Meyarivan, "A Fast Elitist MultiObjective Genetic Algorithm: NSGA-II", IEEE Transactions on Evolutionary Computation, vol. 6, p. 182-197, 2000.

[86] J. Kennedy y R. Eberhart, "Particle Swarm Optimization", en , IEEE International Conference on Neural Networks, 1995. Proceedings, vol. 4, Diciembre 1995, pp. $1942-1948$ vol.4.

[87] Negnevitsky, Artificial Intelligence. Pearson Education.

[88] D. W. Marquardt, "An Algorithm for Least-Squares Estimation of Nonlinear Parameters", Journal of the Society for Industrial and Applied Mathematics, vol. 11, no. 2, pp. 431-441, Junio 1963.

[89] M. Hagan y M. Menhaj, "Training Feed-Forward Networks with the Marquardt Algorithm", IEEE Transactions on Neural Networks, vol. 5, no. 6, pp. 989-993, 1994. 
[90] J. Cabrejas, D. Calabuig, N. Cardona, A. Fernández, M. García, D. González, D. Martín-Sacristán, J. Monserrat, J. Olmos, y S. Ruiz, 3GPP LTE: Hacia la 4 G móvil. MARCOMBO, 2011.

[91] R. Jain, D. Chiu, y W. Hawe, "A Quantitative Measure of Fairness And Discrimination for Resource Allocation in Shared Computer System", DEC Technical Report 301, 1984.

[92] (2011, Julio) Registro público de concesiones de telecomunicaciones. Página web: http://oficinavirtual.mityc.es/SETSL_RegConcesiones/

[93] (2009, Marzo) Consulta pública del ministerio de industria, turismo y comercio sobre el uso de la banda de frecuencias de 2.500 a $2.690 \mathrm{mhz}$ y sobre posibles nuevas modalidades de la explotación de las bandas de frecuencias de $900 \mathrm{mhz}, 1.800 \mathrm{mhz}$ y $3,5 \mathrm{ghz}$. Página web: http://www.mityc.es/es-es/gabineteprensa/notasprensa/ documents/npresultadosconsultapublica110309.pdf

[94] TS 05.05 Radio Transmission and Reception, 3GPP Std.

[95] J. M. Sadiq, A. Ozoheve, y A. U. Usman, "Minimizing Interference on GSM BCCH Channel Using Particle Swarm Optimization", Journal of Mobile Communication, vol. 4, no. 3, pp. 91-95, Marzo 2010.

[96] A. Eisenblätter, "Frequency Planning in GSM Networks: Models, Heuristics, and Lower Bounds", Ph.D. dissertation, 2001.

[97] D. Martín-Sacristán, J. F. Monserrat, J. Cabrejas-Peñuelas, D. Calabuig, S. Garrigas, y N. Cardona, "On the Way towards Fourth-Generation Mobile: 3GPP LTE and LTE-advanced", EURASIP J. Wirel. Commun. Netw., vol. 2009, pp. 4:1 -4:10, Marzo 2009.

[98] R. Ratasuk, D. Tolli, y A. Ghosh, "Carrier Aggregation in LTEAdvanced", en Vehicular Technology Conference (VTC 2010-Spring), 2010 IEEE 71st, Mayo 2010, pp. 1 -5.

[99] Z. Shen, A. Papasakellariou, J. Montojo, D. Gerstenberger, y F. Xu, "Overview of 3GPP LTE-advanced Carrier Aggregation for 4G Wireless Communications", Communications Magazine, IEEE, vol. 50, no. 2, pp. 122 -130, Febrero 2012.

[100] H. Wang, C. Rosa, y K. Pedersen, "Performance of Uplink Carrier Aggregation in LTE-Advanced Systems", en Vehicular Technology Conference Fall (VTC 2010-Fall), 2010 IEEE 72nd, Septiembre 2010, pp. 1 -5. 
[101] R. Tandra, A. Sahai, y S. Mishra, "What is a Spectrum Hole and What Does it Take to Recognize One?", Proceedings of the IEEE, vol. 97, no. 5, pp. $824-848$, Mayo 2009.

[102] I. Mitola, J. y J. Maguire, G.Q., "Cognitive Radio: Making Software Radios More Personal", Personal Communications, IEEE, vol. 6, no. 4, pp. 13 -18, Agosto 1999.

[103] S. Haykin, "Cognitive Radio: Brain-Empowered Wireless Communications", Selected Areas in Communications, IEEE Journal on, vol. 23, no. 2, pp. $201-220$, Febrero 2005.

[104] IEEE Standard for Local and Metropolitan Area Networks-Part 21: Media Independent Handover, Media Independent Handover Services Working Group Std. IEEE 802.21.

[105] BT1368: Planning Criteria for Digital Terrestrial Television Services in the VHF/UHF Bands, ITU-R Std.

[106] BT1786: Criterion to Assess the Impact of Interference to the Terrestrial Broadcasting Service, ITU-R Std.

[107] S. Kawade y M. Nekovee, "Cognitive Radio-Based Urban Wireless Broadband in Unused TV Bands", en Radioelektronika (RADIOELEKTRONIKA), 2010 20th International Conference, Abril 2010, pp. 1 -4.

[108] B. Modlic, G. Sisul, y M. Cvitkovic, "Digital dividend - Opportunities for New Mobile Services", en ELMAR, 2009. ELMAR '09. International Symposium, Septiembre 2009, pp. 1 -8.

[109] X. Zhao, Z. Guo, y Q. Guo, "A Cognitive Based Spectrum Sharing Scheme for LTE Advanced Systems", en Ultra Modern Telecommunications and Control Systems and Workshops (ICUMT), 2010 International Congress on, Octubre 2010, pp. $965-969$.

[110] S. Hussain y X. Fernando, "Spectrum Sensing in Cognitive Radio Networks: Up-to-Date Techniques and Future Challenges", en Science and Technology for Humanity (TIC-STH), 2009 IEEE Toronto International Conference, Septiembre 2009, pp. $736-741$.

[111] Y. Xu, Y. Sun, Y. Li, Y. Zhao, y H. Zou, "Joint Sensing Period and Transmission Time Optimization for Energy-Constrained Cognitive Radios", EURASIP J. Wirel. Commun. Netw., vol. 2010, pp. 92:1 -92:16, Abril 2010. 
[112] D. Cabric, S. Mishra, y R. Brodersen, "Implementation Issues in Spectrum Sensing for Cognitive Radios", en Signals, Systems and Computers, 2004. Conference Record of the Thirty-Eighth Asilomar Conference on, vol. 1, Noviembre 2004, pp. 772 - 776 Vol.1.

[113] Y. Zeng, Y. Liang, A. Hoang, y E. Peh, "Reliability of Spectrum Sensing Under Noise and Interference Uncertainty", en Communications Workshops, 2009. ICC Workshops 2009. IEEE International Conference on, Junio 2009, pp. 1-5.

[114] L. Bixio, M. Ottonello, M. Raffetto, y C. S. Regazzoni, "Comparison among Cognitive Radio Architectures for Spectrum Sensing", EURASIP J. Wireless Comm. and Networking, vol. 2011, 2011.

[115] M. Mustonen, M. Matinmikko, y A. Mammela, "Cooperative Spectrum Sensing Using Quantized Soft Decision Combining", en Cognitive Radio Oriented Wireless Networks and Communications, 2009. CROWNCOM '09. 4th International Conference on, Junio 2009, pp. 1-5.

[116] L. Xiao, K. Liu, y L. Ma, "A Weighted Cooperative Spectrum Sensing in Cognitive Radio Networks", en Information Networking and Automation (ICINA), 2010 International Conference on, vol. 2, Octubre 2010, pp. $\mathrm{V} 2-45-\mathrm{V} 2-48$.

[117] Y. Choi y K. Shin, "Opportunistic Access of TV Spectrum Using Cognitive-Radio-Enabled Cellular Networks", Vehicular Technology, IEEE Transactions on, vol. 60, no. 8, pp. 3853 -3864, Octubre 2011.

[118] Q. Pan, Y. Chang, R. Zheng, X. Zhang, Y. Wang, y D. Yang, "Solution of Information Exchange for Cooperative Sensing in Cognitive Radios", en Wireless Communications and Networking Conference, 2009. WCNC 2009. IEEE, Abril 2009, pp. $1-4$.

[119] A. Masri, C. Chiasserini, y A. Perotti, "Control Information Exchange through UWB in Cognitive Radio Networks", en Wireless Pervasive Computing (ISWPC), 2010 5th IEEE International Symposium on, Mayo 2010, pp. $110-115$.

[120] H. Celebi y H. Arslan, "Utilization of Location Information in Cognitive Wireless Networks", Wireless Communications, IEEE, vol. 14, no. 4, pp. 6 -13, Agosto 2007.

[121] FCC, "In the Matter of Unlicensed Operation in the TV Broadcast Bands and Additional Spectrum for Unlicensed Devices Below $900 \mathrm{MHz}$ and in the 3 GHz Band", FCC, Tech. Rep. 04-113, 2004. 
[122] M. Marcus y A. Lippman, "Reclaiming the Vast Wasteland: The Engineering Case", New America Foundation, Wireless Future Project, Tech. Rep., 2005.

[123] H. Nam, M. Ghorbel, y M. Alouini, "Location-Based Resource Allocation for OFDMA Cognitive Radio Systems", en Cognitive Radio Oriented Wireless Networks Communications (CROWNCOM), 2010 Proceedings of the Fifth International Conference on, Junio 2010, pp. $1-5$.

[124] TS 36.133 Technical Specification Group Radio Access Network; Evolved Universal Terrestrial Radio Access (E-UTRA); Requirements for Support of Radio Resource Management, 3GPP Std.

[125] S. Sesia, I. Toufik, y M. Baker, LTE, The UMTS Long Term Evolution: From Theory to Practice. Wiley, 2009.

[126] TS 36.214 Technical Specification Group Radio Access Network; Evolved Universal Terrestrial Radio Access (E-UTRA); Physical Layer; Measurements, 3GPP Std.

[127] F. Digham, M. Alouini, y M. Simon, "On the Energy Detection of Unknown Signals over Fading Channels", en Communications, 2003. ICC '03. IEEE International Conference on, vol. 5, Mayo 2003, pp. 3575 -3579.

[128] A. Ghasemi y E. Sousa, "Collaborative Spectrum Sensing for Opportunistic Access in Fading Environments", en New Frontiers in Dynamic Spectrum Access Networks, 2005. DySPAN 2005. 2005 First IEEE International Symposium on, Noviembre 2005, pp. 131 -136.

[129] X. Gelabert, I. F. Akyildiz, O. Sallent, y R. Agustí, "Operating Point Selection for Primary and Secondary Users in Cognitive Radio Networks", Computer Networks, vol. 53, no. 8, pp. 1158 -1170, Junio 2009.

[130] K. Taniuchi, Y. Ohba, V. Fajardo, S. Das, M. Tauil, Y. Cheng, A. Dutta, D. Baker, M. Yajnik, y D. Famolari, "IEEE 802.21: Media Independent Handover: Features, Applicability, and Realization", Communications Magazine, IEEE, vol. 47, no. 1, pp. 112 -120, Enero 2009.

[131] W. Ren, Q. Zhao, y A. Swami, "Power Control in Cognitive Radio Networks: How to Cross a Multi-Lane Highway", Selected Areas in Communications, IEEE Journal on, vol. 27, no. 7, pp. 1283 -1296, Septiembre 2009. 
[132] TS 36.912 Technical Specification Group Radio Access Network; Feasibility Study for Further Advancements for E-UTRA (LTE-Advanced), 3GPP Std.

[133] Motorola, "3GPP R1-084424: Control Channel Design Issues for Carrier Aggregation in LTE-A", 3GPP, Tech. Rep., 2008.

[134] D. Jiang, H. Wang, E. Malkamaki, y E. Tuomaala, "Principle and Performance of Semi-Persistent Scheduling for VoIP in LTE System", en Wireless Communications, Networking and Mobile Computing, 200\%. WiCom 200\%. International Conference on, Septiembre 2007, pp. 2861 -2864.

[135] R. Rajbanshi, A. M. Wyglinski, y G. J. Minden, "An Efficient Implementation of NC-OFDM Transceivers for Cognitive Radios", en in Proc. of 1st Conf. on Cognitive Radio Oriented Wireless Networks and Commun., Mykonos, 2006.

[136] M. Wellens, J. Riihijarvi, y P. Mahonen, "Modelling Primary System Activity in Dynamic Spectrum Access Networks by Aggregated ON/OFFProcesses", en Sensor, Mesh and Ad Hoc Communications and Networks Workshops, 2009. SECON Workshops '09. 6th Annual IEEE Communications Society Conference on, Junio 2009, pp. 1-6.

[137] Y. Ofuji, A. Morimoto, S. Abeta, y M. Sawahashi, "Comparison of Packet Scheduling Algorithms Focusing on User Throughput in High Speed Downlink Packet Access", en Personal, Indoor and Mobile Radio Communications, 2002. The 13th IEEE International Symposium on, vol. 3, Septiembre 2002, pp. $1462-1466$ vol.3.

[138] TS 36.913 Technical Specification Group Radio Access Network; Requirements for Further Advancements for Evolved Universal Terrestrial Radio Access (E-UTRA) (LTE-Advanced), 3GPP Std.

[139] M. Nekovee, "A Survey of Cognitive Radio Access to TV White Spaces", International Journal of Digital Multimedia Broadcasting, vol. 2010, pp. $1-11,2010$.

[140] J. P. M. Torregoza, R. Enkhbat, y W. Hwang, "Joint Power Control, Base Station Assignment, and Channel Assignment in Cognitive Femtocell Networks", EURASIP J. Wirel. Commun. Netw., vol. 2010, pp. 6:1-6:12, Enero 2010.

[141] M. Rahman, H. Yanikomeroglu, y W. Wong, "Interference Avoidance with Dynamic Inter-Cell Coordination for Downlink LTE System", en 
Proceedings of the 2009 IEEE conference on Wireless Communications 8 Networking Conference, ser. WCNC'09. Piscataway, NJ, USA: IEEE Press, 2009, pp. 1238-1243.

[142] 3GPP, "Technical Specification Group Radio Access Network; Home eNode B (HeNB) Radio Frequency (RF) Requirements Analysis", 3GPP, Tech. Rep., 2011.

[143] TS 36.300 Evolved Universal Terrestrial Radio Access (E-UTRA) and Evolved Universal Terrestrial Radio Access Network (E-UTRAN); Overall Description, 3GPP Std.

[144] TS 36.420 Evolved Universal Terrestrial Radio Access Network (EUTRAN); X2 General Aspects and Principles, 3GPP Std.

[145] V. MacDonald, "The Cellular Concept", Bell System Technical Journal, vol. Vol. 58 No. 1, pp. 15-41, Jan 1979.

[146] J. F. Monserrat, J. Calabuig, A. Fernandez-Aguilella, y D. GomezBarquero, "Joint Delivery of Unicast and E-MBMS Services in LTE Networks", Broadcasting, IEEE Transactions on, vol. 58, no. 2, pp. $157-167$, Junio 2012. 